\author{
Universidade DE SÃO PAULO \\ INSTITUTO DE QUÍMICA \\ Programa DE Pós-GRAduAÇÃo EM QuímicA
}

Ana Paula Mangoni

\title{
Química Supramolecular de Complexos Ter-Imínicos de Ferro(II)
}

Versão corrigida da Tese conforme resolução CoPGr 5890 O original encontra-se disponível na Secretaria de Pós-Graduação do IQ-USP

São Paulo

Data do depósito na SPG:

07/03/2019 
Ana Paula Mangoni

\title{
Química Supramolecular de Complexos Ter-Imínicos de Ferro(II)
}

\author{
Tese apresentada ao Instituto de Química \\ da Universidade de São Paulo para obtenção do \\ Título de Doutora em Química.
}

Orientador: Prof. Dr. Henrique Eisi Toma

São Paulo 
Autorizo a reprodução e divulgação total ou parcial deste trabalho, por qualquer meio convencional ou eletronico, para fins de estudo e pesquisa, desde que citada a fonte.

Ficha Catalográfica elaborada eletronicamente pelo autor, utilizando o programa desenvolvido pela Seção Técnica de Informática do ICMC/USP e adaptado para a Divisão de Biblioteca e Documentação do Conjunto das Químicas da USP

Bibliotecária responsável pela orientação de catalogação da publicação: Marlene Aparecida Vieira - CRB - 8/5562

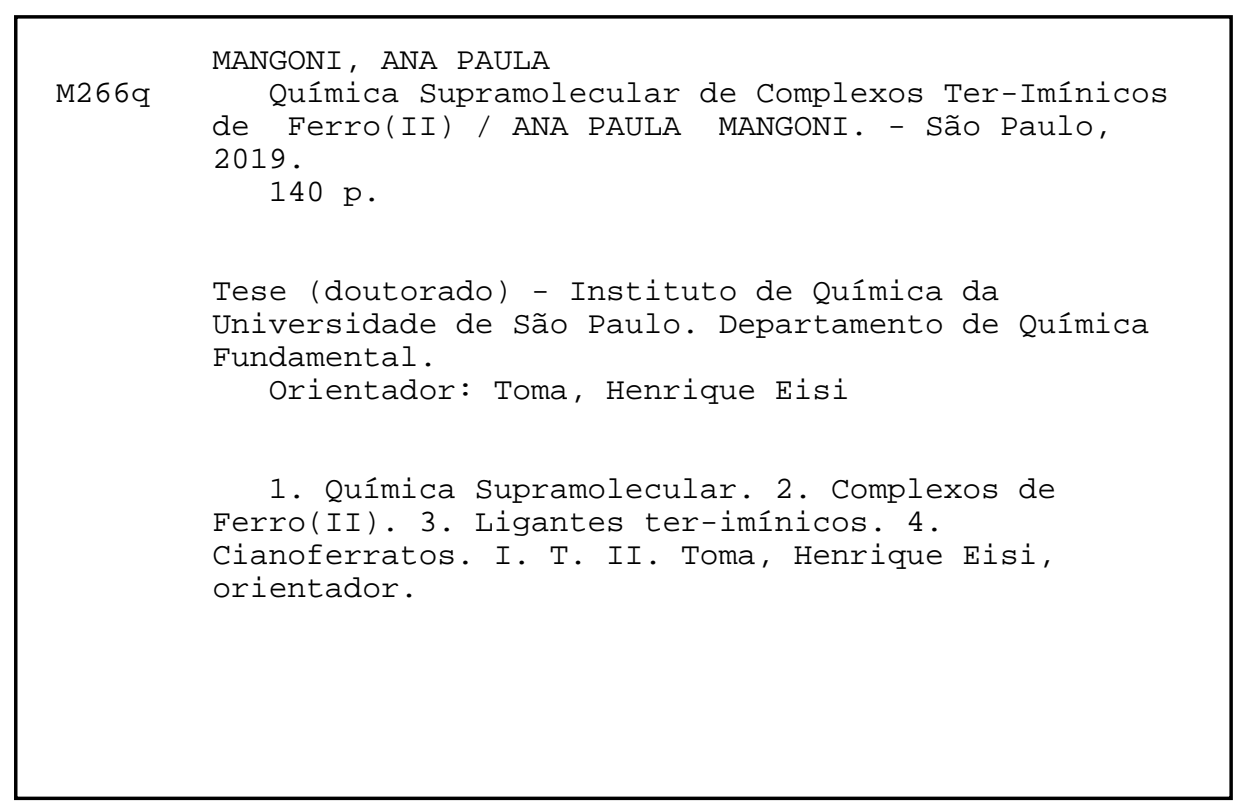



Aos meus pais, Marques e Marilene, às minhas irmãs, Josiane e Andréia, e ao Allan, por todo amor e carinho. 


\section{AGRADECIMENTOS}

Ao professor Henrique Eisi Toma pela oportunidade, orientação, disponibilidade sem igual. Por toda a ajuda oferecida, em todos os aspectos e em vários momentos.

Ao professor Koiti Araki, que assim como o prof. Toma, nunca deixou faltar nada no laboratório e sempre esteve dispostos a conversar sobre ciência, tentando proporcionar um ambiente saudável e criativo para o desenvolvimento dos nossos trabalhos.

Ao Allan pelo carinho, paciência, ajuda com o $\mathrm{LT}_{\mathrm{E}} \mathrm{X}$ e com tantos outros programas, por estar sempre ao meu lado (não importanto o horário e o local) me ajudando a transpor os obstáculos que surgiram ao logo de todos esses anos de companheirismo.

Aos meus pais, Marilene e Marques, pelo amor incondicional. Por sempre fazerem o possível e o impossível para que suas filhas conquistassem seus sonhos. Por todo o carinho e dedicação que sempre tiveram comigo. Por serem o exemplo mais belo de pessoas altruístas. Obrigada por sempre serem o meu porto seguro.

Às minhas irmãs, Josiane e Andréia, pelo amor, carinho, incentivo. Por entenderem minha ausência frequente. Aos meus cunhados, Fabiano e Gilmar, por todo o incentivo.

À minha nonna Rosalina, que a sua maneira, construiu uma família super unida e que nunca deixou que seus netinhos se sentissem sozinhos, mesmo a milhares de quilômetros de distância. Muito obrigada por todo o amor e carinho ao longo da minha vida.

Aos pais do Allan, Terezinha e Allan, e à irmã, Allinny, por todo o incentivo e preocupação demonstrados de forma muito carinhosa ao longo de todos esses anos.

Ao George, meu melhor amigo ever! Que além da amizade também foi muito importante nos primeiro passos, desde empréstimos de solventes/reagentes até plotagem de dados. Fora toda a convivência pessoal e científica que deixaram os primeiros anos de doutorado mais leves e divertidos (sua risada ainda ecoa na nossa casa!).

Às minhas amigas que estão longe, Queite, Angela, Estela e Bárbara, por todas as mensagens e ligações com palavras de incentivo e carinho. Obrigada por sempre estarem presentes na minha vida, mesmo que na forma virtual, e compreenderem minhas longas fases de isolamento.

Aos meus amigos e colaboradores Tiago (Borra), Bruno, Juan e Alexander por sempre serem tão prestativos e dispostos a ajudar em tudo o que fosse preciso e solicitado, além de terem sempre um ombro amigo para os desabafos rotineiros e normais aos seres humanos! 
Meninos, vocês foram indispensáveis nessa longa caminhada! Um muito obrigada em letras garrafais!

Aos meus amigos: Adriana, Diego, Michele, Vanessa, Camila, Julio, Cléia, Kassio, Maurício Portiolli, Rute, Tayana, por sempre estarem prsentes, incentivando, ajudando no que fosse preciso, compartilhando um cafézinho, lanchinho ou exercícios físicos (...) com risadas ou desabafos. Todos esses anos de IQ não teriam sido agradáveis sem ter vocês por perto.

Aos meus amigos/compadres de longa data, Fabi, André, Marciani, Pépe, Cibele, Alesandro, e minhas afilhadas Laura, Clara e Alice, por todo o incentivo, carinho e preocupação ao longo dessa caminhada. Por também entenderem e aceitarem minha ausência.

Aos nossos vizinhos de laboratório e amigos, Rodolfo, Ronaldo, Laís, Ricardo, Cida, todo o grupo da Prof ${ }^{\mathrm{a}}$ Ana Maria, da Prof ${ }^{\mathrm{a}}$ Vera, da Prof ${ }^{\mathrm{a}}$ Denise, do Prof ${ }^{\mathrm{o}}$ Alcindo, por proporcionarem um ambiente amigável nos corredores do IQ, principalmente no B2T, por nunca negarem ajuda e/ou empréstimo de reagentes e/ou equipamentos. Muito obrigada pela convivência sempre agradável e amigável que vocês proporcionaram!

Aos colegas de laboratório (me desculpem caso esqueci de alguém): Sabrina, Roberta, Mayara, Daiana, Maria Rosana, Maria Luiza, André, Daniel (Peru), Sérgio, Geoanne, Jorge Shinohara, Josué, Bill, Helton, Fernando, Robson, Delmarcio, Daniel, Jonnatan, ICs Henrique, Luiz Gustavo, Leandro, João, Ken e Mariana (filhos, sobrinhos e netos de coração), por todos os momentos de descontração na salinha do café, afinal a "zoeira"no LQSN não tem limites! Por todas as tentativas, por parete de alguns, em manter o grupo forte e unido, até mesmo nas faxinas, por toda a juda científica direta ou indireta e por todas as adversidades vividas, afinal, isso também nos faz crescer!

Aos técnicos Alceu, Marcelo e Ulisses, em especial Alceu e Marcelo, por sempre estarem dispostos a nos ajudar, independente do que fosse pedido e do horário, por manterem o laboratório em ordem, por nos ajudarem com a utilização dos equipamentos, nos ajudando nas realizações das mais diversas medidas. Por todo o bom humor diário! Vocês fazem toda a diferença para o funcionamento do laboratório!

Ao Bruno, Jorge e Marcelo, pela ajuda com as medida de espectroscopia Raman.

Aos servidores da Central Analítica (IQ-USP), sempre dispostos a nos atender e a fazer as medidas solicitadas da melhor maneira possível! Muito obrigada por toda a paciência que sempre tiveram ao me atender.

Aos servidores técnico-administrativos do IQ, em especial, Milton e Marcelo, por toda a ajuda prestada.

Ao Professor Breno e às Professoras Ana Maria e Denise pelas discussões e sugestões no Exame de Qualificação.

À psicóloga Elza por ter me ajudado a enfrentar os problemas e olhá-los de outro ângulo, nossas longas conversas durante o último ano foram muito importantes. Ao psiquiatra Flávio, pelas duras e verdadeiras palavras que fizeram com que eu me olhasse de 
outra maneira.

Ao grupo de professores e funcionários da Fieb (ITB- Parque Imperial), em especial à Heidy, Ariadne e ao Silvio, por todo o apoio e por acreditarem em mim.

As minhas mais novas amigas: Adriana, Cristina, Emanuelle, Marina e Regina, por todo carinho, incentivo, conversas, dicas de trabalho e de vida, entre tantas outras coisas. Vocês foram extremamente importantes nesses últimos meses!

Ao CNPq, pela bolsa de Doutorado (Processo: 140484/2014-0) e apoio financeiro para que a realização deste trabalho fosse possível.

À FAPESP pelo apoio financeiro indispensável à realização do trabalho de pesquisa desenvolvido pelo nosso grupo.

Ao Instituto de Química da Universidade de São Paulo pela disponibilidade das suas instalações para a realização deste trabalho.

A todos os brasileiros que arduamente e honestamente trabalham e pagam impostos, que não são poucos. Vocês também são responsáveis pela realização deste trabalho.

Muito Obrigada! 
A verdadeira viagem de descobrimento não consiste em procurar novas paisagens, e sim em ter novos olhos.

Marcel Proust 


\section{RESUMO}

\section{MANGONI, A. P. Química Supramolecular de Complexos Ter-Imínicos de Ferro}

(II). 2019. 133 f. Tese (Doutorado) - Programa de Pós-Graduação em Química - Instituto de Química, Universidade de São Paulo, São Paulo.

A química dos complexos de bis(ter-iminas) de ferro(II) contendo os ligantes tridentados fenilterpiridina (phtpy), piridilterpiridina (pytpy), fenilterpirazina (phtpz) e piridilterpirazina (pytpz) foi tratada nesta Tese. Os complexos exibem configuração de spin baixo, exibindo coloração violeta intensa decorrentes de transições de transferência de carga do ferro(II) para a ter-imina, $d \pi-p \pi^{*}$. Suas configurações lineares rígidas mostram-se adequadas para a realização de montagens supramoleculares com íons de metais de transição, explorando a ligação entre os grupos piridina e pirazina, e este aspecto distinto foi especialmente focado neste trabalho. A química sintética dos ligantes, obtidos a partir do método de Kröhnke modificado, e dos complexos bis-substituídos foi aqui elaborada com excelentes resultados. A caracterização dos ligantes e dos complexos foi realizada a partir de análises de CHN, espectroscopia eletrônica, RMN e Raman, espectrometria de massas e voltametria cíclica. Os estudos teóricos foram realizados utilizando métodos semiempíricos ZINDO/S. Todos os complexos exibem forte efeito Raman ressonante associado ao cromóforo ferro(II)ter-imínico. Os grupos piridil e pirazil (L) podem ser protonados em soluções fortemente ácidas, e também podem atuar como ligantes pontes formando uma série de sucessivos complexos de bi à heptanucleares, com o íon pentacianidoferrato(II). Tais complexos exibem novas bandas de transferência de carga no visível, refletindo as propriedades eletrônicas do cromóforo periférico $\left\{F e^{I I}(C N)_{5} L\right\}$. Seus espectros de Raman ressonante foram investigados em comparação com os complexos mononucleares correspondentes. Na presença de íons de metais de transição, Mn(II), Co(II), Ni(II), Cu(II), $\mathrm{Zn}$ (II) e Fe(III), os complexos supra-moleculares de pentacianidoferrato(II) formam uma série de compostos análogos ao Azul da Prússia, produzindo filmes moleculares de grande interesse como novos materiais poliméricos e eletrocatalíticos.

Palavras-chave: Química supramolecular, complexos de ferro(II), ligantes terimínicos, cianoferratos . 


\section{ABSTRACT}

\section{MANGONI, A. P. Supramolecular Chemistry of Ter-Imine Iron(II) Complexes.}

2019. 133 p. Thesis (Doctoral) - Graduate Program in Chemistry - Instituto de Química, Universidade de São Paulo, São Paulo.

The chemistry of bis(ter-imine)iron(II) complexes containing the phenylterpyridine (phtpy), pyridylterpyridine (pytpy), phenylterpyrazine (phtpz) and pyridylterpyrazine (pytpz) tridentate ligands is dealt with in this Thesis. The complexes exhibit low spin configuration, displaying strong red-violet colors arising from iron(II) to ter-imine, $d \pi-p \pi *$ charge-transfer transitions. Their rigid linear configurations proved suitable for performing supramolecular assemblies with transition metal ions, by exploring the bridging pyridine and pyrazine moieties, and this distinct aspect has been specially focused on this work. The synthetic chemistry of the ligands, obtained from the Kröhnke method, and of the bis-substituted complexes was here elaborated with excellent results. Characterization of the ligands and complexes was carried out based on CHN analyses, electronic, NMR and Raman spectroscopy, mass spectrometry and cyclic voltammetry. Theoretical studies were carried out using ZINDO/S semiempirical methods. All the complexes exhibit strong resonance Raman effect associated with the iron(II) ter-imine chromophore. The pyridyl and pyrazyl groups (L) can be protonated in strongly acidic solutions, and can also act as bridging ligands forming a series of successive, bi-to-heptanuclear complexes with the pentacyanidoferrate(II) ion. Such complexes display new charge-transfer bands in the visible, reflecting the electronic properties of the $\left\{F e^{I I}(C N)_{5} L\right\}$ peripheral chromophore. Their resonance Raman spectra have been investigated in comparison with the corresponding mononuclear complexes. In the presence of transition metal ions, $\mathrm{Mn}$ (II), $\mathrm{Co}(\mathrm{II}), \mathrm{Ni}(\mathrm{II}), \mathrm{Cu}(\mathrm{II}), \mathrm{Zn}(\mathrm{II})$ and $\mathrm{Fe}(\mathrm{III})$ ions, the pentacyanidoferrate(II)-supramolecular complexes form a series of Prussian blue type of compounds, yielding molecular films of great interest as new conducting polymeric and electrocatalytic materials.

Keywords: Supramolecular chemistry, iron(II) complexes, ter-imine ligands, cyanoferrates . 


\section{LISTA DE FIGURAS}

1.1 Construção de estruturas com diferentes geometrias pela abordagem de ligação direcional. Os centros metálicos têm um grande efeito direcional nas formas geométricas resultantes. Os metais são introduzidos com ligantes direcionais ou bloqueadores. Figura adaptada da referência [18]. . . . . . . 25

1.2 Estrutura dos ligantes 2,2'-bipiridina e 2,2':6',2'-terpiridina (destaque em vermelho para os grupos $\mathrm{N}=\mathrm{C}-\mathrm{C}=\mathrm{N}$ e $\mathrm{N}=\mathrm{C}-\mathrm{C}=\mathrm{N}-\mathrm{C} \ldots \mathrm{C} \ldots \mathrm{N}) . \ldots . . . \quad 27$

1.3 As duas abordagens sintéticas básicas para terpiridinas. (a) montagem do anel por acoplamento cruzado e (b) via formação do anel central. As linhas onduladas indicam locais onde há a formação de ligações C-C. . . . . . . . 28

1.4 Possível montagem do ligante com pirazinas substituindo as piridinas do anel quelato através da coordenação bimetálica sequencial. Figura adaptada

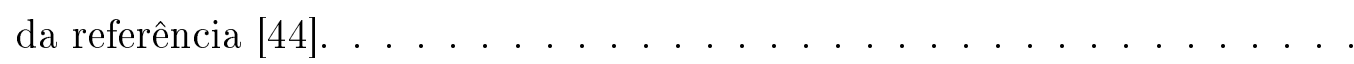

1.5 Representação esquemática das várias maneiras em que a informação pode ser transferida em uma molécula. Figura adapdada da referência [24]. . . . 32

1.6 Esquema do processo de formação e crescimento dos filmes automontados obtidos pela redução eletroquímica de íons $F e^{3+}$ e sua coordenação a clusters modificados com ligantes terpiridínicos. Topo: Formação de um polímero de coordenação usando o complexo de ponte $\left[\mathrm{Ru}_{3} \mathrm{O}\left(\mathrm{CH}_{3} \mathrm{COO}\right)_{6}(\text { pytpy })_{3}\right]^{+}$; Inferior (A-F): (A) A varredura cíclica leva a formação de espécies $F e^{2+}$ (B) que são prontamente coordenados pelos ligantes terpiridínicos do cluster (C). À medida que mais ciclos são realizados mais íons $F e^{2+}$ são gerados e as estruturas "sementes" começam a crescer (D)-(E). O crescimento do filme leva a saturação do eletrodo $(\mathrm{F})$, diminuindo a taxa de formação de íons coordenantes $\left(\mathrm{Fe}^{2+}\right)$. Figura adaptada da referência [61]. . . . . . . . 34

1.7 Ilustração esquemática do processo de coordenação em etapas para a formação de um complexo metálico bis-terpiridínico sobre um substrato. Figura adapdada da referência [62]. . . . . . . . . . . . . . . . 35

1.8 (a) Diagrama qualitativo dos orbitais moleculares do $C N^{-}$. (b) Esquema de sobreposição orbital na retrodoação $\pi$ para o ligante cianeto. Figura adapdada da referência [75]. . . . . . . . . . . . . . . . . 37 
1.9 Representação esquemática do íon pentacianidoferrato(II) monocoordenativo. 38

1.10 Estrutura da supramolécula $\left[R u(b p z)_{3}\left\{F e(C N)_{5}\right\}_{6}\right]$ sintetizada por Toma e Lever [86]. . . . . . . . . . . . . . . . . . 39

2.1 Estrutura dos complexos sintetizados: $\left[\mathrm{Fe}(\text { phtpy })_{2}\right]^{2+},\left[\mathrm{Fe}(\text { pytpy })_{2}\right]^{2+},\left[\mathrm{Fe}(\text { phtpz })_{2}\right]^{2+}$ $\mathrm{e}\left[\mathrm{Fe}(\text { pytpz })_{2}\right]^{2+}$.

4.1 Esquema de síntese one-pot para os ligantes: a)phtpy e pytpy e b)phtpz e

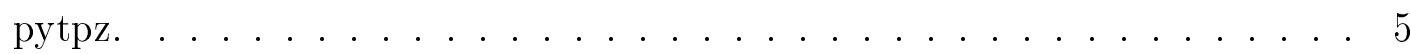

4.2 Ilustração das interações estéricas e da mudança de ambiente químico dos prótons 6 e 3' no ligante terpiridínico livre e com a formação do complexo. (A) estrutura da terpiridina com a identificação dos prótons; (B) conformação para o ligante terpiridínico livre, onde pode-se observar que o próton 3' tem como vizinho o átomo de nitrogênio; (C) próton 6 localizado acima do plano do anel aromático do ligante adjacente; (D) a formação do complexo muda a vizinhança do próton 3', que passa agora a ser vizinho do próton 3. Figura adapdada da referência $[24] \ldots \ldots$. . . . . . . . . 55

4.3 Espectro ${ }^{1} \mathrm{H}-\mathrm{RMN}\left(\mathrm{CDCl}_{3}, 500 \mathrm{MHz}\right)$ do ligante phtpy. Os sinais foram ajustados em função do sinal do $C D C l_{3} \ldots \ldots \ldots$. . . . . . . 56

4.4 Espectro ${ }^{1} \mathrm{H}-\mathrm{RMN}\left(\mathrm{CD}_{3} \mathrm{CN}, 500 \mathrm{MHz}\right)$ do complexo $\left[\mathrm{Fe}(\text { phtpy })_{2}\right]^{2+}$. Os sinais foram ajustados em função do sinal do TMS.

4.5 Espectro ${ }^{1} \mathrm{H}-\mathrm{RMN}\left(\mathrm{CDCl}_{3}, 300 \mathrm{MHz}\right)$ do ligante pytpy. Os sinais foram ajustados em função do sinal do TMS.

4.6 Espectro ${ }^{1} \mathrm{H}-\mathrm{RMN}\left(\mathrm{CD}_{3} \mathrm{CN}, 300 \mathrm{MHz}\right)$ do complexo $\left[\mathrm{Fe}(\text { pytpy })_{2}\right]^{2+}$. Os sinais foram ajustados em função do sinal $C D_{3} C N$. . . . . . . . . . . 58

4.7 Espectro ${ }^{1} \mathrm{H}-\mathrm{RMN}\left(\mathrm{CDCl}_{3}, 500 \mathrm{MHz}\right)$ do ligante phtpz. Os sinais foram ajustados em função do sinal de $C D C l_{3}$. . . . . . . . . . . . . 59

4.8 Espectro ${ }^{1} \mathrm{H}-\mathrm{RMN}\left(\mathrm{C}_{3} \mathrm{D}_{6} \mathrm{O}, 300 \mathrm{MHz}\right)$ do complexo $\left[\mathrm{Fe}(\text { phtpz })_{2}\right]^{2+}$. Os sinais foram ajustados em função do sinal $C_{3} D_{6} O \ldots \ldots$. . . . . . . 60

4.9 Espectro ${ }^{1} \mathrm{H}-\mathrm{RMN}\left(\mathrm{D}_{2} \mathrm{O}, \mathrm{CF}_{3} \mathrm{COOD}, 500 \mathrm{MHz}\right)$ do ligante pytpz. Os sinais foram ajustados em função do sinal de $D_{2} O$.

4.10 Espectro ${ }^{1} \mathrm{H}-\mathrm{RMN}\left(\mathrm{CD}_{3} \mathrm{CN}, 500 \mathrm{MHz}\right)$ do complexo $\left[\mathrm{Fe}(\text { pytpz })_{2}\right]^{2+}$. Os sinais foram ajustados em função do sinal $C D_{3} C N \ldots$. . . . . . . . 62

4.11 Espectro eletrônico do complexo $\left[\mathrm{Fe}(\text { phtpy })_{2}\right]\left(P F_{6}\right)_{2}$ em acetonitrila, incluindo a deconvolução gaussiana das bandas na região do visível. . . . . .

4.12 Espectro eletrônico do complexo $\left[\mathrm{Fe}(\text { pytpy })_{2}\right]\left(\mathrm{PF}_{6}\right)_{2}$ em acetonitrila, incluindo a deconvolução gaussiana das bandas na região do visível. . . . . . . 64

4.13 Espectro eletrônico do complexo $\left[F e(p h t p z)_{2}\right]\left(P F_{6}\right)_{2}$ em acetonitrila, incluindo a deconvolução gaussiana das bandas na região do visível. 
4.14 Espectro eletrônico do complexo $\left[\mathrm{Fe}(\text { pytpz })_{2}\right]\left(P F_{6}\right)_{2}$ em acetonitrila, incluindo a deconvolução gaussiana das bandas na região do visível. . . . . . 65

4.15 Orbitais moleculares (HOMO/LUMO) envolvidos nas transições observadas experimentalmente para o complexo $\left[\mathrm{Fe}(\text { phtpy })_{2}\right]^{2+}$ na região do visível. 67

4.16 Orbitais moleculares (HOMO/LUMO) envolvidos nas transições observadas experimentalmente para o complexo $\left[\mathrm{Fe}(\text { pytpy })_{2}\right]^{2+}$ na região do visível. 68

4.17 Orbitais moleculares (HOMO/LUMO) envolvidos nas transições observadas experimentalmente para o complexo $\left[F e(p h t p z)_{2}\right]^{2+}$ na região do visível. 70

4.18 Orbitais moleculares (HOMO/LUMO) envolvidos nas transições observadas experimentalmente para o complexo $\left[F e(p y t p z)_{2}\right]^{2+}$ na região do visível. 71

4.19 Efeitos da protonação no complexo $\left[F e(p y t p y)_{2}\right]^{2+}$ - variação espectral em função do pH e reprodução interna em maiores detalhes. . . . . . . . . . . 72

4.20 Orbitais moleculares (HOMO/LUMO) envolvidos nas transições observadas experimentalmente para o complexo $\left[\mathrm{Fe}(\text { pytpy })_{2}\right]^{2+}$ na região do visível em meio ácido. . . . . . . . . . . . . . . . . . . . 73

4.21 Curva de titulação do complexo $\left[\mathrm{Fe}(\text { pytpy })_{2}\right]^{2+} \ldots \ldots \ldots$. . . . . . . 74

4.22 Efeitos da protonação no complexo $\left[F e(p y t p z)_{2}\right]^{2+}$ - variação espectral em função do pH e reprodução interna em maiores detalhes. . . . . . . . . . . 75

4.23 Curva de titulação do complexo $\left[\mathrm{Fe}(\text { pytpz })_{2}\right]^{2+} \ldots \ldots \ldots \ldots$. . . . . 76

4.24 Orbitais moleculares (HOMO/LUMO) envolvidos nas transições observadas experimentalmente para o complexo $\left[F e(p y t p z)_{2}\right]^{2+}$ na região do visível em meio fortemente ácido (protonação total) . . . . . . . . . . . . . 7

4.25 Efeitos da protonação no complexo $[F e(p h t p z) 2]^{2+}$ - variação espectral em função do pH e reprodução interna em maiores detalhes. . . . . . . . . . . 78

4.26 Orbitais moleculares (HOMO/LUMO) envolvidos nas transições observadas experimentalmente para o complexo $\left[F e(p h t p z)_{2}\right]^{2+}$ na região do visível em meio fortemente ácido (protonação total) . . . . . . . . . . . . . 79

4.27 Espectros Raman ressonante do complexo $\left[\mathrm{Fe}(\text { phtpy })_{2}\right]^{2+}$ excitado em 633 , 532 e $488 \mathrm{~nm}$, destacando os orbitais moleculares envolvidos nas transições eletrônicas correspondentes.

4.28 Espectros Raman ressonante do complexo $\left[\mathrm{Fe}(\text { pytpy })_{2}\right]^{2+}$ excitado em 633 , 532 e $488 \mathrm{~nm}$, destacando os orbitais moleculares envolvidos nas transições eletrônicas correspondentes. . . . . . . . . . . . . . .

4.29 Espectros Raman ressonante do complexo $\left[\mathrm{Fe}(\text { phtpz })_{2}\right]^{2+}$ excitado em 633 e $488 \mathrm{~nm}$, destacando os orbitais moleculares envolvidos nas transições eletrônicas correspondentes. . . . . . . . . . . . . . . . .

4.30 Espectros Raman ressonante do complexo $\left[\mathrm{Fe}(\text { pytpz })_{2}\right]^{2+}$ excitado em 633 e $488 \mathrm{~nm}$, destacando os orbitais moleculares envolvidos nas transições eletrônicas correspondentes. . . . . . . . . . . . . . . 84 
5.1 Geometria molecular otimizada $\left(M M^{+}\right)$para o complexo trinuclear $\left[\left\{F e(C N)_{5}\right\}(\mu-\right.$ pytpy) $F e(\mu-$ pytpy $\left.)\left\{F e(C N)_{5}\right\}\right]^{4-}$.

5.2 Monitoração espectrofotométrica da interação do complexo $\left[F e(p y t p y)_{2}\right]^{2+}$ com íons $\left[\mathrm{Fe}(\mathrm{CN})_{5}\right]^{3-}$ (1 e 2 equivalentes) em solução aquosa. . . . . . . 88

5.3 Espectros Raman comparativos dos complexos $\left[\mathrm{Fe}(\text { pytpy })_{2}\right]^{2+} \mathrm{e}\left[\left\{\mathrm{Fe}(\mathrm{CN})_{5}\right\}(\mu-\right.$ pytpy) $F e(\mu-$ pytpy $\left.)\left\{F e(C N)_{5}\right\}\right]^{4-}$ com excitação em $633 \mathrm{~nm}$. . . . . . 89

5.4 Monitoração do potencial redox dos íons $\left[\mathrm{Fe}(\mathrm{CN})_{5}\right]^{3-}$ coordenados aos ligantes piridínicos do complexo $\left[\mathrm{Fe}(\text { pytpy })_{2}\right]^{2+} \ldots \ldots \ldots$. . . . . . 90

5.5 Geometria molecular otimizada $\left(M M^{+}\right)$para o complexo pentanuclear $\left[F e(\mu-p h t p z)\left\{F e(C N)_{5}\right\}_{4}\right]^{10-} \ldots \ldots \ldots \ldots \ldots \ldots \ldots \ldots$

5.6 Monitoração espectrofotométrica da interação do complexo $\left[F e(p h t p z)_{2}\right]^{2+}$ com íons $\left[\mathrm{Fe}(\mathrm{CN})_{5}\right]^{3-}$ (1 a 4 equivalentes) em solução aquosa. . . . . . . . 92

5.7 Espectros Raman comparativos dos complexos $\left[F e(p h t p z)_{2}\right]^{2+}$ e $[F e(\mu-$ phtpz $\left.)_{2}\left\{F e(C N)_{5}\right\}_{4}\right]^{10-}$ com excitação em $633 \mathrm{~nm}$. . . . . . . . . . . 93

5.8 Espectros Raman comparativos dos complexos $\left[\mathrm{Fe}(\text { phtpz })_{2}\right]^{2+} \mathrm{e}[\mathrm{Fe}(\mu-$

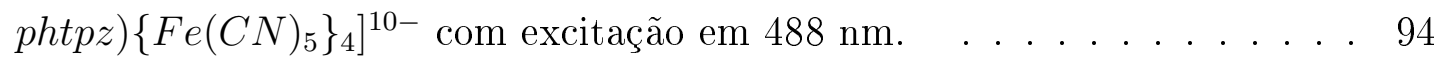

5.9 Monitoração do potencial redox dos íons $\left[\mathrm{Fe}(\mathrm{CN})_{5}\right]^{3-}$ coordenados aos ligantes pirazínicos do complexo $\left[F e^{I I}(p h t p z)_{2}\right]^{2+} \ldots \ldots \ldots$. . . . . . 95

5.10 Geometria molecular otimizada $\left(M M^{+}\right)$para o complexo pentanuclear $\left[F e(\mu-p y t p z)_{2}\left\{F e(C N)_{5}\right\}_{6}\right]^{16-} \ldots \ldots \ldots \ldots \ldots \ldots$

5.11 Monitoração espectrofotométrica da interação $\left[\mathrm{Fe}(\text { pytpz })_{2}\right]^{2+} \operatorname{com}$ íons $\left[\mathrm{Fe}(\mathrm{CN})_{5}\right]^{3-}$ em solução aquosa. . . . . . . . . . . . . . . . . 97

5.12 Espectros Raman comparativos dos complexos $\left[\mathrm{Fe}(\text { pytpz })_{2}\right]^{2+}$ e $[\mathrm{Fe}(\mu-$ pytpz) $\left.\left\{\mathrm{Fe}(\mathrm{CN})_{5}\right\}_{6}\right]^{16-}$ com excitação em $633 \mathrm{~nm}$. . . . . . . . . . 98

5.13 Monitoração do potencial redox dos íons $\left[\mathrm{Fe}(\mathrm{CN})_{5}\right]^{3}$ coordenados aos ligantes pirazínicos do complexo $\left[F e(p y t p z)_{2}\right]^{2+} \ldots \ldots \ldots$. . . . . . . 99

5.14 Espectros eletrônicos dos compostos $F e_{x}^{I I I}\left[F e(p y t p z)_{2}\left\{F e(C N)_{5}\right\}_{6}\right]$ e $Z n_{x}\left[F e(p y t p z)_{2}\left\{F e(C N)_{5}\right\}_{6}\right]$ suspensos em filme de PVA. . . . . . . . 101

5.15 Espectros Raman dos compostos poliméricos $F e_{x}^{I I I}\left[\mathrm{Fe}(\text { pytpz })_{2}\left\{\mathrm{Fe}(\mathrm{CN})_{5}\right\}_{6}\right]$ e $Z n_{x}\left[F e(p y t p z)_{2}\left\{F e(C N)_{5}\right\}_{6}\right]$ em PVA, em comparação com o do composto inicial em solução. . . . . . . . . . . . . . . . . . . . 103

5.16 Espectros eletrônicos dos compostos $F e_{x}^{I I I}\left[F e(p h t p z)_{2}\left\{F e(C N)_{5}\right\}_{4}\right]$ e $Z n_{x}\left[F e(p h t p z)_{2}\left\{F e(C N)_{5}\right\}_{4}\right]$ suspensos em filme de PVA. . . . . . . . 104

5.17 Espectros Raman dos compostos poliméricos $F e_{x}^{I I I}\left[\mathrm{Fe}(p h t p z)_{2}\left\{\mathrm{Fe}(\mathrm{CN})_{5}\right\}_{4}\right]$ e $Z n_{x}\left[F e(p h t p z)_{2}\left\{F e(C N)_{5}\right\}_{4}\right]$ em PVA, em comparação com o do composto inicial em solução. . . . . . . . . . . . . . . . . 105

5.18 Espectros eletrônicos dos compostos $F e_{x}^{I I I}\left[\mathrm{Fe}(\text { pytpy })_{2} \quad\left\{\mathrm{Fe}(\mathrm{CN})_{5}\right\}_{4}\right] \quad$ e $Z n_{x}\left[\mathrm{Fe}(\text { pytpy })_{2}\left\{\mathrm{Fe}(\mathrm{CN})_{5}\right\}_{4}\right]$ suspensos em filme de PVA. . . . . . . 106 
5.19 Espectros Raman dos compostos poliméricos $\mathrm{Fe}_{x}^{I I I}\left[\mathrm{Fe}(\text { pytpy })_{2}\left\{\mathrm{Fe}(\mathrm{CN})_{5}\right\}_{4}\right]$ e $Z n_{x}\left[\mathrm{Fe}(\text { pytpy })_{2}\left\{\mathrm{Fe}(\mathrm{CN})_{5}\right\}_{4}\right]$ em PVA, em comparação com o do composto inicial em solução. . . . . . . . . . . . . . . . . . 107

5.20 Polímero de coordenação gerado pela formação de pontes intramoleculares nos complexos em estudo, mediadas por íons de metais de transição. . . . 111

A.1 Espectro ESI-MS do complexo $\left[\mathrm{Fe}(\text { phtpy })_{2}\right]\left(\mathrm{PF}_{6}\right)_{2}$. . . . . . . . . . 126

A.2 Espectro ESI-MS do complexo $\left[\mathrm{Fe}(\text { pytpy })_{2}\right]\left(\mathrm{PF}_{6}\right)_{2}$. . . . . . . . . 126

A.3 Espectro ESI-MS do complexo $\left[\mathrm{Fe}(\text { phtpz })_{2}\right]\left(\mathrm{PF}_{6}\right)_{2}$. . . . . . . . . . 127

A.4 Espectro ESI-MS do complexo $\left[\mathrm{Fe}(\text { pytpz })_{2}\right]\left(\mathrm{PF}_{6}\right)_{2}$. . . . . . . . . 127

C.1 Monitoração espectrofotométrica da titulação do complexo $\left[F e(p h t p y)_{2}\right]^{2+}$ com íons $\left[\mathrm{Fe}(\mathrm{CN})_{5}\right]^{3-}(1,2$ e 4 equivalentes $)$ em solução aquosa. . . . . . . 129

C.2 Espectro eletrônico do íon $\left[\mathrm{Fe}(\mathrm{CN})_{5}\right]^{3-}$ em solução aquosa. . . . . . . . . . 130 


\section{LISTA DE TABELAS}

3.1 Solventes e reagentes utilizados nas sínteses e caracterizações. . . . . . . 44

4.1 Valores dos deslocamentos químicos do ligante phtpy livre e do complexo $\left[\mathrm{Fe}(\text { phtpy })_{2}\right]^{2+}$ obtidos em soluções de $C D C l_{3}$ e $C D_{3} C N$, respectivamente. $\quad 57$

4.2 Valores dos deslocamentos químicos do ligante pytpy livre e do complexo $\left[\mathrm{Fe}(\text { pytpy })_{2}\right]^{2+}$ obtidos em soluções de $C D C l_{3}$ e $C D_{3} C N$, respectivamente. $\quad 59$

4.3 Valores dos deslocamentos químicos do ligante phtpz livre e do complexo $\left[F e(p h t p z)_{2}\right]^{2+}$ obtidos em soluções de $C D C l_{3}$ e acetona-d6, respectivamente. 61

4.4 Valores dos deslocamentos químicos do ligante pytpz livre e do complexo $\left[\mathrm{Fe}(\text { pytpz })_{2}\right]^{2+}$ obtidos em soluções de trifluoretanol e $C D_{3} C N$, respectivamente. . . . . . . . . . . . . . . . 63

4.5 Espectros eletrônicos com deconvolução de bandas, simulação teórica (ZIN$\mathrm{DO} / \mathrm{S})$ e atribuição. . . . . . . . . . . . . . . . . 66

4.6 Espectros eletrônicos com deconvolução de bandas, simulação teórica (ZIN$\mathrm{DO} / \mathrm{S})$ para o complexo $\left[\mathrm{Fe}(\text { pytpy })_{2}\right]^{2+} \ldots \ldots \ldots \ldots$. . . . . . . . 67

4.7 Espectros eletrônicos com deconvolução de bandas, simulação teórica (ZIN$\mathrm{DO} / \mathrm{S})$ e atribuição. . . . . . . . . . . . . . . . . 69

4.8 Espectros eletrônicos com deconvolução de bandas, simulação teórica (ZIN$\mathrm{DO} / \mathrm{S})$ e atribuição. . . . . . . . . . . . . . . . 70

5.2 Picos Raman para os complexos $\left[\mathrm{Fe}(\text { phtpy })_{2}\right]^{2+}$ e $\left[\mathrm{Fe}(\text { phtpz })_{2}\right]^{2+}$ e a supramolécula derivada com atribuição provisória. . . . . . . . . . . 108

5.1 Picos Raman para o complexo $\left[\mathrm{Fe}(\text { pytpy })_{2}\right]^{2+}$ e a supramolécula derivada com atribuição provisória. . . . . . . . . . . . . . . . . . 109

5.3 Picos Raman para o complexo $\left[F e(p y t p z)_{2}\right]^{2+}$ e a supramolécula derivada com atribuição provisória. . . . . . . . . . . . . . . . . 109

B.1 Comprimentos de onda e intensidades $(\log \varepsilon)$ das bandas dos complexos ter-imínicos de $\mathrm{Fe}(\mathrm{II}) \ldots \ldots \ldots$. . . . . . . . . . . . . 128 


\title{
LISTA DE ABREVIATURAS E SIGLAS
}

\author{
bpy 2,2'-bipiridina \\ CA Central Analítica \\ DFT Density Functional Theory \\ EPH Eletrodo Padrão de Hidrogênio \\ ESI-MS ElectroSpray Ionization Mass Spectrometry (espectrometria de massas por elec- \\ trospray) \\ $\mathrm{Fe}(\text { pytpy })_{2}^{2+}$ Complexo de ferro(II) com o ligante 4'(4-piridil)-2,2':6'2"terpiridina \\ $\mathrm{Fe}(\text { phtpy })_{2}^{2+}$ Complexo de ferro(II) com o ligante 4'-fenil-2,2':6',2"terpiridina \\ $F e(p y t p z)_{2}^{2+}$ Complexo de ferro(II) com o ligante 2,6-bis(2-pirazil)-4,4'-bipiridina \\ $\mathrm{Fe}(\text { phtpz })_{2}^{2+}$ Complexo de ferro(II) com o ligante 2,6-di(2-pirazinil)-4-(fenil)-piridina \\ F.O. $\quad$ Força do oscilador \\ HOMO Highest Occupied Molecular Orbital (orbital molecular ocupado de mais alta \\ energia) \\ IQ Instituto de Química \\ L Ligante \\ LUMO Lowest Unoccupied Molecular Orbital (orbital molecular desocupado de mais \\ baixa energia) \\ M Metal \\ $M M^{+} \quad$ Mecânica Molecular \\ MOF Metal Organic Framework \\ OM Orbital Molecular \\ phtpy 4'-fenil-2,2':6',2'terpiridina \\ pytpy 4'(4-piridil)-2,2':6'2'terpiridina \\ phtpz 2,6-di(2-pirazinil)-4-(fenil)-piridina \\ pytpz 2,6-bis(2-pirazil)-4,4'-bipiridina \\ PM3 Parameterized Model Number 3 \\ RMN Ressonância Magnética Nuclear \\ TCML Transferência de Carga Metal Ligante \\ TIL Transferência Interna do Ligante
}


TIM Transição Interna do Metal

TMS Tetrametilsilano

tpy 2,2':6'2"-terpiridina

USP Universidade de São Paulo

UV-Vis Ultravioleta-Visível

ZINDO/S Método semi-empírico de cálculo teórico de orbitais moleculares baseados na aproximação do Zerner's spectroscopy version of the Intermediate Neglect of Differential Overlap

$\varepsilon \quad$ Absortividade molar

$\delta \quad$ Deslocamento químico (em ppm - partes por milhão) 


\section{SUMÁRIO}

LISTA DE FIGURAS

LISTA DE TABELAS

1 INTRODUÇÃO 22

1.1 Química supramolecular ....................... 22

1.2 Ligantes ter-imínicos e complexos metálicos . . . . . . . . . . . 26

1.2.1 Ligantes imínicos . . . . . . . . . . . . . . . . 26

1.2.2 Compostos imínicos de ferro(II) . . . . . . . . . . . . . 29

1.2.3 Utilização de ligantes terpiridínicos em química supramolecular . . 31

1.3 Cianidoferratos: breves considerações . . . . . . . . . . . . . 36

2 OBJETIVOS 40

3 MATERIAIS E MÉTODOS

3.1 Materiais e reagentes . . . . . . . . . . . . . . . . 43

3.2 Técnicas de caracterização . . . . . . . . . . . . . . . . . 44

3.2.1 Análise elementar . . . . . . . . . . . . . . . . . . . 44

3.2.2 Espectrometria de massas . . . . . . . . . . . . . . 45

3.2.3 Ressonância magnética nuclear . . . . . . . . . . . . . 45

3.2.4 Espectroscopia eletrônica de absorção na região do ultravioletavisível (UV-Vis) . . . . . . . . . . . . . . . . . . 45

3.2.5 Espectroscopia vibracional por espalhamento Raman . . . . . . . . 45

3.2 .6 Eletroquímica . . . . . . . . . . . . . . . . . . 46

3.2 .7 Cálculos teóricos . . . . . . . . . . . . . 46

3.3 Sínteses . . . . . . . . . . . . . . . . . . . 47

3.3.1 Síntese do ligante 4'-fenil-2,2':6',2"terpiridina (phtpy) _ . . . . . 47

3.3.2 Síntese do ligante 4'(4-piridil)-2,2':6'2"terpiridina (pytpy) . . . . . . 47

3.3.3 Síntese do ligante 2,6-di(2-pirazinil)-4-(fenil)-piridina (phtpz) . . . . 48

3.3.4 Síntese do ligante 2,6-bis(2-pirazil)-4,4'-bipiridina (pytpz) $\ldots . . .48$

3.3.5 Síntese do complexo $\left[\mathrm{Fe}(\text { phtpy })_{2}\right]\left(\mathrm{PF}_{6}\right)_{2} \ldots \ldots \ldots \ldots$. . . . . 48

3.3.6 Síntese do complexo $\left[F e(p y t p y)_{2}\right]\left(P F_{6}\right)_{2} \ldots \ldots \ldots \ldots$ 
3.3.7 Síntese do complexo $\left[F e(p h t p z)_{2}\right]\left(P F_{6}\right)_{2} \ldots \ldots \ldots \ldots \ldots \ldots$

3.3.8 Síntese do complexo $\left[F e(p y t p z)_{2}\right]\left(P F_{6}\right)_{2} \ldots \ldots \ldots \ldots \ldots \ldots$

3.4 Troca dos contra-íons dos complexos $\left(\mathrm{PF}_{6}^{-}\right)$por $\left(\mathrm{Cl}^{-}\right) \ldots \ldots \ldots \ldots$

3.5 Reação dos complexos com $\mathrm{Na}_{3}\left[\mathrm{Fe}(\mathrm{CN})_{5}\left(\mathrm{NH}_{3}\right)\right] .3 \mathrm{H}_{2} \mathrm{O} \ldots \ldots \ldots \ldots . .51$

4 CARACTERIZAÇÃO DOS COMPLEXOS DE Fe(II) COM LIGANTES TER-IMÍNICOS 52

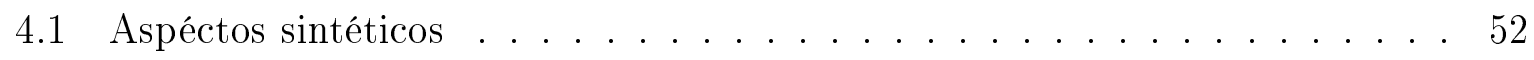

4.2 Caracterização dos complexos de $\mathrm{Fe}(\mathrm{II}) \ldots \ldots \ldots \ldots \ldots \ldots$

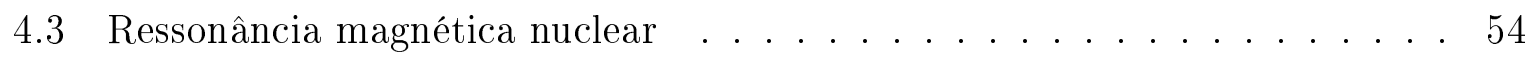

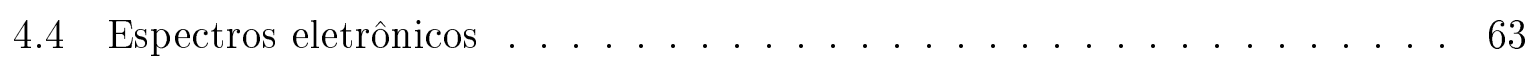

4.4 .1 Atribuição e simulação computacional . . . . . . . . . . . . . 63

4.4.2 Protonação e características ácido-base . . . . . . . . . . . 71

4.5 Espectros Raman ressonante . . . . . . . . . . . . . . . . . 79

5 QUÍMICA SUPRAMOLECULAR COORDENATIVA 86

5.1 Interação do complexo $\left[\mathrm{Fe}(\text { pytpy })_{2}\right]^{2+} \operatorname{com}\left[\mathrm{Fe}(\mathrm{CN})_{5}\right]^{3-} \ldots \ldots \ldots .87$

5.2 Interação do complexo $\left[\mathrm{Fe}(\text { phtpz })_{2}\right]^{2+} \operatorname{com}\left[\mathrm{Fe}(\mathrm{CN})_{5}\right]^{3-} \ldots \ldots \ldots \ldots 90$

5.3 Interação do complexo $\left[\mathrm{Fe}(\text { pytpz })_{2}\right]^{2+} \operatorname{com}\left[\mathrm{Fe}(\mathrm{CN})_{5}\right]^{3-} \ldots \ldots \ldots \ldots 95$

5.4 Interação dos complexos terpiridínicos e terpirazínicos modificados com cianoferratos, e íons de metais de transição . . . . . . . . . . . . . . 99

5.5 Considerações sobre os experimentos de reatividade dos complexos . . . . 110

6 CONCLUSÕES 112

7 REFERÊNCIAS BIBLIOGRÁFICAS $\quad 114$

Anexo A Resultados de espectrometria de massas (ESI-MS) 126

$\begin{array}{ll}\text { Anexo B Valores de absortividade molar } & 128\end{array}$

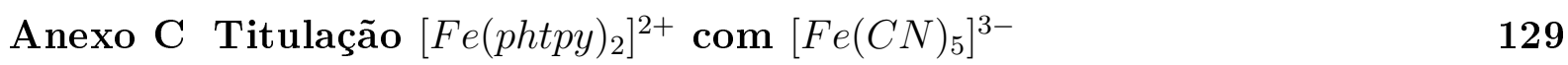

$\begin{array}{ll}\text { Anexo D Súmula Curricular } & 131\end{array}$ 


\section{Capítulo 1}

\section{INTRODUÇÃO}

\subsection{Química supramolecular}

A Química Supramolecular foi conceituada por Jean-Marie Lehn, na década de 1980, como a química além da molécula. Ela se baseia no entendimento das interações e afinidades específicas entre as moléculas que originam sistemas ou estruturas de maior complexidade, cada molécula agindo sinergisticamente umas com as outras [1].

Em 1987, J. M. Lehn, C. J. Pederson e D. J. Cram receberam o Prêmio Nobel de Química por seus trabalhos pioneiros em automontagem e reconhecimento molecular, processos estes que representam o conceito básico de química supramolecular, onde as interações envolvidas são principalmente de natureza não covalente $[2,3]$. O reconhecimento molecular pode ser entendido como a expressão da energia e da informação contida na ligação de um substrato a um receptor, que de certo modo é uma evolução do conceito chave e fechadura de Emil Fischer [4].

A natureza é a grande inspiração para processos supramoleculares artificiais. As interações não covalentes intermoleculares são de grande importância para a maioria dos processos biológicos como, por exemplo, nas reações enzimáticas, no reconhecimento celular, na regulação da expressão dos genes pelas proteínas ligadas ao DNA, dentre tantos outros $[5,6,7,8,9,10]$. A especificidade e a precisão exibidas pelos sistemas biológicos são derivadas do reconhecimento mútuo altamente direcionado exibido pelos componentes de uma estrutura, podendo ter sido o fenômeno da auto-organização o responsável pelo 
surgimento da própria vida [11, 12].

Uma das estratégias para a obtenção de estruturas supramoleculares na escala nanométrica é a bottom up, ou construção de "baixo para cima"[13, 14, 15]. Nesta abordagem, as nanoestruturas são construídas a partir de átomos individuais ou molécula por molécula. Para isso, é necessária a utilização de processos de auto-organização ( self-assembly) e reconhecimento molecular, isto é, sistemas capazes de espontaneamente formar arquiteturas supramoleculares funcionais que possam desempenhar funções como transporte químico [16, 17]. Essas ideias são inspiradas na organização, reatividade e seletividade dos processos que ocorrem a nível supramolecular na natureza, em especial nos seres vivos.

O que se busca é a síntese de moléculas que possam ser utilizadas como blocos de construção (building blocks) para sistemas mais complexos, de preferência que consigam se auto-organizar [16, 17]. Os sistemas biológicos, como já comentados, são um exemplo de organização tridimensional de seus componentes com alto grau de complexidade que pode ser conseguido a partir de blocos de construção relativamente simples (aminoácidos, açúcares, ácidos graxos, etc.). Essa automontagem a partir de moléculas simples pode ser conseguida por meio de compostos contendo grupos funcionais capazes de gerar tais interações.

Um outro tipo de interação, que tem sido amplamente utilizado em química supramolecular é a coordenação de metais. Como já reconhecido por Lehn, a Química Supramolecular pode ser considerada uma generalização da Química de Coordenação. Ela também é chamada de Química Metalosupramolecular e estuda a montagem de estruturas supramoleculares através da interação com íons metálicos. Vem ganhando destaque ao longo das últimas décadas devido às suas várias características que convergem com o escopo dessa área de pesquisa. A especificidade das interações é definida através do número de coordenação, geometria do íon metálico e o tipo do arranjo espacial dos ligantes.

Os compostos de coordenação podem ser utilizados como diferentes unidades de montagem, visto que os metais apresentam diversas geometrias. Pode-se, ainda, projetar e controlar o tamanho, a força da ligação de coordenação e os grupos funcionais disponí- 
veis para interações com outros blocos através da coordenação com diferentes tipos de ligantes. As supramoléculas podem ser obtidas por meio de reações de automontagem e podem se regenerar espontaneamente. Também pode-se conseguir diferentes estruturas utilizando a abordagem de ligação direcional, onde os centros metálicos agem como unidades direcionais das formas resultantes, como é monstrado na Figura 1.1 [18]. Os metais utilizados nessas estratégias fornecem locais de coordenação apropriados para a forma desejada. Nessa abordagem, os metais são introduzidos com ligantes de direcionamento ou de bloqueio, disponibilizando apenas locais de coordenação para os ligantes que entram na estrutura com o ângulo apropriado para constituir a forma geométrica que se almeja. Como pode ser observado na Figura 1.1, um macrociclo dinuclear pode ser montado utilizando um complexo metalíco com um ângulo de $60^{\circ}$ entre os locais coordenadamente lábeis e com um ligante rígido com ângulo de $120^{\circ}$ (A). Este mesmo complexo metálico de partida pode ser empregado para construir um composto triangular, utilizando-se um ligante linear (B). Para se construir uma supramolécula quadrada pode-se usar um complexo de partida em que o metal tenha um ângulo de $90^{\circ}$ entre os locais de coordenação e um ligante linear rígido $(\mathrm{C})$ ou utilizar um composto de coordenação com um ângulo de $180^{\circ}$ entre os sítios lábeis e um ligante que apresente um ângulo de $90^{\circ}$ entre os átomos coordenantes $(\mathrm{D})$. 
A)

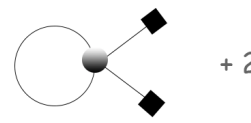<smiles>CCC</smiles>
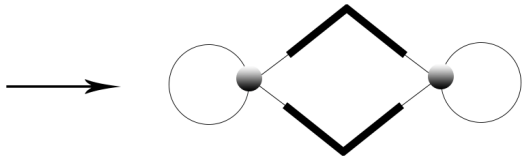

B)<smiles>CC1(C)CCCCC1</smiles><smiles>CCCCCCC</smiles>
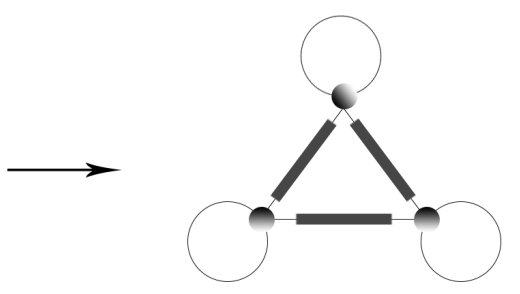

C)<smiles>CC1(C)CCCCC1</smiles><smiles>C1CCCCC1</smiles>

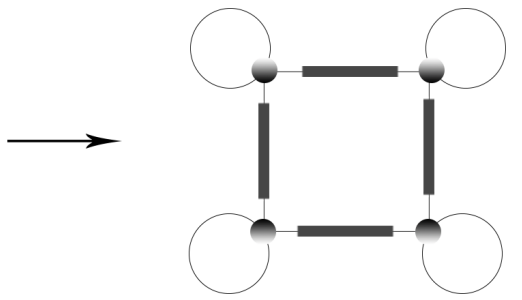

D)

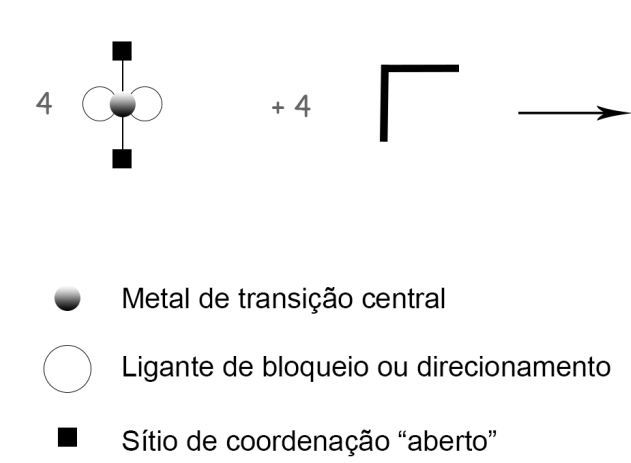

Figura 1.1: Construção de estruturas com diferentes geometrias pela abordagem de ligação direcional. Os centros metálicos têm um grande efeito direcional nas formas geométricas resultantes. Os metais são introduzidos com ligantes direcionais ou bloqueadores. Figura adaptada da referência [18].

Como já mencionado, a química de coordenação é uma ferramenta poderosa para sintetizar materiais funcionais controlados por dimensão, mas uma das vantagens marcantes na utilização de metais de transição reside, sem dúvida, na diversidade de comportamento exibida pelos mesmos em função das configurações eletrônicas, das propriedades redox, catalíticas e fotoquímicas, possibilitando o planejamento e síntese de novos materiais $[19,20]$.

Uma das estratégias da química inorgânica supramolecular é a que utiliza "complexos como metais e complexos como ligantes". Balzani e colaboradores [21, 22, 23] utilizaram ligantes contendo dois sítios de coordenação, como por exemplo a 2,3-dipiridilpirazina, 
para a preparação de complexos ponte (complexos ligantes) e outros ligantes (ex.: 2,2'bipiridina, 1,10-fenantrolina, entre outros), nos complexos terminais. Esses pesquisadores preparam complexos com até 13 centros metálicos. Todos luminescentes em solução à temperatura ambiente.

O centro metálico desempenha um papel crítico, tanto na determinação das propriedades químicas e fotofísicas da supramolécula, quanto no controle da cinética de montagem e da labilidade ou inércia geral do complexo. Em geral, centros metálicos cineticamente inertes $\left(d^{3}\right.$ ou $\left.d^{6}\right)$ são utilizados como blocos de construção pré-formados, enquanto os íons metálicos lábeis (geralmente os íons da primeira série de transição) são mais frequentemente utilizados em reações de automontagem espontâneas [24].

Os nanomateriais formados a partir de compostos de coordenação podem ser utilizados para diferentes aplicações, como por exemplo em sistemas integrados funcionais, onde os complexos transportadores de elétrons podem conferir propriedades redox multieletrônicas às supramoléculas, podendo gerar espécies fotoativas [4, 25, 26, 27, 28, 29].

A Química e a Física dos materiais gerados a partir da nanotecnologia molecular é um campo de pesquisa interdisciplinar de grande interesse devido às imensas potencialidades de criação e aplicação desses materiais.

\subsection{Ligantes ter-imínicos e complexos metálicos}

\subsubsection{Ligantes imínicos}

Os ligantes que contém o grupo $\mathrm{N}=\mathrm{C}-\mathrm{C}=\mathrm{N}$, como a 2,2'-bipiridina (bpy), são comumente chamados de ligantes di-imínicos. Por conveniência, os ligantes que contém o arranjo $\mathrm{N}=\mathrm{C}-\mathrm{C}=\mathrm{N}-\mathrm{C}$...C...N (... denotados como uma ligação simples ou dupla) como a molécula 2,2':6',2'-terpiridina (tpy), podem ser chamados como ligantes ter-imínicos. As estruturas desses ligantes está ilustrada na Figura 1.2. 


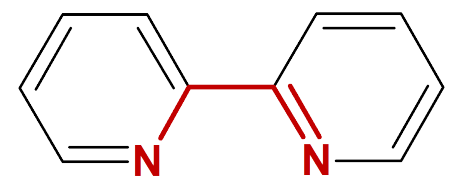

2,2'-bipiridina

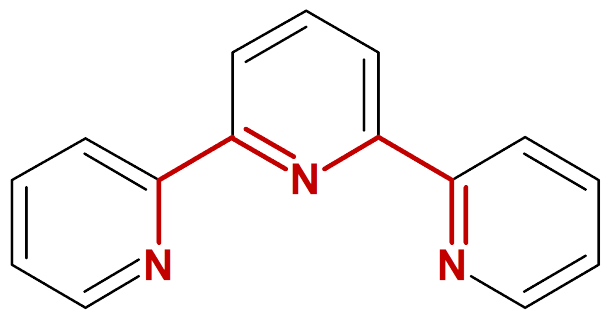

2,2':6',2-terpiridina

Figura 1.2: Estrutura dos ligantes 2,2'-bipiridina e 2,2':6',2"-terpiridina (destaque em vermelho para os grupos $N=C-C=N$ e $N=C$ - $C=N-C \ldots C \ldots N)$.

No final do século XIX, Fritz Blau sintetizou pela primeira vez um ligante di-imínico heterocíclico bidentado, a 2,2'-bipiridina, e descobriu sua excelente capacidade em formar compostos com sais ferrosos que apresentavam elevada estabilidade e intensa coloração vermelha $[30,31,32,33]$. Esse químico austríaco dificilmente poderia prever o importante papel que essa classe de ligantes desempenhou no desenvolvimento da química de coordenação e, mais tarde, na química supramolecular.

A primeira síntese de terpiridina foi relatada em 1932 por Morgan e Burstall [34], por meio da condensação oxidativa da piridina utilizando cloreto de ferro(III), tendo como produto majoritário a bipiridina, o qual era o objetivo do trabalho. Essa rota sintética além de apresentar um baixo rendimento para a molécula de terpiridina (subproduto da reação), não é segura nem conveniente, pois foi realizada a uma pressão de $50 \mathrm{~atm}$ e a $340{ }^{\circ} \mathrm{C}$. Esses mesmos autores relataram a reação da terpiridina com sais de ferro(II), originando compostos de cor púrpura.

Ao longo do tempo foram propostos vários outros métodos para a síntese da terpiridina e seus derivados, desde abordagens em que o núcleo da tpy era construído a partir de três anéis de piridina, através de reações de acoplamento cruzado não seletivo de Ulmann ou reações de Stille ou Suzuki, até a construção do anel central (Figura 1.3) [35]. Os métodos de acoplamento cruzado dependem da disponibilidade de 2,6'-haloderivados apropriados e de condições reacionais severas onde grupos substituintes da piridina não se conservam intactos, diminuindo as possibilidades de variações nas funcionalizações das tpy [24]. 


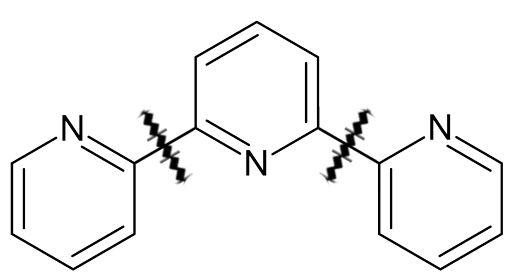

(a)

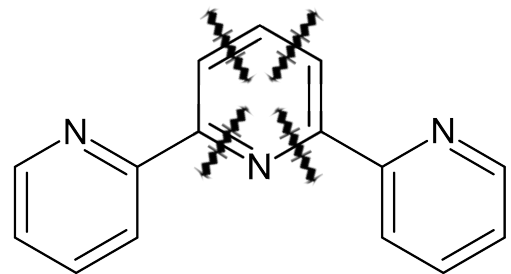

(b)

Figura 1.3: As duas abordagens sintéticas básicas para terpiridinas. (a) montagem do anel por acoplamento cruzado e (b) via formação do anel central. As linhas onduladas indicam locais onde há a formação de ligações $C$ - $C$.

A rota sintética apresentada por Kröhnke e colaboradores, em 1976 [36], foi um marco no desenvolvimento de derivados terpiridínicos. Nessa metodologia, a síntese ocorre em duas etapas, tendo como primeira a formação de um composto $\alpha$ - $\beta$-insaturado, o qual origina um enolato. A segunda etapa consiste na geração de um íon piridínio, seguida por uma reação de adição de Michael, para a geração de uma diona. Essa diona sofre um processo de ciclização formando o anel piridínico central.

O desenvolvimento de rotas sintéticas mais amigáveis impulsionou a síntese de novos ligantes derivados da terpiridina, com a substituição de grupos funcionais na posição 4' da piridina central, possibilitando que esses ligantes fossem modificados conforme o objetivo de sua utilização. As aplicações dessa classe de ligantes são as mais diversas, como controlar processos de automontagem, além de modificações nas propriedades dos complexos que resultem da coordenação com centros metálicos. Alguns exemplos de modificações são o uso de halogênios e grupos contendo o átomo de enxofre para a eletrodeposição em eletrodos [37, 38], uso de grupos fenilas para a interação com ciclodextrinas [39] e de grupos carboxilatos ou fosfatos para modificação de superfícies de semi-condutores [40, 41]. Também pode-se adicionar grupos doadores ou aceitadores de elétrons, que possam modular as propriedades dos centros metálicos.

Em 2005, Plé e colaboradores [42] reportaram a síntese de ligantes derivados da terpiridina com substituição de um ou mais anéis de piridina por anéis de pirazina. Esses novos ligantes são interessantes para a construção de matrizes de coordenação por duas razões principais. A primeira delas é por seus componentes eletrônicos serem alterados em consequência da natureza da pirazina; ela apresenta um caráter $\sigma$-doador mais fraco 
e $\pi$-aceptor forte, característica essa que geralmente estabiliza spin baixo e aumenta o potencial redox do par $M^{2+} / M^{3+}$ do complexo, em relação ao análogo de piridina. A segunda, é devido ao aumento do número de átomos de nitrogênio no ligante, por consequência da substituição de um ou mais anéis de piridina por pirazina, resultando num aumento do número desses átomos coordenantes na periferia, possibilitando a coordenação a outros centros metálicos, como representado na Figura 1.4, e formação de compostos supramoleculares [43].

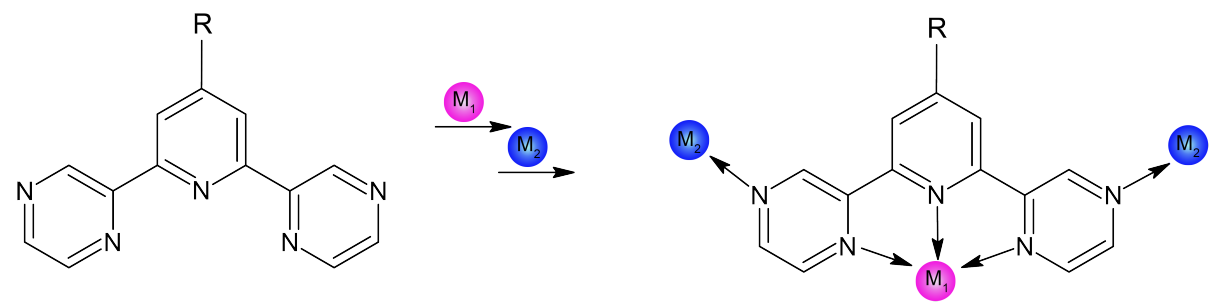

Figura 1.4: Possível montagem do ligante com pirazinas substituindo as piridinas do anel quelato através da coordenação bimetálica sequencial. Figura adaptada da referência [44].

\subsubsection{Compostos imínicos de ferro(II)}

No Brasil, os estudos de complexos de Ferro com ligantes contendo N-heteroátomos, começaram com os trabalhos de Pawel Krumholz [45]. Esse notável cientista foi um dos primeiros a relacionar as transições eletrônicas desses compostos de coordenação com a natureza da ligação metal-ligante $[46,47,48]$. Utilizou o conceito de retrodoação para explicar as características espectrais, de estabilidade e comportamento cinético desses complexos $[49,50,51,52]$. Também descobriu que com a adição de um terceiro ligante bidentado a complexos Fe(II) bis-di-iminas há alteração no estado de spin do metal, dentre tantas outras contribuições [45, 46, 53]. Krumholz foi um dos cientistas mais importante de sua época em relação ao estudo de complexos ferro-imínicos bi e multidentados, tornandose uma referência nacional e internacional.

Na década de 1950, Kozo Sone [46] realizou um estudo comparativo dos espectros eletrônicos de complexos coloridos de ferro(II) com vários ligantes orgânicos contendo o átomo de nitrogênio, como a bpy, fenantrolina, dimetilglioxima. Sone introduziu a ideia de que a cor dos compostos de Fe(II) com esses ligantes estava relacionada a um elemento 
estrutural comum a esses compostos, um anel quelante insaturado de cinco membros formado entre o ligante e o íon ferro(II), considerando-o como a espécie cromófora.

A síntese de complexos alifáticos $\alpha$-di-imínicos de ferro(II) realizada posteriormente, mostrou características espectrais muito semelhantes ao dos complexos com bpy, corroborando com o conceito do cromóforo de Sone. A deslocalização eletrônica no grupo ferro(II)-di-imina foi sugerida como a explicação dessas propriedades espectrais. Essa deslocalização foi descrita como a retrodoação de elétrons do orbital d preenchido do metal para os orbitais $\pi^{*}$ vazios do ligante.

Com o desenvolvimento da Espectroscopia Raman Ressonante pode-se aperfeiçoar o entendimento das transições relacionadas ao cromóforo desses complexos. Os modos vibracionais que mostram intensidade Raman melhoradas são aquelas vibrações ativas nas transições eletrônicas, no caso, associadas com o cromóforo [54].

A terpiridina e seus análogos, geralmente, atuam como ligantes tridentados através dos três átomos de nitrogênio. Ao se coordenar ao íon metálico como um ligante quelante é necessária uma mudança em sua conformação de trans,trans, observada no ligante livre, para a conformação cis,cis, devido ao impedimento estereo espacial, o que causa uma mudança na cinética de coordenação [24]. A unidade estrutural mais comumente encontrada é a $M(t p y)_{2}$, com proporção metal:tpy de 1:2, possuindo, idealmente, simetria $D_{2 d}$. O complexo $\left[\mathrm{Fe}(\mathrm{tpy})_{2}\right]^{2+}$ possui uma alta constante de formação $(\operatorname{logK} 1 \mathrm{~K} 2=20,9)$ e alta estabilidade, com coordenação quase quantitativa, em que a segunda constante de formação e cerca de 200 vezes maior que a primeira [55].

Nesses sistemas clássicos $\left[\mathrm{FeN}_{6}\right]^{2+}$ de spin baixo que tem como ligantes $N$ derivados da di-imina bidentada: 2,2'-bipiridina e da ter-imina tridentada: 2,2':6',2"'-terpiridina, a alta estabilidade, cor intensa e a natureza de spin baixo são explicados não apenas pelo elevado poder $\sigma$-doador intrínseco de sistemas imínicos, mas também pela disponibilidade de orbitais $\pi^{*}$ vazios de baixa energia nas moléculas dos ligantes. Estes orbitais estão orientados adequadamente para que haja interação com os orbitais $\mathrm{d} \pi$ preenchidos do átomo de metal e, dessa forma, reforçam a interação metal-ligante. Esses sistemas e seus derivados foram cruciais para o desenvolvimento dos estudos de equilíbrio de spin (spin 
crossover) [56].

Embora os sistemas Fe(II)-bpy e Fe(II)-tpy, e seus análogos, sejam ambos de spin baixo, há algumas diferenças importantes entre esses dois sistemas. Por mais que a distância média virtual de Fe-N seja a mesma $(\sim 1,96 \AA A)$, no $\left[F e(t p y)_{2}\right]^{2+}$ as distâncias $F e-$ $N_{\text {central }}$ são muito mais curtas que a $F e-N_{\text {distal }}$, fazendo com que a unidade $\left[F e N_{6}\right]^{2+}$ sofra uma compressão tetragonal [56]. Por causa da coordenação meridional, essa interação é necessariamente concentrada ao longo do eixo $N_{\text {central }}-F e-N_{\text {central }}$. Em sistemas tridentados mais rígidos, como esses, o ligante é de campo mais fraco do que as di-iminas, o que fez com que complexos com ligantes análogos a terpiridina se tornassem um modelo para o ajuste fino da força de campo para estudos de spin crossover [56].

\subsubsection{Utilização de ligantes terpiridínicos em química supramo- lecular}

A química supramolecular visa o desenvolvimento de estratégias adequadas para o controle de estruturas, sendo a construção utilizando as terpiridinas ou análogos substituídos como blocos de construção, uma das maneiras para tal. Essa classe de moléculas são um dos ligantes mais apropriados para a construção de sistemas supramoleculares através da coordenação com metal, que é relativamente forte e dirigida. Arquiteturas estendidas podem ser obtidas por auto-organização.

A automontagem coordenativa vem sendo cada vez mais empregada para a obtenção de sistemas supramoleculares. Quando se faz uso de ligantes derivados de terpiridinas com grupos coordenantes adequadamente distribuídos e orientados, tem-se uma vasta gama de possibilidades dos mais variados tipos de blocos de construção [57, 58, 59, 60]. Por isso, ao longo dos anos, a quantidade de publicações sobre a utilização desses ligantes para esse fim é significativa.

Ligantes quelantes são de grande interesse, uma vez que permitem a construção de arquiteturas supramoleculares definidas e possuem uma maior estabilidade em comparação com a ligação de hidrogênio [57]. A utilização de ligantes análogos à terpiridina com grupos substituintes na posição 4 é particularmente vantajosa, uma vez que mantém um 
vetor linear entre os substituintes [58]. A informação, mais frequentemente a transferência de energia ou elétrons, pode passar diretamente entre os dois grupos substituintes em interações ligante-ligante, ou do ligante para o metal ou do metal para o ligante, os dois últimos processos combinados podem gerar transferência gradual em uma tríade, como representado na Figura 1.5 [24].

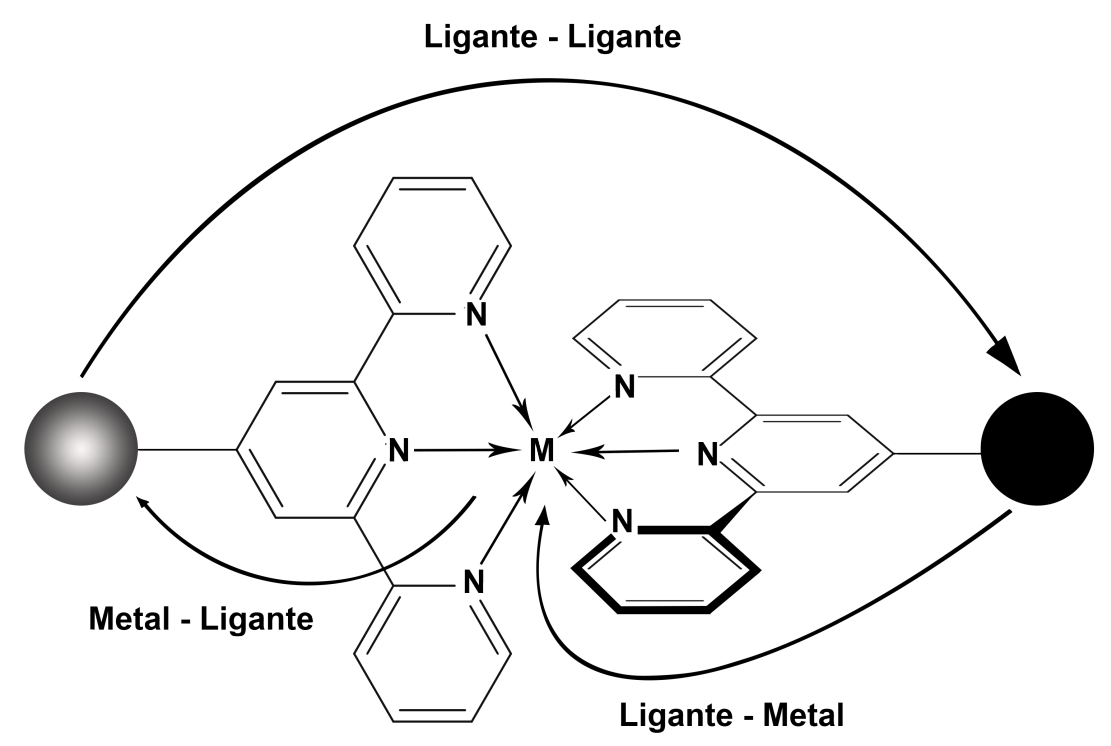

Figura 1.5: Representação esquemática das várias maneiras em que a informação pode ser transferida em uma molécula. Figura adapdada da referência [24].

A estratégia bottom up através da síntese de polímeros de coordenação supramoleculares utilizando derivados de terpiridinas visando a obtenção de nanomateriais versáteis e funcionais tem sido extensivamente utilizada. Em 2012, Toma et al. [61] desenvolveram uma nova rota sintética para o preparo de estruturas supramoleculares através da automontagem coordenativa induzida eletroquimicamente. Para tal estudo os autores utilizaram um complexo trinuclear de acetado de rutênio, genericamente chamado de cluster de rutênio, e o ligante 4'(4-piridil)-2,2':6'2"terpiridina (pytpy). A montagem coordenativa eletroquimicamente ativada foi demonstrada utlizando íons de ferro. Para induzir e controlar a automotagem coordenativa dos filmes poliméricos usou-se a voltametria cíclica.

Os clusters trinucleares de rutênio utilizado nesse trabalho, são blocos de construção adequados para a formação de estruturas moleculares nanométricas, pois possuem um núcleo triangular robusto, além de três locais de coordenação, que podem ser combinados 
com os ligantes em ponte gerando estruturas prolongadas. Tais compostos são interessantes modificadores de eletrodos devido às suas propriedades eletroquímicas e catalíticas, podendo apresentar aplicações em diferentes campos, como na eletrocatálise, no desenvolvimento de sensores e dispositivos para a conversão de energia. O ligante pytpy, utilizado pelos autores, liga-se ao cluster de rutênio de forma monodentada através do átomo de nitrogênio da piridina axial, de modo que os anéis terpiridínicos apresentam-se espacialmente apontados para fora, a partir dos três vértices do núcleo triangular, podendo, dessa forma, coordenar-se a íons de metais de transição.

Os filmes automontados foram preparados a partir de soluções do cluster contendo o ligante pytpy e de $\mathrm{FeCl}_{3}$. Ao se iniciar os ciclos voltamétricos há a formação das espécies $\mathrm{Fe}^{2+}$, sendo elas as responsáveis por promoverem a automongagem das estruturas estendidas sobre o eletrodo de platina. O ligantes terpiridínicos possuem baixa afinidade para íons $\mathrm{Fe}^{3+}$, mas forma complexos bisquelato de spin baixo muito estáveis e inertes com íons de $\mathrm{Fe}^{2+}$.

Os espectros eletrônicos dos filmes obtidos após cada ciclo mostraram que após o primeiro ciclo há a redução do cluster, mas a partir do segundo ciclo em diante há a coordenação de íons ferro(II) aos ligantes terpiridínicos do cluster, indicando a formação das espécies estendidas na superfície do eletrodo. Na Figura 1.6 encontra-se a representação esquemática desse novo conceito para a geração de estruturas supramoleculares. 


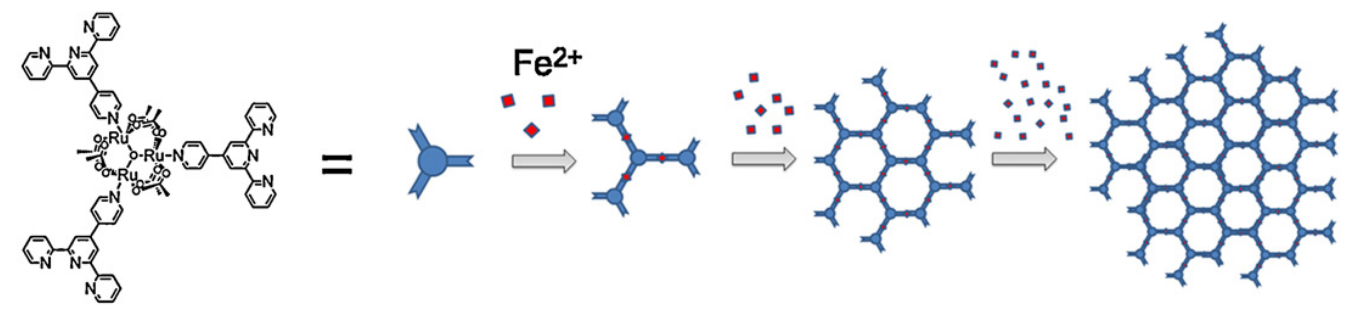

A

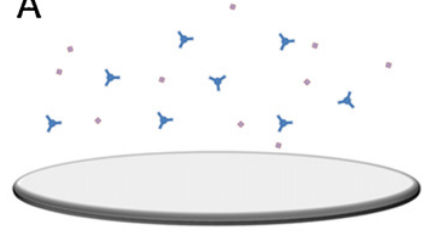

D

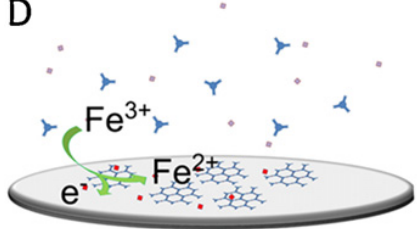

B

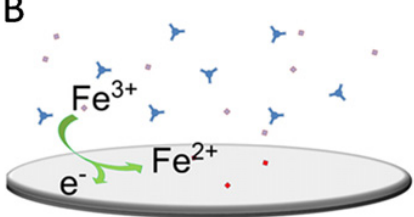

$\mathrm{E}$

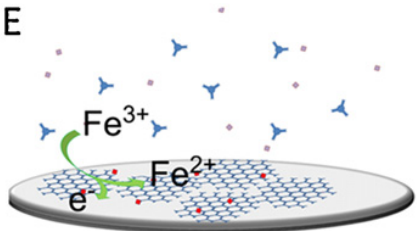

C

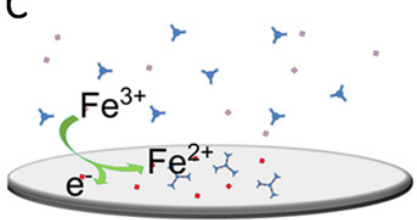

$\mathrm{F}$

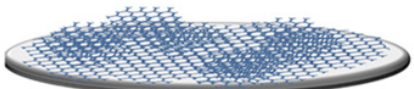

Figura 1.6: Esquema do processo de formação e crescimento dos filmes automontados obtidos pela redução eletroquímica de íons $\mathrm{Fe}^{3+}$ e sua coordenação a clusters modificados com ligantes terpiridinicos. Topo: Formação de um polímero de coordenação usando o complexo de ponte $\left[\mathrm{Ru}_{3} \mathrm{O}\left(\mathrm{CH}_{3} \mathrm{COO}\right)_{6}(\text { pytpy })_{3}\right]^{+}$; Inferior $(A-F)$ : (A) A varredura cíclica leva a formação de espécies $\mathrm{Fe}^{2+}(B)$ que são prontamente coordenados pelos ligantes terpiridínicos do cluster $(C)$. $\grave{A}$ medida que mais ciclos são realizados mais ions $\mathrm{Fe}^{2+}$ são gerados e as estruturas "sementes" começam a crescer (D)-(E). O crescimento do filme leva a saturação do eletrodo $(F)$, diminuindo a taxa de formação de ions coordenantes $\left(F e^{2+}\right)$. Figura adaptada da referência [61].

O controle de condução de elétrons em fios ou redes moleculares pode ser conseguida através da combinação de unidades de montagem adequadas. A terpiridina pode estabilizar íons metálicos com baixos e elevados estados de oxidação (devido ao seu poder $\sigma$-doador, de retrodoação e efeito quelante) e, dessa forma, os compostos de coordenação formados podem exibir reações redox multieletrônicas em solução, o que torna os materiais poliméricos em que as unidades $M(t p y)_{2}$ são ligadas através de ligantes orgânicos $\pi$-conjugados com potencial para a eletrônica molecular.

Nishimori e colaboradores [62] relataram a construção de fios e redes moleculares em superfícies de silício e ouro através do conceito de automontagem coordenativa, utilizando complexos terpiridínicos de ferro e cobalto. Na Figura 1.7 é ilustrado o processo de automontagem desses fios. Primeiramente o ligante terpiridínico é ancorado na superfície de um substrato, em seguida há a coordenação a um íon metálico e repetição dessa unidade 
com ligantes $\pi$-conjugados, com o objetivo de se aumentar a extensão do fio molecular. Sendo possível terminar essa extensão com uma extremidade contendo uma fração redoxativa, com a finalidade de reações de transferência de elétrons de longo alcance. Através desse método pode-se conectar diferentes íons metálicos e ligantes e se ter uma combinação de múltiplas funcionalidades.

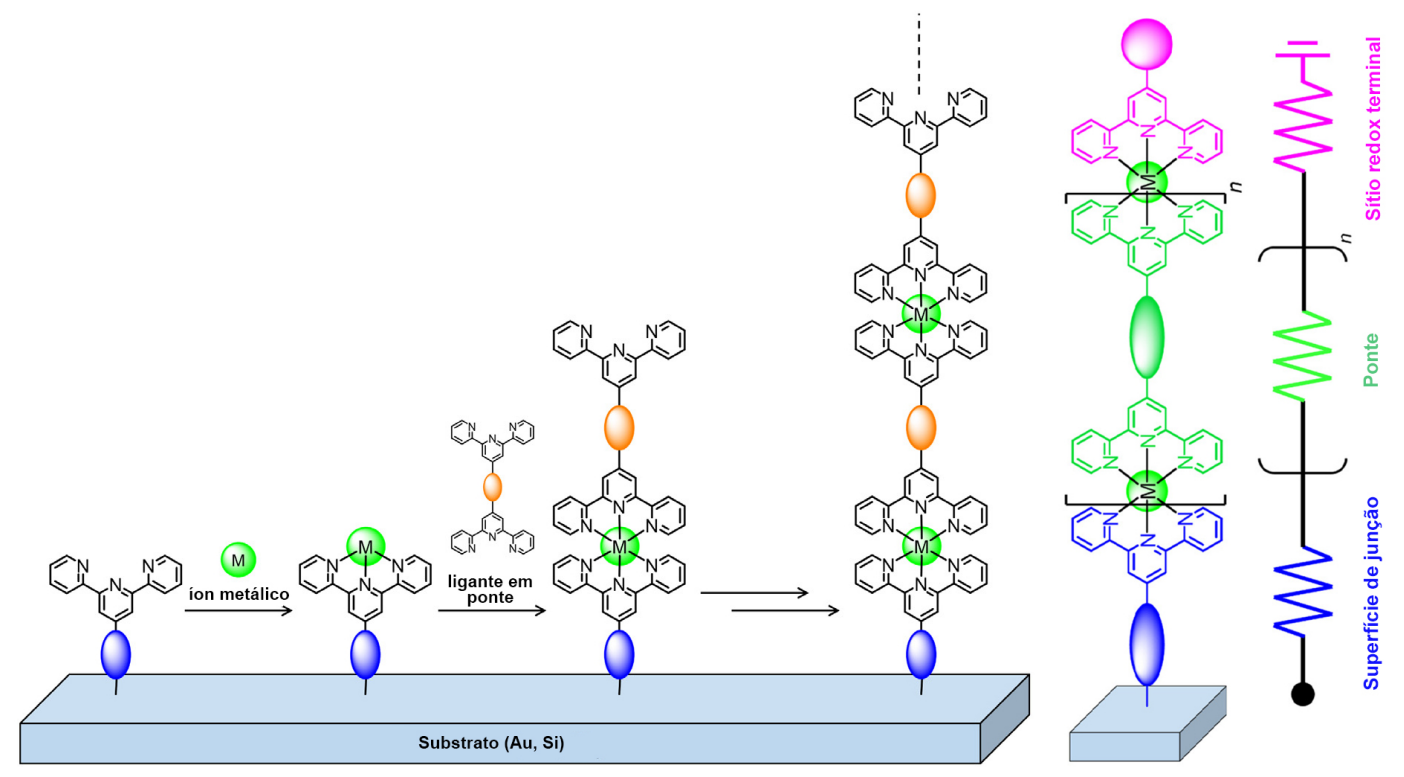

Figura 1.7: Ilustração esquemática do processo de coordenação em etapas para a formação de um complexo metálico bis-terpiridinico sobre um substrato. Figura adapdada da referência [62].

Compostos de coordenação de rutênio com ligantes terpiridínicos são amplamente estudados para utilização da energia solar na produção de energia elétrica [63], fotossíntese artificial [64], entre outras aplicações. No entanto, devido à baixa abundância natural desse metal, custo (valor de mercado) e toxicidade, os cientistas buscam alternativas mais viáveis, e como candidatos óbvios estão os complexos de Fe(II), pois este elemento é da mesma família do rutênio, compartilhando suas propriedades, além de apresentar alta abundância natural e estabilidade química.

Um estudo recente [65] mostrou a capacidade de complexos de ferro com ligantes heterocíclicos contendo nitrogênio (coordenados ao ferro via carbeno e piridina) em gerar fotoelétrons na banda de condução de dióxido de titânio, apresentando um rendimento quântico de $92 \%$ a partir do estado da ${ }^{3} T C M L$ (transferência de carga do metal para o ligante). Resultado extremamente interessante e importante no sentido de impulsionar 
pesquisas utilizando íons metálicos de ferro, uma vez que para esses estudos geralmente se usa metais menos abundantes e que são inviáveis em larga escala.

O Laboratório de Química Supramolecular e Nanotecnologia (LQSN) do Instituto de Química (IQ) da Universidade de São Paulo (USP), há décadas realiza estudos de complexos imínicos com metais de transição [66, 67, 68, 69, 70, 71], no âmbito de contribuir com o desenvolvimento da nanotecnologia molecular no país.

\subsection{Cianidoferratos: breves considerações}

A química dos cianidoferratos teve início com o descobrimento do Azul da Prússia, primeiro pigmento azul sintético obtido acidentalmente em 1704 por Diesbach na Alemanha [72], e um dos primeiros compostos de coordenação descritos na literatura.

Na química dos cianidoferratos uma classe importante de complexos são os formados pelo íon pentacianidoferrato(II), que são representados genericamente por $\left[\mathrm{Fe}(\mathrm{CN})_{5} L\right]^{n-}$, onde $\mathrm{L}$ pode ser os mais variados tipos de ligantes.

Os pentacianidoferratos podem ser facilmente preparados a partir do aminpentacianidoferrato(II), $\left[\mathrm{Fe}(\mathrm{CN})_{5}\left(\mathrm{NH}_{3}\right)\right]^{3-}$, que geralmente se apresenta na forma de sais de sódio ou de potássio. Esse complexo apresenta coloração amarela devido às transições de campo cristalino, pois seus ligantes não apresentam orbitais vazios de baixa energia para interações de transferência de carga.

Uma característica marcante desse íon complexo é a presença de cinco íons cianetos ligados fortemente ao metal. O íon Fe(II), apresenta configuração spin baixo $\left(3 d^{6}\right)$, mantido em campo octaédrico pelos cinco ligantes cianetos, receptores $\pi$, de campo forte. Seu orbital molecular ocupado de maior energia (HOMO) apresenta simetria $\sigma$, de caráter do carbono, sendo o responsável pela ligação preferencial metal-carbono [73, 74]. O orbital molecular de mais baixa energia (LUMO) desse ligante apresenta simetria $\pi$, de caráter do nitrogênio, sendo o responsável pela retrodoação $\pi$. Na Figura 1.8 está a representação do diagrama qualitativo de orbitais moleculares e o esquema de retrodoação $\pi$ para o ligante cianeto [75]. 


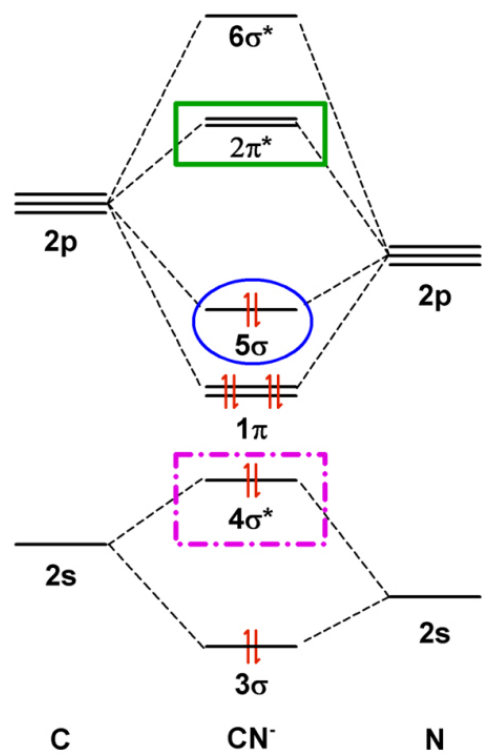

(a)

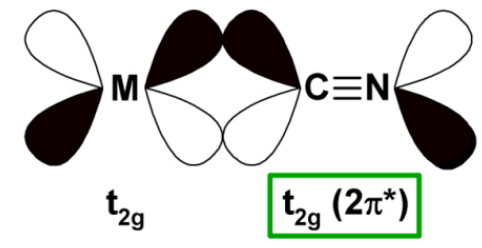

Retrodoação $\pi$

Figura 1.8: (a) Diagrama qualitativo dos orbitais moleculares do $C \mathrm{~N}^{-}$. (b) Esquema de sobreposição orbital na retrodoação $\pi$ para o ligante cianeto. Figura adapdada da referência [75].

Uma característica interessante dos cianoferratos é a capacidade de se coordenarem a outros metais, como o ligante cianeto é um ligante ambidentado, isto é, tanto os átomos de nitrogênio, quanto os átomos de carbono são capazes de estabelecer ligações com centros metálicos distintos simultaneamente.

Em 1979, Toma fez um extenso trabalho com correlações estruturais e reatividade dos cianoferratos [76]. Estudos demonstram que a simples diluição do aminpentacianidoferrato(II) em solução aquosa gera o íon $\left[\mathrm{Fe}(\mathrm{CN})_{5}\left(\mathrm{H}_{2} \mathrm{O}\right)\right]^{3-}$ (equação 1.1), de forma rápida e direta $[77,78]$.

$$
\left[\mathrm{Fe}(\mathrm{CN})_{5}\left(\mathrm{NH}_{3}\right)\right]^{3-}+\mathrm{H}_{2} \mathrm{O} \rightarrow\left[\mathrm{Fe}(\mathrm{CN})_{5}\left(\mathrm{H}_{2} \mathrm{O}\right)\right]^{3-}+\mathrm{NH}_{3}
$$

O íon $\left[\mathrm{Fe}(\mathrm{CN})_{5}\left(\mathrm{H}_{2} \mathrm{O}\right)\right]^{3-}$ é tipicamente monocoordenativo devido aos cianetos inertes, (Figura 1.9), sendo que a sexta posicão de coordenação pode ser utilizada para ancorar moléculas diversas, o que o tornou interessante, entre outras aplicações, como uma sonda para sistemas biomiméticos [79]. 


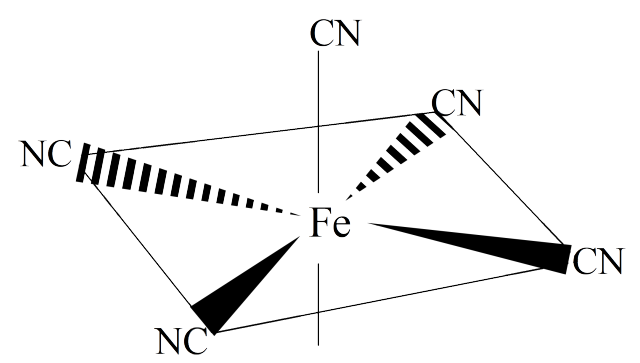

Figura 1.9: Representação esquemática do ion pentacianidoferrato(II) monocoordenativo.

Diferentemente do caráter inerte dos cianetos, no complexo $\left[\mathrm{Fe}(\mathrm{CN})_{5} \mathrm{H}_{2} \mathrm{O}\right]^{3-}$, a água coordenada apresenta-se lábil em solução (equação 1.2). Os resultados desses estudos indicam que as reações de substituição no íon aquapentacianidoferrato(II) completam-se em frações de segundos. Característica esta que possibilita a síntese direta de uma série de complexos de pentacianidoferrato(II).

$$
\left[\mathrm{Fe}(\mathrm{CN})_{5}\left(\mathrm{H}_{2} \mathrm{O}\right)\right]^{3-}+\mathrm{L} \rightarrow\left[\mathrm{Fe}(\mathrm{CN})_{5} L\right]^{n-}+\mathrm{H}_{2} \mathrm{O}
$$

A natureza do ligante L determina as propriedades desses complexos. A velocidade de rompimento da ligação Fe-L é relacionada à forma de campo cristalino do ligante, portanto, uma característica das propriedades coordenantes de L.

Em geral, na série dos pentacianidoferratos, os complexos com ligantes aromáticos nitrogenados são os mais amplamente estudados e constituem uma classe especial de compostos. Ao contrário dos demais complexos da série, eles apresentam uma coloração intensa, originada da transição de transferência de carga. Essa classe de complexos teve início com os estudos de Toma e Malin em 1973 [77, 80] e, desde então, uma vasta quantidade de trabalhos com as mais diversas aplicações foi publicada, como por exemplo: para corantes [81], detecção de oximas [82], [83], materiais híbridos orgânicos-inorgânicos para a adsorção de metais [84], biossensores [85], dispositivos eletrocrômicos, entre inúmeros outros.

O grupo do LQSN/IQ-USP, iniciado e comandado pelo professor Toma, além de ter sido um dos pioneiros, tem grande experiência na utilização de íons pentacianidoferrato(II) para preparar supramoléculas polinucleares. Em 1986, Toma e Lever [86] pu- 
blicaram os resultados referentes ao estudo de complexos heptanucleares formados pela coordenação de 6 grupos pentacianidoferratos aos nitrogênios periféricos do complexo tris(bipirazina)rutênio(II), supramolécula ilustrada na Figura 1.10.

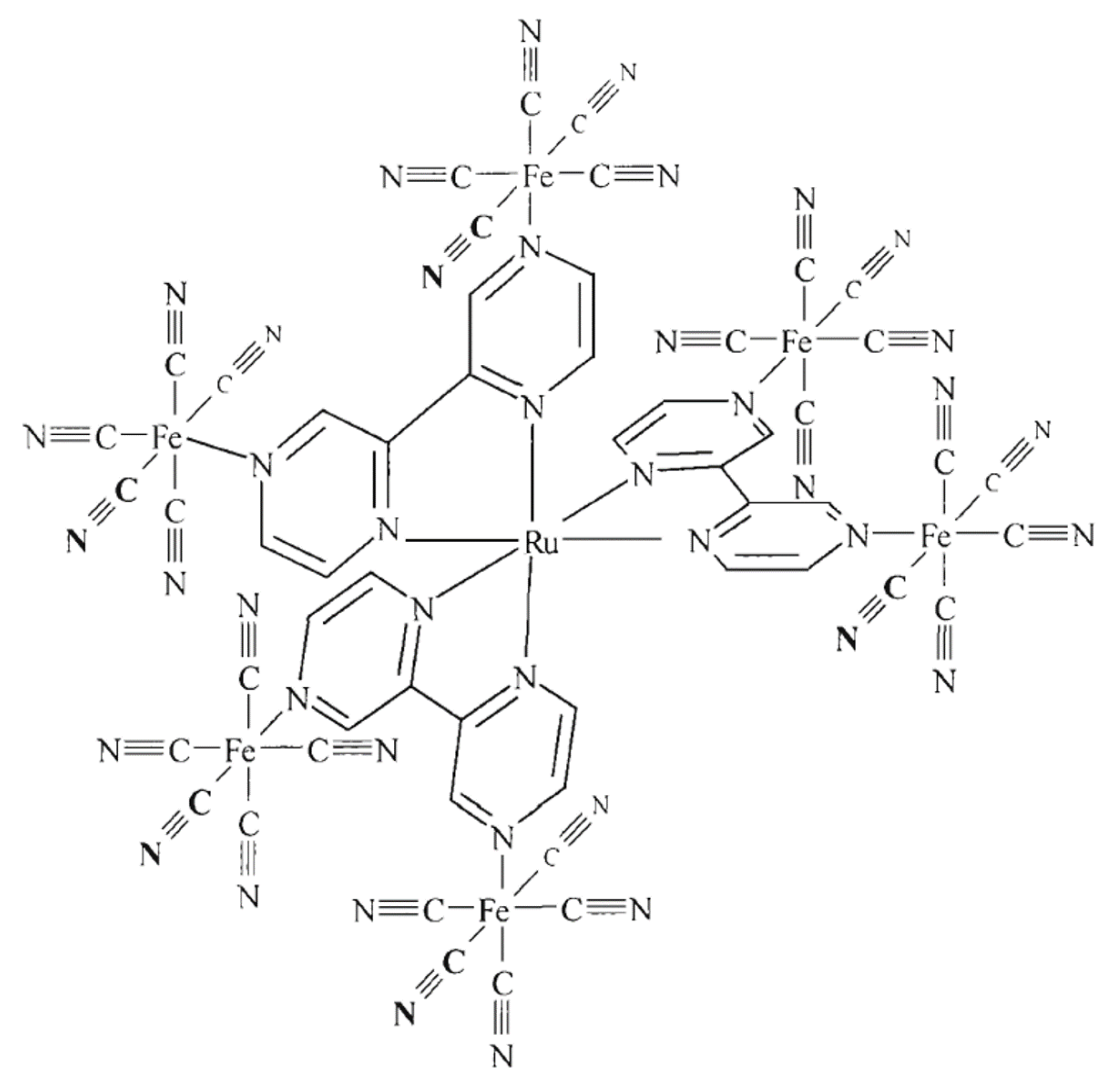

Figura 1.10: Estrutura da supramolécula $\left[R u(b p z)_{3}\left\{F e(C N)_{5}\right\}_{6}\right]$ sintetizada por Toma e Lever [86].

Pentacianidoferratos como complexos periféricos são interessantes, pois podem se coordenar a outros metais de transição, podendo gerar cadeias poliméricas tridimensionais, gerando compostos análogos ao Azul da Prússia. Desde a síntese desse compostos polinuclear, os estudos envolvendo síntese de supramoléculas com o íon complexo pentacianidoferrato(II) não cessaram [87, 88, 89]. 


\section{Capítulo 2}

\section{OBJETIVOS}

O principal objetivo desta Tese é o estudo das propriedades espectroscópicas de supramoléculas polinucleares sintetizadas através do conceito de sef-assembly.

Heterociclos aromáticos contendo o átomo de nitrogênio têm sido usados extensivamente há muitas décadas em química de coordenação com a maioria dos metais de transição. Os compostos heterocíclicos aromáticos de seis membros, como os utilizados no presente trabalho, apresentam orbitais $\pi$ com energias relativamente baixas que atuam como bons receptores de densidade eletrônica do orbital $d$ dos metais de transição, na interação do tipo retrodoação metal-ligante [90].

Complexos binucleares ou multinucleares que contêm dois ou mais centros metálicos ligados em pontes, por ligantes multidentados, podem exibir interações metal-metal como por exemplo, acoplamento magnético e intervalência. A comunicação entre os centros metálicos é mediada pelo ligante em ponte, geralmente através do sistema $\pi$ desse ligante. Ao variar a distância entre os centros metálicos, as propriedades $\pi$ doador/receptor do ligante e o grau de conjugação entre os locais de coordenação, pode-se controlar a extensão dessas interações.

As pirazinas possuem orbirtais $\pi^{*}$ com energia relativamente baixa, sendo um excelente $\pi$-receptor de densidade eletrônica do orbital d dos metais, o que facilita a transferência de elétrons (ou a transferência de energia) entre os centros metálicos quando esses ligantes são usados como ligantes ponte. Estudos mostraram que a coordenação a um átomo de nitrogênio não afeta significativamente a capacidade doadora dos outros átomos de 
nitrogênio do anel aromático [90]. Dessa forma, torna-se relevante o estudo de estruturas supramoleculares empregando, como blocos de construção, complexos contendo ligantes análgos a terpiridinas funcionalizadas.

Na presente Tese, serão apresentadas a síntese e caracterização dos complexos ilustrados na Figura 2.1 e o resultado das interações desses complexos com o íon complexo pentacianidoferrato(II).

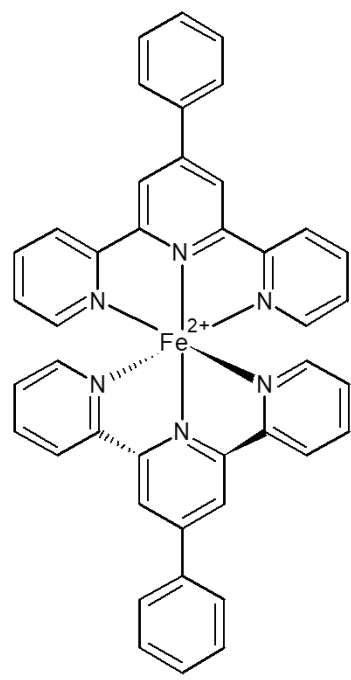

Ligante: 4-fenil-2,2':6' 2"-terpiridina Complexo: $\left[\mathrm{Fe}(\mathrm{phtpy})_{2}\right]^{2+}$

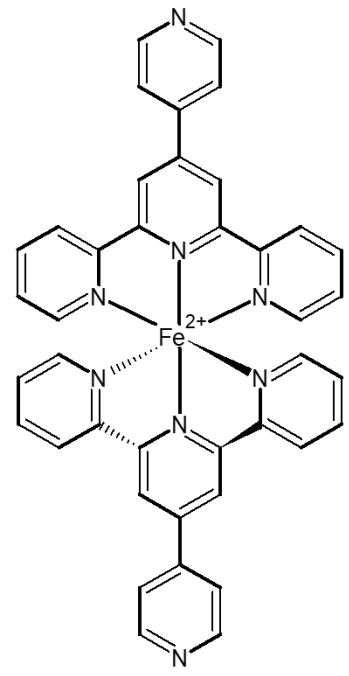

Ligante: 4'(4-piridil)-2,2':6'2'-terpiridina Complexo: $\left[\mathrm{Fe}(\mathbf{p y t p y})_{2}\right]^{2+}$

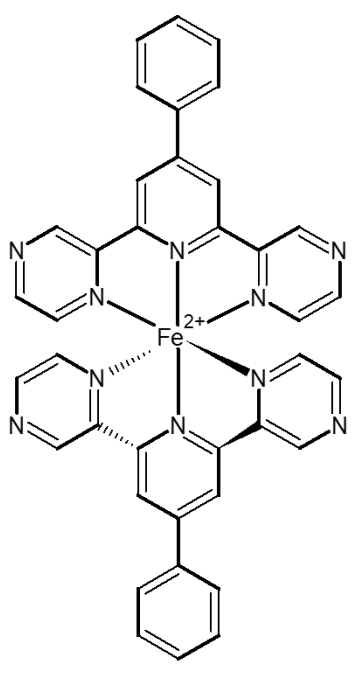

Ligante: 2,6-di(2-pirazinil)-4-(feinl)-piridina Complexo: $\left[\mathbf{F e}(\mathbf{p h t p z})_{2}\right]^{2+}$

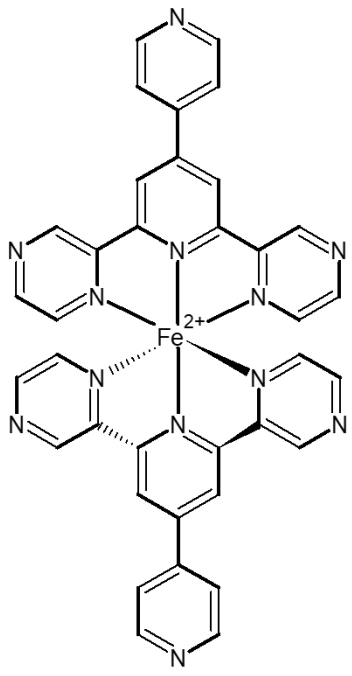

Ligante: 2,6-di(2 pirazinil)-4,4'-bipiridina Complexo: $\left[\mathbf{F e}(\text { pytpz })_{2}\right]^{2+}$

Figura 2.1: Estrutura dos complexos sintetizados: $\left[\mathrm{Fe}(\text { phtpy })_{2}\right]^{2+},\left[\mathrm{Fe}(\text { pytpy })_{2}\right]^{2+}$, $\left[F e(p h t p z)_{2}\right]^{2+} e\left[F e(p y t p z)_{2}\right]^{2+}$.

Os objetivos específicos estão listados abaixo:

(i) Sintezar e caracterizar os ligantes ter-imínicos;

(ii) Sintezar e caracterizar os complexos ter-imínicos de ferro(II) através de microanálise, espectrometria de massas, ressonância magnética nuclear, espectroscopia eletrônica e vibracional (Raman);

(iii) Racionalizar os resultados experimentais com o auxílio de métodos computacionais (modelagem molecular);

(iv) Estudar a reatividade desses complexos através da interação com o íon complexo pentacianidoferrato(II); 
(v) Estudar as propriedades espectroscópicas das supramoléculas;

(vi) Sintetizar compostos análogos ao Azul da Prússia. 


\section{Capítulo 3}

\section{MATERIAIS E MÉTODOS}

Neste capítulo estão descritas as técnicas de caracterização, juntamente com os detalhes computacionais e os procedimentos de sínteses dos ligantes e dos complexos.

A descrição experimental referente à síntese dos análogos do polímero de coordenação Azul da Prússia, será feita no Capítulo 5.

\subsection{Materiais e reagentes}

Os solventes e os reagentes utilizados nos procedimentos experimentais, sínteses e medidas de caracterização, foram de grau analítico, obtidos comercialmente e estão listados na Tabela 3.1. Nenhum reagente foi purificado previamente.

O composto aminpentacianidoferrato(II) de sódio $\left(\mathrm{Na}_{3}\left[\mathrm{Fe}(\mathrm{CN})_{5}\right] .3 \mathrm{H}_{2} \mathrm{O}\right)$ utilizado, foi preparado conforme descrito na literatura [91]. 
Tabela 3.1: Solventes e reagentes utilizados nas sínteses e caracterizaçôes.

\begin{tabular}{|c|c|c|}
\hline Solvente / Reagente & Composição & Procedência \\
\hline 2-acetilpirazina & $\mathrm{C}_{6} \mathrm{H}_{6} \mathrm{~N}_{2} \mathrm{O}$ & Sigma-Aldrich ${ }^{\circledR}$ \\
\hline 2-acetilpiridina & $\mathrm{C}_{7} \mathrm{H}_{7} \mathrm{NO}$ & Sigma-Aldrich ${ }^{\circledR}$ \\
\hline Acetona & $\mathrm{C}_{3} \mathrm{H}_{6} \mathrm{O}$ & Synth \\
\hline Acetona-d6 & $C D_{3} C O C D_{3}$ & Sigma-Aldrich ${ }^{\circledR}$ \\
\hline Acetonitrila & $\mathrm{C}_{2} \mathrm{H}_{3} \mathrm{~N}$ & Synth \\
\hline Acetonitrila-d3 & $D_{3} C C N$ & Sigma-Aldrich ${ }^{\circledR}$ \\
\hline Ácido Clorídrico & $\mathrm{HCl}$ & Synth \\
\hline Álcool etílico & $\mathrm{C}_{2} \mathrm{H}_{6} \mathrm{O}$ & Synth \\
\hline Benzaldeído & $\mathrm{C}_{6} \mathrm{H}_{5} \mathrm{CHO}$ & Sigma-Aldrich ${ }^{\circledR}$ \\
\hline Brometo de Potássio & $K B r$ & Merk \\
\hline Cloreto de Lítio & $\mathrm{LiCl}$ & Synth \\
\hline Cloreto de Potássio & $K C l$ & Synth \\
\hline Clorofórmio & $\mathrm{CHCl}_{3}$ & Synth \\
\hline Clorofórmio-d & $\mathrm{CDCl}_{3}$ & Sigma-Aldrich ${ }^{\circledR}$ \\
\hline Hexafluorofosfato de amônio & $\mathrm{NH}_{4} \mathrm{PF}_{6}$ & Sigma-Aldrich ${ }^{\circledR}$ \\
\hline Hidróxido de Amônio & $\mathrm{NH}_{4} \mathrm{OH}$ & Synth \\
\hline Hidróxido de Potássio & $K O H$ & Synth \\
\hline 4-piridilcarboxialdeído & $\mathrm{C}_{6} \mathrm{H}_{5} \mathrm{NO}$ & Sigma-Aldrich ${ }^{\circledR}$ \\
\hline Sulfato de amônio e ferro(II) & $\mathrm{Fe}\left(\mathrm{NH}_{4}\right)_{2}\left(\mathrm{SO}_{4}\right)_{2} \cdot 6 \mathrm{H}_{2} \mathrm{O}$ & Synth \\
\hline 2,2,2-trifluoretanol & $\mathrm{CF}_{3} \mathrm{CH}_{2} \mathrm{OH}$ & Sigma-Aldrich ${ }^{\circledR}$ \\
\hline 2,2,2-trifluoretanol-1,1- $d_{2}$ & $\mathrm{CF}_{3} \mathrm{CD}_{2} \mathrm{OH}$ & Sigma-Aldrich ${ }^{\circledR}$ \\
\hline
\end{tabular}

\subsection{Técnicas de caracterização}

\subsubsection{Análise elementar}

As análises elementares $(\mathrm{C}, \mathrm{H}, \mathrm{N})$ foram realizadas na Central Analítica $(\mathrm{CA})$ do Instituto de Química da Universidade de São Paulo (IQ/USP) em um equipamento Perkin Elmer modelo 2400. Os resultados de análise elementar serão apresentados seguindo o formato: $\mathrm{X} \%=$ valor experimental (valor calculado), seguindo a ordem $\mathrm{C}, \mathrm{H}, \mathrm{N}$ dos elementos. 


\subsubsection{Espectrometria de massas}

Os espectros de massa foram adquiridos ultilizando um espectrômetro da Bruker Daltonics, modelo Esquire 3000 Plus, em modo de injeção direta e com fonte de ionização por electronspray (ESI) e analisador do tipo ion trap. As medidas foram realizadas na CA-IQ/USP. As amostras foram solubilizadas em metanol ou acetonitrila. Os espectros ESI-MS foram obtidos no modo positivo utilizando voltagens típicas de $4,5 \mathrm{kV}$ no capilar e encontram-se no apêndice A.

\subsubsection{Ressonância magnética nuclear}

Os espectros de Ressonância Nuclear Magnética de Hidrogênio $\left({ }^{1} H-R M N\right)$ foram obtidos em um espectrômetro Varian 300 MHz, modelo INOVA 1 e/ou um espectrômetro da Bruker, modelo AIII de $500 \mathrm{MHz}$, da CA-IQ/USP, utilizando solventes deuterados adequados. Os deslocamentos químicos são indicados em parte por milhão (ppm) e foram ajustados em relação ao sinal padrão do Tetrametilsilano (TMS) ou do solvente usado.

\subsubsection{Espectroscopia eletrônica de absorção na região do ultravioleta- visível (UV-Vis)}

A caracterização por espectroscopia eletrônica na região do UV-Vis foi realizada utilizando um espectrofotômetro com detector de rede de diodos da marca Hewlett-Packard, modelo HP-8453-A, com cubeta de quartzo com caminho óptico de $1 \mathrm{~cm}$, na região de 200 a 1000 nm. Para as amostras sólidas (análogos do Azul da Prússia), os espectros foram obtidos suspendendo as partículas em gel de álcool polivinílico (PVA), seguido de secagem, a fim de gerar filmes finos e transparentes, adequados para o monitoramento óptico.

\subsubsection{Espectroscopia vibracional por espalhamento Raman}

Para a obtenção dos espectros Raman foi utilizado um Microscópio Raman Confocal da Witec, com laser de excitação em 488, 532 e $633 \mathrm{~nm}$. Os espectros foram registrados 
na faixa de 100 a $4000 \mathrm{~cm}^{-1}$.

\subsubsection{Eletroquímica}

As medidas de voltametria de onda quadrada foram registradas em um potenciostato da Metrohm, modelo Autolab PGSTAT30. A célula eletroquímica utilizada para as medidas foi do tipo convencional de três eletrodos sob atmosfera de $N_{2}$. Como eletrodo de trabalho utilizou-se um eletrodo de carbono vítreo, como eletrodo auxiliar um fio de platina, e como eletrodo de referência um eletrodo de $\mathrm{Ag} / \mathrm{AgCl}\left(1,00\right.$ mol. $\left.L^{-1}\right)$. Os potenciais medidos foram convertidos para a escala EPH adicionando 0,222 V. Cloreto de potássio (0,1 mol. $\left.L^{-1}\right)$ foi usado como eletrólito suporte.

\subsubsection{Cálculos teóricos}

A química teórica e computacional vem se tornando, ou poderíamos ser ousados em afirmar, que já se tornou uma ferramenta indispensável para o químico do século XXI. Atualmente, a química teórica oferece vários métodos e formalismos para o cálculo das propriedades desejadas, quanto maior o rigor teórico, maior o custo computacional. As metodologias mais baratas computacionalmente, produzem resultados aproximados, mas úteis e adequados para certas finalidades. Os métodos semi-empíricos são computacionalmente mais baratos que os métodos ab initio e podem ser utilizados em sistemas com quantidades elevadas de átomos, sendo eles leves ou pesados [92, 93, 94, 95, 96, 97].

Os cálculos semi-empíricos foram feitos com o pacote de progamas da HyperChem 8,0 com otimização prévia por mecânica molecular $\left(M M^{+}\right)$, usando o algorítimo de gradiente conjugado de Polak-Ribiere com um nível mínimo de convergência de $1.10^{-5} \mathrm{kcal}$. $\mathrm{A}$ 1. $m o l^{-1}$.

Os OM foram obtidos usando método semi-empírico ZINDO/S, limite de convergência 0,0001, parâmetros de sobreposição orbital $\sigma-\sigma 1,257$ e $\pi-\pi 0,585$ ou variável. Os espectros eletrônicos foram computados considerando excitações com interação de configuração simples (CIS, do inglês Configuration Interaction Singles), com espaço ativo de 20 orbitais moleculares de fronteira (H-9, ..., HOMO, LUMO, ..., L+9). O procedimento 
de cálculo foi baseado em ciclos interativos $M M^{+} / \mathrm{ZINDO} / \mathrm{S}$, até atingir a convergência desejada na estrutura e espectro.

\subsection{Sínteses}

\subsubsection{Síntese do ligante 4'-fenil-2,2':6',2'terpiridina (phtpy)}

Para a síntese de todos os ligantes (phtpy, pytpy, pytpz, pytpz) foi utilizada a metodologia descrita na referência [98].

Em um balão de fundo redondo, solubilizou-se 1,0 mL de benzaldeído (10 mmol) em $50 \mathrm{~mL}$ de etanol, e em seguida foram adicionados a essa solução 1,5 g de KOH, 2,3 mL de 2-acetilpiridina (20 mmol) e $30 \mathrm{~mL}$ de $\mathrm{NH}_{4} \mathrm{OH}$. Essa mistura foi deixada sob agitação magnética por 6 h. Logo nas primeiras horas já se observava a formação do produto sob forma de precipitado. Ao final de $6 \mathrm{~h}$ de reação o precipitado foi filtrado em funil de Buchner com placa de vidro sinterizado e lavado com $30 \mathrm{~mL}$ de água e $90 \mathrm{~mL}(3 \mathrm{x} 30$ mL) de etanol. O sólido obtido foi purificado por recristalização em mistura etanol/água. O material isolado foi seco em dessecador sob pressão reduzida.

Rendimento: $52 \%$. Análise para $C_{21} H_{15} N_{3}\left(\mathrm{MM}=309,36 \mathrm{~g}_{\mathrm{mol}} \mathrm{mo}^{-1}\right), \mathrm{CHN} \exp ($ calc $) \%$ : 80,27(81,53); 4,72(4,89); 13,21(13,58). ESI-MS (m/z) exp(calc) $[p h t p y-H]^{+}: 310,1(310,36)$.

\subsubsection{Síntese do ligante 4'(4-piridil)-2,2':6'2"terpiridina (pytpy)}

Foram adicionados 1,95 mL de 4-piridilcarboxialdeído (20 mmol), 3 g de KOH e 60 $\mathrm{mL}$ de etanol em um balão de fundo redondo. Ligou-se a agitação e esperou-se que todo hidróxido fosse dissolvido para então adicionar 4,6 $\mathrm{mL}$ de 2 -acetilpiridina (41 mmol) e 30 mL de $\mathrm{NH}_{4} \mathrm{OH}$. O precipitado obtido após $6 \mathrm{~h}$ de reação foi filtrado, lavado com água até se obter um pH neutro e então lavado com $40 \mathrm{~mL}$ de etanol. O ligante foi purificado por recristalização em mistura etanol/água, isolado através de filtração e seco em dessecador sob pressão reduzida.

Rendimento: $59 \%$. Análise para $C_{20} H_{14} N_{4}\left(\mathrm{MM}=310,35 \mathrm{~g} \cdot \mathrm{mol}^{-1}\right), \mathrm{CHN} \exp ($ calc $) \%$ : 77,23(77,40); 4,75(4,55); 17,60(18,05). ESI-MS(m/z) exp(calc) $[p y t p y-H]^{+}: 311,0(311,35)$. 


\subsubsection{Síntese do ligante 2,6-di(2-pirazinil)-4-(fenil)-piridina (phtpz)}

Para a síntese do ligante phtpz foi dissolvido 1,5 g de $\mathrm{KOH}$ em $30 \mathrm{~mL}$ de etanol e, após a dissolução completa do hidróxido adicionou-se 2,40 g de 2-acetilpirazina (20 mmol) e 1,0 mL de benzaldeído (10 mmol). A está solução foram adicionados $24 \mathrm{~mL}$ de $\mathrm{NH}_{4} \mathrm{OH}$ e o sistema foi então deixado sob agitação magnética a temperatura ambiente por $6 \mathrm{~h}$. A reação forma um precipitado (composto desejado) que foi filtrado e lavado com água até que a mesma apresentasse um pH neutro, seguido por lavagem com etanol. Em seguida o ligante foi recristalizado em mistura clorofórmio/etanol, filtrado e seco em dessecador sob pressão reduzida.

Rendimento: $37 \%$. Análise para $C_{19} H_{13} N_{5}\left(\mathrm{MM}=311,34 \mathrm{~g}_{\mathrm{g}} \mathrm{mol}^{-1}\right), \mathrm{CHN} \exp (\mathrm{cal}) \%$ : 74,47(73,30); 4,22(4,21); 22,30(22,49). ESI-MS (m/z) exp(calc) $[p h t p z-H]^{+}: 312,12(312,34)$.

\subsubsection{Síntese do ligante 2,6-bis(2-pirazil)-4,4'-bipiridina (pytpz)}

Em um balão de fundo redondo foram adicionados 2,5 g de 2-acetilpirazina (20 mmol), $1 \mathrm{~mL}$ de 4-piridilcarboxialdeído $(10 \mathrm{mmol})$ e $30 \mathrm{~mL}$ de etanol para dissolvê-los. A está solução foram adicionados $1,58 \mathrm{~g}$ de $\mathrm{KOH}$ e $24 \mathrm{~mL}$ de $\mathrm{NH}_{4} \mathrm{OH}$. Essa solução foi mantida sob agitação magnética à temperatura ambiente por $6 \mathrm{~h}$. Houve a formação de um precipitado, o qual foi filtrado e lavado com água e etanol. O ligante foi purificado por recristalização em mistura clorofórmio/etanol 3:2 v/v, isolado por filtração à vácuo e seco em dessecador sob pressão reduzida.

Rendimento: $42 \%$. Análise para $C_{18} H_{12} N_{6}\left(\mathrm{MM}=312,33 \mathrm{~g} \cdot \mathrm{mol}^{-1}\right)$, CHN $\exp (\mathrm{cal}) \%$ : 69,01(69,22); 3,71(3,87); 26,64(26,91). ESI-MS (m/z) exp(calc) [pytpz-H $]^{+}: 313,3(313,33)$.

\subsubsection{Síntese do complexo $\left[F e(p h t p y)_{2}\right]\left(P F_{6}\right)_{2}$}

Para a síntese do complexo $\left[\mathrm{Fe}(\text { phtpy })_{2}\right]\left(\mathrm{PF}_{6}\right)_{2}$, solubilizou-se $136 \mathrm{mg}$ de $\left(\mathrm{NH}_{4}\right)_{2}$ $\mathrm{Fe}\left(\mathrm{SO}_{4}\right)_{2} .6 \mathrm{H}_{2} \mathrm{O}$ em $25 \mathrm{~mL}$ de água deionizada, sob fluxo de $\mathrm{N}_{2}$. Em seguida, adicionou-se, gota a gota, uma solução contendo $100 \mathrm{mg}$ de ligante previamente dissolvidos em trifluoroetanol $(4 \mathrm{~mL})$. Essa mistura foi deixada sob fluxo de $N_{2}$ e agitação magnética por 
3 h. Precipito-se o complexo através da adição a uma solução saturada de $N H_{4} P F_{6}$. O precipitado foi então filtrado, lavado com água e seco em dessecador sob pressão reduzida.

Rendimento: 80\%. Análise para $C_{42} H_{30} N_{6} P_{2} F_{12} F e\left(\mathrm{MM}=964,50 \mathrm{~g} \cdot \mathrm{mol}^{-1}\right), \mathrm{CHN}$ $\exp (\mathrm{cal}) \%: 51,47(52,30) ; 3,22(3,14) ; 8,56(8,71)$.

\subsubsection{Síntese do complexo $\left[F e(\text { pytpy })_{2}\right]\left(P F_{6}\right)_{2}$}

O complexo $\left[\mathrm{Fe}(\text { pytpy })_{2}\right]\left(\mathrm{PF}_{6}\right)_{2}$ foi preparado da mesma forma que o anterior: 0,200 $\mathrm{g}$ de sulfato de amônio e ferro(II) foram solubilizados em $30 \mathrm{~mL}$ de água deionizada, previamente deixada sob fluxo de $N_{2}$, e adicionado à essa solução $0,150 \mathrm{~g}$ de ligante previamente dissolvido em $4 \mathrm{~mL}$ de uma mistura clorofórmio/etanol. O sistema foi deixado sob agitação por $2 \mathrm{~h}$, sob fluxo de $N_{2}$ a temperatura ambiente. Em seguida, realizou-se a precipitação do complexo através da adição de uma solução saturada de $N H_{4} P F_{6}$. O precipitado foi separado por centrifugação, lavado com água (30 mL, 3 vezes) e seco em dessecador sob baixa pressão.

Rendimento: 89\%. Análise para $C_{40} H_{28} N_{8} P_{2} F_{12} F e\left(\mathrm{MM}=966,48 \mathrm{~g} \cdot \mathrm{mol}^{-1}\right), \mathrm{CHN}$ $\exp (\mathrm{cal}) \%: 47,91(49,71) ; 3,04(2,92) ; 11,24(11,59)$.

\subsubsection{Síntese do complexo $\left[F e(p h t p z)_{2}\right]\left(P F_{6}\right)_{2}$}

$\mathrm{Na}$ síntese do complexo $\left[\mathrm{Fe}(\mathrm{phtpz})_{2}\right]\left(\mathrm{PF}_{6}\right)_{2}$ foram adicionados $200 \mathrm{mg}$ de $\left(\mathrm{NH}_{4}\right)_{2}$ $\mathrm{Fe}\left(\mathrm{SO}_{4}\right)_{2} \cdot 6 \mathrm{H}_{2} \mathrm{O}$ em $30 \mathrm{~mL}$ de água deionizada e, em seguida, adicionados $150 \mathrm{mg}$ do ligante previamente dissolvidos em trifluoroetanol $(4 \mathrm{~mL})$. Essa solução foi deixada sob fluxo de $N_{2}$ e agitação magnética por 3 h. Realizou-se a precipitação do complexo com solução saturada contendo íons $P F_{6}^{-}$. A mistura foi, então, filtrada e lavada com água. $\mathrm{O}$ precipitado foi seco em dessecador sob pressão reduzida.

Rendimento: $77 \%$. Análise para $C_{38} H_{26} N_{10} P_{2} F_{12} F e\left(\mathrm{MM}=968,45 \mathrm{~g} \cdot \mathrm{mol}^{-1}\right), \mathrm{CHN}$ $\exp (\mathrm{cal}) \%: 46,49(47,13) ; 2,96(2,71) ; 14,49(14,46)$. 


\subsubsection{Síntese do complexo $\left[F e(\text { pytpz })_{2}\right]\left(P F_{6}\right)_{2}$}

Em um balão de fundo redondo foram adicionados $35 \mathrm{~mL}$ de água deionizada sob fluxo de $N_{2}$ e agitação magnética. Em seguida adicionaram-se $200 \mathrm{mg}$ de sulfato ferroso amoniacal, sempre com o borbulhamento de $N_{2}$ na solução. Dissolveram-se $150 \mathrm{mg}$ do ligante pytpz em $4 \mathrm{~mL}$ de trifluoretanol e, então, adicionou-se a mistura (gota a gota) na solução contendo íons $\mathrm{Fe}^{2+}$. A reação de complexação ocorre logo que se inicia a adição da solução contendo o ligante. Para garantir um melhor rendimento a reação foi deixada sob agitação e fluxo de $N_{2}$ por $3 \mathrm{~h}$. Para a precipitação do complexo adicionou-se à mistura uma solução contendo íons $P F_{6}^{-}$. O precipitado foi filtrado em funil de Buchner com placa de vidro sinterizado e lavado com água. O composto foi seco em dessecador sob pressão reduzida.

Rendimento: $82 \%$. Análise para $\mathrm{C}_{36} \mathrm{H}_{24} \mathrm{~N}_{12} P_{2} F_{12} \mathrm{Fe}\left(\mathrm{MM}=970,43 \mathrm{~g} \cdot \mathrm{mol}^{-1}\right), \mathrm{CHN}$ $\exp (\mathrm{cal}) \%: 45,49(44,56) ; 2,59(2,49) ; 17,40(17,32)$.

\subsection{Troca dos contra-íons dos complexos $\left(P F_{6}^{-}\right)$por $\left(C l^{-}\right)$}

Para as reações com o complexo aminpentacianidoferrato de sódio tri-hidratado $\left(\mathrm{Na}_{3}\right.$ $\left.\left[\mathrm{Fe}(\mathrm{CN})_{5} \mathrm{NH}_{3}\right] .3 \mathrm{H}_{2} \mathrm{O}\right)$ precisou-se trocar os contra-íons dos complexos $\mathrm{PF}_{6}^{-}$por $\mathrm{Cl}^{-}$e, dessa forma, deixá-los solúveis em água, pois o aminpentacianidoferrato é solúvel em água e, mesmo em etanol, sua solubilidade é baixa.

Para a troca dos contra-íons, preparou-se uma solução saturada de LiCl em acetona. Solubilizou-se o complexo com contra-íon $P F_{6}^{-}$no mínimo de acetonitrila possível e adicionou-se, lentamente sobre a solução de LiCl. Observou-se a precipitação total do complexo, agora com o contra-íon $\mathrm{Cl}^{-}$. Centrifugou-se a mistura e, então, lavou-se o sólido três vezes com acetona. Para secagem, deixou-se o complexo em dessecador sob pressão reduzida. 


\subsection{Reação dos complexos com $\mathrm{Na}_{3}\left[\mathrm{Fe}(\mathrm{CN})_{5}\left(\mathrm{NH}_{3}\right)\right] \cdot 3 \mathrm{H}_{2} \mathrm{O}$}

Para as reações entre os complexos $\left[F e(p y t p y)_{2}\right]^{2+},\left[F e(p y t p z)_{2}\right]^{2+}$ e $\left[F e(p h t p z)_{2}\right]^{2+}$ e $\mathrm{Na}_{3}\left[\mathrm{Fe}(\mathrm{CN})_{5}\left(\mathrm{NH}_{3}\right)\right] \cdot 3 \mathrm{H}_{2} \mathrm{O}$, dissolveu-se uma quantidade de massa adequada para se ter uma concentração mínima compatível com cada técnica. Todos os experimentos foram realizados sob fluxo de $N_{2}$ e com a adição de alíquotas correspondendo aos equivalentes molares do íon pentacianidoferrato(II). 


\section{Capítulo 4}

\section{CARACTERIZAÇÃO DOS \\ COMPLEXOS DE Fe(II) COM \\ LIGANTES TER-IMÍNICOS}

\subsection{Aspéctos sintéticos}

Desde a primeira síntese da tpy até o momento muitas rotas foram propostas para a introdução de substituintes na posição 4'. Uma abordagem clássica, até o início desse século era baseada na condensação de dois equivalentes de 2-acetilpiridina com um aldeído apropriado. A formação do anel de piridina central é conseguida através da reação do intermediário dicetona com a amônia a temperaturas elevadas [58]. Diversas variações foram relatadas, como por exemplo, uma rota que envolve o isolamento da enona intermediária, mas quase todas envolvendo uma etapa comum, na qual o anel central de piridina é formado.

Uma outra maneira de se obter as terpiridinas é através da metodologia na qual todos os três anéis piridínicos estão presentes nos reagentes de partida, incluindo a reação entre 2,2'-bipiridina com 2-piridil-lítio, a reação de acoplamento de Stille [99] entre as 2,6dihalopiridinas e 2-trialquilestanilpiridina e a reação de acoplamento cruzado de Suzuki [100] entre 4'-bromo-tpy e ácido/ester aril-borônico. 
Para todas as abordagens supracitadas os tempos de reações eram relativamente longos e houve a necessidade de purificação dos produtos por cromatografia em coluna. Em 2005, Hanan e Wang [98] relataram uma síntese one-pot para uma variedade de ligantes baseados em tpy com substituintes aromáticos na posição 4'. Nesse procedimento o enolato de 2-acetilpiridina é gerado por $\mathrm{KOH}$, sob condições moderadas. Em seguida, ocorre a condensação do aldol e a adição de Michael, à temperatura ambiente. O intermediário de dicetona solúvel forma o anel de piridina central tendo como fonte de nitrogênio o hidróxido de amônio.

Tendo em vista a facilidade da metodologia proposta por Hanan e Wang [98] para a síntese dessa classe de ligantes, optamos por escolhê-la como rota sintética para a obtenção dos ligantes utilizados no presente estudo. Um esquema resumido da síntese encontra-se Figura 4.1.

a)<smiles>CC(=O)c1ccccn1</smiles>

b)<smiles>CC(=O)c1cncc([18OH])n1</smiles><smiles>Cc1ccncc1-c1ccccc1</smiles>

Figura 4.1: Esquema de sintese one-pot para os ligantes: a)phtpy e pytpy e b)phtpz e pytpz. 


\subsection{Caracterização dos complexos de Fe(II)}

\subsection{Ressonância magnética nuclear}

Os ligantes e os complexos mononucleares sintetizados foram caracterizados estruturalmente através da espectroscopia de Ressonância Magnética Nuclear de Hidrogênio. Os complexos octaédricos bis-quelatos apresentam configuração eletrônica $\left(d^{6}\right)$ de spin baixo, devido ao campo forte dos ligantes, portanto, diamagnéticos e adequados para análise de RMN.

A comparação entre os espectros de ${ }^{1} H R M N$ dos ligantes e os seus respectivos complexos mostram deslocamentos químicos característicos para os prótons da posição 6 dos anéis laterais. A causa desse comportamento é inerente à configuração do complexo, em que os ligantes estão perpendiculares entre si. Assim, esses prótons no bis-complexo estão localizados acima do plano do anel aromático axial do ligante, causando esse deslocamento observado. Além da influência da ligação metal-ligante, o ambiente químico também é diferente, uma vez que os átomos de nitrogênio do ligante livre possuem uma orientação anti nas estruturas cristalinas, mas a orientação nos complexos deve ser syn para coordenação do nitrogênio [35]. Os sinais dos outros prótons apontam mudanças menos significativas quando comparados ao ligante livre. A Figura 4.2 contém uma ilustração das interações estéricas e da mudança de ambiente químico dos prótons 6 e 3' no ligante terpiridínico livre e com a formação do complexo. 


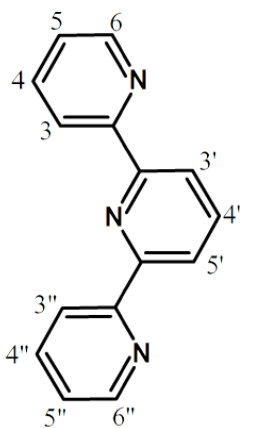

(A)

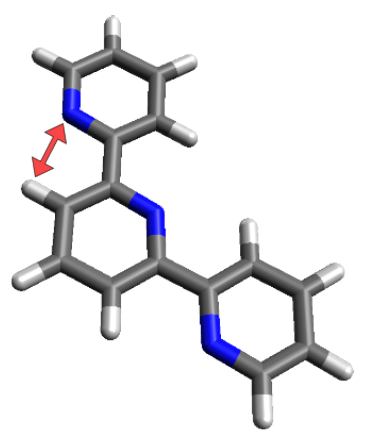

(B)

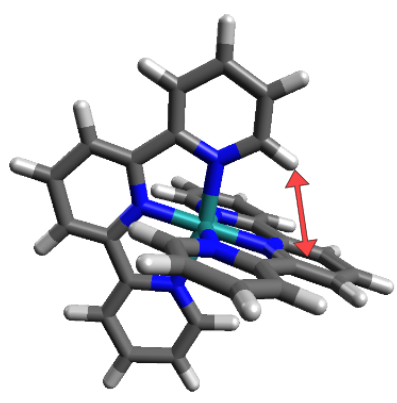

(C)

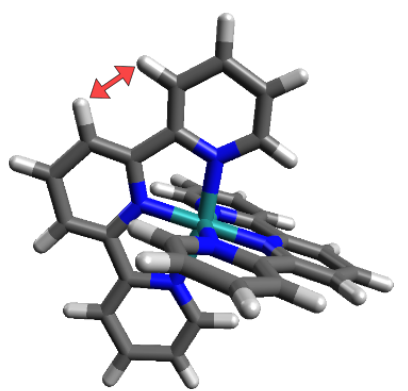

(D)

Figura 4.2: Ilustração das interações estéricas e da mudança de ambiente químico dos prótons 6 e 3' no ligante terpiridínico livre e com a formação do complexo. (A) estrutura da terpiridina com a identificação dos prótons; (B) conformação para o ligante terpiridínico livre, onde pode-se observar que o próton 3' tem como vizinho o átomo de nitrogênio; (C) próton 6 localizado acima do plano do anel aromático do ligante adjacente; (D) a formação do complexo muda a vizinhança do próton 3', que passa agora a ser vizinho do próton 3. Figura adapdada da referência [24]

Outras características dos espectros podem ser notadas, como, por exemplo, um único espectro para ambos os anéis quelantes nos compostos, bem como para ambos os anéis aromáticos terminais de cada ligante. Isto confirma a simetria $D_{2 d}$ dos complexos na escala de tempo de RMN.

Nas Figuras 4.3 e 4.4 encontram-se os espectros de ${ }^{1} H-R M N$ do ligante phtpy e do complexo $\left[\mathrm{Fe}(\text { phtpy })_{2}\right]^{2+}$. Os deslocamentos químicos foram expressos em partes por milhão (ppm). Para o ligante livre pode se observar três sinais na região mais desblindada, um singlete (s) em 8,76 ppm, um dublete (d) em 8,74 ppm e um duplo dublete (dd) em 8,69 ppm, referentes aos prótons 3', 6 e 3, respectivamente. Os sinais em 7,91 e 7,88 ppm são atribuídos aos prótons 4 e $o$, sendo um triplete $(\mathrm{t})$ e um dublete na mesma região. Aos prótons $m, p$ e 5 são atribuídos os sinais na região mais blindada em 7,52; 7,46 e 7,37 ppm (todos multiplete $(\mathrm{m})$ ), respectivamente. As atribuições foram baseadas em dados da literatura [71, 101]. A coordenação resulta em um desvio do deslocamento químico para a maioria dos prótons, como pode ser visto na Tabela 4.1, onde se encontra a lista de atribuições do ligante livre e do complexo de ferro(II) formado por ele. Os prótons na posição orto dos anéis piridínicos adjacentes, identificados como 6, são deslocados em mais de 1 ppm para a região mais blindada do espectro. Esses prótons estão direcionados preferencialmente para uma região de densidade eletrônica dos elétrons $t_{2 g}$ do metal e dos 
elétrons $\pi$ do outro ligante, resultando em uma blindagem adicional do spin nuclear [102].

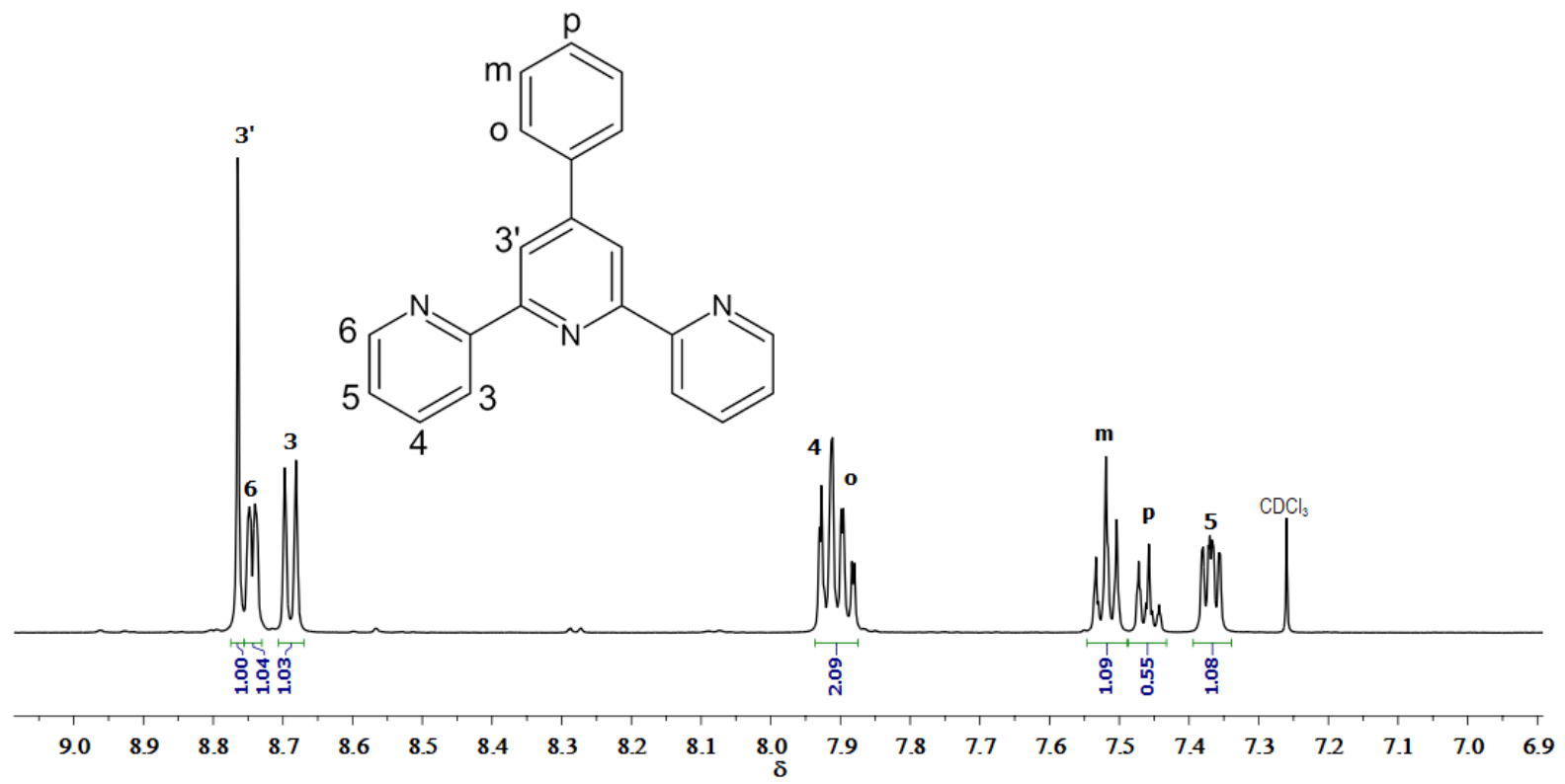

Figura 4.3: Espectro ${ }^{1} \mathrm{H}-\mathrm{RMN}\left(\mathrm{CDCl}_{3}, 500 \mathrm{MHz}\right)$ do ligante phtpy. Os sinais foram ajustados em função do sinal do $\mathrm{CDCl}_{3}$.
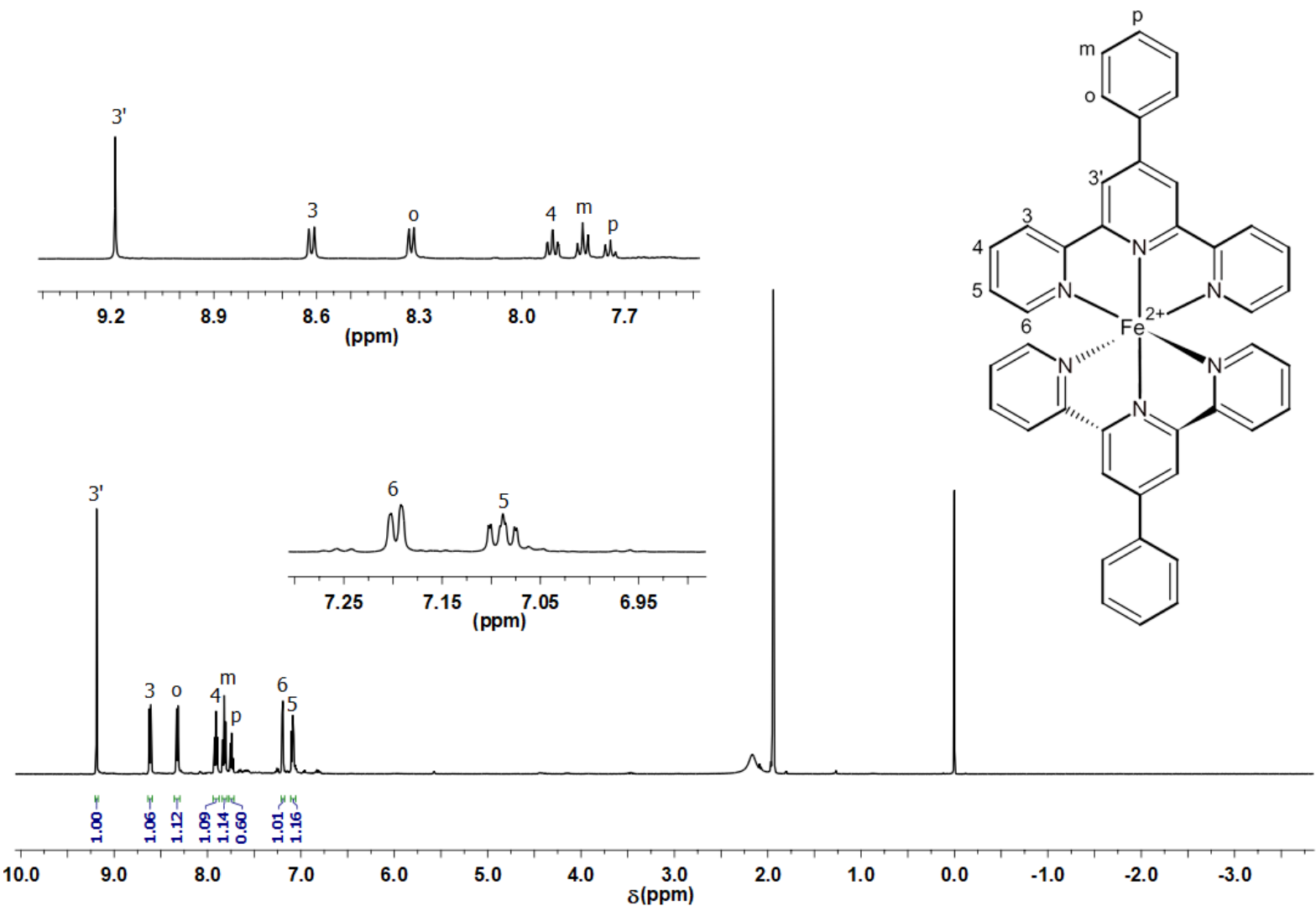

Figura 4.4: Espectro ${ }^{1} \mathrm{H}-\mathrm{RMN}\left(\mathrm{CD}_{3} \mathrm{CN}, 500 \mathrm{MHz}\right)$ do complexo $\left[\mathrm{Fe}(\text { phtpy })_{2}\right]^{2+}$. Os sinais foram ajustados em função do sinal do TMS. 
Tabela 4.1: Valores dos deslocamentos químicos do ligante phtpy livre e do complexo $\left[\mathrm{Fe}(\text { phtpy })_{2}\right]^{2+}$ obtidos em soluçôes de $\mathrm{CDCl}_{3}$ e $C D_{3} C N$, respectivamente.

\begin{tabular}{ccc}
\hline Próton & $\begin{array}{c}\text { Ligante livre } \\
\text { phtpy }\end{array}$ & $\begin{array}{c}\text { Complexo } \\
{\left[\mathrm{Fe}(\text { phtpy })_{2}\right]^{2+}}\end{array}$ \\
\hline $\mathrm{p}$ & $7,46(\mathrm{~m})$ & 7,74 \\
$\mathrm{~m}$ & $7,52(\mathrm{~m})$ & 7,82 \\
$\mathrm{o}$ & $7,88(\mathrm{~d})$ & 8,33 \\
3 & $8,76(\mathrm{~s})$ & 9,19 \\
3 & $8,69(\mathrm{~d})$ & 8,62 \\
4 & $7,91(\mathrm{t})$ & 7,91 \\
5 & $7,37(\mathrm{~m})$ & 7,09 \\
6 & $8,74(\mathrm{dd})$ & 7,20 \\
\hline
\end{tabular}

$\mathrm{s}=$ singlete, $\mathrm{d}=$ dublete, $\mathrm{dd}=$ duplo dublete, $\mathrm{m}=$ multiplete, $\mathrm{t}=$ triplete

O espectro de ${ }^{1} \mathrm{H}-\mathrm{RMN}$ do ligante pytpy, em clorofórmio deuterado $\left(\mathrm{CDCl}_{3}\right)$ pode ser visualizado na Figura 4.5. Na região desblindada do espectro, observam-se sinais não resolvidos entre os deslocamentos químicos 8,79 e 8,66 ppm, sendo provavelmente um duplo dublete em 8,79 ppm, um singlete em 8,77 ppm e dois dubletes em 8,75 e 8,68 ppm, correspondente aos prótons $1,3,7$ e 4, respectivamente. O multiplete em 7,91 ppm foi atribuído ao próton 5 e o duplo dublete em 7,81 ao próton 2 . Ao sinal da região mais blindada ao próton 6 .

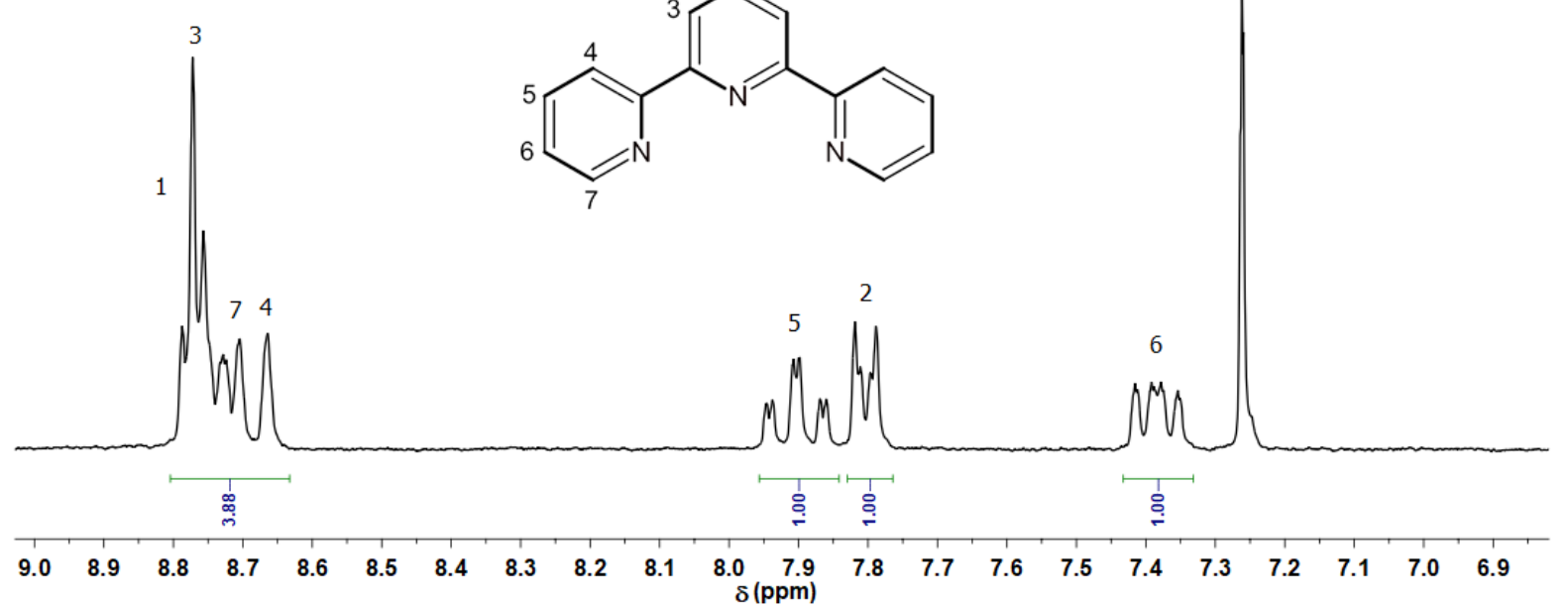

Figura 4.5: Espectro ${ }^{1} \mathrm{H}-\mathrm{RMN}\left(\mathrm{CDCl} \mathrm{l}_{3}, 300 \mathrm{MHz}\right)$ do ligante pytpy. Os sinais foram ajustados em função do sinal do TMS. 
Na Figura 4.6 é apresentado o espectro de ${ }^{1} \mathrm{H}-\mathrm{RMN}$ do complexo $\left[\mathrm{Fe}(\text { pytpy })_{2}\right]^{2+}$ em acetonitrila deuterada. Observam-se sete sinais com as seguintes atribuições: o único singlete em 9,22 ppm ao próton do anel piridínico central, com numeração 3, os dois duplos dubletes são atribuídos aos prótons 1 e 2 do anel piridínico axial, com deslocamentos químicos 9,01 e 8,22 ppm, respectivamente, sendo que o mais desblindado é atribuído ao próton mais próximo ao átomo de nitrogênio. Os dois dubletes do espectro, um com deslocamento químico igual a 8,60 e o outro com deslocamento químico 7,17 ppm são atribuídos aos prótons 4 e 7, respectivamente. O triplete, com deslocamento químico 7,93 ppm, é atribuído ao próton 6 e o multiplete em 7,09 ppm ao próton 5. Na Tabela 4.2 estão a lista de atribuições dos sinais de ambos ligante e complexo, os quais estão de acordo com os dados publicados por Constable e Thompson. [103].
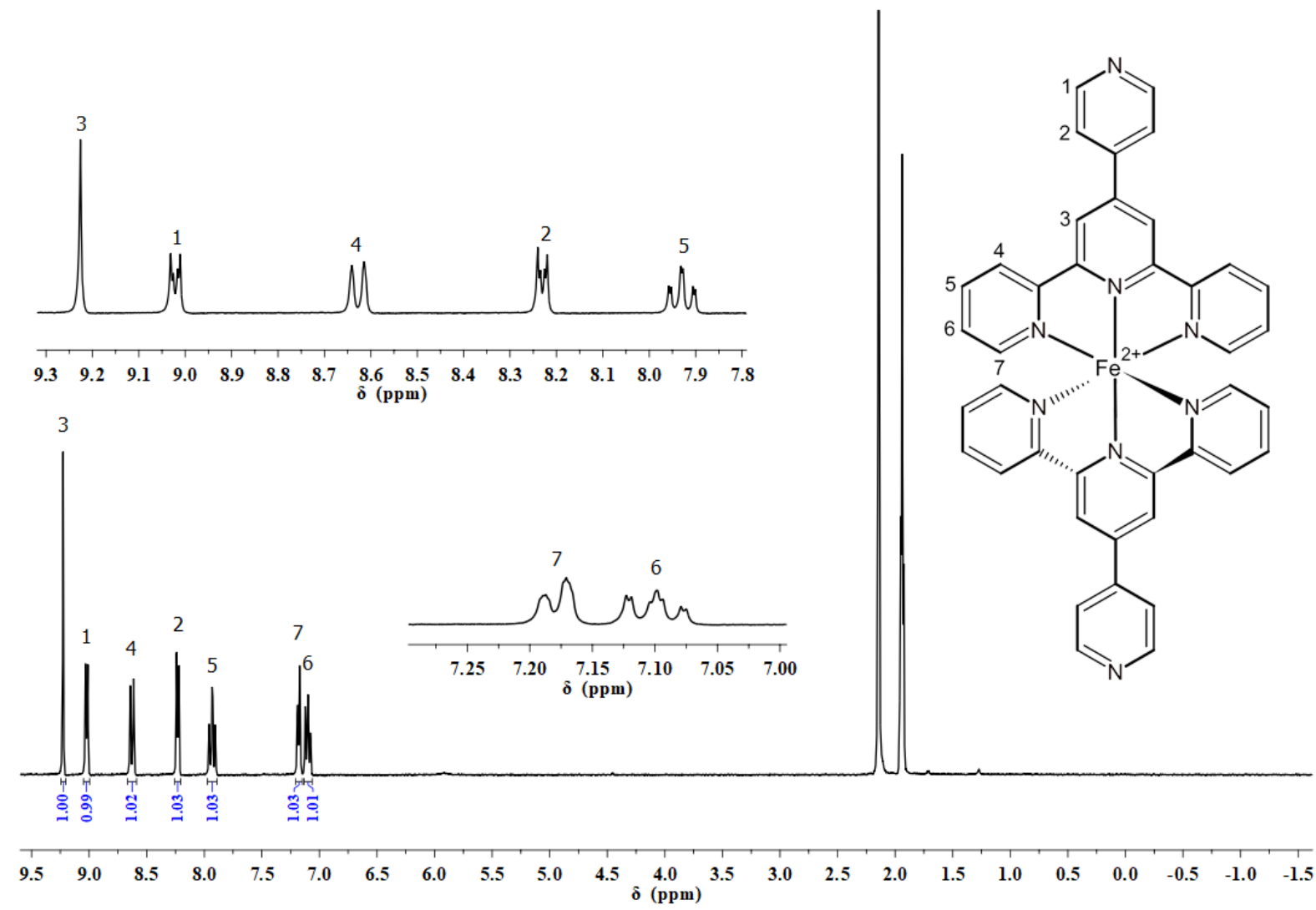

Figura 4.6: Espectro ${ }^{1} \mathrm{H}-\mathrm{RMN}\left(\mathrm{C} \mathrm{D}_{3} \mathrm{CN}, 300 \mathrm{MHz}\right)$ do complexo $\left[\mathrm{Fe}(\text { pytpy })_{2}\right]^{2+}$. Os sinais foram ajustados em funçâo do sinal $C D_{3} C N$. 
Tabela 4.2: Valores dos deslocamentos químicos do ligante pytpy livre e do complexo $\left[\mathrm{Fe}(\text { pytpy })_{2}\right]^{2+}$ obtidos em soluçôes de $C D C l_{3}$ e $C D_{3} C N$, respectivamente.

\begin{tabular}{ccc}
\hline Próton & $\begin{array}{c}\text { Ligante livre } \\
\text { pytpy }\end{array}$ & $\begin{array}{c}\text { Complexo } \\
{\left[\mathrm{Fe}(\text { pytpy })_{2}\right]^{2+}}\end{array}$ \\
\hline 1 & $8,79(\mathrm{dd})$ & $9,01(\mathrm{dd})$ \\
2 & $7,81(\mathrm{dd})$ & $8,22(\mathrm{dd})$ \\
3 & $8,77(\mathrm{~s})$ & $9,22(\mathrm{~s})$ \\
4 & $8,68(\mathrm{~d})$ & $8,60(\mathrm{~d})$ \\
5 & $7,91(\mathrm{~m})$ & $7,09(\mathrm{~m})$ \\
6 & $7,42-7,35$ & $7,93(\mathrm{t})$ \\
7 & $8,75(\mathrm{~d})$ & $7,17(\mathrm{~d})$ \\
\hline
\end{tabular}

$\mathrm{s}=$ singlete, $\mathrm{d}=$ dublete, $\mathrm{dd}=$ duplo dublete, $\mathrm{m}=$ multiplete, $\mathrm{t}=$ triplete

O espectro de ${ }^{1} H-R M N$ do ligante phtpz encontra-se na Figura 4.7. As atribuições para esse ligante foram feitas baseadas no trabalho de Zhang et al. [44]. Pode-se observar que há três multipletes nas posições: 8,67 ppm (próton 5 e 6); 7,54 ppm (próton 1) e 7,50 ppm (próton a), um duplo dublete em 7,88 (próton 2), um dublete em 9,88 ppm (próton 4) e um singlete em 8,74 ppm (próton 3).

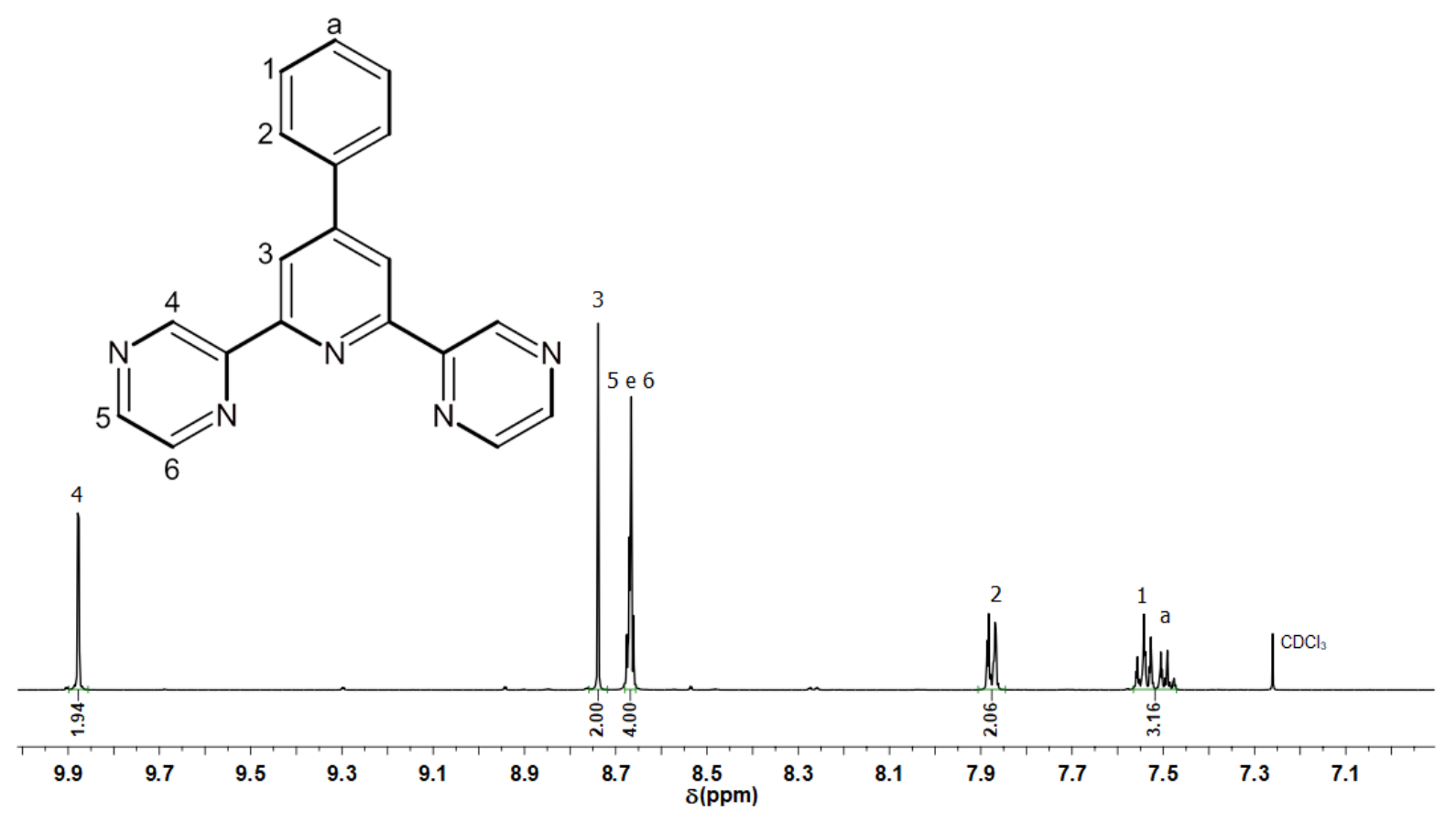

Figura 4.7: Espectro ${ }^{1} \mathrm{H}-\mathrm{RMN}\left(\mathrm{CDCl}_{3}, 500 \mathrm{MHz}\right)$ do ligante phtpz. Os sinais foram ajustados em função do sinal de $\mathrm{CDCl}_{3}$.

Pode-se visualizar na Figura 4.8 o espectro de ${ }^{1} H-R M N$ do complexo $\left[\mathrm{Fe}(\text { phtpz })_{2}\right]^{2+}$ em acetona deuterada. Esse espectro apresenta as regiões com menores resoluções compa- 
radas com os outros espectros, o que torna a atribuição mais complicada. Ao se integrar os sinais chega-se a 13 prótons como o esperado para o complexo. Entre 7,87 e 7,77 ppm há uma mistura de sinais, provavelmente sendo os sinais dos prótons da fenila, prótons $a$, 1 e 2. Os dois dubletes, 10,1 ppm (não resolvido) e 8,39 ppm, são atribuídos aos prótons 4 e 6 . O duplo dublete bem resolvido, em 7,30 ppm, corresponde ao sinal do próton 5 e o único singlete, em 9,80 ppm, ao próton 3. Na Tabela 4.3 encontra-se as atribuições referentes à esse sistema.
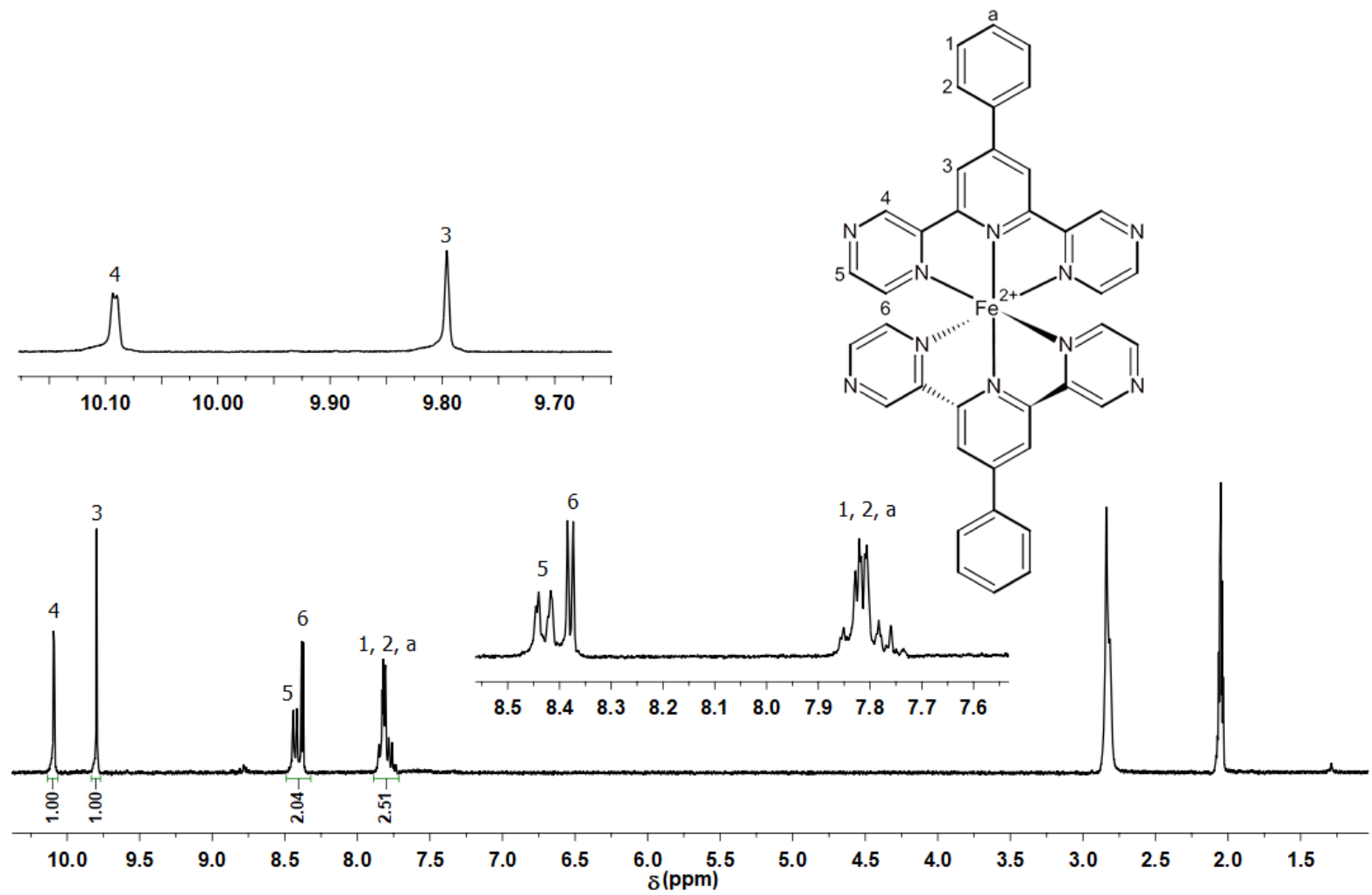

Figura 4.8: Espectro ${ }^{1} \mathrm{H}-\mathrm{RMN}\left(\mathrm{C}_{3} \mathrm{D}_{6} \mathrm{O}, 300 \mathrm{MHz}\right)$ do complexo $\left[\mathrm{Fe}(\text { phtpz })_{2}\right]^{2+}$. Os sinais foram ajustados em função do sinal $C_{3} D_{6} O$. 
Tabela 4.3: Valores dos deslocamentos químicos do ligante phtpz livre e do complexo $\left[\mathrm{Fe}(\text { phtpz })_{2}\right]^{2+}$ obtidos em soluçôes de $\mathrm{CDCl}_{3}$ e acetona-d6, respectivamente.

\begin{tabular}{ccc}
\hline Próton & $\begin{array}{c}\text { Ligante livre } \\
\text { phtpz }\end{array}$ & $\begin{array}{c}\text { Complexo } \\
{\left[\text { Fe }(\text { phtpz })_{2}\right]^{2+}}\end{array}$ \\
\hline $\mathrm{a}$ & $7,50(\mathrm{~m})$ & $7,87-7,77$ \\
1 & $7,54(\mathrm{~m})$ & $7,87-7,77$ \\
2 & $7,88(\mathrm{dd})$ & $7,87-7,77$ \\
3 & $7,74(\mathrm{~s})$ & $9,80(\mathrm{~s})$ \\
4 & $9,88(\mathrm{~d})$ & $10,1(\mathrm{~d})$ \\
5 & $8,67(\mathrm{~m})$ & $7,30(\mathrm{dd})$ \\
6 & $8,67(\mathrm{~m})$ & $8,39(\mathrm{~d})$ \\
\hline $\mathrm{s}=$ singlete, $\mathrm{d}=$ dublete, $\mathrm{dd}=$ duplo dublete, $\mathrm{m}=$ multiplete
\end{tabular}

No espectro de ${ }^{1} H-R M N$ do ligante pytpz (Figura 4.9) observa-se um duplo dublete $(\delta=9,27 \mathrm{ppm})$ na região mais desblindada, seguido de um duplo dublete $(\delta=8,71 \mathrm{ppm})$, atribuídos aos prótons 4 e 1, respectivamente. Em 8,38 ppm há um singlete atribuído ao próton 3, em 8,32 ppm um duplo dublete atribuído ao próton 6 e em 8,26 ppm um dublete atribuído ao próton 5 . Na região mais blindada está o sinal do próton $2(\delta=7,89 \mathrm{ppm})$.<smiles>c1cc(-c2cc(-c3cnccn3)nc(-c3cnccn3)c2)ccn1</smiles>
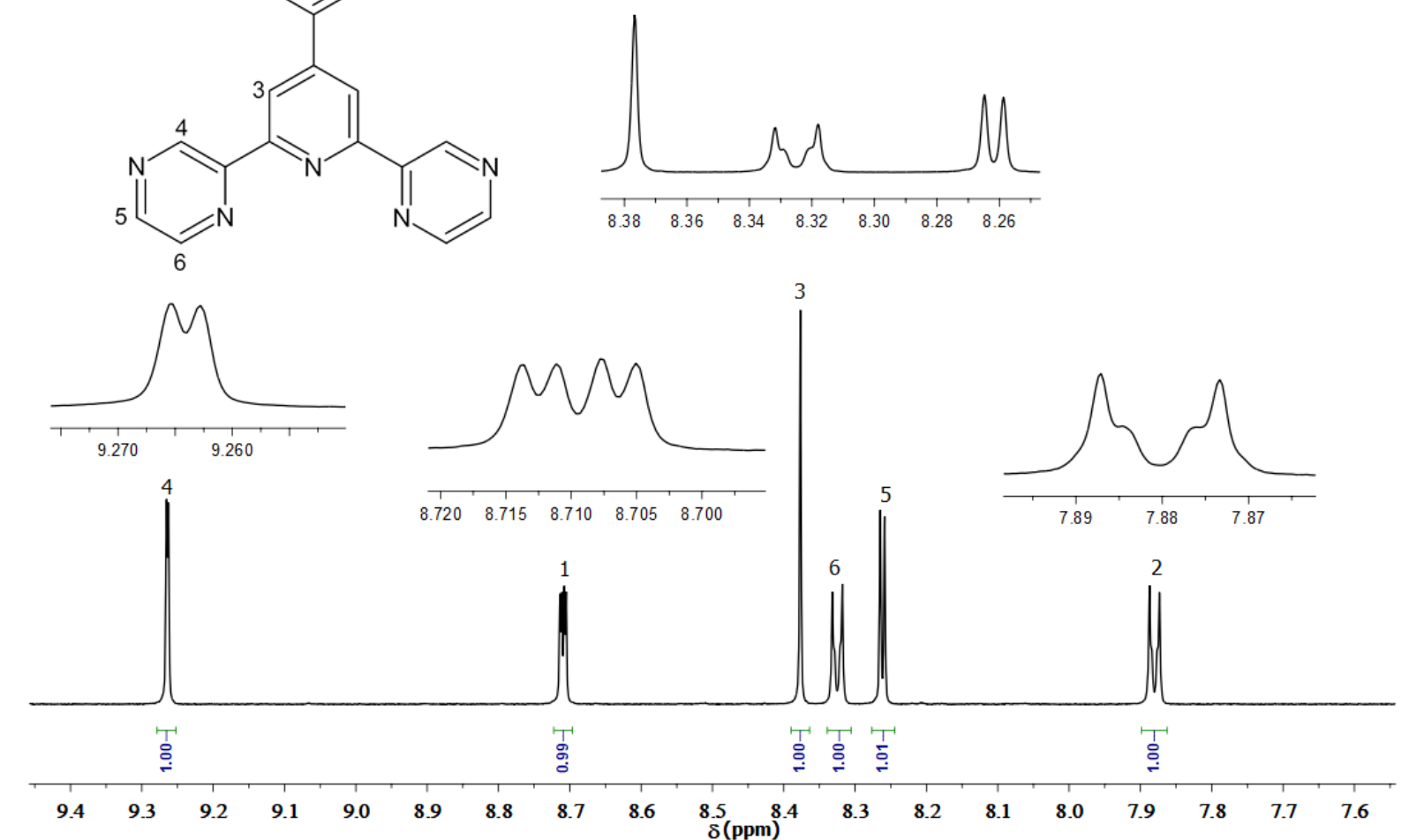

Figura 4.9: Espectro ${ }^{1} \mathrm{H}-\mathrm{RMN}\left(\mathrm{D}_{2} \mathrm{O}, \mathrm{CF}_{3} C O O D, 500 \mathrm{MHz}\right)$ do ligante pytpz. Os sinais foram ajustados em funçâo do sinal de $\mathrm{D}_{2} \mathrm{O}$. 
O espectro de ${ }^{1} H-R M N$ do complexo de $F e(I I)$ com o ligante pytpz encontra-se na Figura 4.10. Podem-se observar seis sinais, o dublete na região mais blindada (campo baixo) com deslocamento químico igual a 9,69 ppm é atribuído ao próton 4 da pirazina e o singlete $\operatorname{com} \delta=9,35 \mathrm{ppm}$ corresponde ao próton 3 da piridina central. O duplo dublete em 9,05 ppm é atribuído ao próton 1 e o duplo dublete em $\delta=8,23$ ppm ao próton 2 , ambos da piridina axial. Em 8,29 ppm observa-se um dublete e em 7,30 ppm um duplo dublete correspondente aos prótons 6 e 5, respectivamente, da pirazina. As atribuições estão de acordo com as relatadas na literatura [43]. Os deslocamentos químicos, do ligante livre (pytpz) e do complexo, referentes aos sinais observados nos espectros e suas respectivas atribuições encontram-se na Tabela 4.4 .

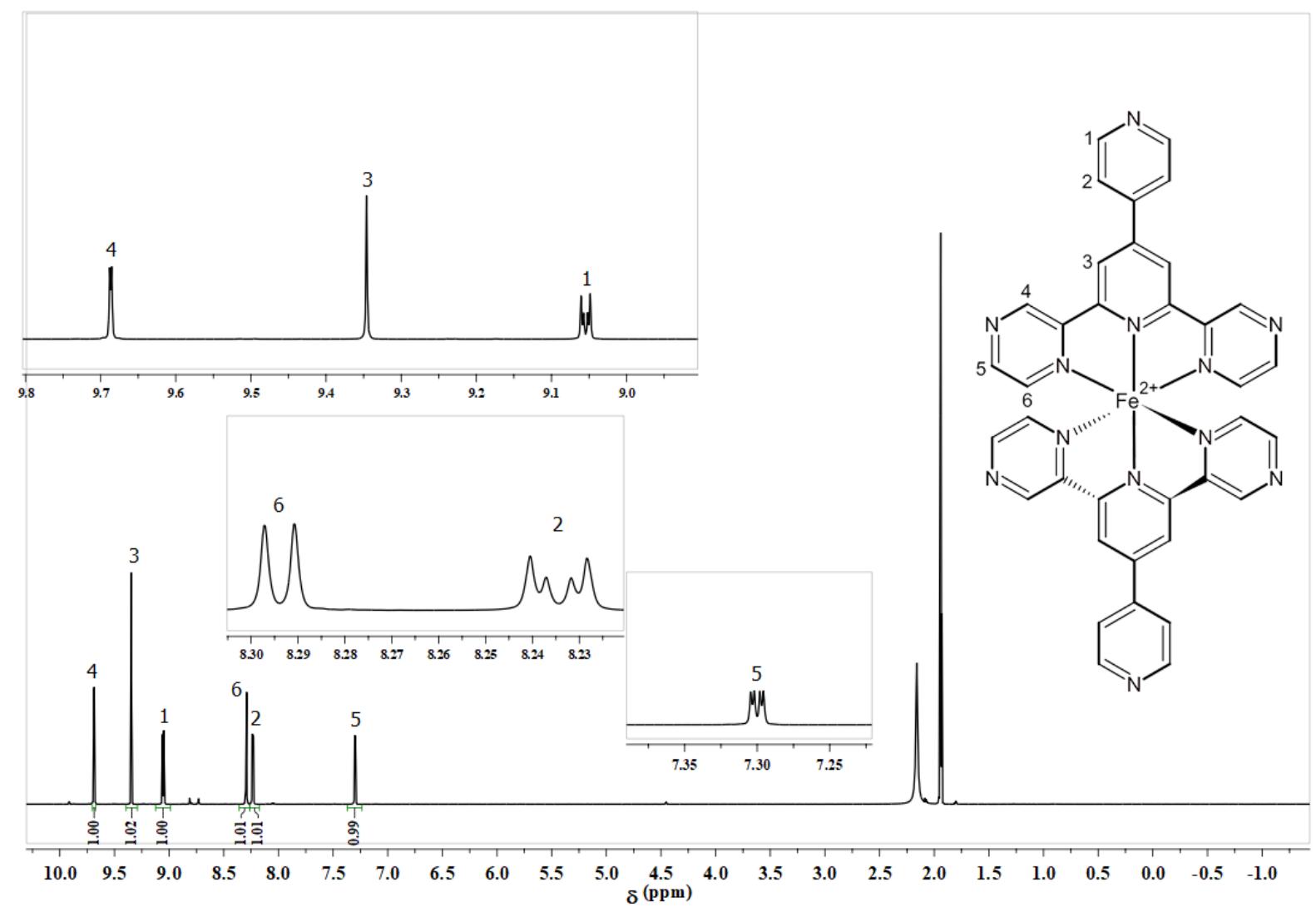

Figura 4.10: Espectro ${ }^{1} \mathrm{H}-\mathrm{RMN}\left(\mathrm{CD} \mathrm{D}_{3} \mathrm{CN}, 500 \mathrm{MHz}\right)$ do complexo $\left[\mathrm{Fe}(\text { pytpz })_{2}\right]^{2+}$. Os sinais foram ajustados em função do sinal $C D_{3} C N$. 
Tabela 4.4: Valores dos deslocamentos químicos do ligante pytpz livre e do complexo $\left[\mathrm{Fe}(\text { pytpz })_{2}\right]^{2+}$ obtidos em soluções de trifluoretanol e $C D_{3} C N$, respectivamente.

\begin{tabular}{ccc}
\hline Próton & $\begin{array}{c}\text { Ligante livre } \\
\text { pytpz }\end{array}$ & $\begin{array}{c}\text { Complexo } \\
{\left[F e(p y t p z)_{2}\right]^{2+}}\end{array}$ \\
\hline 1 & 8,71 & $9,05(\mathrm{dd})$ \\
2 & 7,89 & $8,23(\mathrm{dd})$ \\
3 & 8,38 & $9,35(\mathrm{~s})$ \\
4 & 9,27 & $9,69(\mathrm{~d})$ \\
5 & 8,26 & $7,30(\mathrm{dd})$ \\
6 & 8,32 & $8,29(\mathrm{~d})$ \\
\hline
\end{tabular}

\subsection{Espectros eletrônicos}

\subsubsection{Atribuição e simulação computacional}

Os complexos ter-imínicos de ferro(II) apresentam espectros eletrônicos bastante semelhantes (Figuras 4.11, 4.12, 4.13 e 4.14), com uma banda larga, estruturada, na região do visível, e um conjunto de bandas envolvendo principalmente as transições internas ( $\mathrm{p} \pi$ - $\left.\mathrm{p} \pi^{*}\right)$ nos ligantes, na região do ultra-violeta.

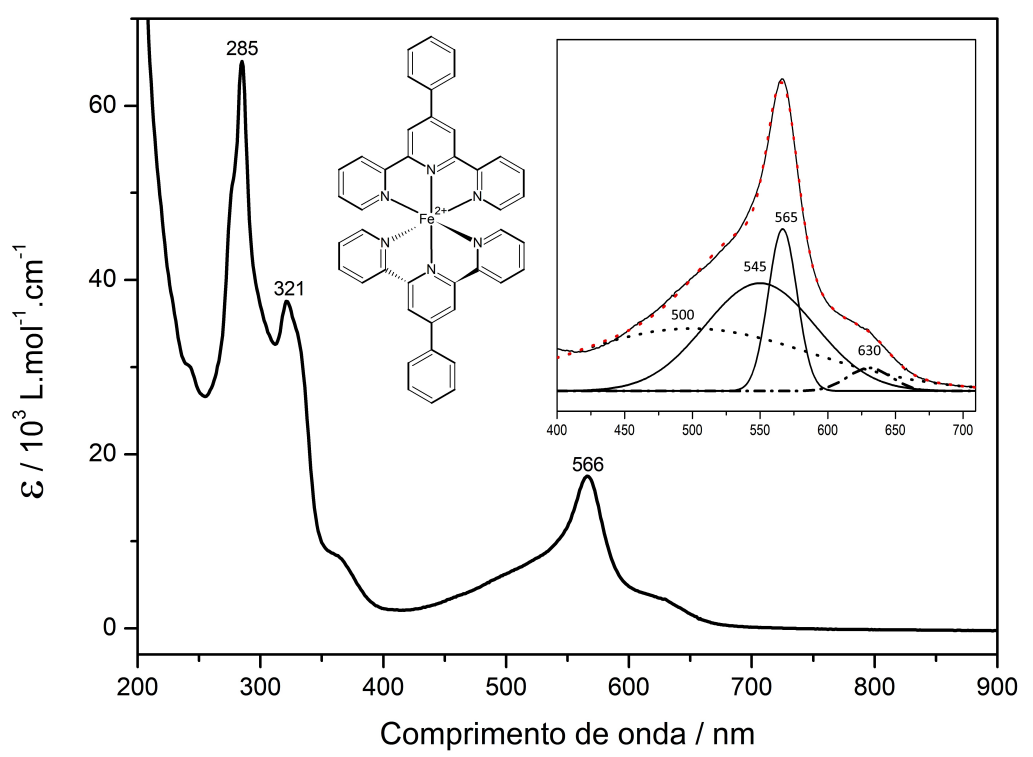

Figura 4.11: Espectro eletrônico do complexo $\left[\mathrm{Fe}(\text { phtpy })_{2}\right]\left(\mathrm{PF}_{6}\right)_{2}$ em acetonitrila, incluindo a deconvolução gaussiana das bandas na região do visível. 


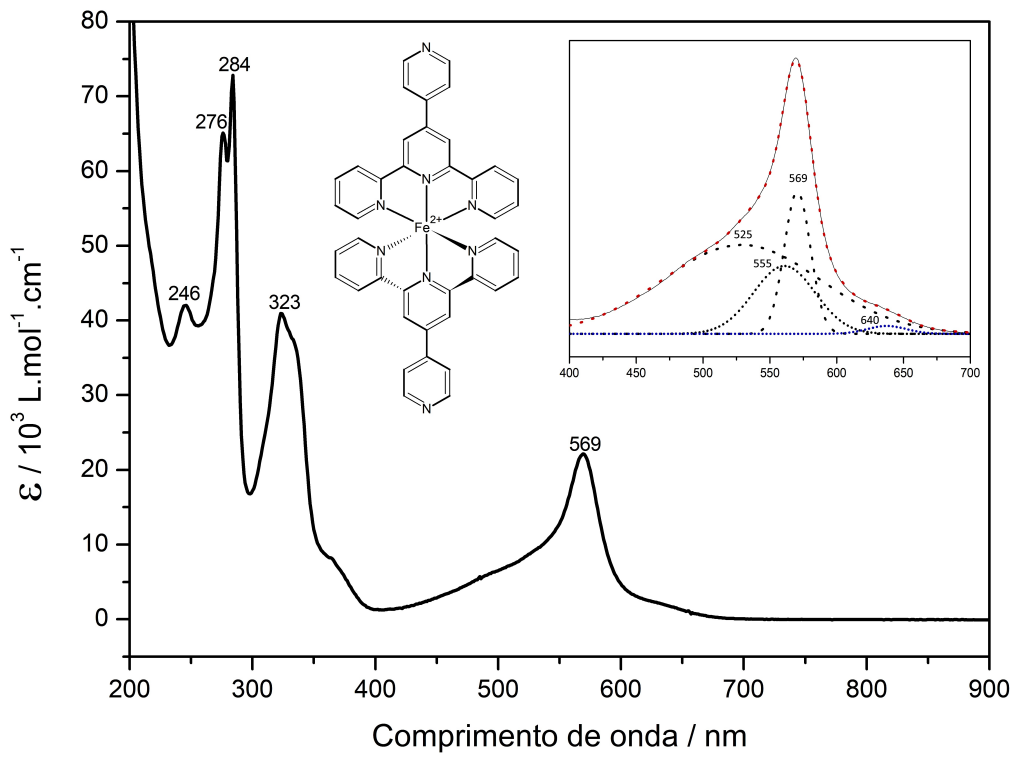

Figura 4.12: Espectro eletrônico do complexo $\left[\mathrm{Fe}(\text { pytpy })_{2}\right]\left(\mathrm{PF}_{6}\right)_{2}$ em acetonitrila, incluindo a deconvolução gaussiana das bandas na região do visivel.

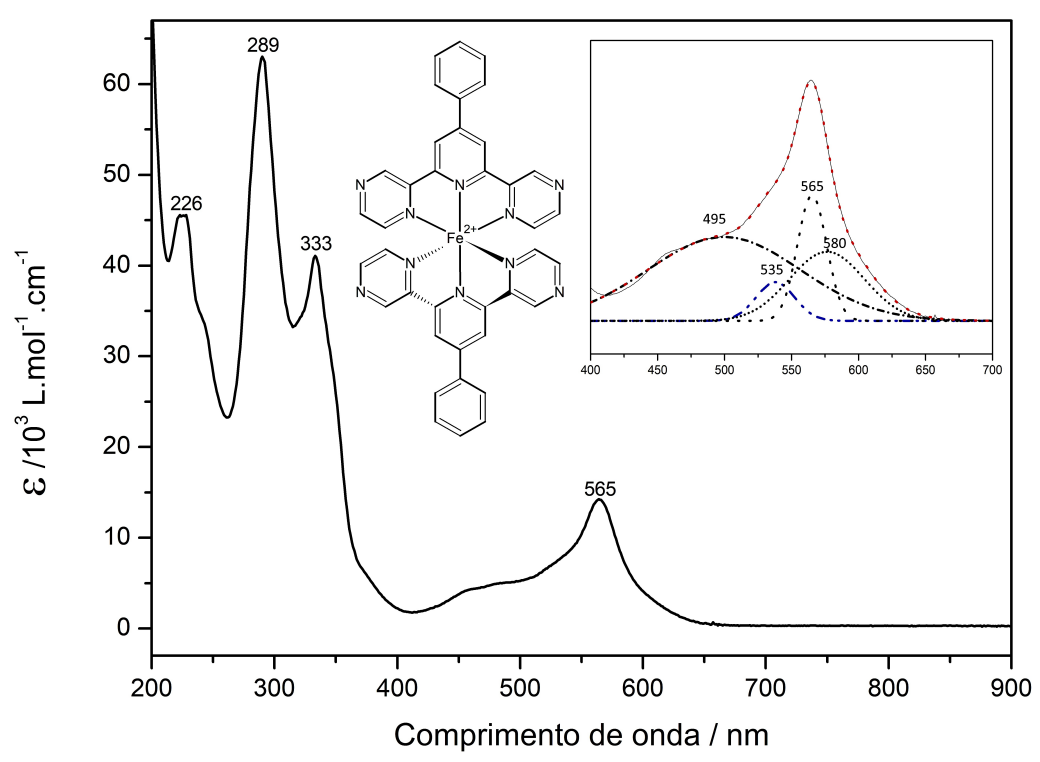

Figura 4.13: Espectro eletrônico do complexo $\left[\mathrm{Fe}(\mathrm{phtpz})_{2}\right]\left(\mathrm{PF}_{6}\right)_{2}$ em acetonitrila, incluindo a deconvolução gaussiana das bandas na região do visível. 


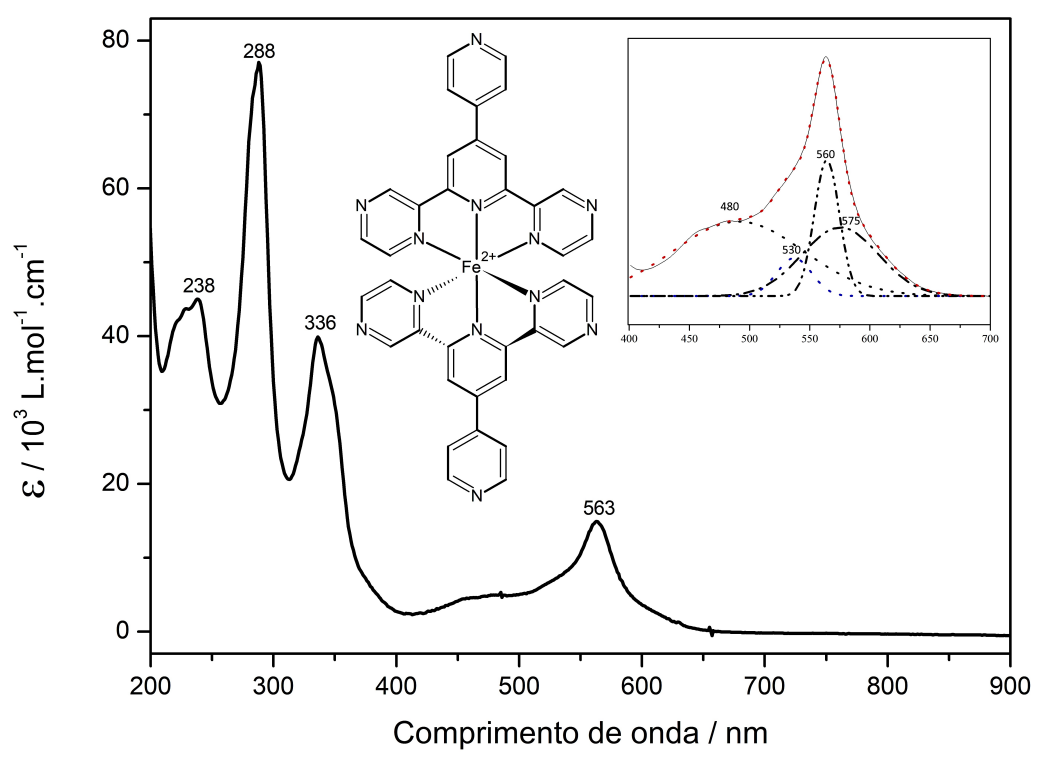

Figura 4.14: Espectro eletrônico do complexo $\left[\mathrm{Fe}(\text { pytpz })_{2}\right]\left(\mathrm{PF}_{6}\right)_{2}$ em acetonitrila, incluindo a deconvolução gaussiana das bandas na região do visivel.

As bandas na região do visível são típicas de complexos ferro(II)-di-imínicos, e foram atribuídas por Krumholz [50] a transições de transferência de carga metal-ligante (TCML), ou $F e(I I) d \pi \rightarrow(d i-i m i n a) p \pi$. Nos complexos ter-imínicos de ferro(II), o espectro na região do visível pode ser deconvoluído em pelo menos 4 bandas principais, mostradas na expansão inserida nas Figuras 4.11, 4.12, 4.13 e 4.14. As deconvoluções foram feitas com o software OriginPro 8.5 empregando o ajuste Gaussiano para as regiões selecionadas (Peakfit). Os dois componentes limítrofes, de maior e menor energia, parecem ser relativamente mais largos, ao passo que os componentes centrais têm um perfil mais estreito. De modo geral, o alargamento de bandas está relacionado com as semelhanças e diferenças das curvas de potencial no estado fundamental e excitado. Por isso, sistemas com maior rigidez estrutural tendem a apresentar bandas mais finas, e esse pode ser o caso do cromóforo ferro(II)-ter-imina. A deslocalização eletrônica para os anéis aromáticos pode contribuir para o alargamento das bandas nos complexos. Outro fato curioso está no perfil das duas bandas mais finas, centrais.

Essas duas bandas ocorrem sempre conjugadas, e também são observadas nos complexos ferro(II) $\alpha$-di-imínicos, com um espaçamento energético em torno de $1500 \mathrm{~cm}^{-1}$. Essa 
constatação levou Krumholz [50] a sugerir que se trata de um esquema vibrônico, onde a segunda banda fina seria apenas um desdobramento vibracional da banda principal [49] [51]. Essa hipótese foi rediscutida por Paoli et al.[104], e interpretada como desdobramento dos níveis eletrônicos em virtude do abaixamento da simetria dos complexos.

Nesta Tese os espectros foram tratados inicialmente através de cálculos de mecânica quântica ao nível Hartree-Fock, semi-empíricos, utilizando a metodologia desenvolvida por M. Zerner, conhecida como ZINDO/S. Com a evolução dos recursos computacionais, os métodos semi-empíricos estão cedendo lugar para métodos computacionais alternativos, como o DFT, com algum ganho de qualidade a despeito do maior tempo e limitações na complexidade dos sistemas. Em complexos como elevado número de átomos, como os abordados aqui, os métodos semi-empíricos tem sido extremamente úteis, e de aplicação imediata na maioria dos complexos. Em nosso grupo, os métodos semi-empíricos tem sido usados de forma rotineira, pela praticidade, na discussão dos espectros. Quando necessário, os cálculos são aperfeiçoados com outros métodos em função dos objetivos almejados.

Os cálculos ZINDO/S para o complexo $\left[\mathrm{Fe}(\text { phtpy })_{2}\right]^{2+}$ proporcionaram uma concordância razoável com os dados experimentais, como pode ser visto na Tabela 4.5.

Tabela 4.5: Espectros eletrônicos com deconvolução de bandas, simulação teórica (ZINDO/S) e atribuição.

\begin{tabular}{cccc}
\hline Complexo & $\begin{array}{c}\lambda_{\max .} \text { Exp. } \\
\text { Intensidade }\end{array}$ & $\begin{array}{c}\lambda_{\max } \text { Teórico } \\
\text { (força osc.) }\end{array}$ & $\begin{array}{c}\text { Atribuição } \mathrm{MO} \rightarrow \mathrm{MO}^{*} \\
(\mathrm{ZINDO} / \mathrm{S})\end{array}$ \\
\hline$\left[\mathrm{Fe}(\text { phtpy })_{2}\right]^{2+}$ & $630 \mathrm{~m}$, larga & $624(0,01)$ & $115(\mathrm{Fe}) \rightarrow 118 / 9(\mathrm{Fe}+\mathrm{tpy})$ \\
\hline & $565 \mathrm{f}$, fina & $591(0,26)$ & $117(\mathrm{Fe}) \rightarrow 118 / 9(\mathrm{Fe}+\mathrm{tpy})$ \\
\hline & $545 \mathrm{~m}$, larga & $513(0,080)$ & $116(\mathrm{Fe}) \rightarrow 121(\mathrm{tpy})$ \\
\hline & $500 \mathrm{~m}$, larga & $467(0,26)$ & $115(\mathrm{Fe}) \rightarrow 120(\mathrm{tpy})$ \\
\hline
\end{tabular}

Orbitais moleculares descritos nas Figuras 4.15

Os orbitais moleculares envolvidos estão ilustrados na Figura 4.15. 


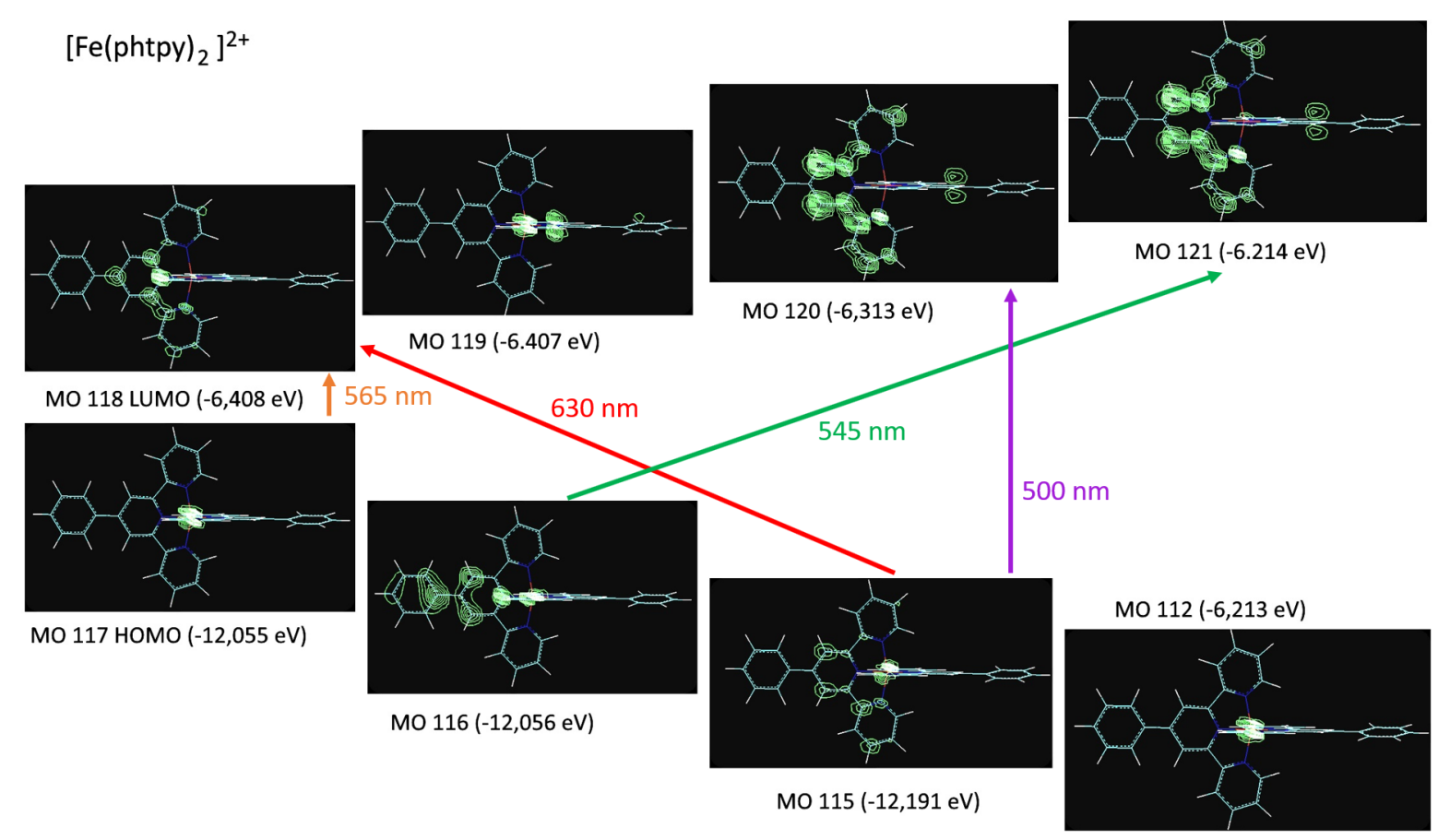

Figura 4.15: Orbitais moleculares (HOMO/LUMO) envolvidos nas transições observadas experimentalmente para o complexo $\left[\mathrm{Fe}(\text { phtpy })_{2}\right]^{2+}$ na região do visivel.

A banda principal, em $565 \mathrm{~nm}$, é relativamente fina, e é atribuída à transição MO117 (HOMO) centrada no íon metálico, $F e(I I) d \pi$, para o MO118/9 (LUMO), degenerado, centrado no grupo ter-imínico. A banda de menor energia, em 630 nm, envolve a transição do MO115, deslocalizado no anel Fe-terpiridina, para o MO118/119. O alargamento observado pode ser resultante da deslocalização eletrônica no estado fundamental. O mesmo comentário se aplica às bandas em 545 e 500 nm, que envolvem os MOs 120 e 121 bastante deslocalizados sobre o anel terpiridínico.

As bandas simuladas teoricamente do complexo $\left[\mathrm{Fe}(\text { pytpy })_{2}\right]^{2+}$ estão mostradas na Tabela 4.6.

Tabela 4.6: Espectros eletrônicos com deconvolução de bandas, simulação teórica (ZINDO/S) para o complexo $\left[\mathrm{Fe}(\text { pytpy })_{2}\right]^{2+}$

\begin{tabular}{cccc}
\hline Complexo & $\begin{array}{c}\lambda_{\max .} \text { Exp. } \\
\text { Intensidade }\end{array}$ & $\begin{array}{c}\lambda_{\max } \text { Teórico } \\
\text { (força osc.) }\end{array}$ & $\begin{array}{c}\text { Atribuição MO } \rightarrow \mathrm{MO}^{*} \\
(\text { ZINDO } / \mathrm{S})\end{array}$ \\
\hline$\left[\mathrm{Fe}(\text { pytpy })_{2}\right]^{2+}$ & $640 \mathrm{w}$, fina & $603(0,01)$ & $115(\mathrm{Fe}) \rightarrow 118 / 9(\mathrm{Fe}+$ tpy $)$ \\
\hline & $569 \mathrm{f}$, fina & $567(0,16)$ & $114(\mathrm{Fe}) \rightarrow 118 / 9(\mathrm{Fe}+$ tpy $)$ \\
\hline $555 \mathrm{~m}$, larga & $490(0,033)$ & $114(\mathrm{Fe}) \rightarrow 121(\mathrm{Fe}+$ tpy $)$ \\
\hline & $525 \mathrm{~m}$, larga & $448(0,177)$ & $115(\mathrm{Fe}) \rightarrow 120($ tpy $)$ \\
\hline & Orbitais moleculares descritos nas Figuras 4.16
\end{tabular}


A banda principal em 569 nm tem um aspecto fino, e é atribuída à transição MO114 centrada no íon de $F e(I I) d \pi$ para o MO118/119 envolvendo principalmente o grupo

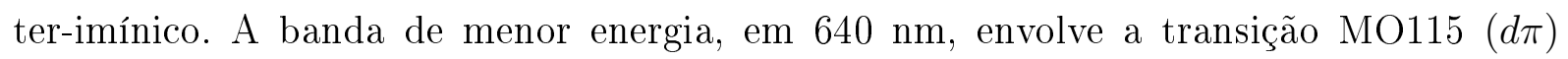
para o MO118/119. As bandas em 555 e $525 \mathrm{~nm}$, envolvem as transições entre os MOs 114/115 localizados no íon de $F e(I I)$ para os MOs 120 e 121, mais deslocalizados no anel terpiridínico. Na Figura 4.16 estão ilustrados os orbitais moleculares envolvidos nas transições eletrônicas descritas.

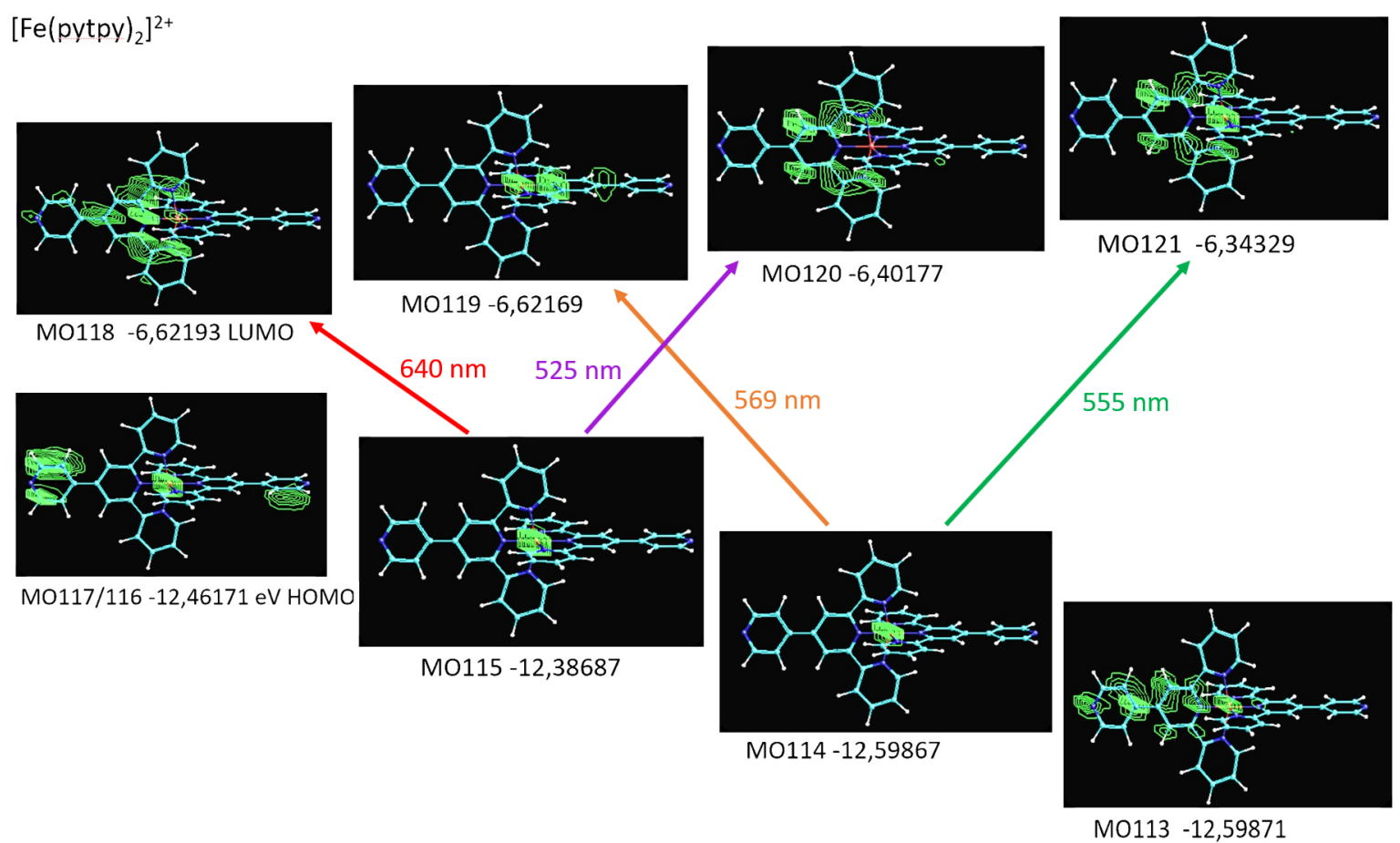

Figura 4.16: Orbitais moleculares (HOMO/LUMO) envolvidos nas transições observadas experimentalmente para o complexo $\left[\mathrm{Fe}(\text { pytpy })_{2}\right]^{2+}$ na região do visivel.

Para o complexo $\left[\mathrm{Fe}(p h t p z)_{2}\right]^{2+}$ o resultado da simulação teórica está mostrado na Tabela 4.7. 
Tabela 4.7: Espectros eletrônicos com deconvolução de bandas, simulação teórica (ZINDO/S) e atribuição.

\begin{tabular}{cccc}
\hline Complexo & $\begin{array}{c}\lambda_{\max } \text { Exp. } \\
\text { Intensidade }\end{array}$ & $\begin{array}{c}\lambda_{\max } \text { Teórico } \\
\text { (força osc.) }\end{array}$ & $\begin{array}{c}\text { Atribuição } \mathrm{MO} \rightarrow \mathrm{MO}^{*} \\
(\text { ZINDO } / \mathrm{S})\end{array}$ \\
\hline$\left[\mathrm{Fe}(\text { phtpz })_{2}\right]^{2+}$ & $580 \mathrm{~m}$, larga & $605(0,003)$ & $\begin{array}{c}113(\mathrm{Fe}+\mathrm{tpz}) \\
\rightarrow 118 / 9(\mathrm{Fe}+\mathrm{tpz})\end{array}$ \\
\hline & $565 \mathrm{~s}$, fina & $565(0,196)$ & $111(\mathrm{Fe}) \rightarrow 118 / 9(\mathrm{Fe}+\mathrm{tpz})$ \\
\hline & $535 \mathrm{w}$, fina & $518(0,023)$ & $116(\mathrm{Fe}+\mathrm{tpz}) \rightarrow 121(\mathrm{tpz})$ \\
\hline & $495 \mathrm{~s}$, larga & $463(0,523)$ & $113(\mathrm{Fe}+\mathrm{tpz}) \rightarrow 120(\mathrm{tpz})$ \\
\hline
\end{tabular}

Orbitais moleculares descritos nas Figuras 4.17

A banda principal em $565 \mathrm{~nm}$, tem aspecto fino, e provém da transição envolvendo o MO111, centrado essencialmente no $F e(I I)$, para o MO degenerado 118/119 que tem um caráter bastante deslocalizado no sistema Fe(II)-terpirazínico (vide Figura 4.17). A banda de menor energia em 580 nm, envolve a excitação do MO113 para o MO118/9, ambos deslocalizados sobre o anel Fe-terpirazina. Provavelmente por isso, ela fica mais larga e aparece deslocada para maior energia, em relação aos derivados terpiridínicos. Curiosamente, a banda em $535 \mathrm{~nm}$ envolve a transição entre o MO116 com forte participação do grupo fenila, para o MO121 deslocalizado sobre o anel Fe-terpirazina. Já a banda em 495 nm é bastante larga e intensa, envolvendo a excitação entre o MO113 e o MO121, ambos deslocalizados sobre o anel Fe-terpirazínico. 


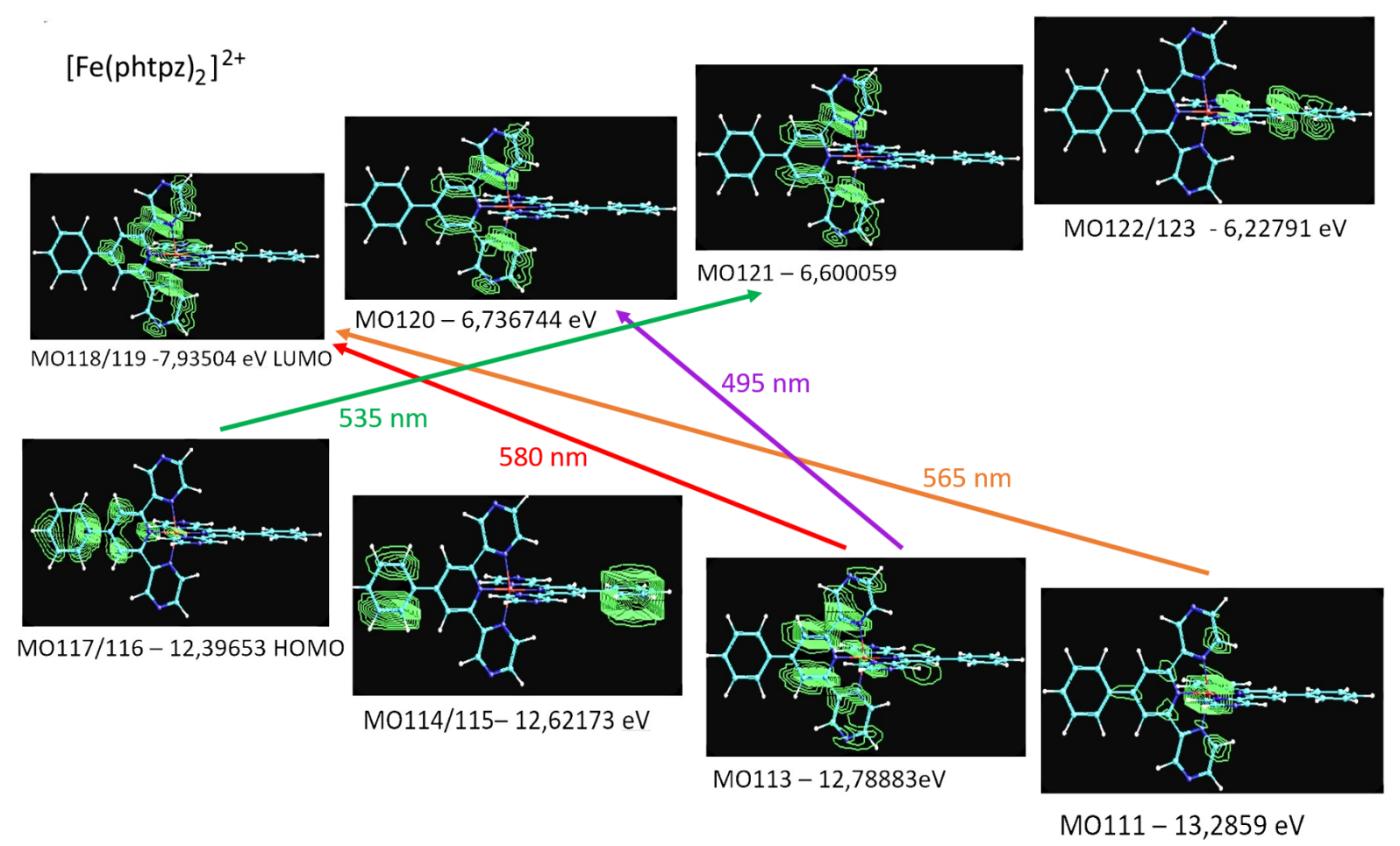

Figura 4.17: Orbitais moleculares (HOMO/LUMO) envolvidos nas transiçôes observadas experimentalmente para o complexo $\left[\mathrm{Fe}(\text { phtpz })_{2}\right]^{2+}$ na região do visivel.

No caso do complexo $\left[\mathrm{Fe}(\text { pytpz })_{2}\right]^{2+}$ a simulação teórica está compilada na Tabela 4.8.

Tabela 4.8: Espectros eletrônicos com deconvolução de bandas, simulação teórica (ZINDO/S) e atribuição.

\begin{tabular}{cccc}
\hline Complexo & $\begin{array}{c}\lambda_{\max .} \text { Exp. } \\
\text { Intensidade }\end{array}$ & $\begin{array}{c}\lambda_{\max } \text { Teórico } \\
\text { (força osc.) }\end{array}$ & $\begin{array}{c}\text { Atribuição } \mathrm{MO} \rightarrow \mathrm{MO}^{*} \\
(\mathrm{ZINDO} / \mathrm{S})\end{array}$ \\
\hline$\left[\mathrm{Fe}(\text { pytpz })_{2}\right]^{2+}$ & $575 \mathrm{~m}$, larga & $646(0,001)$ & $\begin{array}{c}116(\mathrm{Fe}+\mathrm{tpz}) \\
\rightarrow 118 / 9(\mathrm{Fe}+\mathrm{tpz})\end{array}$ \\
\hline & $564(0,041)$ & $114(\mathrm{Fe}) \rightarrow 118 / 9(\mathrm{Fe}+\mathrm{tpz})$ \\
\hline & $530 \mathrm{~s}$, fina, fina & $511(0,069)$ & $114(\mathrm{Fe}) \rightarrow 121(\mathrm{tpz})$ \\
\hline & $480 \mathrm{~s}$, larga & $477(0,240)$ & $115(\mathrm{Fe}+\mathrm{tpz}) \rightarrow 120(\mathrm{tpz})$ \\
\hline
\end{tabular}

Orbitais moleculares descritos nas Figuras 4.18

Os orbitais moleculares do complexo $\left[\mathrm{Fe}(\text { pytpz })_{2}\right]^{2+}$ envolvidos nas transições eletrônicas estão ilustrados na Figura 4.18. A banda principal, em $560 \mathrm{~nm}$ é fina, e envolve a transição entre o MO114 centrado no íon de $F e(I I)$ e o MO118/119 deslocalizado no sistema Fe-terpirazínico. A banda de menor energia é larga e deslocada para $575 \mathrm{~nm}$, envolvendo os MOs 115 e 118/9, ambos deslocalizados no sistema Fe-terpirazina. A banda em 480 nm também é bastante larga e envolve os MOs 115 e 120 deslocalizados no sistema 
Fe-terpirazina.

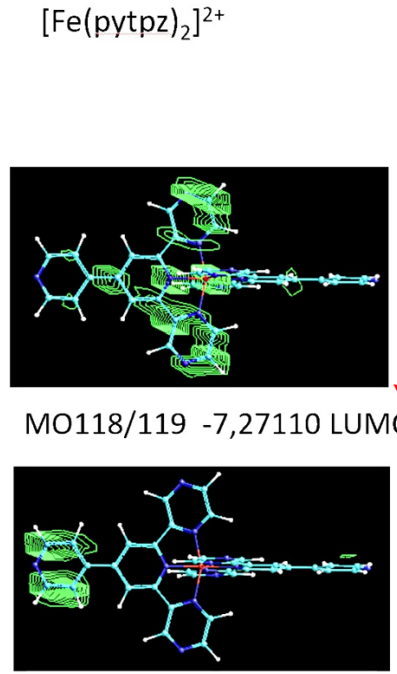

M0117/116 -12,56781 HOMO

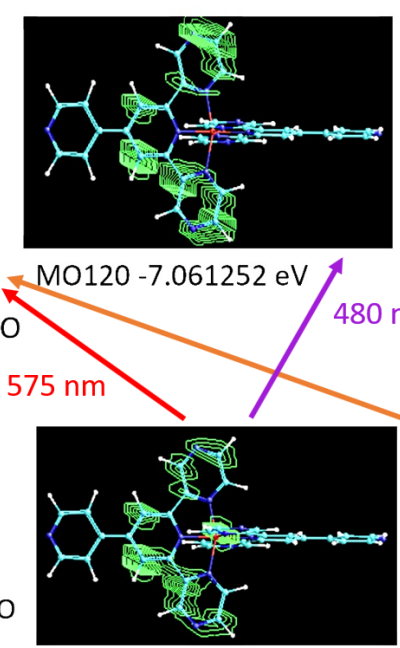

M0115-13,00272 eV
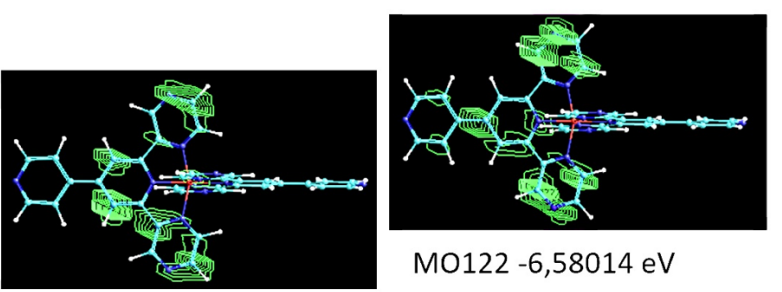

M0122 -6,58014 eV

M0121 -6915526 eV $\mathrm{nm}$

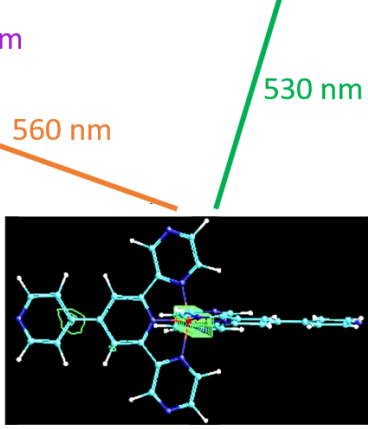

M0114/113 -13.09134 eV

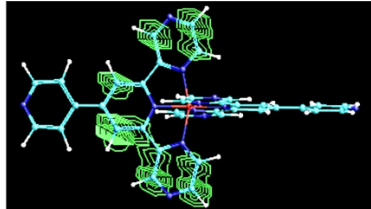

M0112 -13.29922 eV

Figura 4.18: Orbitais moleculares (HOMO/LUMO) envolvidos nas transições observadas experimentalmente para o complexo $\left[\mathrm{Fe}(\text { pytpz })_{2}\right]^{2+}$ na região do visivel.

\subsubsection{Protonação e características ácido-base}

Os complexos com grupos piridínicos e pirazínicos estão sujeitos à protonação, e os efeitos decorrentes no espectro foram registrados nas Figuras 4.19 4.20 4.21. Os compostos de coordenação mononucleares sintetizados foram analisados por espectrofotometria em meio aquoso com eletrólito $\mathrm{KCl} 0,5 \mathrm{~mol} . \mathrm{L}^{-1}$, para controle da força iônica do meio. Os espectros de absorção foram obtidos acidificando-se as amostras com alíquotas de solução de $\mathrm{HCl}$ até se chegar ao pH desejado.

No caso do complexo $\left[\mathrm{Fe}(\text { pytpy })_{2}\right]^{2+}$ a protonação dos nitrogênios piridínicos ocorre no intervalo de $p H 1-4$, provocando alterações no espectro visível e UV, como pode ser visto na Figura 4.19. 


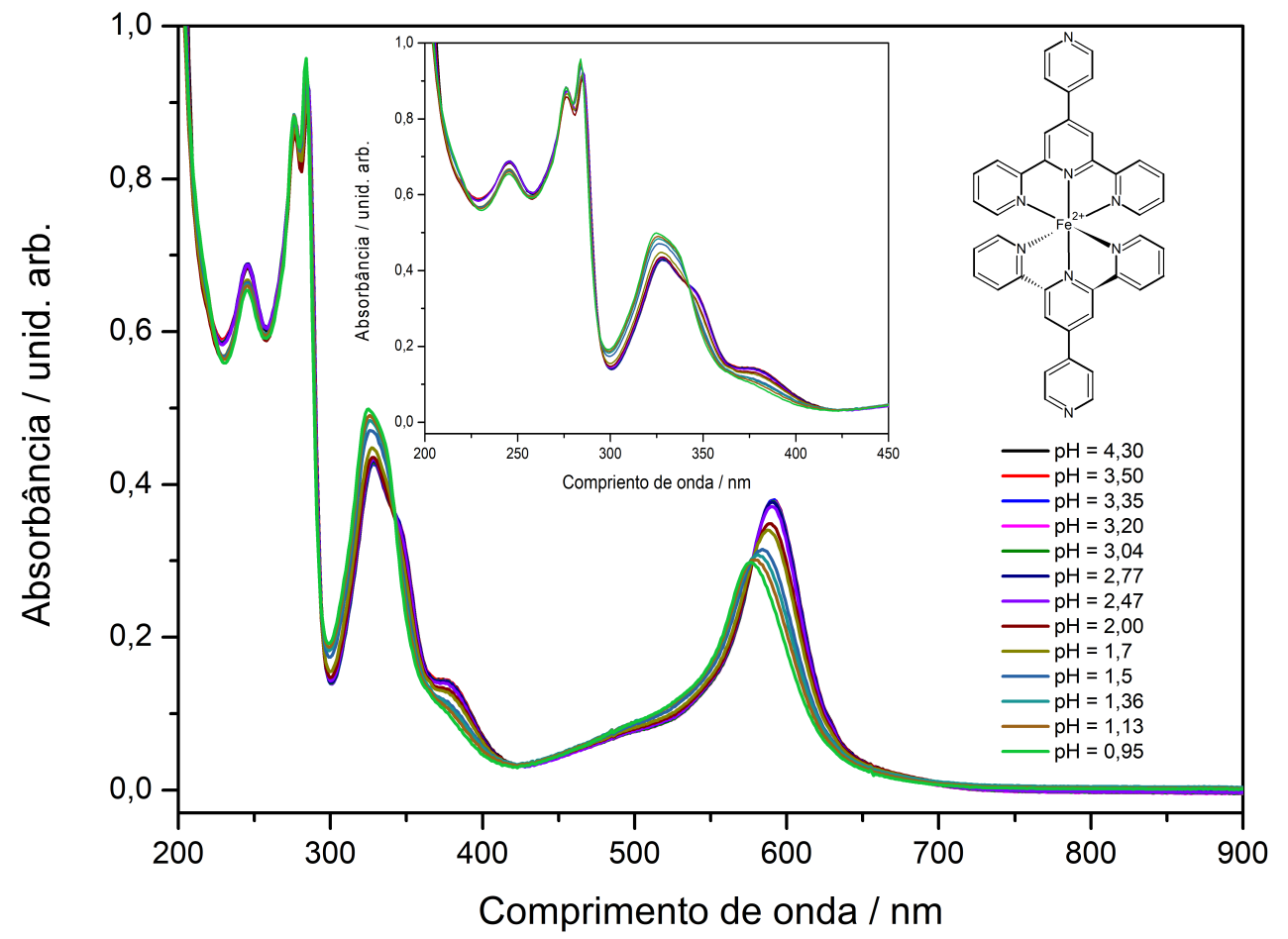

Figura 4.19: Efeitos da protonação no complexo $\left[\mathrm{Fe}(\text { pytpy })_{2}\right]^{2+}$ - variação espectral em função do pH e reprodução interna em maiores detalhes.

De acordo com a simulação espectral (Figura 4.20), a protonação dos grupos piridínicos leva a uma banda prevista em $617 \mathrm{~nm}(\mathrm{f}=0.225)$ em comparação com $600 \mathrm{~nm}$ observada experimentalmente. Essa banda provém da transição MO115 centrado no íon de ferro, para o MO118/119 envolvendo o ligante pytpy protonado. 
$\left[\mathrm{Fe}(\text { pytpyH })_{2}\right]^{4+}$

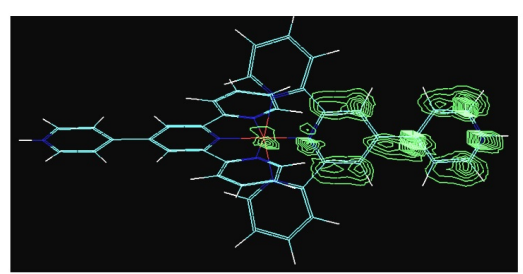

M0118 $-11.148 \mathrm{eV}$

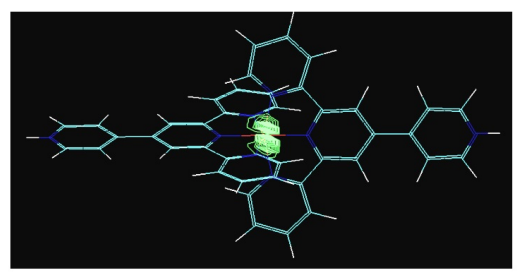

M0117 $-16.436 \mathrm{eV}$

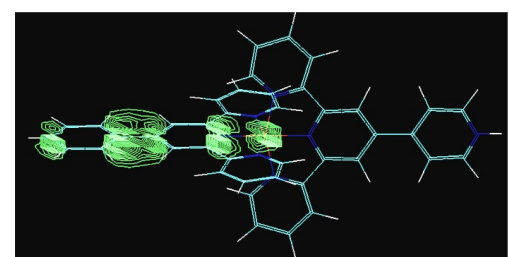

MO119 $-11.148 \mathrm{eV}$

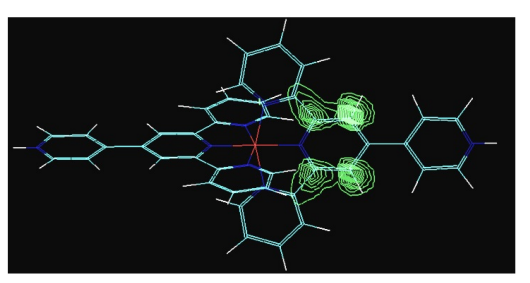

MO120 $-10.410 \mathrm{eV}$

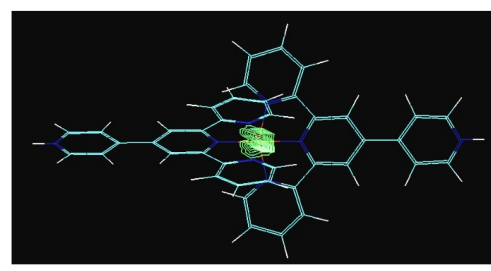

M0116 $-16.642 \mathrm{eV}$

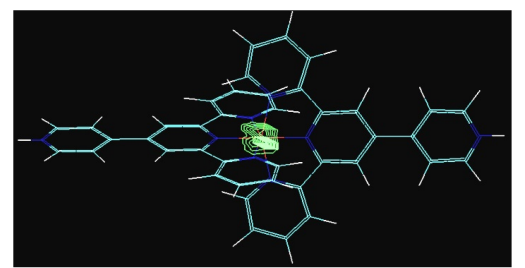

M0115 -16.642 eV

Figura 4.20: Orbitais moleculares (HOMO/LUMO) envolvidos nas transiçôes observadas experimentalmente para o complexo $\left[\mathrm{Fe}(\text { pytpy })_{2}\right]^{2+}$ na região do visivel em meio ácido.

A estimativa de $p K a$ nesse complexo foi feito através das curvas de titulação em vários comprimentos de onda, como ilustrado na Figura 4.21, conduzindo a $p K_{p y 1}=1,6$ e $p K_{p y 2}=2,8$. A mudança da banda TCML para diminuir a energia é compatível com a redução na energia dos níveis $\pi^{*}$ do ligante mediante a protonação. 


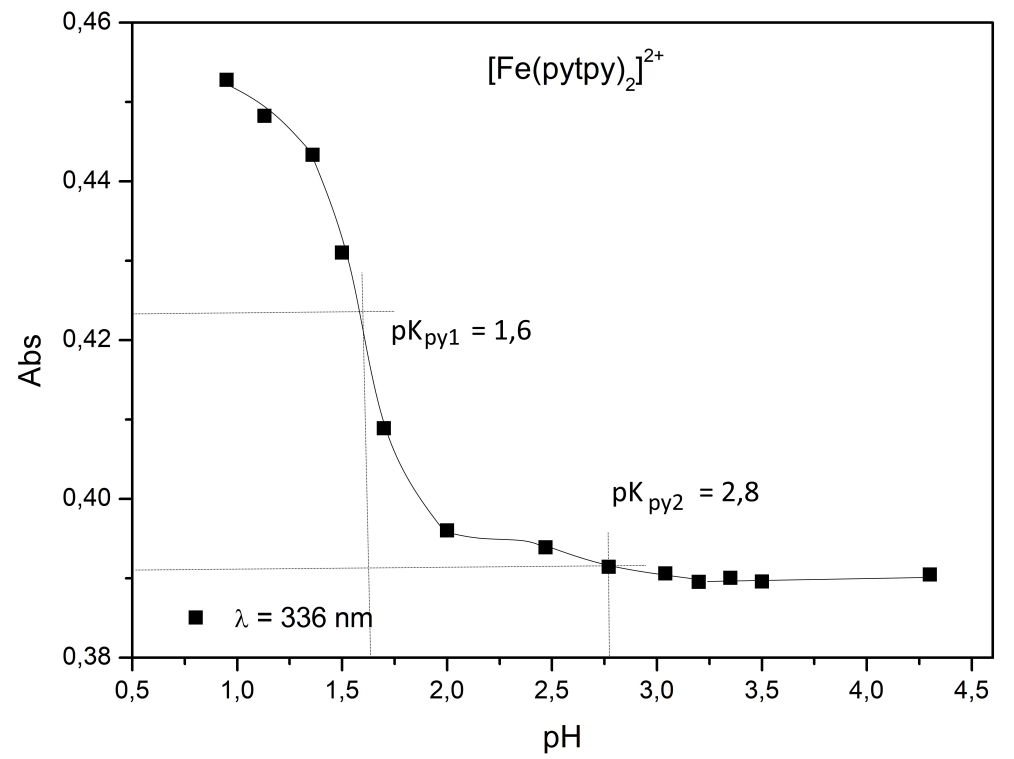

Figura 4.21: Curva de titulação do complexo $\left[\mathrm{Fe}(\text { pytpy })_{2}\right]^{2+}$.

A variação espectral do complexo $\left[F e(p y t p z)_{2}\right]^{2+}$ com o $\mathrm{pH}$ pode ser vista na Figura 4.22. 


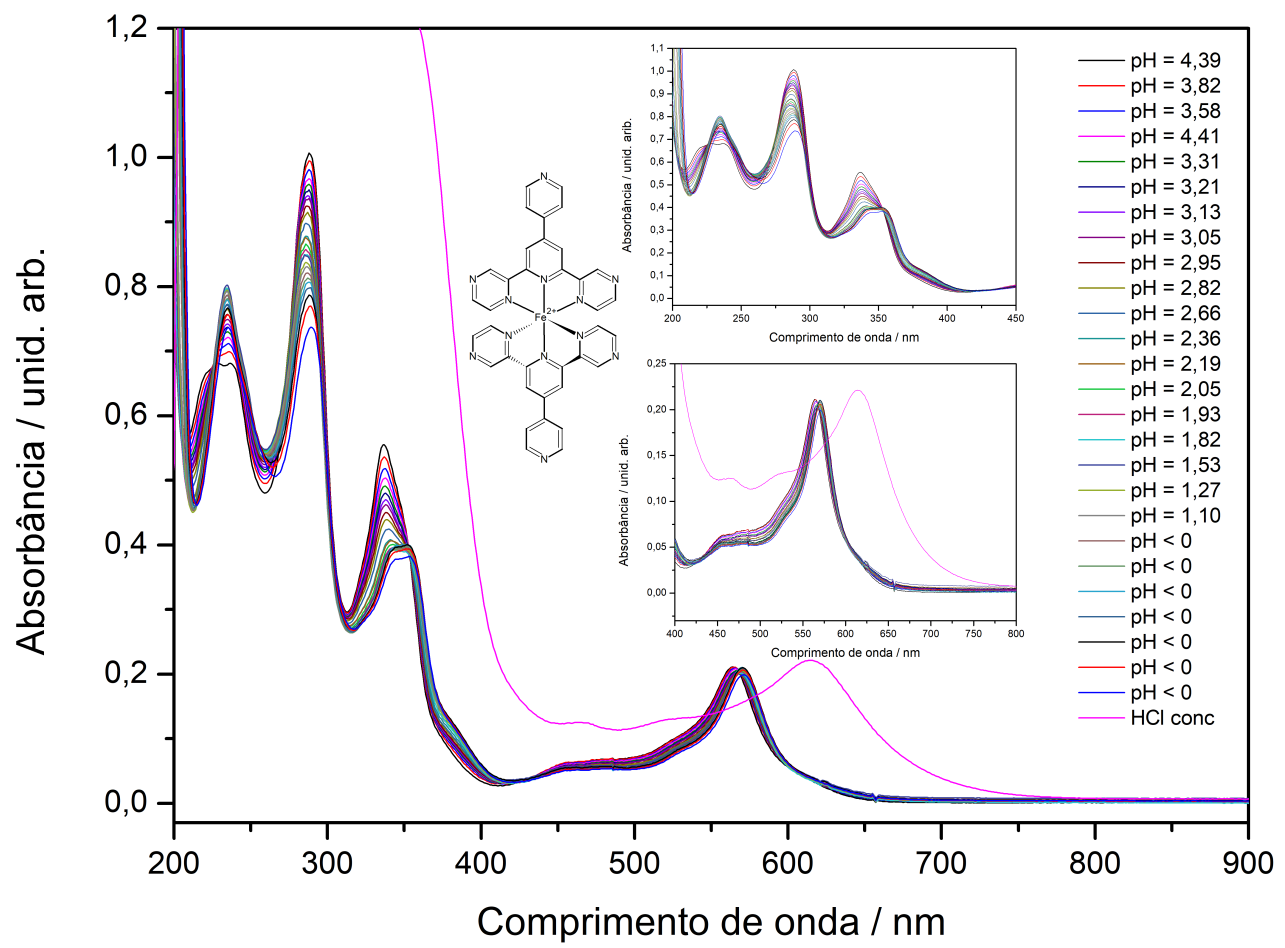

Figura 4.22: Efeitos da protonação no complexo $\left[\mathrm{Fe}(\text { pytpz })_{2}\right]^{2+}$ - variação espectral em função do pH e reprodução interna em maiores detalhes.

Da mesma forma que no caso anterior, as mudanças na faixa de $p H 1-4$ leva a um padrão semelhante à protonação da piridina. A protonação dos aneis pirazínicos só é observada abaixo de $p H=0$, em meio de $\mathrm{HCl}$ concentrado. A curva de titulação correspondente a este complexo está ilustrada na Figura 4.23. 


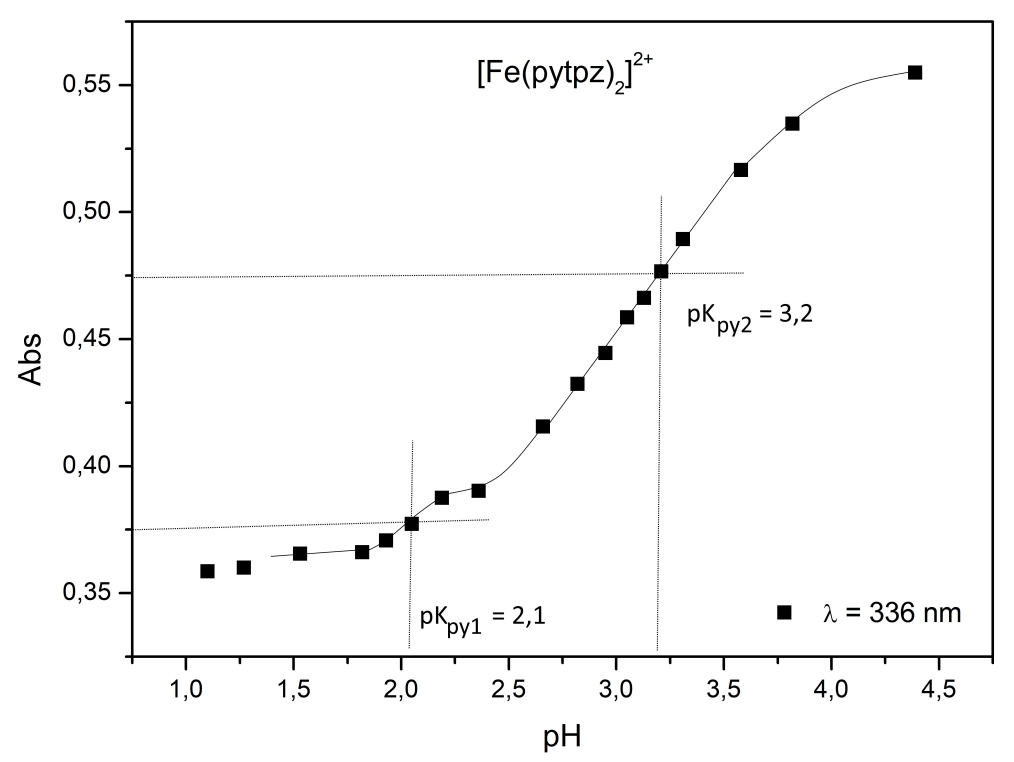

Figura 4.23: Curva de titulação do complexo $\left[\mathrm{Fe}(\text { pytpz })_{2}\right]^{2+}$.

O fato surpreendente observado é o aumento do pKa dos grupos piridínicos nesse complexo, em relação ao caso anterior. Esse efeito é bastante expressivo e parece indicar um aumento da interação de retrodoação $F e-L$ no complexo terpirazínico, como já observado por Toma [91] em complexos de pentacianidoferratos com piridina e pirazina.

Outro aspecto marcante é o deslocamento da banda de transferência de carga na região do visível, para $610 \mathrm{~nm}$. Esse efeito foi simulado teoricamente, conforme ilustrado na Figura 4.24 . 
$\left[\mathrm{Fe}\left(\mathrm{pytpz}_{3}\right]^{8+}\right.$

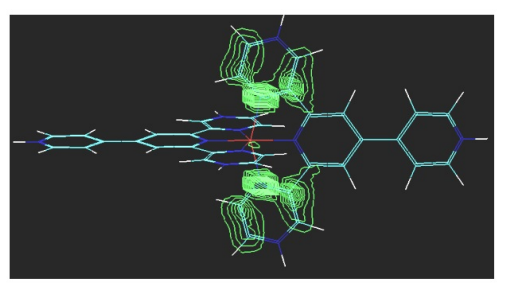

MO118/119 $-21.876 \mathrm{eV}$

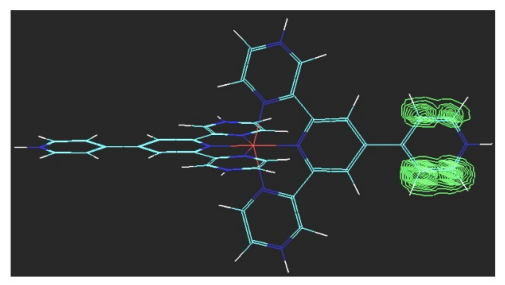

MO116/117 $-25.540 \mathrm{eV}$

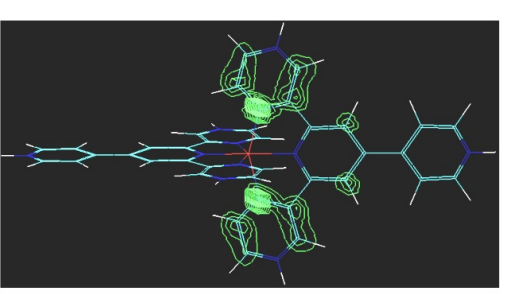

M0120 $-21.711 \mathrm{eV}$

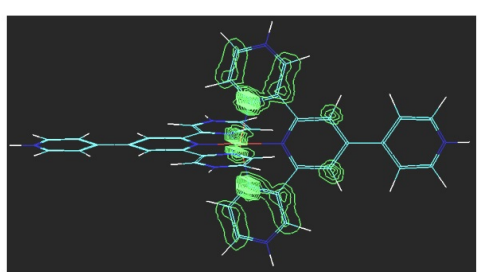

M0121 $-21.523 \mathrm{eV}$

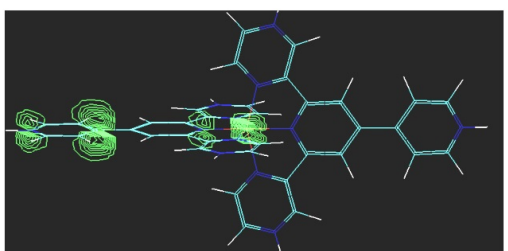

M0115/114 -26.873 eV

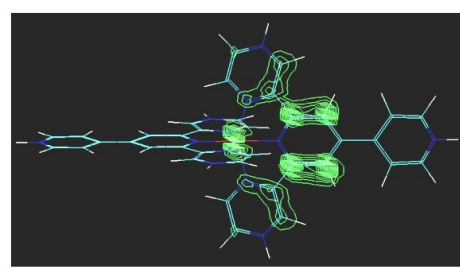

MO $113-27.201 \mathrm{eV}$

Figura 4.24: Orbitais moleculares (HOMO/LUMO) envolvidos nas transições observadas experimentalmente para o complexo $\left[\mathrm{Fe}(\text { pytpz })_{2}\right]^{2+}$ na região do visivel em meio fortemente ácido (protonação total).

A modelagem teórica prevê uma banda muito intensa em 663 nm, atribuída à transição MO113 (Fe +tpz) para o MO118/119 essencialmente localizado sobre os ligantes terpirazínicos protonados.

No caso do complexo $\left[\mathrm{Fe}(p h t p z)_{2}\right]^{2+}$ o efeito de protonação só é observado em pHs extremamente baixos, envolvendo os anéis pirazínicos, com o aparecimento de uma banda intensa em $645 \mathrm{~nm}$ (Figura 4.25). 


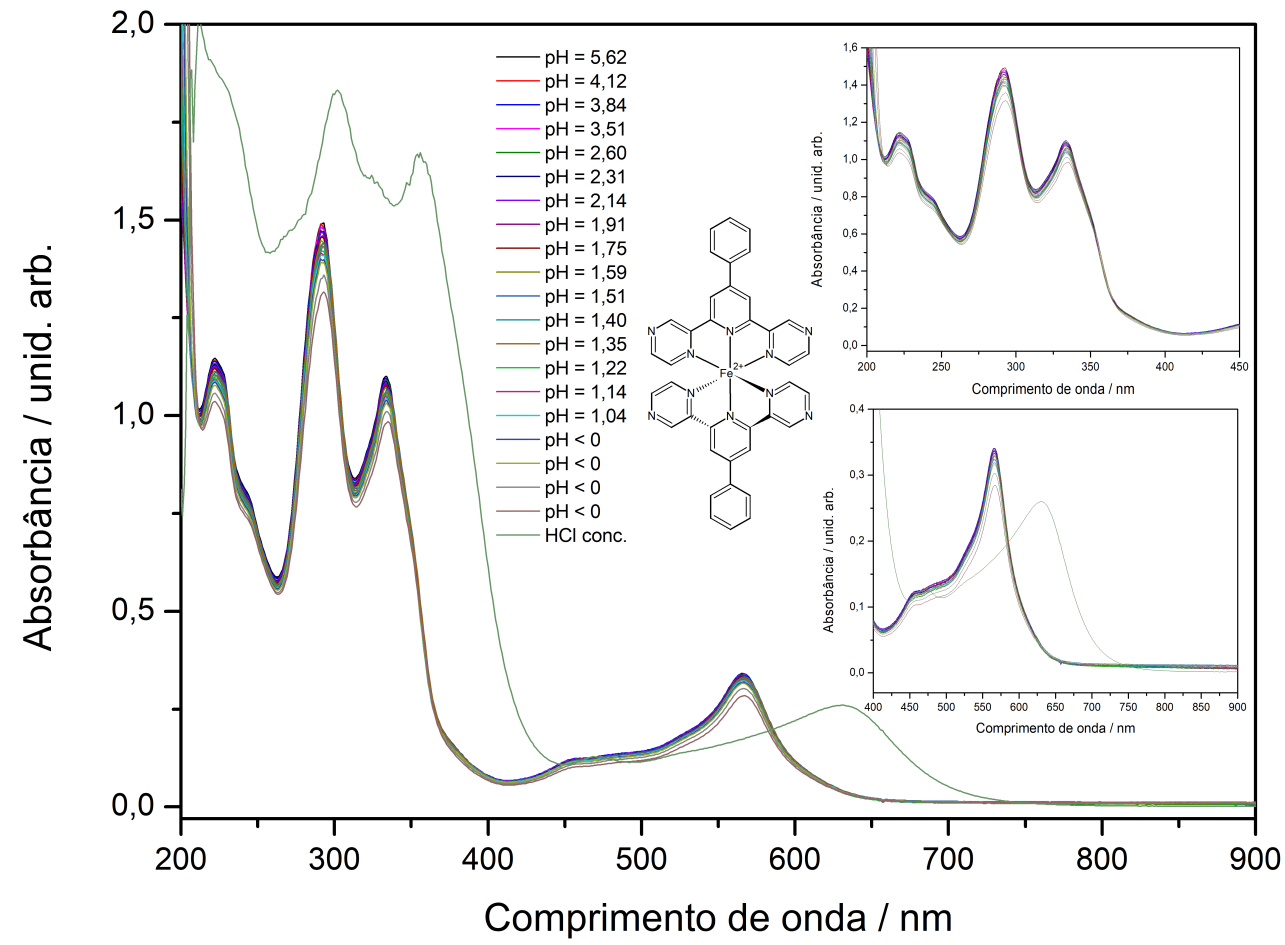

Figura 4.25: Efeitos da protonação no complexo $[\mathrm{Fe}(\text { phtpz }) 2]^{2+}$ - variação espectral em função do pH e reprodução interna em maiores detalhes.

A simulação espectral prevê uma banda muito forte em $688 \mathrm{~nm}$, envolvendo a transição MO117 (centrado no grupo fenil do ligante), para o MO122 (centrado no grupo terpirazina protonado), conforme Figura 4.26. 


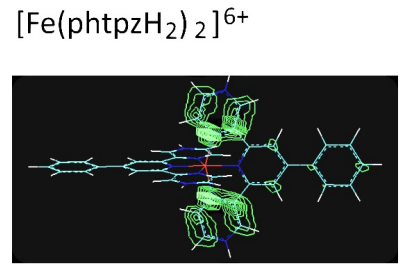

Mo118/119 - $17.367 \mathrm{eV}$

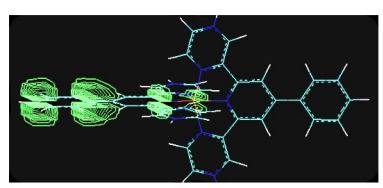

M0116/117 -=20.488 eV

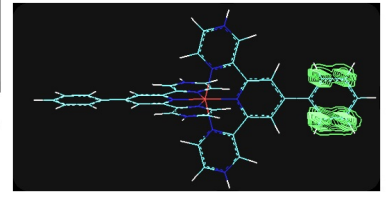

MO115/114 - 20.617 eV

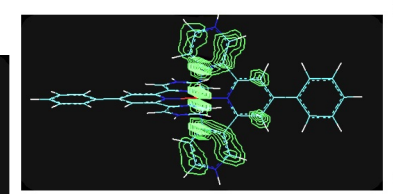

M0121 - $16.878 \mathrm{eV}$

M0120 -17.179 eV

\section{MO121 $16.878 \mathrm{eV}$}

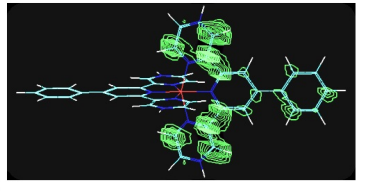

Mo122/123 - $16.234 \mathrm{eV}$

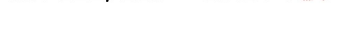


na presença de uma grande quantidade de grupos vibracionais presentes na molécula [108]. Por essa razão, a espectroscopia Raman ressonante tem sido uma ferramenta bastante útil no estudo de metaloproteínas e biomoléculas como os citocromos e a hemoglobina [109].

No caso especial de complexos como os investigados nesta Tese, os espectros Raman permitem diferenciar os níveis eletrônicos envolvidos nas transições em função das ligações químicas presentes, ou de suas simetrias [110]. Fortes espalhamentos Raman ressonate indicam que as transições eletrônicas são permitidas por dipolo elétrico. Para isso, foram utilizados três comprimentos de onda de excitação: 633, 532 e $488 \mathrm{~nm}$, coincidindo com as bandas eletrônicas contidas no perfil espectral dos complexos.

A excitação em $633 \mathrm{~nm}$ deve priorizar a transição eletrônica de menor energia, destacando as características do orbital molecular envolvido. A excitação em $488 \mathrm{~nm}$ deve priorizar a transição eletrônica de maior energia no visível, com seu orbital molecular correspondente. Esses fatos foram de fato constatados nos espectros Raman dos complexos, ilustrados nas Figuras 4.27, 4.28, 4.29, 4.30. A excitação em 532 nm pode envolver a superposição de duas ou mais bandas eletrônicas, e por isso conduz a um perfil composto de vários modos vibracionais decorrentes dos estados envolvidos.

Na Figura 4.27 estão apresentados os espectros Raman do complexo $\left[\mathrm{Fe}(\text { phtpy })_{2}\right]^{2+}$ obtidos com as três diferentes radiações de excitação, em condições de pré-ressonância e ressonância, juntamente com a ilustração dos possíveis orbitais moleculares envolvidos na transição eletrônica responsável pelos modos vibracionais intensificados. Optou-se por utilizar o diagrama de poços de potencial, por eles evidenciarem o grau de recobrimento dos orbiais, quanto maior a intensidade das curvas, maior é o grau de recobrimento e maior é a participação do orbital na transição. Observam-se perfis semelhantes para as três excitações, com os espectros apresentando essecialmente o mesmo conjunto de bandas vibracionais em 1607, 1471, 1362, 1293, 1166, 1021, 830, 693, 655, 504 e $349 \mathrm{~cm}^{-1}$ (os modos vibracionais relacionados a estas energias encontram-se resumidos na parte superior da figura). O espectro obtido com o laser de excitação igual a $633 \mathrm{~nm}$ apresenta um pico em $1037 \mathrm{~cm}^{-1}$ que não é observado nos espectros das outras excitações, e o cálculo teórico indica que a energia de excitação do laser 633 nm está próxima à energia da transição 
eletrônica que envolve principalmente os orbitais do grupo teríminico (anel quelato), sendo este modo vibracional provavelmente está relacionado à piridina central.

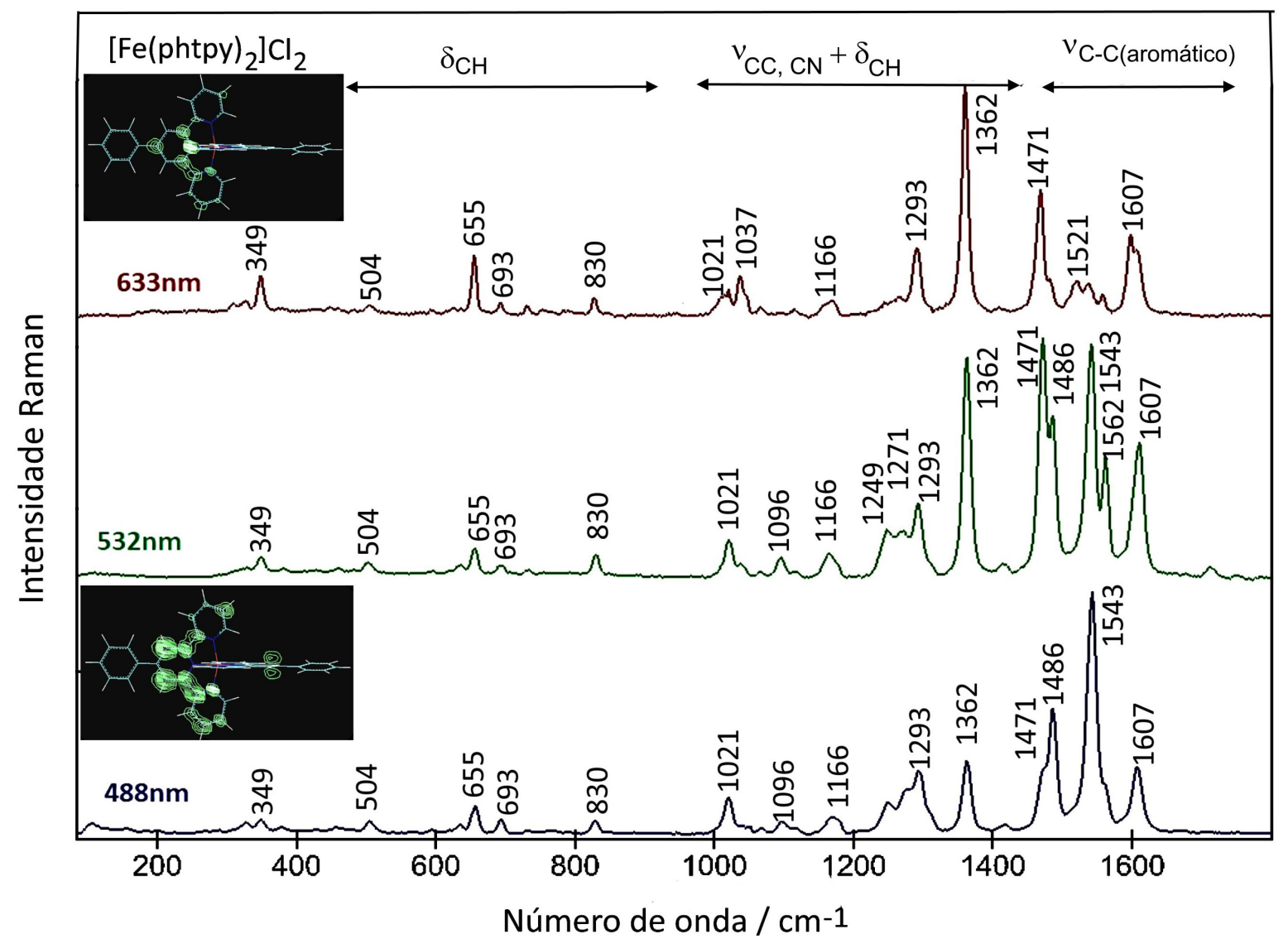

Figura 4.27: Espectros Raman ressonante do complexo $\left[\mathrm{Fe}(\text { phtpy })_{2}\right]^{2+}$ excitado em 633, 532 e $488 \mathrm{~nm}$, destacando os orbitais moleculares envolvidos nas transições eletrônicas correspondentes.

Os espectros com diferentes radiações de excitação do complexo $\left[F e(p y t p y)_{2}\right]^{2+}$ podem ser vistos na Figura 4.28. Observando o diagrama dos orbitais moleculares espera-se que a excitação em $633 \mathrm{~nm}$ ressalte as vibrações envolvidas nas transições eletrônicas que envolvam os orbitais do anel quelato e da piridina axial.

A banda em $656 \mathrm{~cm}^{-1}$ é intensificado com o laser $633 \mathrm{~nm}$, banda esta que deve ter contribuição das vibrações da piridina. Observa-se também um desdobramento do pico em $1029(\lambda=488 \mathrm{~nm})$ em dois picos $\left(1023\right.$ e $\left.1045 \mathrm{~cm}^{-1}\right)$, sendo que provavelmente um deles é pico correspondente à $1029 \mathrm{~cm}^{-1}$, mas deslocado, e o outro, provavelmente, uma vibração do anel piridínico axial. 


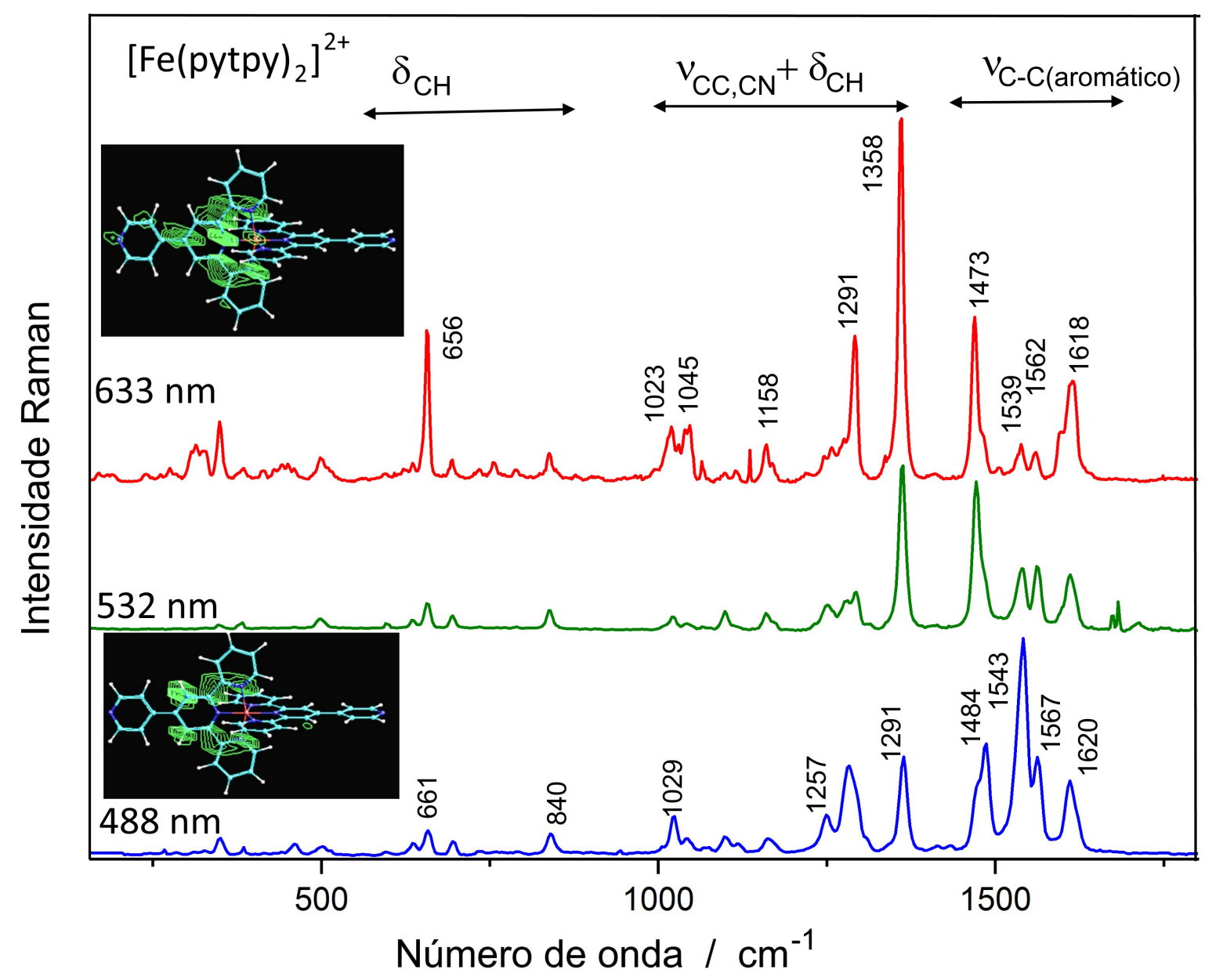

Figura 4.28: Espectros Raman ressonante do complexo $\left[\mathrm{Fe}(\text { pytpy })_{2}\right]^{2+}$ excitado em 633, 532 e $488 \mathrm{~nm}$, destacando os orbitais moleculares envolvidos nas transições eletrônicas correspondentes.

Os espectros Raman do complexo $\left[\mathrm{Fe}(\text { phtpz })_{2}\right]^{2+}$ (Figura 4.29) apresentam perfis de realce de ressonância diferentes, quando comparados aos complexos sem o anel pirazínico. No espectro obtido com o laser $633 \mathrm{~nm}$ observa-se um pico em $660 \mathrm{~cm}^{-1}$, não observado com as outras radiações de excitação. Também observa-se uma intensificação dos picos 730, 1045, 1293 e $1357 \mathrm{~cm}^{-1}$, todos modos vibracionais relacionados ao cromóforo do complexo, como indica a ilustração dos orbitais moleculares. 


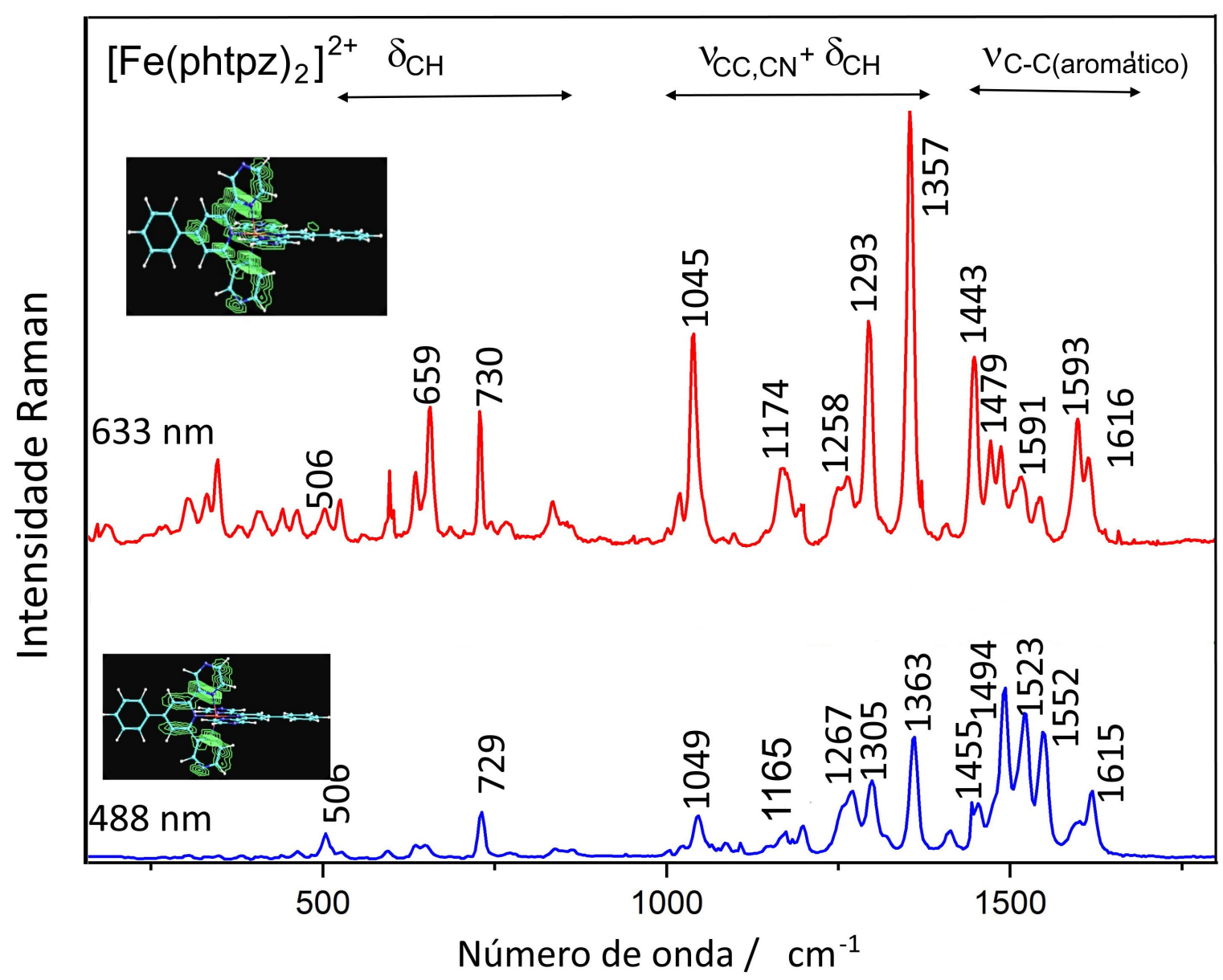

Figura 4.29: Espectros Raman ressonante do complexo $\left[\mathrm{Fe}(\text { phtpz })_{2}\right]^{2+}$ excitado em 633 e 488 $n m$, destacando os orbitais moleculares envolvidos nas transiçôes eletrônicas correspondentes.

Os espectros Raman do complexo $\left[\mathrm{Fe}(\text { pytpz })_{2}\right]^{2+}$, Figura 4.30, apresentam mudanças de perfil muito semelhantes às que ocorrem com o compelxo $\left[F e(p h t p z)_{2}\right]^{2+}$, com uma maior contribuição das transições eletrônicas dos orbitais do anel quelato aos modos de vibração. 


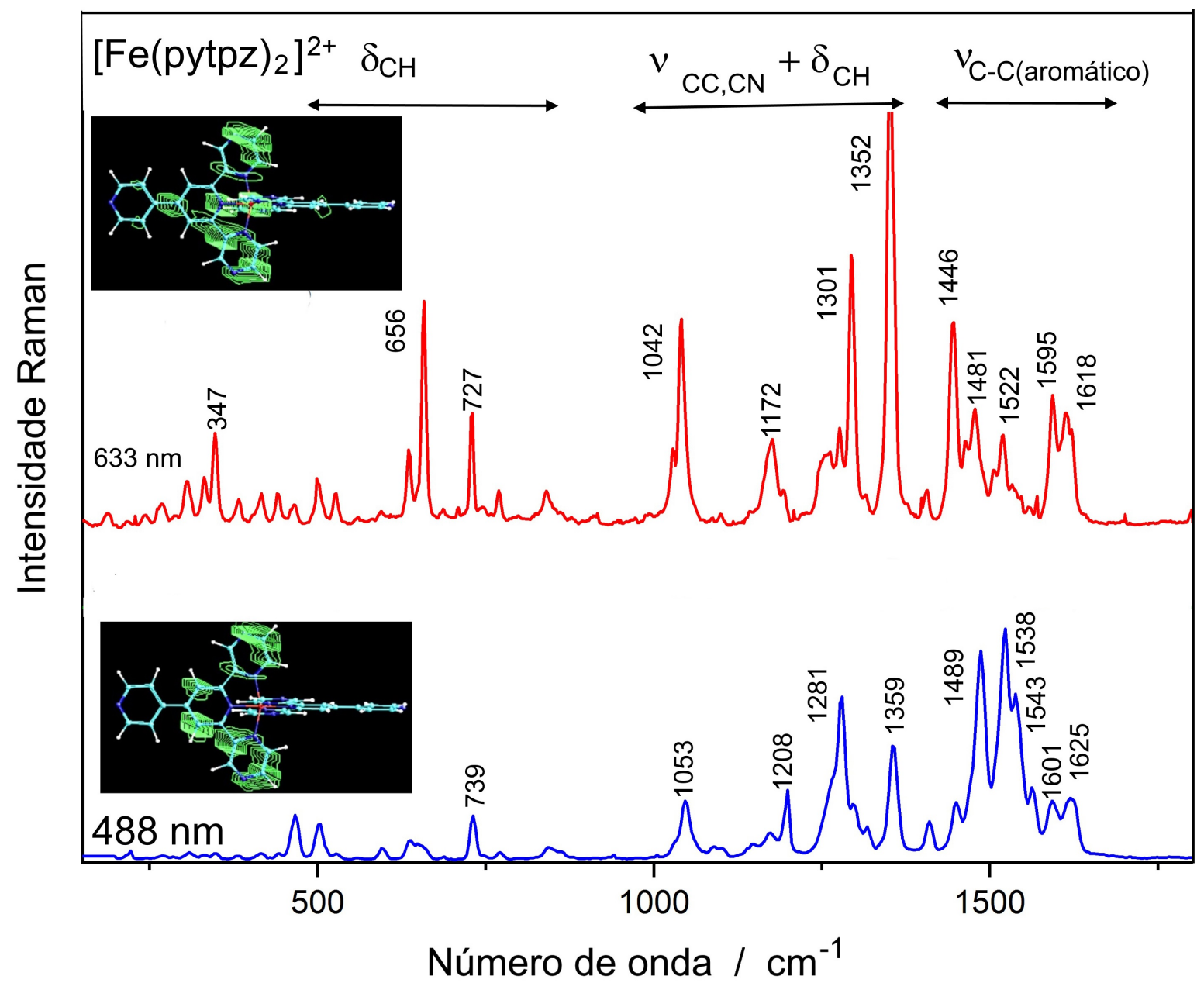

Figura 4.30: Espectros Raman ressonante do complexo $\left[\mathrm{Fe}(\text { pytpz })_{2}\right]^{2+}$ excitado em 633 e 488 $n m$, destacando os orbitais moleculares envolvidos nas transições eletrônicas correspondentes.

Os espectros dos complexos mostram uma complexa mistura de picos, sendo que a diferenciação entre os modos vibracionais das piridinas e pirazinas se torna muito díficil por serem em regiões muito próximas. Na literatura, encontram-se poucos trabalhos com atribuições claras e consistentes dessa classe de complexos. A comparação dos espectros mostrou-se uma ferramenta útil para se diferenciar os picos desses anéis aromáticos tão semelhantes.

Observadas as diferenças e semelhanças dos perfis dos espectros Raman dos complexos com pirazina e piridina no anel quelato, pode-se constatar que os picos em 630, 730, 1040, 1190, 1450 e $1520 \mathrm{~cm}^{-1}$ apareciam com mesmo perfil nos espectros contendo o ligante phtpz e pytpz e não estavam presentes nos espectros dos ligantes phtpy e pytpy. Logo pode-se constatar que são picos relacionadas aos modos vibracionais do anel pirazínico. 
Os picos em aproximadamente 350,650, 1160, 1300 e $1350 \mathrm{~cm}^{-1}$ são observados nos espectros de todos os complexos, sendo provavelmente modos vibracionais referentes ao anel piridínico central do anel quelato.

Em todos os casos é possível notar a diferença dos perfis Raman nos vários comprimentos de onda de excitação, como esperado pelo efeito ressonante. Em geral, a excitação para orbitais moleculares mais deslocalizados na molécula leva a uma intensificação de um maior número de picos vibracionais, explicitando os átomos e ligações envolvidos. Dada a complexidade das moléculas, é difícil fazer a atribuição tentativa de cada pico vibracional, e por isso, a faixa típica de cada tipo de modo vibracional foi inserida no topo das figuras.

Com base nesses resultados, a realização de cálculos mais rigorosos de orbitais moleculares e de espectros vibracionais pode ser bastante gratificante nos trabalhos futuros. 


\section{Capítulo 5}

\section{QUÍMICA SUPRAMOLECULAR COORDENATIVA}

A disponibilidade de grupos piridínicos e pirazínicos nos complexos pode ser explorada na construção de estruturas mais elaboradas, por meio da coordenação de íons metálicos [111, 112, 113, 114, 115, 116, 117, 118, 119, 120]. Essa estratégia supramolecular tem sido desenvolvida de forma sistemática em nosso grupo de pesquisa por várias décadas, com resultados interessantes, como pode ser visto nas referências da literatura [88, 121, 122, 123, 124, 125, 126, 127, 128, 129, 130, 131, 132, 133, 134, 135, 136]. Neste capítulo estão sendo reportados os resultados obtidos da interação dos complexos com o íon $\left[\mathrm{Fe}(\mathrm{CN})_{5}\right]^{3-}$, seguindo uma tradição de pesquisa iniciada por Toma em 1970 [91]. Essa escolha foi motivada pela grande afinidade dos complexos de pentacianidoferrato(II) por ligantes Nheterocíclicos como piridina e pirazina, dando origem a complexos bastante coloridos e estáveis.

Deve ser notado que a coordenação de um íon $\left[\mathrm{Fe}(\mathrm{CN})_{5}\right]^{3-}$ nos complexos em estudo implica na introdução de três unidades de carga negativa. Assim, a coordenação de 6 unidades, no complexo $\left[\mathrm{Fe}(\text { pytpz })_{2}\right]^{2+}$, pode levar a um complexo com carga 16-, sujeito à uma forte repulsão eletrostática na esfera de coordenação. O isolamento desses complexos torna-se bastante difícil, devido aos inúmeros equilíbrios de dissociação envolvidos, e à grande solubilidade dos produtos em meio aquoso. Por essa razão, os estudos foram feitos 
em solução, na presença de algum excesso de íons $\left[\mathrm{Fe}(\mathrm{CN})_{5}\right]^{3-}$, para reduzir os efeitos da dissociação provocada pelo aumento da repulsão eletrostática nos complexos.

\subsection{Interação do complexo $\left[\mathrm{Fe}(\text { pytpy })_{2}\right]^{2+} \operatorname{com}\left[\mathrm{Fe}(\mathrm{CN})_{5}\right]^{3-}$}

O complexo $\left[\mathrm{Fe}(\text { pytpy })_{2}\right]^{2+}$ apresenta uma estrutura linear favorável à associação dos íons $\left[\mathrm{Fe}(\mathrm{CN})_{5}\right]^{3-}$, formando inicialmente um complexo binuclear $[($ pytpy $) \mathrm{Fe}(\mu-$ pytpy) $\left.\left\{\mathrm{Fe}(\mathrm{CN})_{5}\right\}\right]^{-}$, estabilizado por forças químicas e eletrostáticas, e depois um complexo trinuclear $\left[\left\{F e(C N)_{5}\right\}(\mu-p y t p y) F e(\mu-p y t p y)\left\{F e(C N)_{5}\right\}\right]^{4-}$ com os grupos $\left[F e(C N)_{5}\right]^{3-}$ dispostos em sítios opostos, como ilustrado na Figura 5.1.

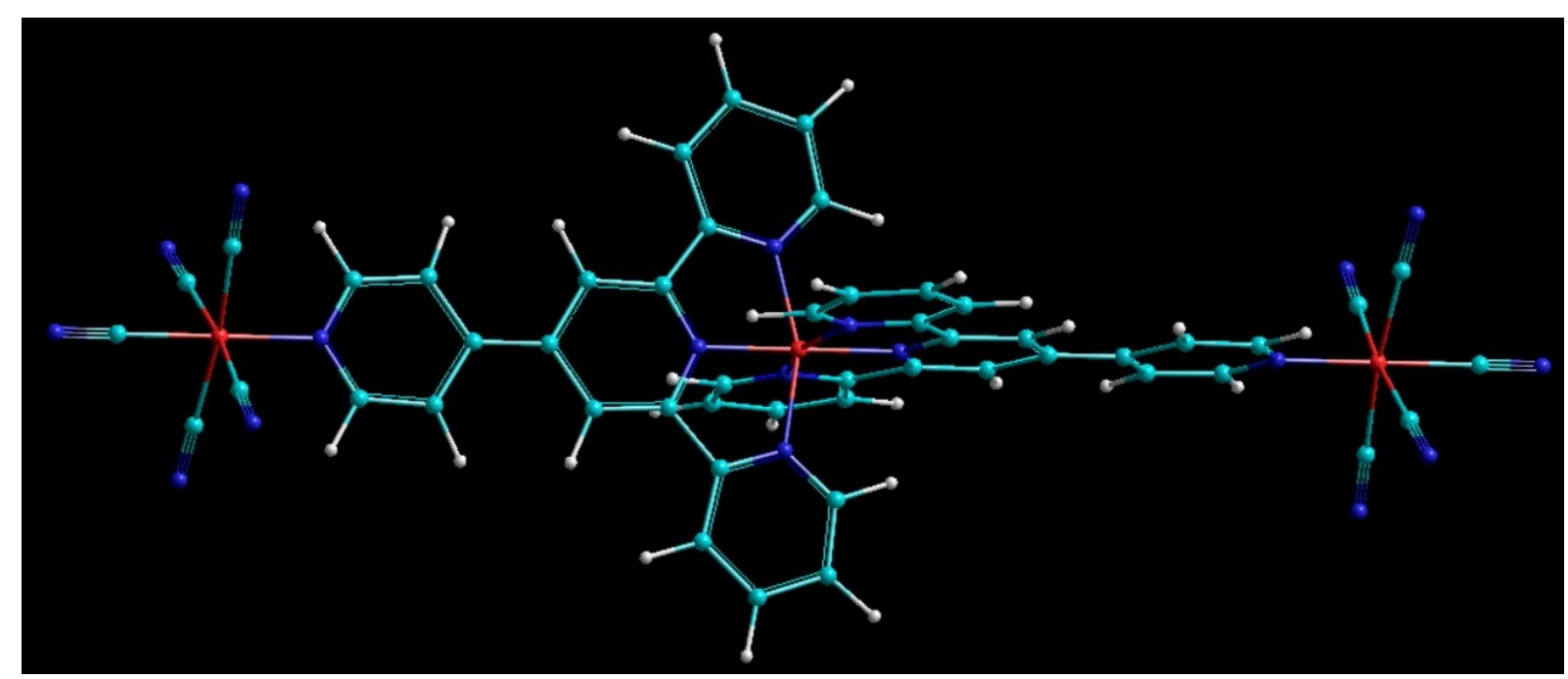

Figura 5.1: Geometria molecular otimizada $\left(M M^{+}\right)$para o complexo trinuclear $\left[\left\{F e(C N)_{5}\right\}(\mu-\text { pytpy }) F e(\mu-\text { pytpy })\left\{F e(C N)_{5}\right\}\right]^{4-}$.

A formação desses complexos foi monitorada por via espectrofotométrica, em solução aquosa, conforme mostrado na Figura 5.2. A coordenação dos íons $\left[\mathrm{Fe}(\mathrm{CN})_{5}\right]^{3-}$ aos grupos piridínicos terminais do complexo $\left[\mathrm{Fe}(\text { pytpy })_{2}\right]^{2+}$ produz uma intensificação das bandas do cromóforo Fe-terpiridina, deslocando a banda de $569 \mathrm{~nm}$ para $575 \mathrm{~nm}$. Observa-se também a intensificação da absorção em $490 \mathrm{~nm}$, atribuída ao cromóforo $\left[(C N)_{5} F e-p y t p y\right]^{3-}$, em analogia aos complexos $\left[F e(C N)_{5} L\right]^{3-}$ estudados por Toma $[80,91]$. 


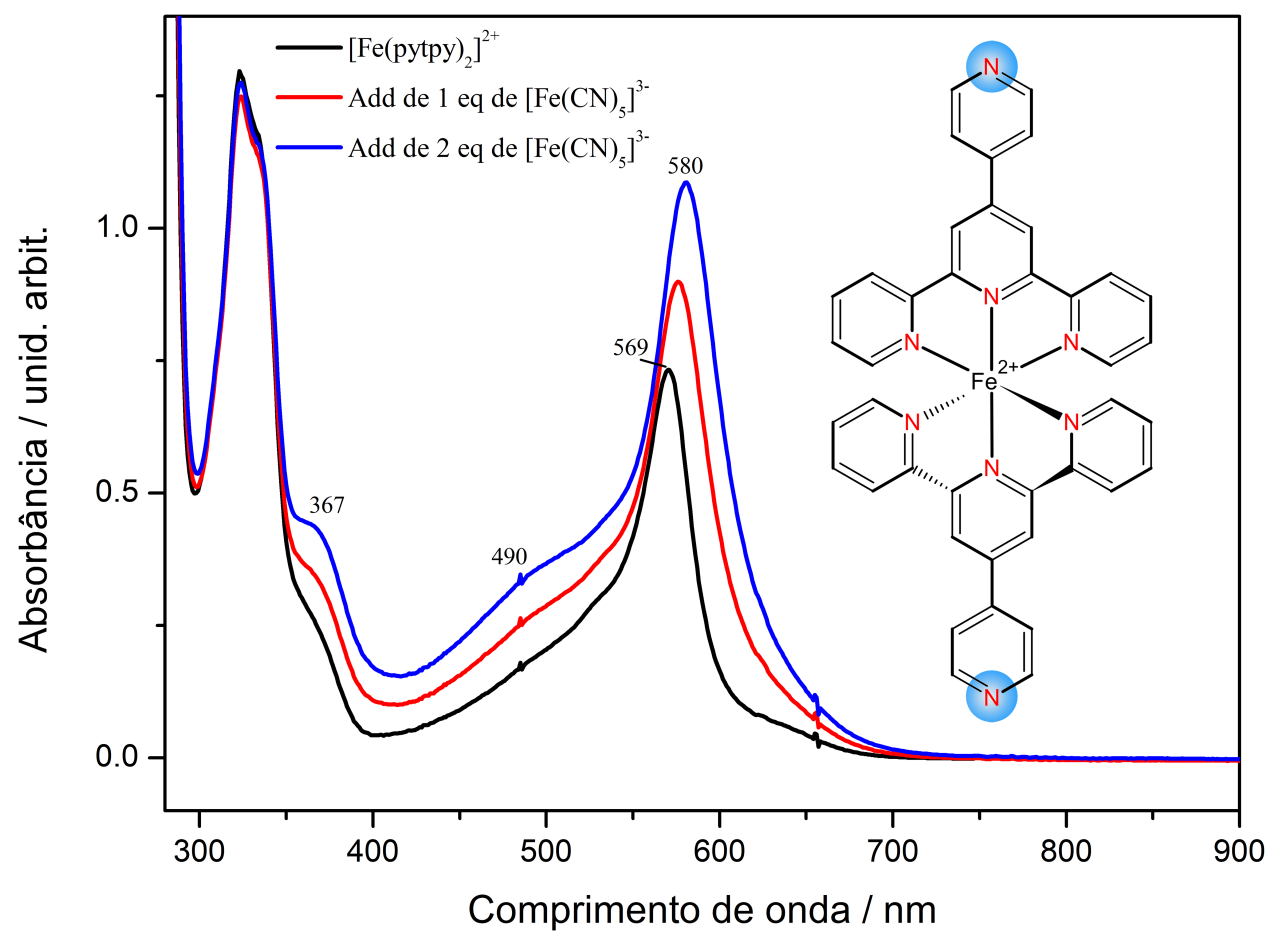

Figura 5.2: Monitoração espectrofotométrica da interação do complexo $\left[\mathrm{Fe}(\text { pytpy })_{2}\right]^{2+}$ com ions $\left[\mathrm{Fe}(\mathrm{CN})_{5}\right]^{3-}$ (1 e 2 equivalentes) em solução aquosa.

O espectro Raman $(633 \mathrm{~nm})$ do complexo trinuclear pode ser visto na Figura 5.3 em comparação com o complexo mononuclear de partida. Os efeitos da coordenação dos íons $\left[\mathrm{Fe}(\mathrm{CN})_{5}\right]^{3-}$ aos grupos piridínicos leva a mudanças de intensidade nas bandas de estiramento C-C nos anéis aromáticos na faixa de 1470-1618 $\mathrm{cm}^{-1}$ e também nas bandas $\nu_{C C, C N}+\delta_{C H}$ por volta de $1290 \mathrm{~cm}^{-1}$. Além disso pode ser notada a presença da banda de estiramento $C \equiv N$ em $2088 \mathrm{~cm}^{-1}$, associada aos íons $\left[\mathrm{Fe}(\mathrm{CN})_{5}\right]^{3-}$. 


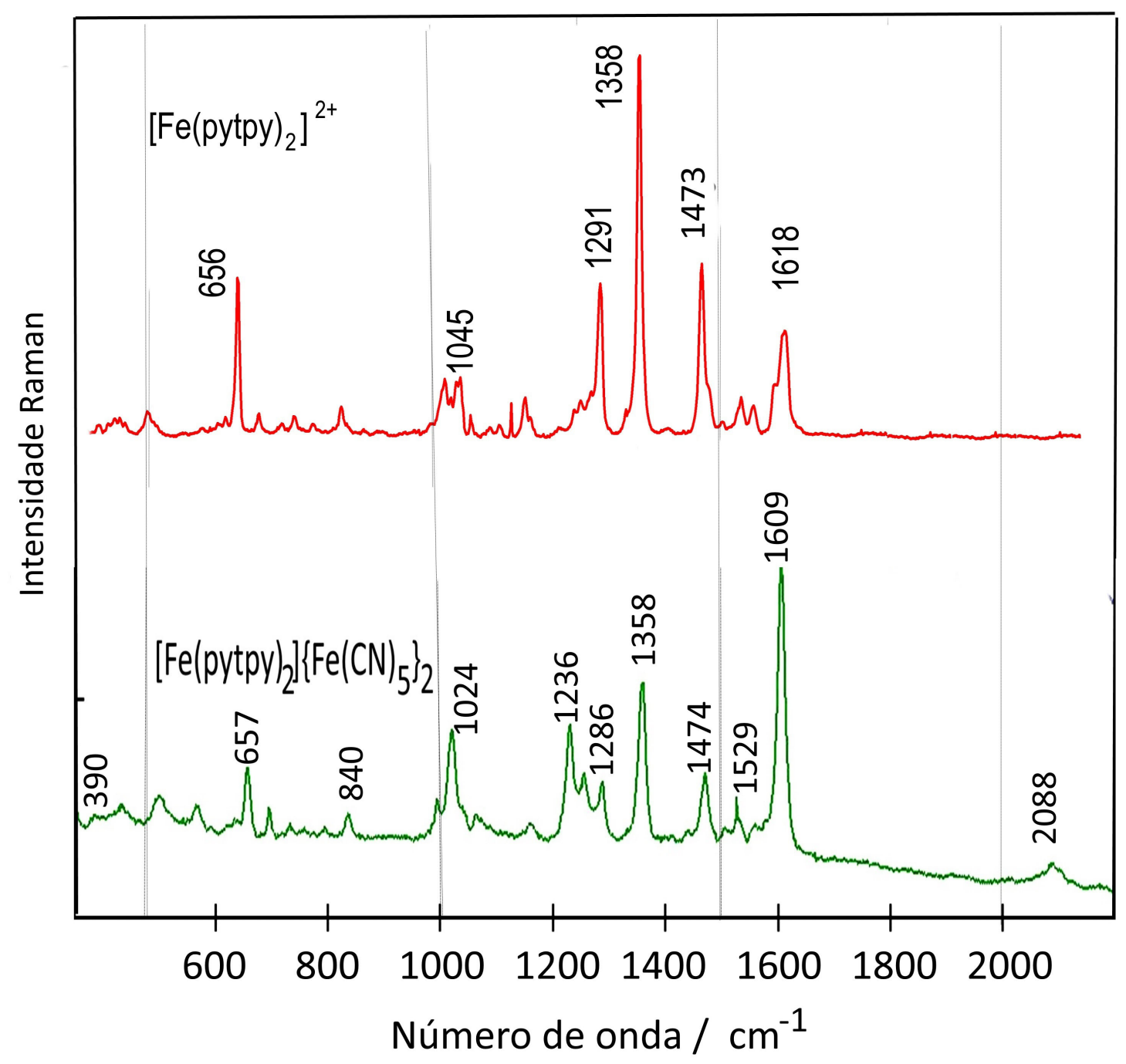

Figura 5.3: Espectros Raman comparativos dos complexos $\left[\mathrm{Fe}(\text { pytpy })_{2}\right]^{2+} e$ $\left[\left\{\mathrm{Fe}(\mathrm{CN})_{5}\right\}(\mu-\text { pytpy }) \mathrm{Fe}(\mu-\text { pytpy })\left\{\mathrm{Fe}(\mathrm{CN})_{5}\right\}\right]^{4-}$ com excitaçâo em $633 \mathrm{~nm}$.

A presença dos grupos $\left[\mathrm{Fe}(\mathrm{CN})_{5}\right]^{3-}$ coordenados aos sítios de piridina também pode ser monitorada eletroquímicamente, como mostrado na Figura 5.4. 


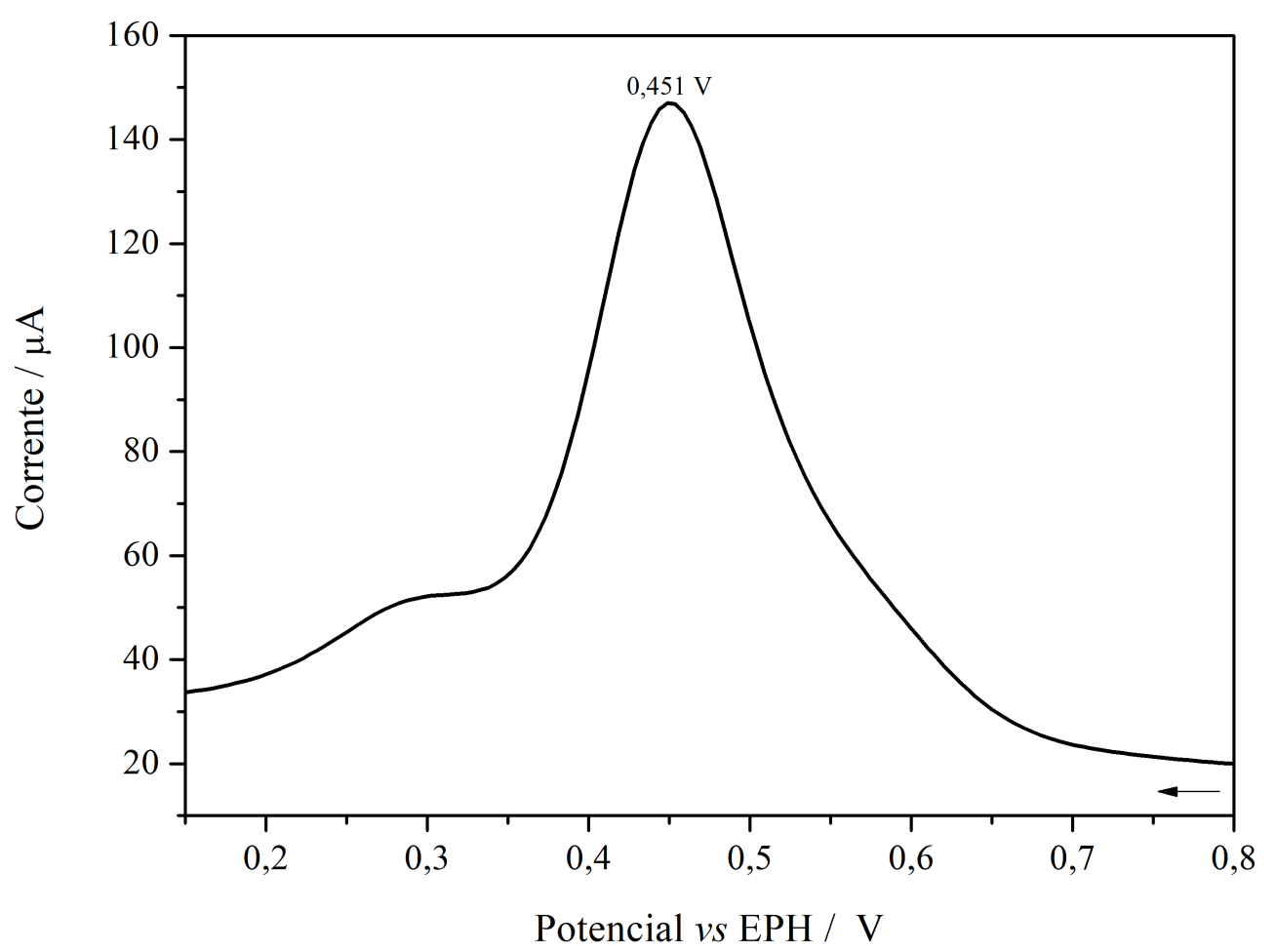

Figura 5.4: Monitoração do potencial redox dos íons $\left[\mathrm{Fe}(\mathrm{CN})_{5}\right]^{3-}$ coordenados aos ligantes piridinicos do complexo $\left[\mathrm{Fe}(\text { pytpy })_{2}\right]^{2+}$.

A formação do complexo trinuclear leva ao aparecimento de um novo pico redox em $0,45 \mathrm{~V}$, atribuido ao par redox $\left[F e^{I I I / I I}(C N)_{5}(\mu-p y t p y)\right]$, ao lado do ombro em $0,32 \mathrm{~V}$ atribuído ao íon $\left[\mathrm{Fe}(\mathrm{CN})_{5} \mathrm{NH}_{3}\right]^{3-}$ residual, em equilíbrio/excesso.

\subsection{Interação do complexo $\left[\mathrm{Fe}(\text { phtpz })_{2}\right]^{2+} \operatorname{com}\left[\mathrm{Fe}(\mathrm{CN})_{5}\right]^{3-}$}

O complexo $\left[\mathrm{Fe}(\mathrm{phtpz})_{2}\right]^{2+}$ apresenta quatro grupos pirazínicos disponíveis para interagir com íons $\left[\mathrm{Fe}(\mathrm{CN})_{5}\right]^{3-}$. Assim como no complexo anterior, a primeira etapa é favorecida pelas forças químicas e eletrostáticas. A entrada do segundo complexo na posição oposta também é igualmente favorável. Contudo a coordenação do terceiro e quarto grupo terá que vencer as forças de repulsão eletrostática devido à proximidade dos grupos $\left[\mathrm{Fe}(\mathrm{CN})_{5}\right]^{3-}$. Isso é possível, considerando a grande afinidade dos íons $\left[\mathrm{Fe}(\mathrm{CN})_{5}\right]^{3-}$ pelos ligantes pirazínicos [80, 91], em virtude das interações de retrodoação.

Na realidade, devido à alta simetria do complexo, os grupos $\left[\mathrm{Fe}(\mathrm{CN})_{5}\right]^{3-}$ sempre ficam 
dispostos em posições equidistantes, como pode ser visto na estrutura otimizada da Figura 5.5 .

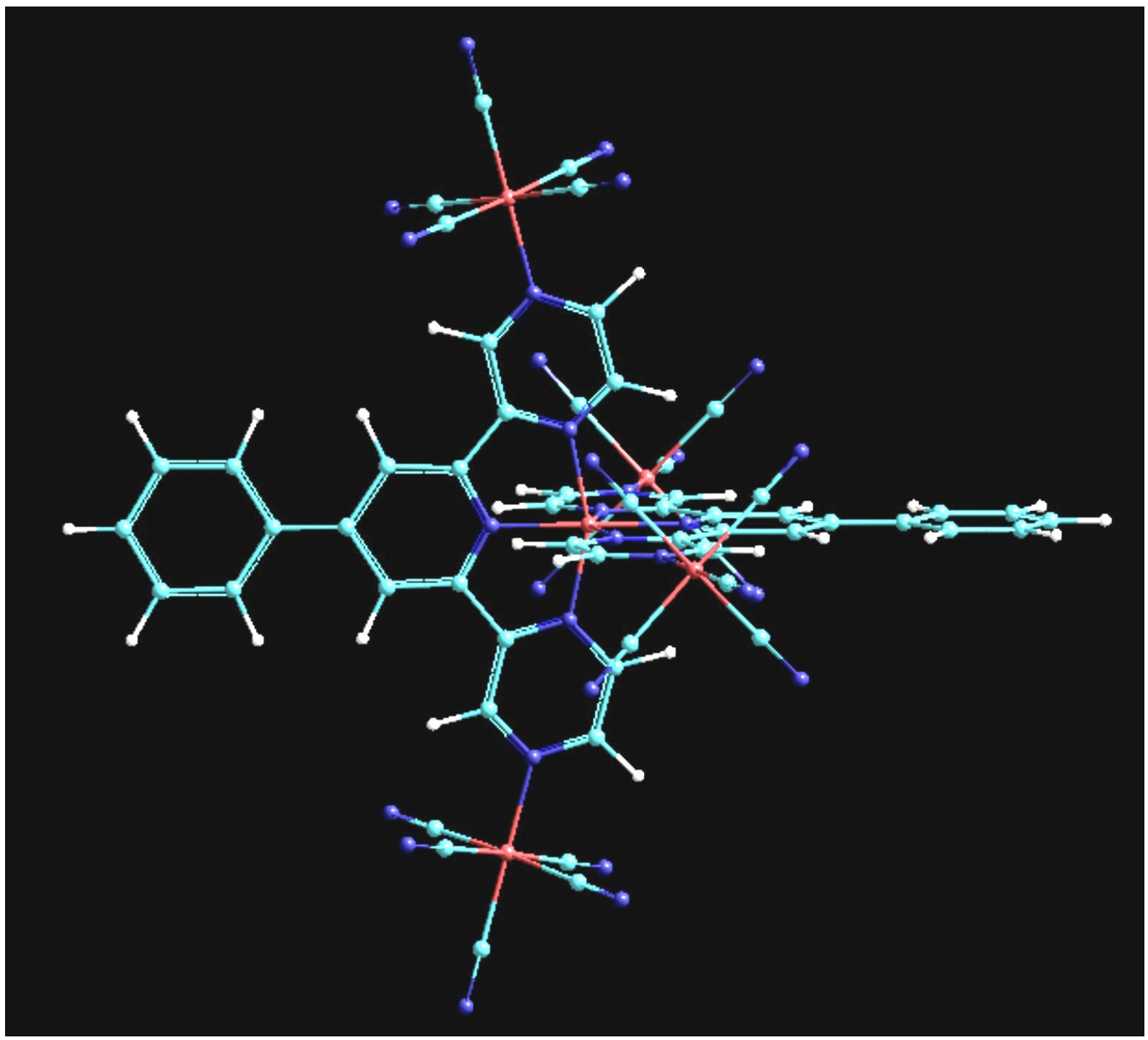

Figura 5.5: Geometria molecular otimizada $\left(M M^{+}\right)$para o complexo pentanuclear $\left[\mathrm{Fe}(\mu-\mathrm{phtp} z)\left\{\mathrm{Fe}(\mathrm{CN})_{5}\right\}_{4}\right]^{10-}$.

A reação do complexo $\left[\mathrm{Fe}(p h t p z)_{2}\right]^{2+}$ com íons $\left[\mathrm{Fe}(\mathrm{CN})_{5}\right]^{3-}$ foi monitorada por via espectrofotométrica, como ilustrado na Figura 5.6. 


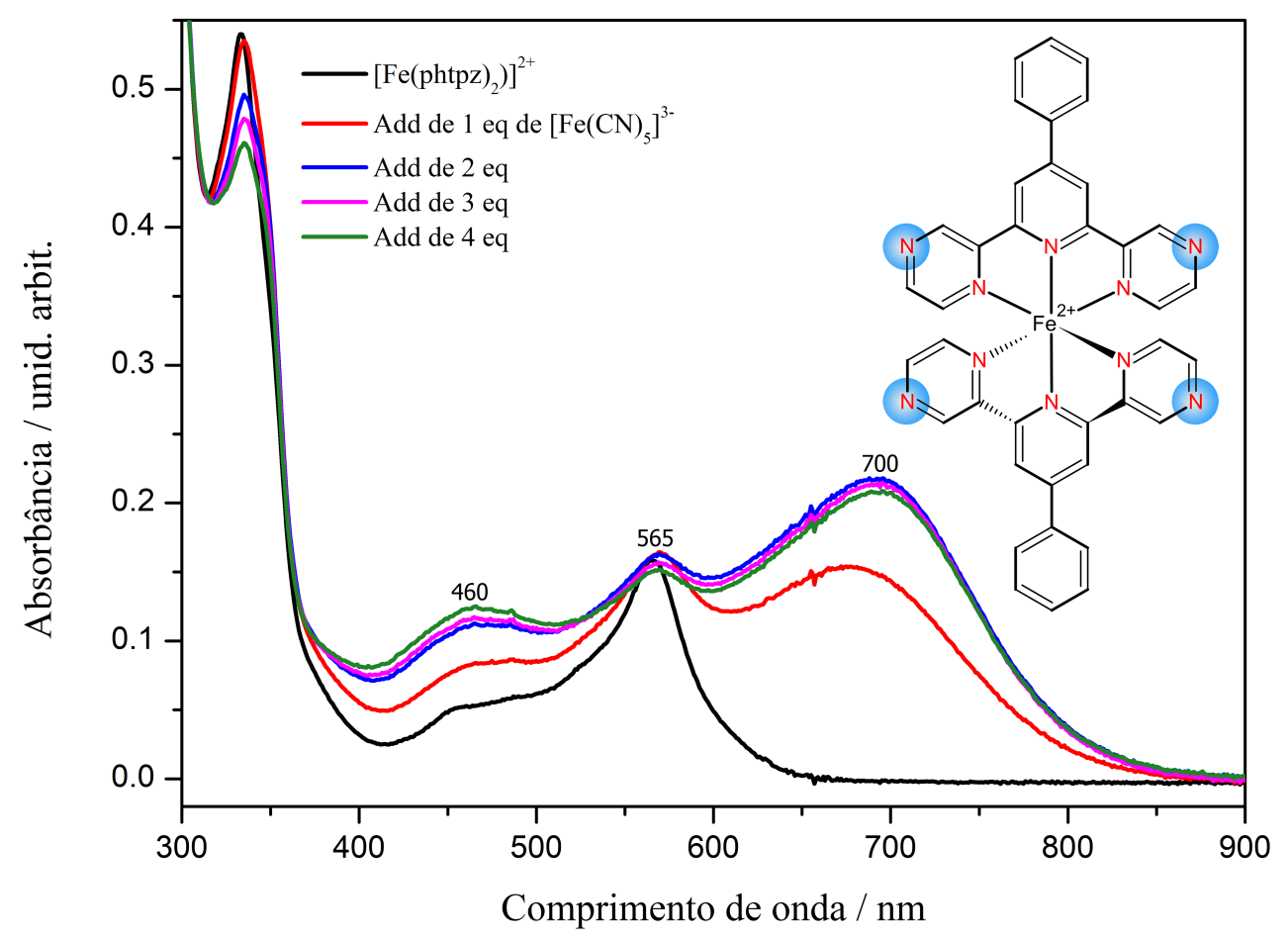

Figura 5.6: Monitoração espectrofotométrica da interação do complexo $\left[\mathrm{Fe}(\text { phtpz })_{2}\right]^{2+}$ com ions $\left[\mathrm{Fe}(\mathrm{CN})_{5}\right]^{3-}$ (1 a 4 equivalentes) em solução aquosa.

A coordenação dos íons $\left[\mathrm{Fe}(\mathrm{CN})_{5}\right]^{3-}$ aos anéis pirazínicos leva ao aparecimento de uma banda ao redor de $460 \mathrm{~nm}$ superposta à banda de maior energia no visível, do cromóforo $F e$ - terpirazina. Essa banda é indicativa da formação dos complexos $\left[F e(C N)_{5}(\mu-\right.$ $p h t p z)]^{3-}$ e é consistente com a transição de transferência de carga $F e^{I I} \rightarrow$ pirazina, previamente reportada por Toma em complexos $\left[F e^{I I}(C N)_{5} L\right]^{3-}[80,91]$. O fato mais curioso é o aparecimento de uma forte absorção em $700 \mathrm{~nm}$, como já observado nos experimentos de protonação e no complexo polinuclear $R u(b p z)_{3} F e(C N)_{5}$ reportado por Toma e Lever em 1986 [86], sendo preservada a banda inicial do cromóforo $F e^{I I}$ - terpirazina em 565 nm. Essa nova banda não é observada no sistema anterior $\left(\left[\mathrm{Fe}(\text { pytpy })_{2}\right]^{2+}\right)$, e sugere a formação de uma estrutura eletrônica deslocalizada entre os 5 íons metálicos, com forte participação de todos os orbitais moleculares envolvidos.

O espectro Raman com excitação em 633 nm (Figura 5.7) mostra um perfil de bandas com forte deslocalização no anel terpirazínico, semelhante ao comportamento já discutido anteriormente para o anel terpiridínico, além da banda vibracional de estiramento $C \equiv N$ 
em 2071 e $2101 \mathrm{~cm}^{-1}$.

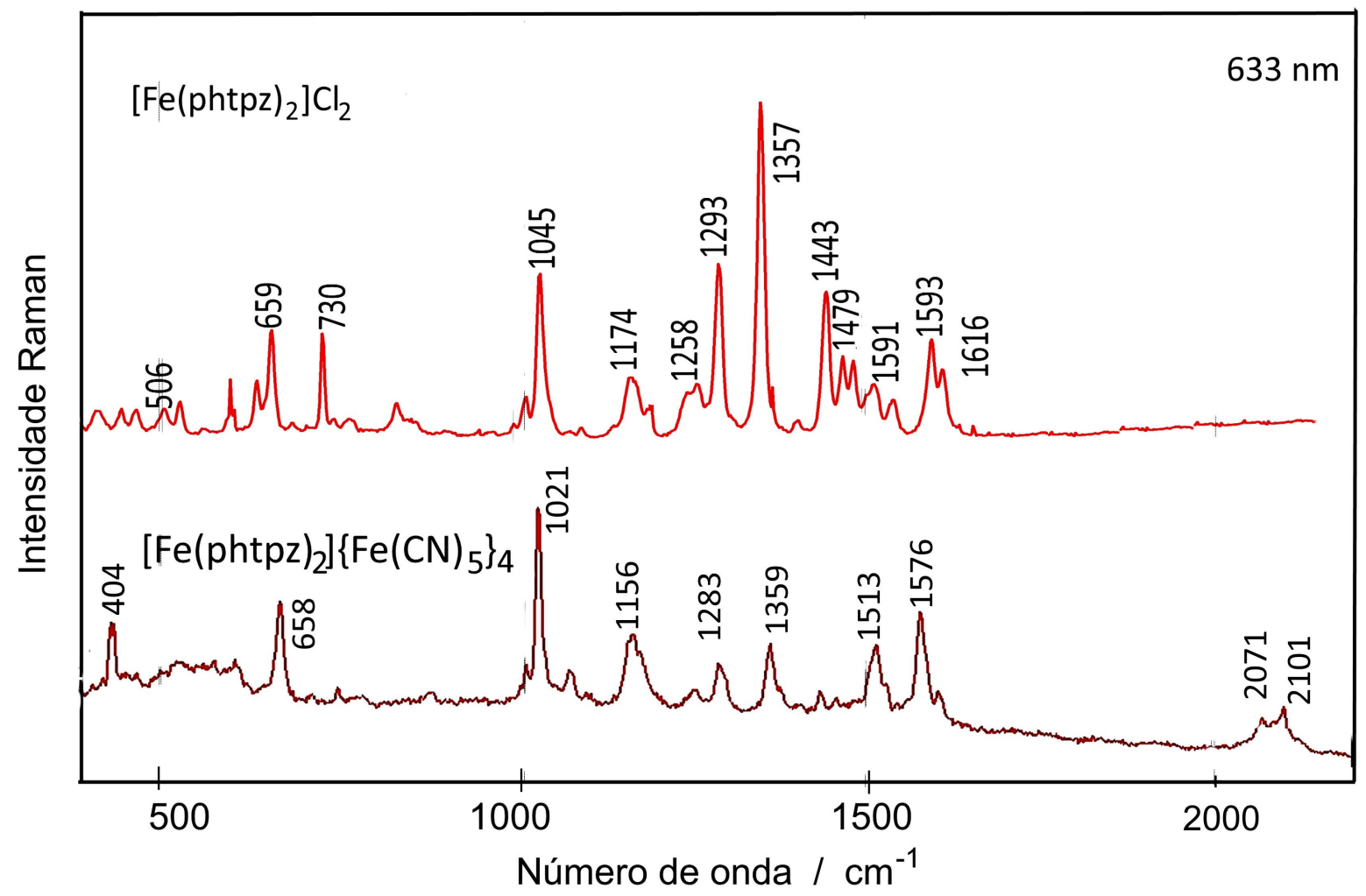

Figura 5.7: Espectros Raman comparativos dos complexos $\left[\mathrm{Fe}(\text { phtpz })_{2}\right]^{2+} e$ $\left[\mathrm{Fe}(\mu-\text { phtpz })_{2}\left\{\mathrm{Fe}(\mathrm{CN})_{5}\right\}_{4}\right]^{10-}$ com excitação em $633 \mathrm{~nm}$.

É interessante notar que nesse sistema a excitação em $488 \mathrm{~nm}$ pode ainda estimular o efeito Raman ressonante no cromóforo $\left[F e^{I I}(C N)_{5}(\text { pirazina })\right]^{3-}$, que apresenta banda nessa região. De fato, o perfil observado no espectro Raman nesse comprimento de onda é bastante distinto do observado com a excitação em $633 \mathrm{~nm}$, como pode ser visto na Figura 5.8. Nesse comprimento de onda contribuem as transições existentes no cromóforo central $\left[F e^{I I}-\right.$ terpirazina $]$ e as transições de transferência de carga nos cromóforos $\left[F e^{I I}(C N)_{5}(\text { pirazina })\right]^{3-}$ periféricos. 


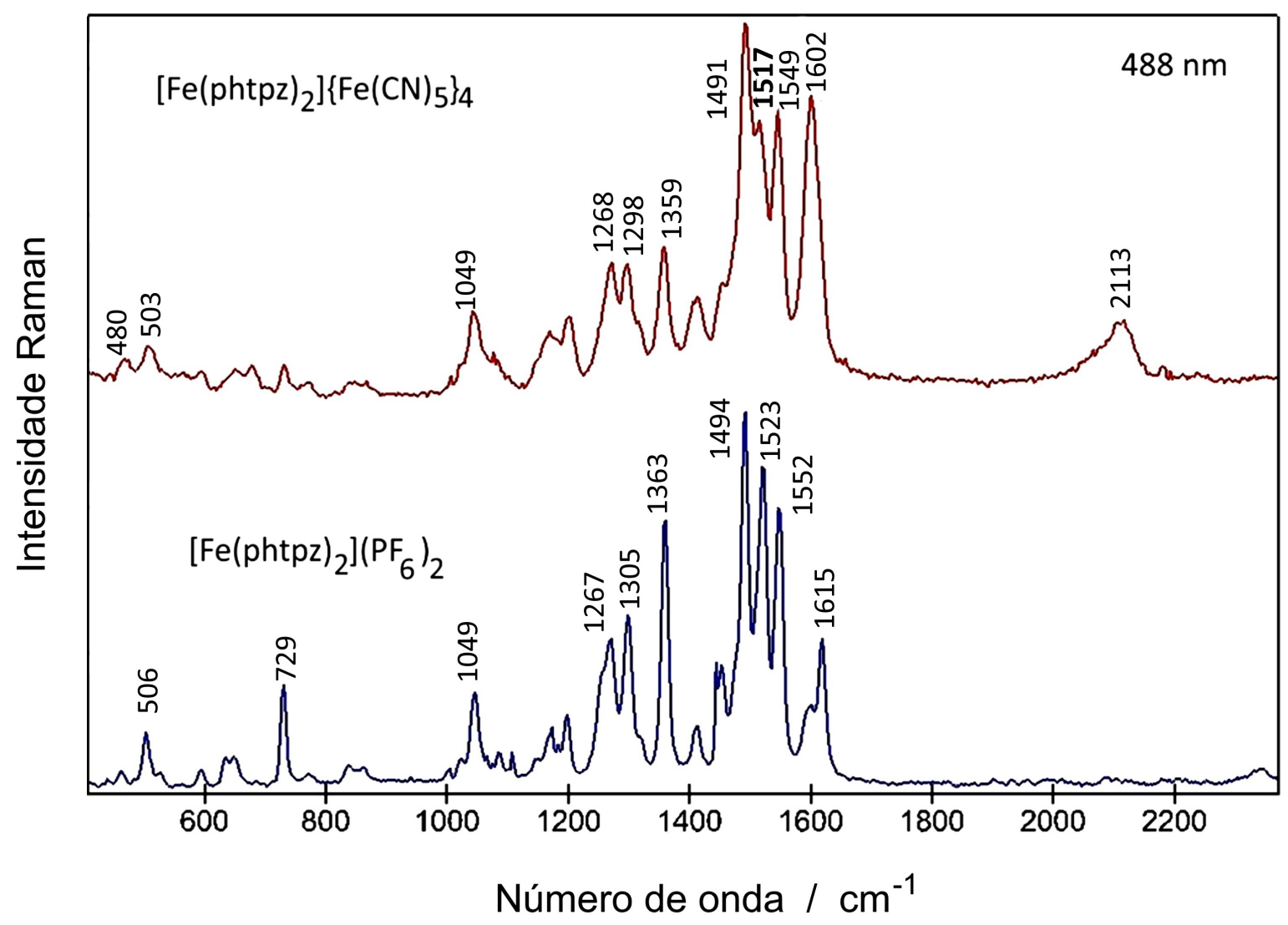

Figura 5.8: Espectros Raman comparativos dos complexos $\left[\mathrm{Fe}(\text { phtpz })_{2}\right]^{2+} e$ $\left[\mathrm{Fe}(\mu-\mathrm{phtpz})\left\{\mathrm{Fe}(\mathrm{CN})_{5}\right\}_{4}\right]^{10-}$ com excitação em $488 \mathrm{~nm}$.

A monitoração eletroquímica desse sistema permite observar o surgimento de uma nova onda em $0,580 \mathrm{~V}$ (Figura 5.9) compatível com o par redox $\left[F e^{I I I / I I}(C N)_{5}(\right.$ pirazina $\left.)\right]$ previamente reportado por Toma [80, 91]. 


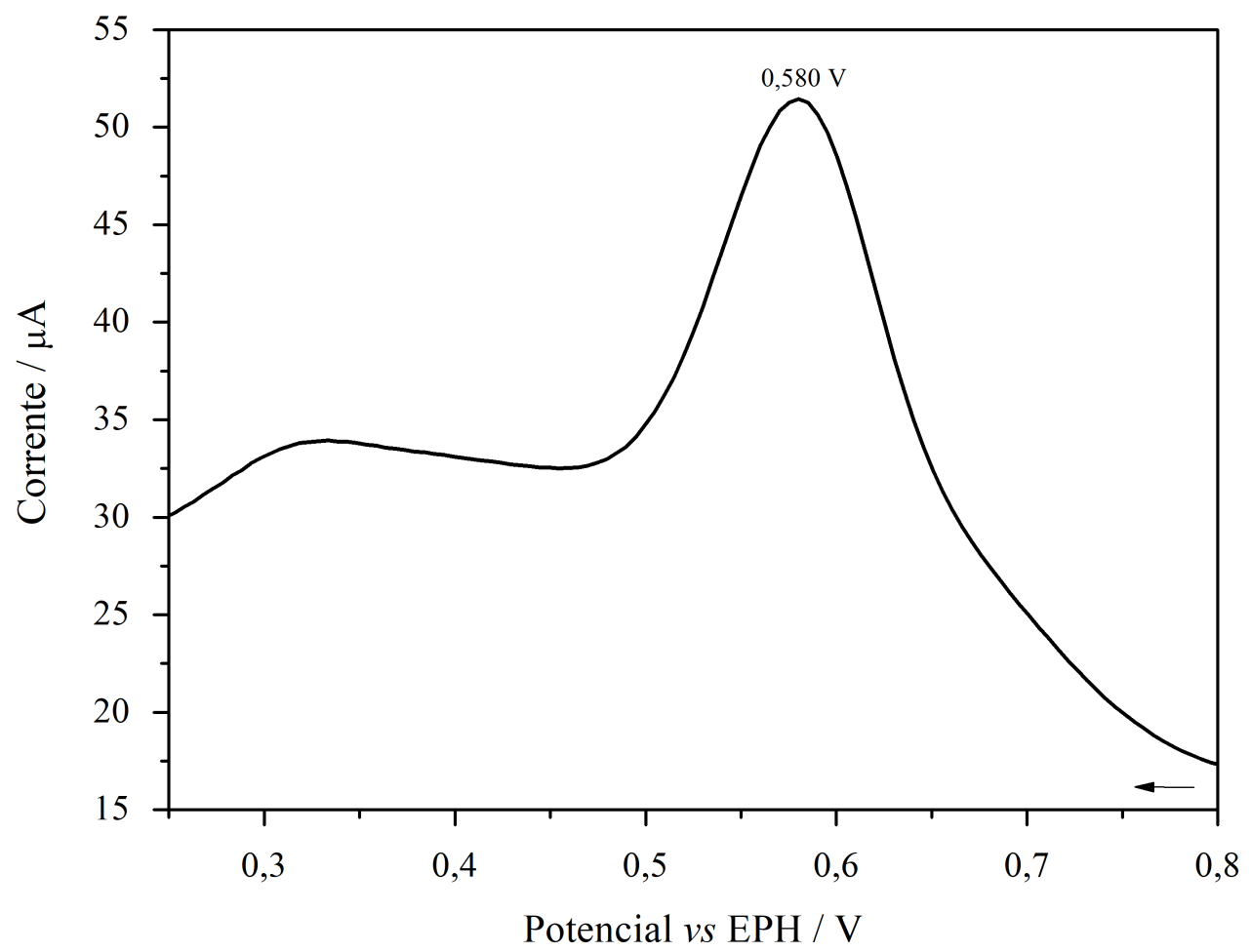

Figura 5.9: Monitoração do potencial redox dos ions $\left[\mathrm{Fe}(\mathrm{CN})_{5}\right]^{3-}$ coordenados aos ligantes pirazínicos do complexo $\left[F e^{I I}(\text { phtpz })_{2}\right]^{2+}$.

\subsection{Interação do complexo $\left[\mathrm{Fe}(\text { pytpz })_{2}\right]^{2+} \operatorname{com}\left[\mathrm{Fe}(\mathrm{CN})_{5}\right]^{3-}$}

O complexo $\left[\mathrm{Fe}^{I I}(\text { pytpz })_{2}\right]^{2+}$ tem uma estrutura e uma simetria adequada para interagir com os íons $\left[\mathrm{Fe}(\mathrm{CN})_{5}\right]^{3-}$ gerando um padrão de distribuição bastante regular que pode minimizar as forças de repulsão eletrostática. A coordenação dos íons $\left[\mathrm{Fe}(\mathrm{CN})_{5}\right]^{3-}$ pode levar à formação de uma espécie heptacoordenada, $\left[\mathrm{Fe}(\mu-p y t p z)_{2}\left\{F e(C N)_{5}\right\}_{6}\right]^{16-}$, como ilustrada na Figura 5.10. 


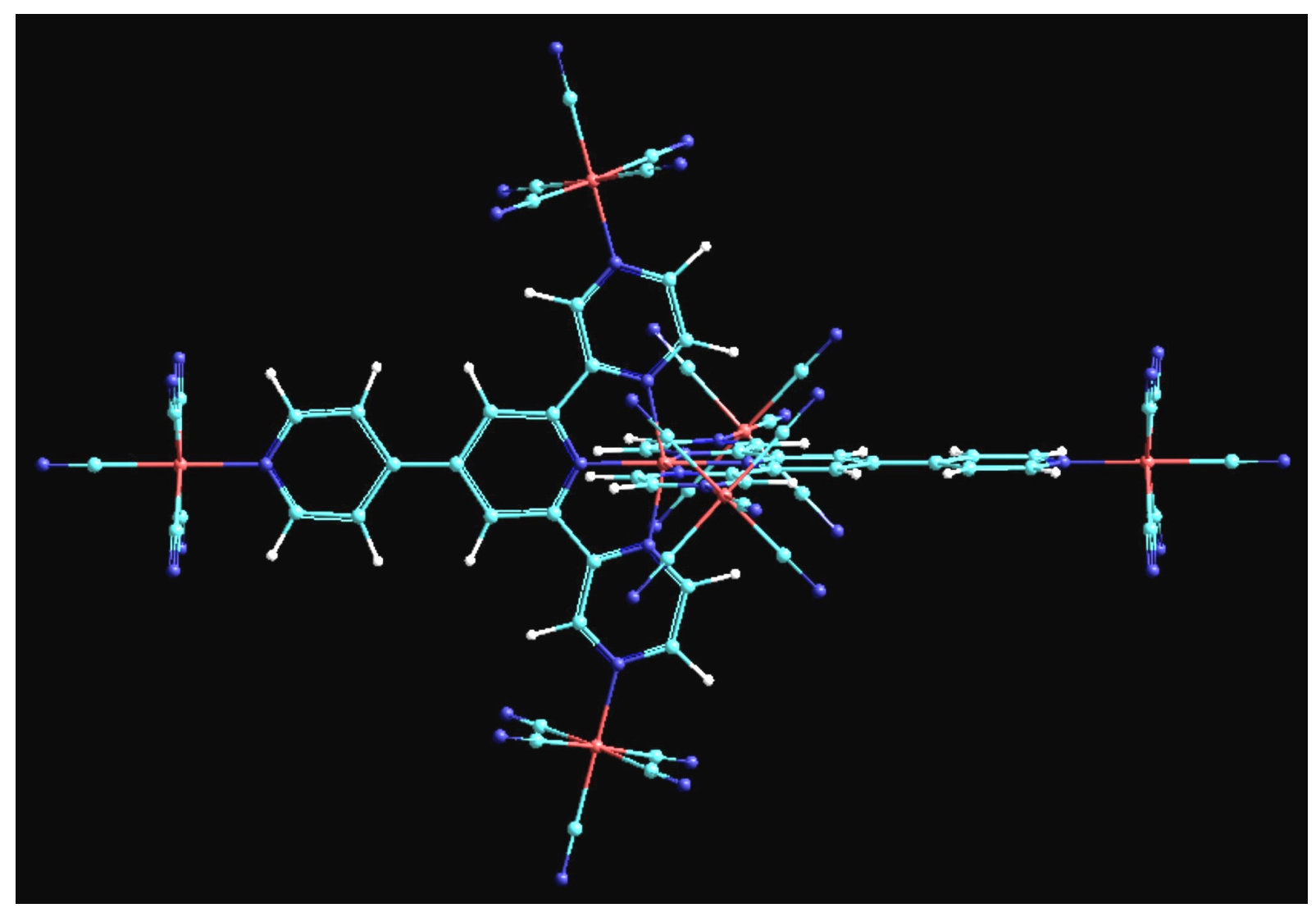

Figura 5.10: Geometria molecular otimizada $\left(M M^{+}\right)$para o complexo pentanuclear $\left[\mathrm{Fe}(\mu-\mathrm{pytpz})_{2}\left\{\mathrm{Fe}(\mathrm{CN})_{5}\right\}_{6}\right]^{16-}$.

Esse sistema inusitado tem precedentes já descritos na literatura, o complexo heptanuclear $\left[R u(b p z)_{3}\left\{F e(C N)_{5}\right\}_{6}\right]^{16-}$ reportado por Toma e Lever [86]. A formação dessas espécies é justificada pela alta afinidade química dos íons $\left[F e^{I I}(C N)_{5}\right]^{3-}$ pelos ligantes pirazínicos. Note-se que o complexo mais estável reportado nessa série é com o ligante Nmetil pirazínio, onde a carga positiva intensifica as interações de retrodoação no sistema.

Assim como realizado para os sistemas anteriores, a monitoração espectrofotométrica de formação dos complexos polimetalados está ilustrada na Figura 5.11. 


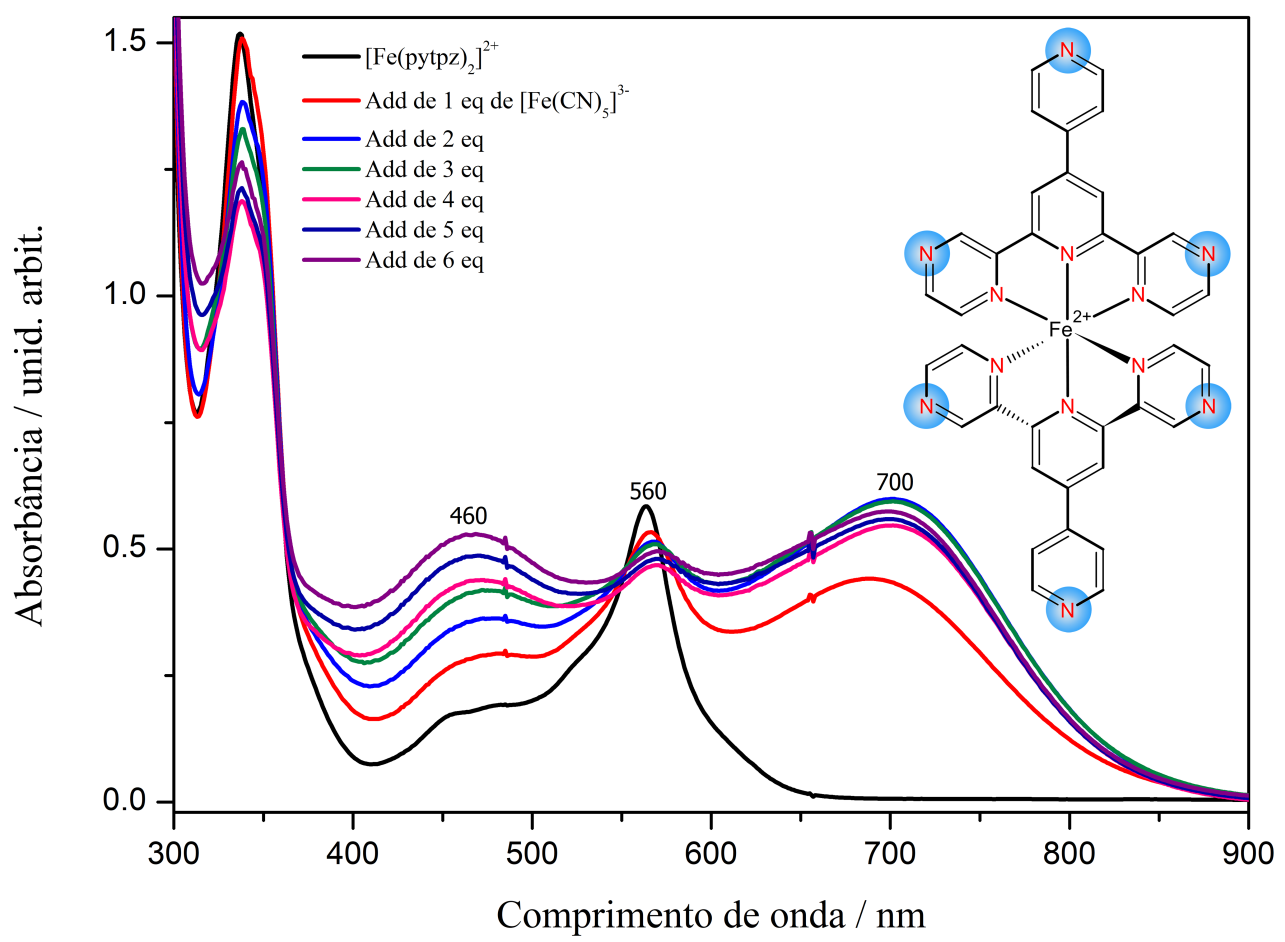

Figura 5.11: Monitoração espectrofotométrica da interação $\left[\mathrm{Fe}(\text { pytpz })_{2}\right]^{2+}$ com íons $\left[\mathrm{Fe}(\mathrm{CN})_{5}\right]^{3-}$ em solução aquosa.

O comportamento mostrado na Figura 5.11 é semelhante ao observado para o sistema $\left[F e(p h t p z)_{2}\right]^{2+}$. O surgimento imediato da banda em $700 \mathrm{~nm}$ é indicativo da associação dos íons $\left[\mathrm{Fe}(\mathrm{CN})_{5}\right]^{3-}$ com as pirazinas, como esperado em termos da afinidade química (retrodoação). A coordenação através dos grupos piridínicos não é bem evidenciada nos espectros, e a banda com intensidade crescente em $460 \mathrm{~nm}$ pode envolver tanto as transições de transferência de carga $F e(I I) \rightarrow$ piridina, como $[F e(I I)] \rightarrow$ pirazina, superpostas às transições no cromóforo $F e(I I)$ - terpirazina central.

Os espectros Raman ressonante mostrados na Figura 5.12 mostram um perfil semelhante ao do sistema $\left[F e(\mu-p h t p z)\left\{F e(C N)_{5}\right\}_{4}\right]^{10-}$ excitado em $633 \mathrm{~nm}$, envolvendo variações na intensidades para os diversos modos vibracionais associados principalmente aos estados eletrônicos do cromóforo central. 


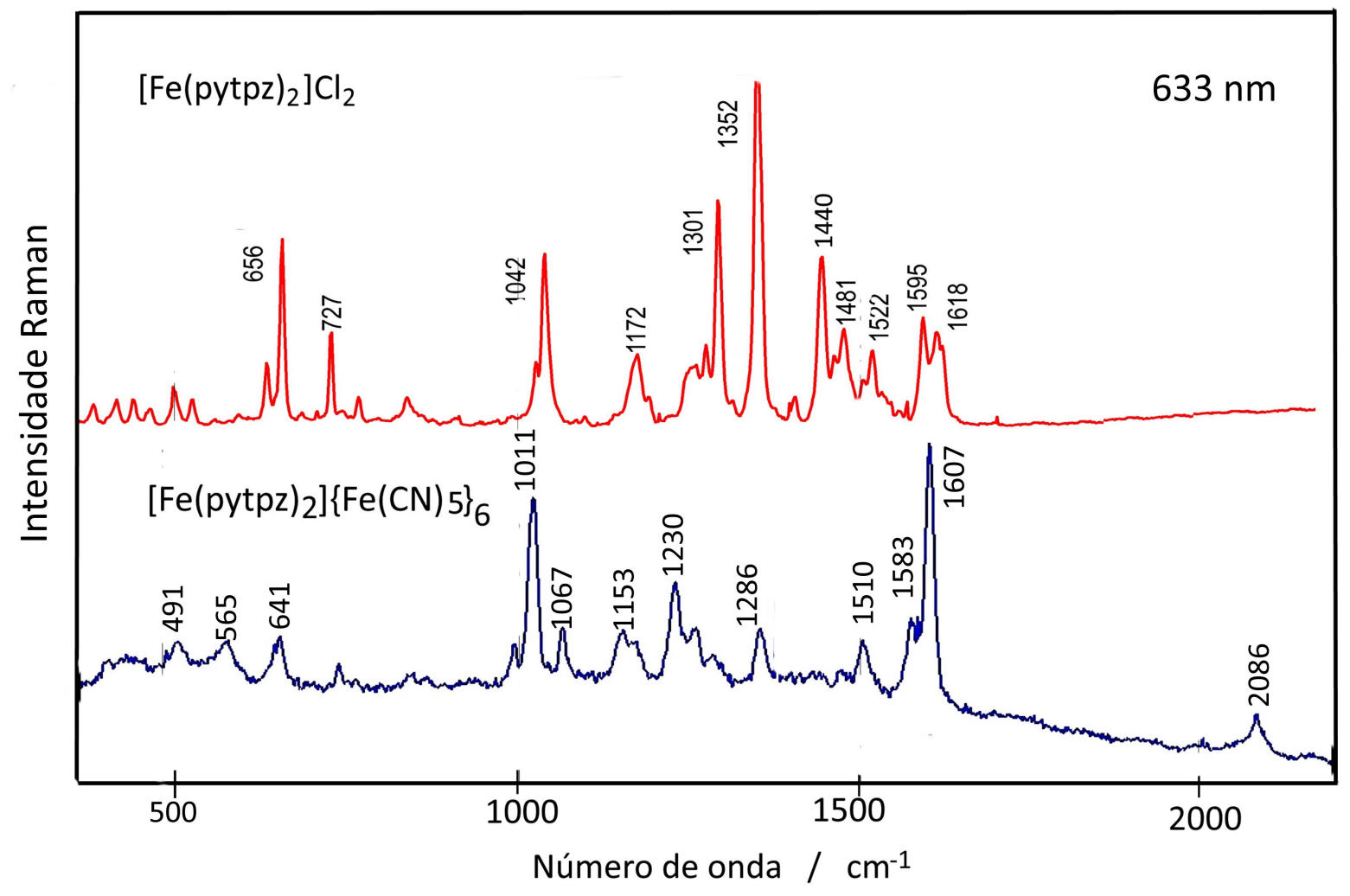

Figura 5.12: Espectros Raman comparativos dos complexos $\left[\mathrm{Fe}(\text { pytpz })_{2}\right]^{2+} e$ $\left[\mathrm{Fe}(\mu-\text { pytpz })\left\{\mathrm{Fe}(\mathrm{CN})_{5}\right\}_{6}\right]^{16-}$ com excitação em $633 \mathrm{~nm}$.

A monitoração eletroquímica ilustrada na Figura 5.13 demonstra claramente a coordenação dos íons $\left[\mathrm{Fe}(\mathrm{CN})_{5}\right]^{3-}$ aos grupos piridínicos e pirazínicos, pelos picos observados em 0,500 e $0.570 \mathrm{~V}$, respectivamente. 


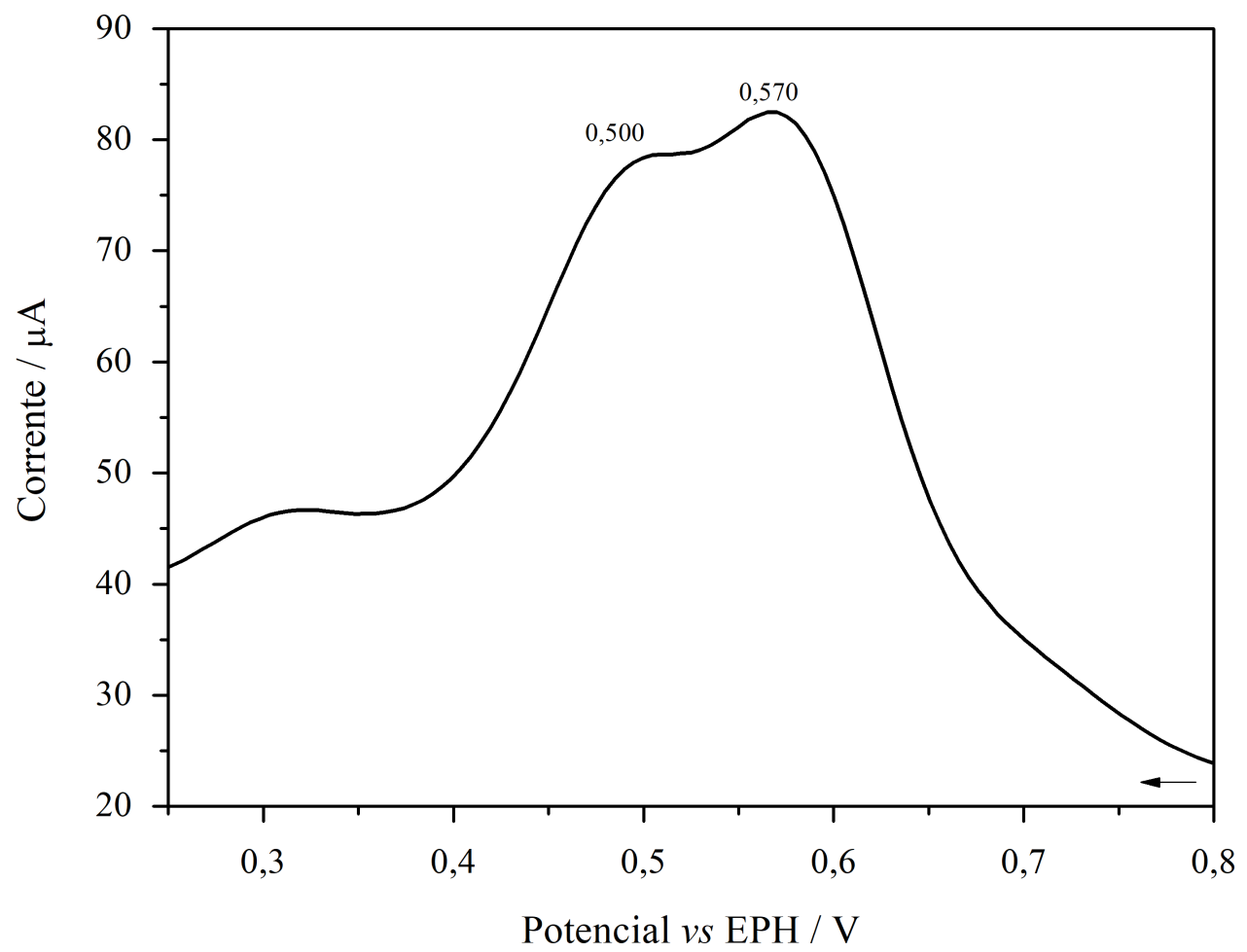

Figura 5.13: Monitoração do potencial redox dos íons $\left[\mathrm{Fe}(\mathrm{CN})_{5}\right]^{3}$ coordenados aos ligantes pirazínicos do complexo $\left[\mathrm{Fe}(\text { pytpz })_{2}\right]^{2+}$.

\subsection{Interação dos complexos terpiridínicos e terpirazí- nicos modificados com cianoferratos, e íons de me- tais de transição}

Os complexos descritos interagem fortemente com íons de metais de transição formando compostos insolúveis, polinucleares, que se enquadram em uma classe genérica conhecida como Azul da Prússia, em deferência ao complexo $\left\{F e_{4}^{I I I}\left[F e^{I I}(C N)_{6}\right]_{3}\right\}$. Os resultados obtidos para a série de complexos com pytpy, phtpz, pytpz mostraram que o perfil espectral e a identidade é mantida após a interação com os íons metálicos $M n^{2+}$, $\mathrm{Co}^{2+}, \mathrm{Ni}^{2+}, \mathrm{Cu}^{2+}$ e $\mathrm{Zn}^{2+}$. Os espectros eletrônicos e Raman foram muito semelhantes com exceção dos compostos com Fe(III). Por isso, a discussão está sendo concentrada apenas em dois exemplos característicos, como os de Zn(II) e com Fe(III). 
O íon $\left[\mathrm{Fe}(\text { pytpz })_{2}\left\{\mathrm{Fe}(\mathrm{CN})_{5}\right\}_{6}\right]^{16-}$ foi gerado em solução, em concentração de 0,005 $\mathrm{mol} \cdot \mathrm{L}^{-1}$, na presença de $10 \%$ de excesso de íons $\left[\mathrm{Fe}(\mathrm{CN})_{5}\right]^{3-}$. Essa solução foi mantida na geladeira, sem qualquer sinal de degradação ao longo de pelo menos duas semanas. Antes de fazer a reação com íons de metais de transição, a solução foi passada por uma coluna de sephadex G-25 para reter a maior parte de íons $\left[\mathrm{Fe}(\mathrm{CN})_{5}\right]^{3-}$ e gerar uma solução praticamente pura do complexo heptanuclear. Essa solução recém eluída da coluna de sephadex foi imediatamente utilizada na reação com íons de metais de transição, em excesso, mediante gotejamento de solução $0,10 \mathrm{~mol} \cdot \mathrm{L}^{-1}$ dos vários íons. Observou-se em todos os casos, a turvação e precipitação dos produtos, que foram isolados por centrifugação a 10.000 rpm por 10 minutos.

A monitoração espectral dos compostos insolúveis, $M_{x}\left\{\left[\mathrm{Fe}(\text { pytpz })_{2}\left\{\mathrm{Fe}(\mathrm{CN})_{5}\right\}_{6}\right]\right\}$, $M_{x}\left\{\left[\mathrm{Fe}(\text { phtpz })_{2}\left\{\mathrm{Fe}(\mathrm{CN})_{5}\right\}_{4}\right]\right\}$ e $M_{x}\left\{\left[\mathrm{Fe}(\text { pytpy })_{2}\left\{\mathrm{Fe}(\mathrm{CN})_{5}\right\}_{2}\right]\right\}$ foi feita após a trituração e incorporação em filmes de álcool polivinílico (PVA). Essa técnica produz um filme de alta transparência adequado para monitoração espectrofotométrica e em microscopia Raman confocal.

Os espectros eletrônicos representativos para os compostos $Z n_{x}\left\{\left[\mathrm{Fe}(\text { pytpz })_{2}\left\{\mathrm{Fe}(\mathrm{CN})_{5}\right\}_{6}\right]\right\}$, e $F e_{x}^{I I I}\left\{\left[F e(p y t p z)_{2}\left\{F e(C N)_{5}\right\}_{6}\right]\right\}$, em filmes de PVA, estão ilustrados na Figura 5.14. 


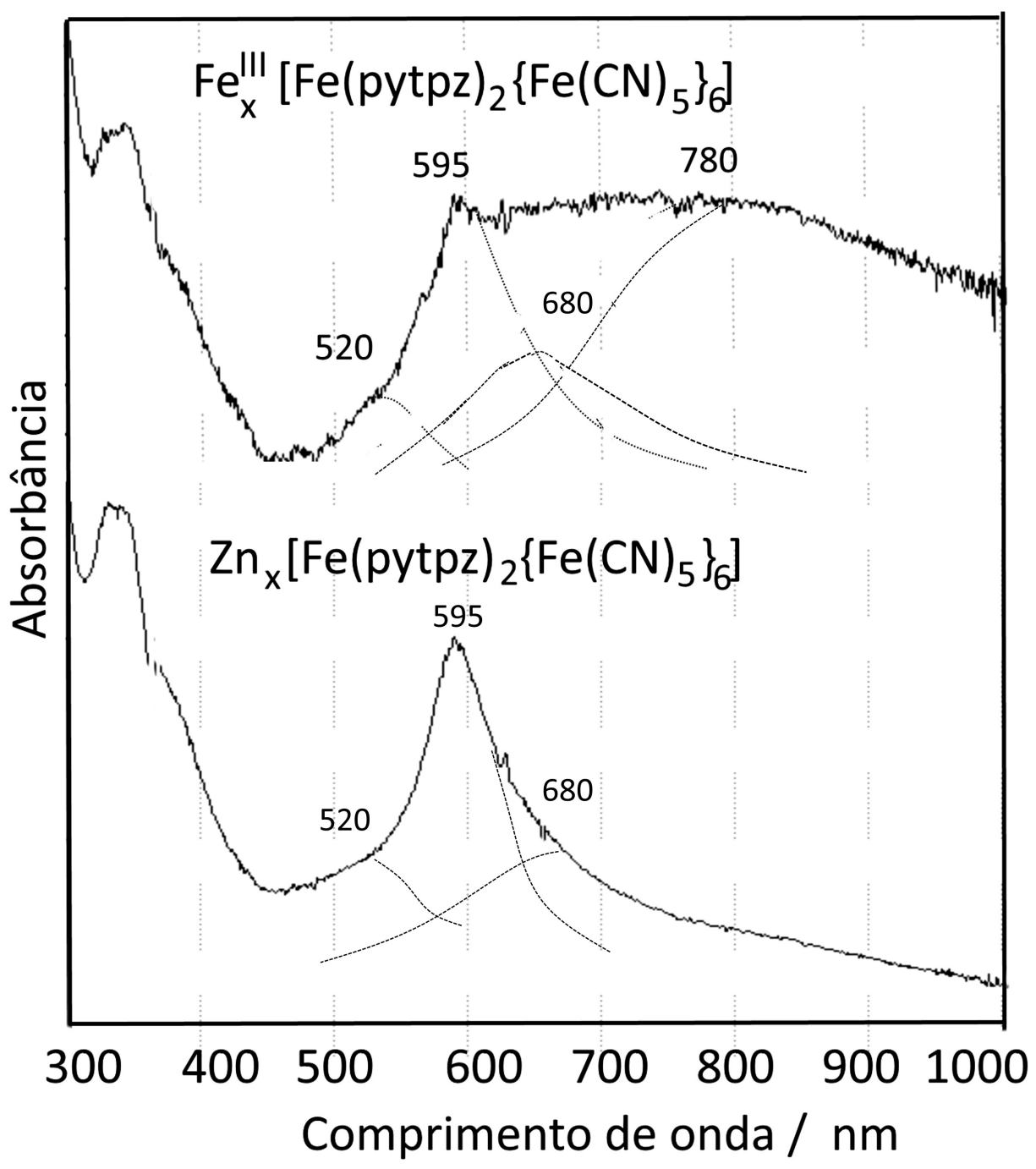

Figura 5.14: Espectros eletrônicos dos compostos $F e_{x}^{I I I}\left[\mathrm{Fe}(\text { pytpz })_{2}\left\{\mathrm{Fe}(\mathrm{CN})_{5}\right\}_{6}\right] \quad e$ $\mathrm{Zn}_{x}\left[\mathrm{Fe}(\text { pytpz })_{2}\left\{\mathrm{Fe}(\mathrm{CN})_{5}\right\}_{6}\right]$ suspensos em filme de PVA.

Os espectros eletrônicos dos compostos de metais de transição $\left(\mathrm{Mn}^{2+}, \mathrm{Co}^{2+}, \mathrm{Ni}^{2+}\right.$, $\mathrm{Cu}^{2+}$ ) mostraram-se semelhantes aos do composto de $\mathrm{Zn}^{2+}$, com o mesmo conjunto de bandas características na região do visível, já discutido anteriormente. No caso do composto de $\mathrm{Fe}^{3+}$, o espectro ilustrado na Figura 5.16 mostra uma banda adicional em 800 nm, semelhante ao observado no complexo de Azul da Prússia. Essa banda pode ser atribuída a uma transição intervalência $F e^{I I}(s b) \rightarrow F e^{I I I}(s a)$ entre os íons $\left[F e^{I I}(C N)_{5}\right]^{3-}$ (spin baixo) e os íons $F e^{3+}$ (spin alto), no grupo $F e^{I I}-C \equiv N-F e^{I I I}$ gerado no composto.

Os espectros Raman confocal correspondentes podem ser vistos na Figura 5.15. O perfil observado para o composto de $Z n^{2+}$ não é muito diferente em relação ao composto 
de $\mathrm{Fe}^{3+}$, com exceção de uma maior intensificação da banda vibracional do grupo cianeto em $2149 \mathrm{~cm}^{-1}$, em caso de $F e^{3+}$. Entretanto, em comparação com o espectro obtido em solução para o complexo inicial $\left[F e(p y t p z)_{2}\left\{F e(C N)_{5}\right\}_{6}\right.$, reproduzido na Figura 5.15, pode-se constatar mudanças bastante significativas no espectro vibracional após a coordenação dos íons metálicos. A banda de estiramento $C \equiv N$ é deslocada de $2086 \mathrm{~cm}^{-1}$ para $2149 \mathrm{~cm}^{-1}$ para os compostos de $F e^{I I I}$ e $Z n^{I I}$, refletindo a coordenação $F e^{I I}-C N-F e^{I I I}$ e $F e^{I I}-C N-Z n^{2+}$. A formação do sólido polimérico também modifica o padrão de intensidade dos picos vibracionais do ligante pytpz, principalmente localizadas em 1386 , 1011 e $641 \mathrm{~cm}^{-1}$. O surgimento da banda em $354 \mathrm{~cm}^{-1}$ pode ser indicativo da ligação $-C N-F e^{I I I}$ e $-C N-Z n^{2+}$. 


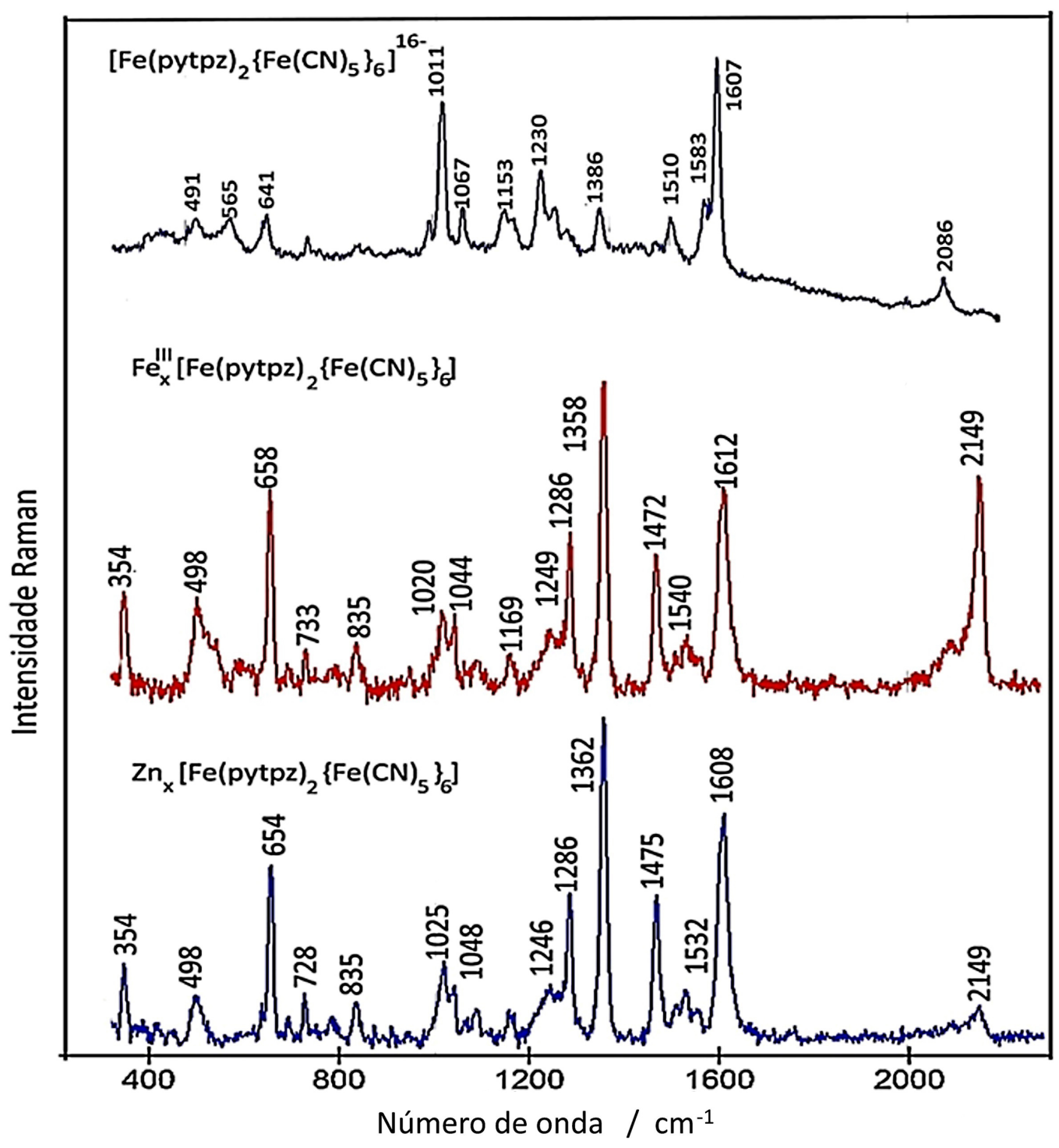

Figura 5.15: Espectros Raman dos compostos poliméricos $F e_{x}^{I I I}\left[\mathrm{Fe}(\text { pytpz })_{2}\left\{\mathrm{Fe}(\mathrm{CN})_{5}\right\}_{6}\right]$ e $\mathrm{Zn}_{x}\left[\mathrm{Fe}(\text { pytpz })_{2}\left\{\mathrm{Fe}(\mathrm{CN})_{5}\right\}_{6}\right]$ em PVA, em comparação com o do composto inicial em solução.

No caso do complexo $\left[\mathrm{Fe}(\mathrm{phtpz})_{2}\left\{\mathrm{Fe}(\mathrm{CN})_{5}\right\}_{4}\right]$ os espectros eletrônicos em filme de PVA para os compostos de Fe(III) e Zn(II) estão mostrados na Figura 5.16, e os espectros Raman estão ilustrados na Figura 5.17. A banda de estiramento $C \equiv N$ é deslocada para $2151 \mathrm{~cm}^{-1}$ refletindo a coordenação dos íons metálicos. A banda de estiramento C-C aromático em $1473 \mathrm{~cm}^{-1}$ fica em evidência nos compostos do tipo Azul da Prússia, sugerindo estar associada aos anéis pirazínicos, que seriam os mais afetados pela coordenação dos íons metálicos. 


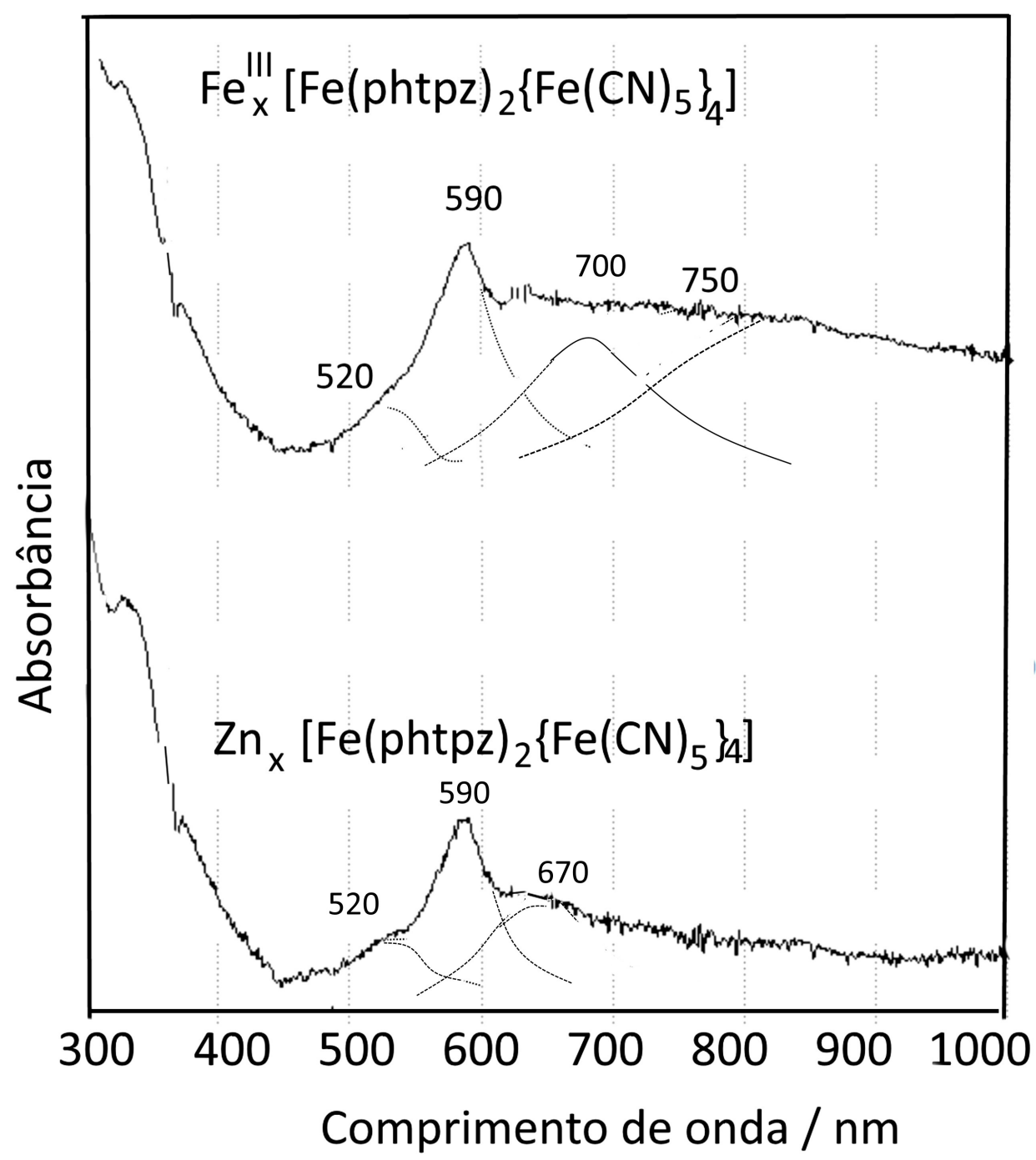

Figura 5.16: Espectros eletrônicos dos compostos $F e_{x}^{I I I}\left[\mathrm{Fe}(\text { phtpz })_{2}\left\{\mathrm{Fe}(\mathrm{CN})_{5}\right\}_{4}\right] \quad e$ $Z n_{x}\left[\mathrm{Fe}(\text { phtpz })_{2}\left\{\mathrm{Fe}(\mathrm{CN})_{5}\right\}_{4}\right]$ suspensos em filme de PVA. 


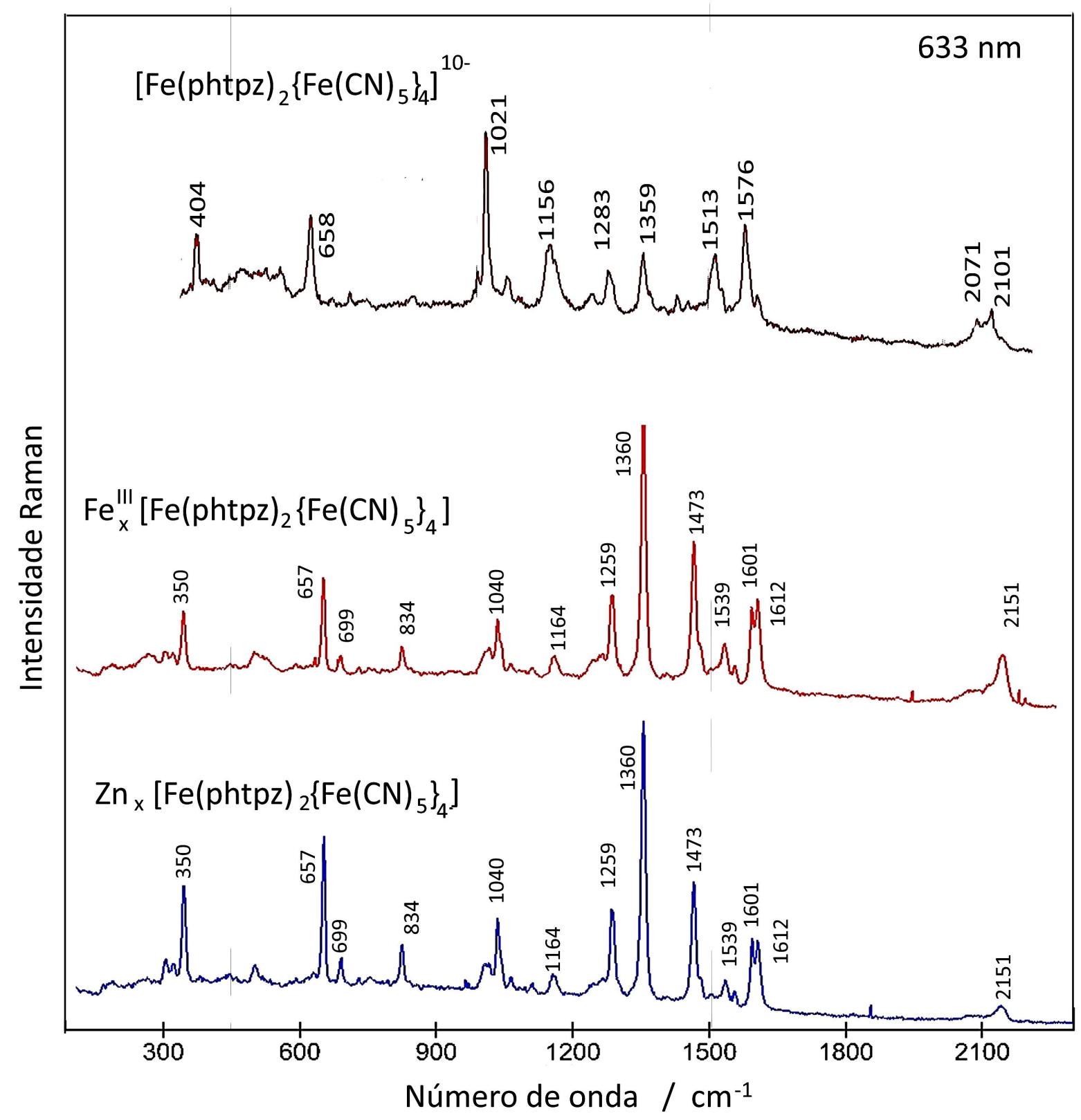

Figura 5.17: Espectros Raman dos compostos poliméricos $F e_{x}^{I I I}\left[\mathrm{Fe}(\text { phtpz })_{2}\left\{\mathrm{Fe}(\mathrm{CN})_{5}\right\}_{4}\right]$ e $Z n_{x}\left[\mathrm{Fe}(\mathrm{phtp} z)_{2}\left\{\mathrm{Fe}(\mathrm{CN})_{5}\right\}_{4}\right]$ em PVA, em comparação com o do composto inicial em solução.

Para o complexo $\left[\mathrm{Fe}(\text { pytpy })_{2}\left\{\mathrm{Fe}(\mathrm{CN})_{5}\right\}_{2}\right]^{4-}$ a interação com os íons metálicos envolve essencialmente os grupos $\left[\mathrm{Fe}(\mathrm{CN})_{5}\right]^{3-}$ coordenados ao terminal piridínico. Como já foi comentado na Figura 5.3, o grupo piridina periférico tem menor envolvimento eletrônico com o cromóforo terpiridínico central, produzindo apenas algumas mudanças de intensidade no espectro Raman. A interação dos grupos $\left[\mathrm{Fe}(\mathrm{CN})_{5}\right]^{3-}$ com íons de $\mathrm{Fe}(\mathrm{III})$ dá origem a uma banda de transição intervalência em $750 \mathrm{~nm}$, como pode ser observado na Figura 5.18, mantendo as bandas do cromóforo Fe-tpy praticamente inalteradas. No 
complexo de $Z n^{2+}$, observa-se apenas as bandas do cromóforo Fe-tpy.

Os espectros Raman com excitação em $633 \mathrm{~nm}$ mostram algumas mudanças em relação ao complexo de partida, após a coordenação dos íons metálicos, porém em menor proporção quando comparados com os derivados pirazínicos das Figuras 5.15 e 5.17. A maior mudança ocorre na região de estiramento C-C aromático, por volta de $1445 \mathrm{~cm}^{-1}$ possívelmente associado aos anéis piridínicos terminais, que seriam mais afetado pela coordenação dos íons metálicos.

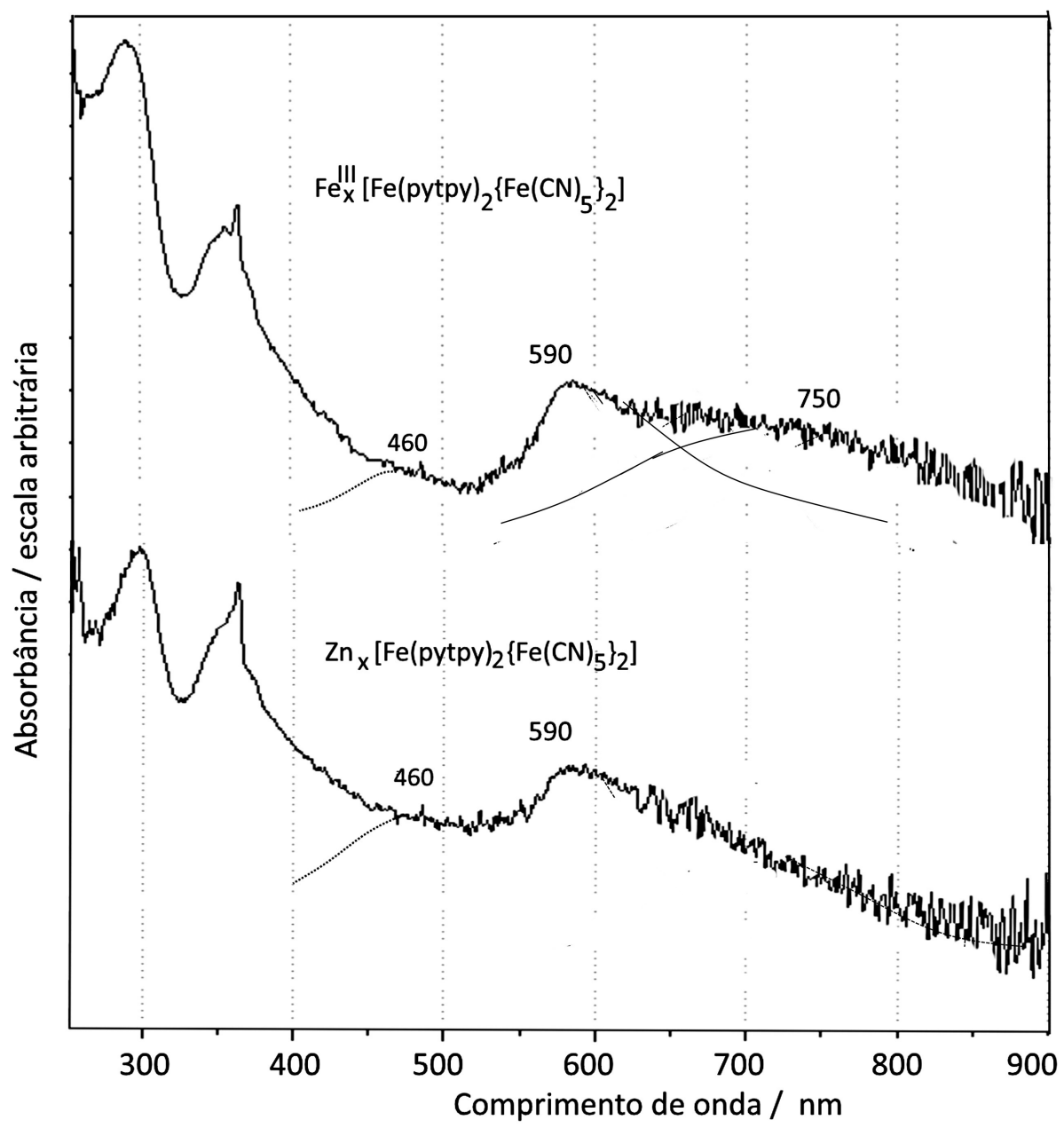

Figura 5.18: Espectros eletrônicos dos compostos $F e_{x}^{I I I}\left[\mathrm{Fe}(\text { pytpy })_{2} \quad\left\{\mathrm{Fe}(\mathrm{CN})_{5}\right\}_{4}\right] \quad e$ $\mathrm{Zn}_{x}\left[\mathrm{Fe}(\text { pytpy })_{2}\left\{\mathrm{Fe}(\mathrm{CN})_{5}\right\}_{4}\right]$ suspensos em filme de PVA. 


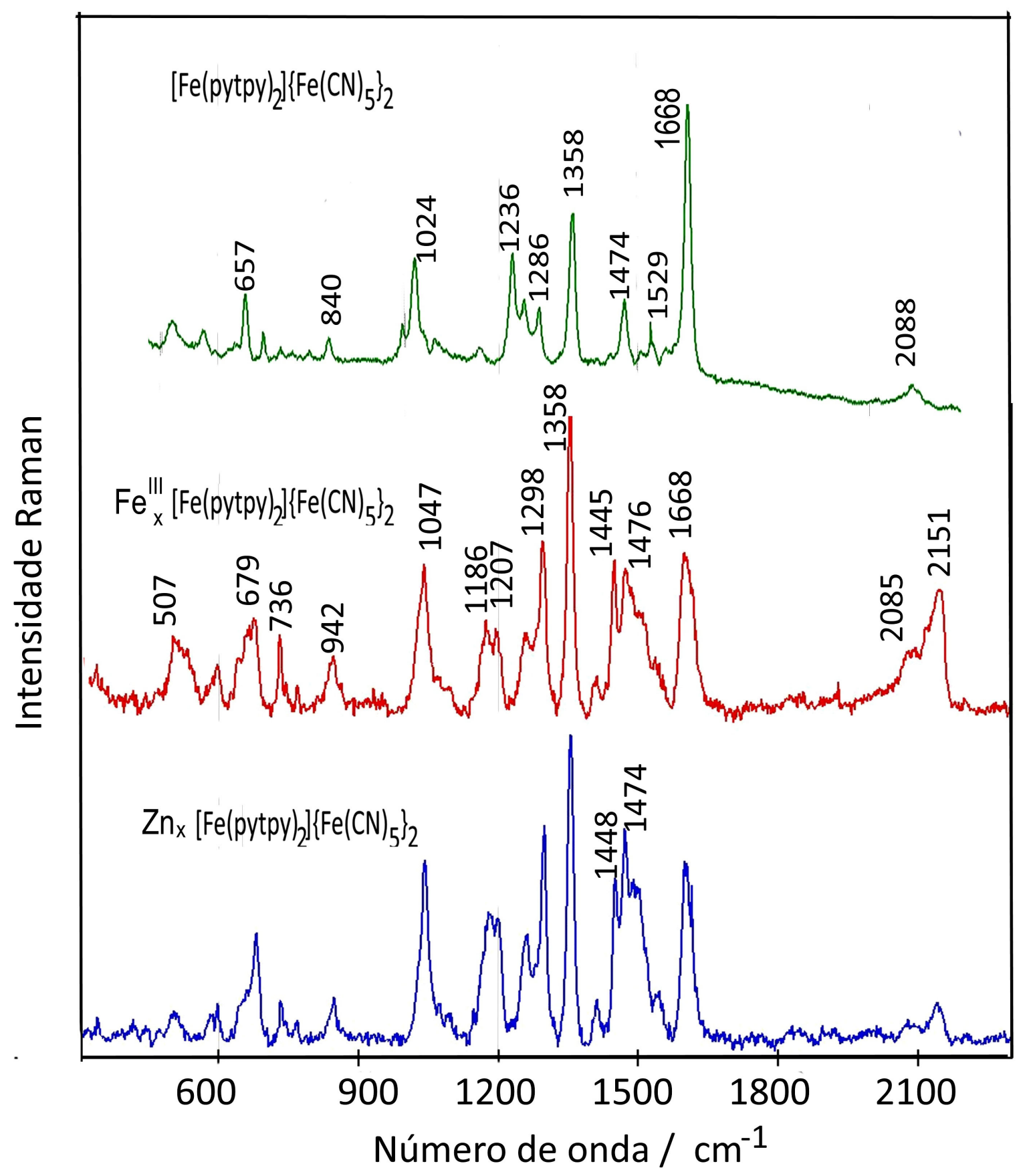

Figura 5.19: Espectros Raman dos compostos poliméricos $F e_{x}^{I I I}\left[\mathrm{Fe}(\text { pytpy })_{2}\left\{\mathrm{Fe}(\mathrm{CN})_{5}\right\}_{4}\right]$ e $\mathrm{Zn}_{x}\left[\mathrm{Fe}(\text { pytpy })_{2}\left\{\mathrm{Fe}(\mathrm{CN})_{5}\right\}_{4}\right]$ em PVA, em comparação com o do composto inicial em solução.

Com o auxílio dos cálculos de orbitais moleculares e com a estratégia de coordenação de outro centro metálico, obtendo um composto que apresenta um cromóforo com transição eletrônica na faixa de energia do laser disponível, fizemos, então, uma atribuição tentativa dos picos referentes às vibrações do anel piridínico, pirazínico e fenílico. As atribuições encontram-se nas Tabelas 5.2, 5.1 e 5.3. 
Tabela 5.2: Picos Raman para os complexos $\left[\mathrm{Fe}(\text { phtpy })_{2}\right]^{2+}$ e $\left[\mathrm{Fe}(\text { phtpz })_{2}\right]^{2+}$ e a supramolécula derivada com atribuição provisória.

\begin{tabular}{|c|c|c|c|c|c|}
\hline $\mathrm{cm}^{-1}$ & {$\left[F e(\text { phtpy })_{2}\right]^{2+}$} & $\mathrm{cm}^{-1}$ & {$\left[F e(p h t p z)_{2}\right]^{2+}$} & $\mathrm{cm}^{-1}$ & {$\left[F e(p h t p z)_{2}\{P C\}_{4}\right]^{10-}$} \\
\hline & & & & 2101 & $\nu C N$ \\
\hline & & & & 2071 & $\nu C N$ \\
\hline 1607 & $\nu C C t p y$ & 1616 & $\nu C C t p z$ & & \\
\hline 1562 & $\nu C C \operatorname{tpy}(c)^{*}$ & 1593 & $\nu C C t p z$ & 1576 & $\nu C N p z$ \\
\hline 1543 & $\nu C C \operatorname{tpy}(p)^{*}$ & 1552 & $\nu C C \operatorname{tpz}$ & & \\
\hline 1521 & $\nu C C \operatorname{tpy}(c)$ & 1523 & $\nu C C t p z$ & 1513 & $\nu C N p z$ \\
\hline 1486 & $\nu C C t p y(p)$ & 1494 & $\nu C C \operatorname{tpz}$ & & \\
\hline \multirow[t]{2}{*}{1471} & $\nu C C t p y$ & 1479 & $\nu C C t p z$ & & \\
\hline & & 1443 & $\nu C C t p z$ & & \\
\hline 1362 & $\nu C C, C N+\delta C H$ tpy & 1357 & $\nu C C t p z$ & 1359 & $\nu C C, C N+\delta C H p z$ \\
\hline 1293 & $\nu C C, C N+\delta C H t p y$ & 1293 & $\nu C C t p z$ & 1283 & $\nu C C, C N+\delta C H p z$ \\
\hline 1271 & $\nu C C, C N+\delta C H p y(p)$ & 1258 & $\nu C C t p z$ & & \\
\hline 1166 & $\nu C C, C N+\delta C H t p y$ & 1174 & $\nu C C, C N+\delta C H t p z$ & 1156 & $\nu C C, C N+\delta C H p z$ \\
\hline 1037 & $\nu C C, C N+\delta C H p y(c)$ & & & & \\
\hline 1021 & $\nu C C, C N+\delta C H t p y$ & 1045 & $\nu C C, C N+\delta C H t p z$ & 1021 & $\nu C C, C N+\delta C H p z$ \\
\hline 693 & $\delta C H,+\delta C C N t p y$ & 730 & $\delta C H, \delta C C N t p z$ & & \\
\hline 655 & $\delta C H,+\delta C C N t p y$ & 659 & $\delta C H, \delta C C N t p z$ & 658 & $\delta C H, \delta C C N p z$ \\
\hline 504 & $\nu F e-N t p y$ & 506 & $\nu F e-N t p z$ & 404 & $\nu F e-C N$ \\
\hline
\end{tabular}


Tabela 5.1: Picos Raman para o complexo $\left[\mathrm{Fe}(\text { pytpy })_{2}\right]^{2+}$ e a supramolécula derivada com atribuição provisória.

\begin{tabular}{|c|c|c|c|}
\hline $\mathrm{cm}^{-1}$ & {$\left[F e(\text { pytpy })_{2}\right]^{2+}$} & $\mathrm{cm}^{-1}$ & {$\left[\mathrm{Fe}(\text { pytpy })_{2}\right]^{+}(\mathrm{PC})$} \\
\hline & & 2088 & $\nu C N$ \\
\hline \multirow[t]{2}{*}{1618} & $\nu C C p y(a)$ & 1609 & $\nu C C p y(a)$ \\
\hline & & 1529 & $\nu C C p y(a)$ \\
\hline 1473 & $\nu C C$ tpy & 1474 & $\nu C C p y$ \\
\hline 1358 & $\nu C C, C N+\delta C H$ tpy & 1358 & $\nu C C, C N+\delta C H t p y$ \\
\hline \multirow[t]{3}{*}{1291} & $\nu C C, C N+\delta C H p y(c)$ & 1286 & $\nu C C, C N+\delta C H p y(c)$ \\
\hline & & 1236 & $\nu C C, C N+\delta C H$ py $(a)$ \\
\hline & & 1045 & $\nu C C, C N+\delta C H$ tpy \\
\hline 1023 & $\nu C C, C N+\delta C H$ tpy & 1023 & $\nu C C, C N+\delta C H$ tpy \\
\hline 656 & $\delta C H, \delta C C N$ tpy & 657 & $\delta C H, \delta C C N$ tpy \\
\hline
\end{tabular}

Tabela 5.3: Picos Raman para o complexo $\left[\mathrm{Fe}(\text { pytpz })_{2}\right]^{2+}$ e a supramolécula derivada com atribuição provisória.

\begin{tabular}{|c|c|c|c|}
\hline $\mathrm{cm}^{-1}$ & {$\left[F e(p y t p z)_{2}\right]^{2+}$} & $\mathrm{cm}^{-1}$ & {$\left[\mathrm{Fe}(\text { pytpz })_{2}\right]^{2+}(P C)$} \\
\hline & & 2086 & $\nu C N$ \\
\hline 1618 & $\nu C C p y(a)$ & 1607 & $\nu C C p y(a)$ \\
\hline 1595 & $\nu C C t p z$ & 1583 & $\nu C C p z$ \\
\hline 1522 & $\nu C C p y(a)$ & 1510 & $\nu C C p y(a)$ \\
\hline 1481 & $\nu C C p y$ & & \\
\hline 1440 & $\nu C C, C N+\delta C H t p z$ & & \\
\hline 1352 & $\nu C C, C N+\delta C H t p z$ & & \\
\hline \multirow[t]{2}{*}{1301} & $\nu C C, C N+\delta C H p y(c)$ & 1286 & $\nu C C, C N+\delta C H p y(c)$ \\
\hline & & 1230 & $\nu C C, C N+\delta C H$ py $(a)$ \\
\hline 1172 & $\nu C C, C N+\delta C H t p z$ & 1153 & $\nu C C, C N+\delta C H p z$ \\
\hline \multirow[t]{2}{*}{1042} & $\nu C C, C N+\delta C H t p z$ & 1067 & $\nu C C, C N+\delta C H t p z$ \\
\hline & & 1011 & $\nu C C, C N+\delta C H p z$ \\
\hline 727 & $\delta C H, \delta C C N t p z$ & & \\
\hline \multirow[t]{3}{*}{656} & $\delta C H, \delta C C N t p z$ & 641 & $\delta C H, \delta C C N p z$ \\
\hline & & 565 & $\delta C H, \delta C C N p z$ \\
\hline & & 491 & $\nu F e-C N$ \\
\hline
\end{tabular}

$\mathrm{c}=$ central; $\mathrm{a}=$ axial; 


\subsection{Considerações sobre os experimentos de reatividade dos complexos}

A presença de grupos piridínicos e pirazínicos terminais possibilita a interação com complexos retrodoadores como $\left[\mathrm{Fe}(\mathrm{CN})_{6}\right]^{3-}$ levando a mudanças seletivas em termos do comportamento espectral, Raman ressonante e eletroquímico. A afinidade maior foi observada para os sítios pirazínicos, que atuam como receptores eletrônicos mais fortes em relação aos grupos piridínicos. Essa interação é suficientemente forte para vencer as barreiras eletrostáticas no complexo e formar espécies pentanucleares com carga -10 , ou heptanucleares com carga -16 .

Todas as espécies geradas com $\left[\mathrm{Fe}(\mathrm{CN})_{5}\right]^{3-}$ interagem fortemente com íons de metais de transição, formando compostos poliméricos insolúveis, semelhantes aos complexos clássicos de Azul da Prússia. Os compostos com Fe(III) apresentam a banda intervalência esperada por volta de $780 \mathrm{~nm}$. Os demais compostos apresentam apenas as bandas típicas do cromóforo $F e(I I)$ - terpiridina ou $F e(I I)$ - terpirazina. A coordenação dos íons metálicos tem um grande efeito sobre os picos Raman do cromóforo, principalmente no caso dos derivados pirazínicos.

A baixa solubilidade dos compostos gerados com íons de metais de transição é mais um indicativo de formação de polímeros de coordenação, como ilustrado na Figura 5.20, podendo inclusive levar a estruturas do tipo MOF (metal organic framework), favorecido pela alta simetria dos compostos. A comprovação dessa hipótese, entretanto, requer estudos mais aprofundados, e dedicados à obtenção de compostos cristalinos para determinação estrutural. 


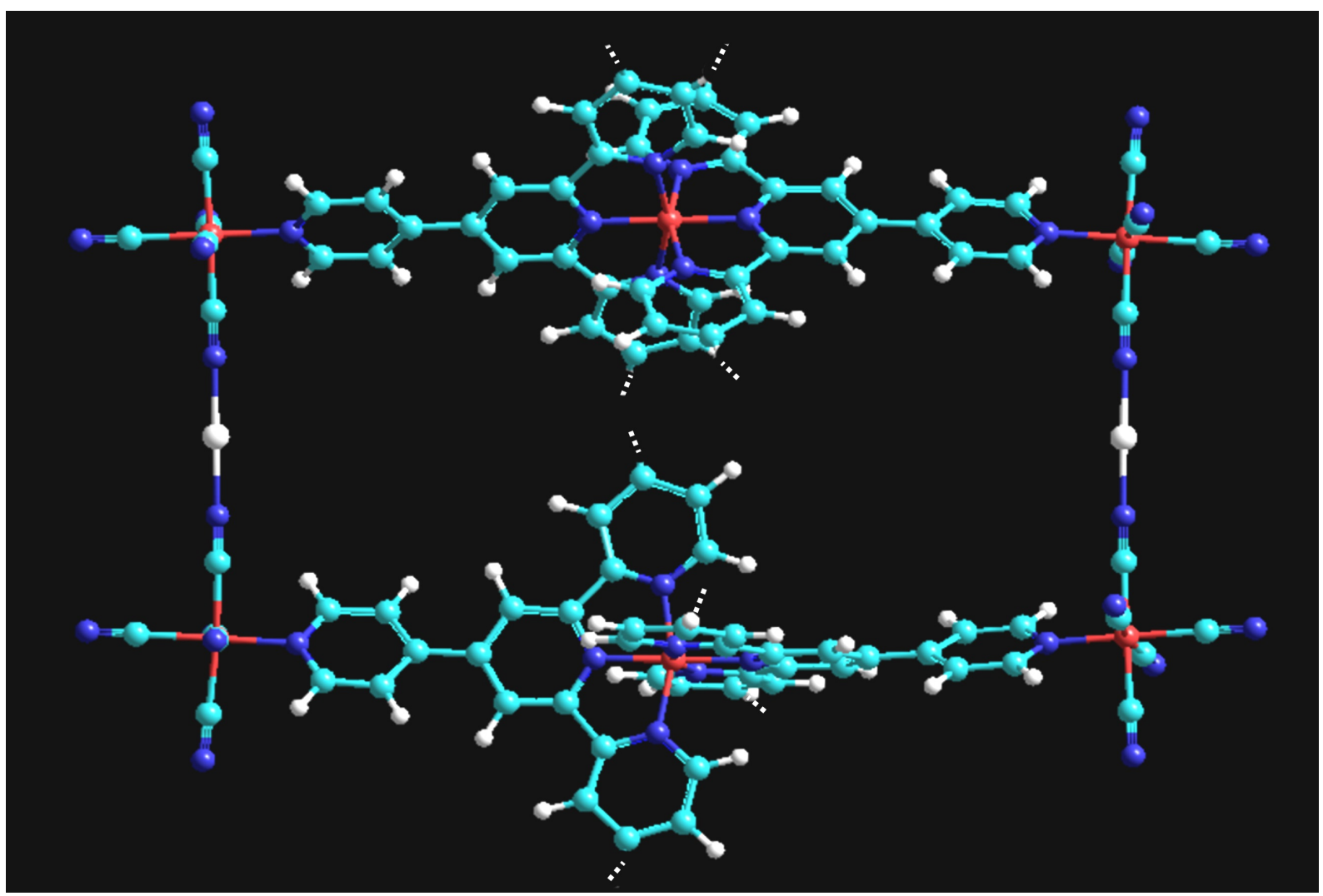

Figura 5.20: Polimero de coordenação gerado pela formação de pontes intramoleculares nos complexos em estudo, mediadas por ions de metais de transição. 


\section{Capítulo 6}

\section{CONCLUSÕES}

Nesta Tese, foram propostas a síntese e a caracterização de uma série de compostos ter-imínicos de ferro(II) que podem ser utilizados como andaimes moleculares para a interação com outros centros metálicos. Os ligantes ter-imínicos análogos à terpiridina funcionalizada foram utilizados como ligantes pontes. Essas moléculas são capazes de atuar como ligantes de binucleação ou polinucleação, pois possuem três ou mais locais propícios à coordenação de metais, podendo ser usados como blocos de construção de arquiteturas supramoleculares.

A caracterização estrutural dos complexos mononucleares foi feita por espectroscopia eletrônica na região do UV-Vis, Raman e ressonância magnética nuclear, mostrando concordância com os resultados encontrados na literatura. O cálculo dos orbitais moleculares dos quatro complexos foi realizado pelo método ZINDO/S, sendo este parametrizado para reproduzir as transições que ocorrem no espectro UV-Vis.

A espectroscopia eletrônica é muito mais que uma técnica de caracterização, sendo uma excelente ferramenta para o entendimento da estrutura eletrônica dos compostos e no presente trabalho foi explorada de forma sistemática. Através da deconvolução das banda característica desses compostos (a banda de transferência de carga do metal para o ligante) e com o auxílio dos resultados dos cálculos de modelagem molecular semiempíricos ZINDO/S efetuou-se a atribuição dos orbitais moleculares envolvidos nas transições eletrônicas observadas.

A utilização da técnica de Raman ressonante é de grande valia em sistemas como esse, 
pois permite correlacionar espectros Raman aos espectros eletrônicos através da utilização de comprimentos de onda de excitação adequados pode-se observar a intensificação seletiva dos modos vibracionais do cromóforo do composto. Estudos teóricos para uma atribuição detalhada das bandas estão em andamento.

A complexação dos ligantes contendo grupos pirazínicos com o íon ferro(II) provoca a estabilização dos orbitais do ligante devido a ligação com grupos eletroatraentes que diminuem a densidade eletrônica dos mesmos. Com a diminuição da energia desses orbitais há uma maior interação com os orbitais $d \pi$ do metal do íon complexo $\left[\mathrm{Fe}(\mathrm{CN})_{5}\right]^{3-}$, maior a retrodoação, como pode ser observado com o surgimento da banda em $700 \mathrm{~nm}$, quando comparada a banda em $458 \mathrm{~nm}$ da interação do ligante pirazína com o pentacianidoferrato.

Todas as supramoléculas geradas com $\left[\mathrm{Fe}(\mathrm{CN})_{5}\right]^{3-}$ interagem fortemente com íons de metais de transição, formando compostos poliméricos insolúveis, semelhantes aos complexos clássicos de Azul da Prússia. A banda de intervalência para os compostos com $F e(I I I)$ é observada por volta de $800 \mathrm{~nm}$. Já os demais compostos formados a partir de outros íons de metais de transição apresentam apenas as bandas típicas do cromóforo $F e(I I)$ - terpiridina ou Fe(II) - terpirazina. Os picos Raman atribuídos ao cromóforo são mais afetados para o caso das supruamoléculas formadas com derivados pirazínicos.

Apesar dos resultados bastante interessantes obtidos, ainda se faz necessário um estudo mais rigoroso com auxílio de cálculos teóricos detalhados.

As supramoléculas sintetizadas no presente trabalho podem ainda ser utilizadas para se obter eletrodos quimicamente modificados, explorando sua atividade eletrocatalítica. Pode-se também explorar a interação dos complexos mononucleares com nanopartículas de ouro e o efeito SERS (Surface Enhanced Raman Scattering). 


\section{Capítulo 7}

\section{REFERÊNCIAS BIBLIOGRÁFICAS}

[1] LEHN, J.-M. Supramolecular chemistry-scope and perspectives molecules, supermolecules, and molecular devices (Nobel Lecture). Angewandte Chemie International Edition in English, Wiley Online Library, v. 27, n. 1, p. 89-112, 1988. Citado na página 22 .

[2] THE Nobel Prize in Chemistry. 1987. https://www.nobelprize.org/prizes/ chemistry/1987/summary/. Accessed: 2019-01-10. Citado na página 22.

[3] LEHN, J. Cryptates: inclusion complexes of macropolycyclic receptor molecules. Pure and Applied Chemistry, De Gruyter, v. 50, n. 9-10, p. 871-892, 1978. Citado na página 22 .

[4] ARAKI, K.; TOMA, H. E. Química de sistemas supramoleculares constituídos por porfirinas e complexos metálicos. Química Nova, SciELO Brasil, v. 25, n. 6/A, p. 962975, 2002. Citado 2 vezes nas páginas 22 e 26.

[5] LEHN, J. Química supramolecular: conceitos e perspectivas. [S.l.]: Lisboa: Instituto Superior Técnico, 2007. Citado na página 22.

[6] TOYOSHIMA, C. Structural aspects of ion pumping by $\mathrm{Ca}^{2+}$-ATPase of sarcoplasmic reticulum. Archives of Biochemistry and Biophysics, Elsevier, v. 476, n. 1, p. 3-11, 2008. Citado na página 22.

[7] FALLER, L. D. Mechanistic studies of sodium pump. Archives of Biochemistry and Biophysics, Elsevier, v. 476, n. 1, p. 12-21, 2008. Citado na página 22.

[8] JEFFERIES, K. C.; CIPRIANO, D. J.; FORGAC, M. Function, structure and regulation of the vacuolar $\left(\mathrm{H}^{+}\right)$-ATPases. Archives of Biochemistry and Biophysics, Elsevier, v. 476, n. 1, p. 33-42, 2008. Citado na página 22.

[9] CIPRIANO, D. J.; WANG, Y.; BOND, S.; HINTON, A.; JEFFERIES, K. C.; QI, J.; FORGAC, M. Structure and regulation of the vacuolar atpases. Biochimica et Biophysica Acta (BBA)-Bioenergetics, Elsevier, v. 1777, n. 7-8, p. 599-604, 2008. Citado na página 22.

[10] WU, C.-C.; RICE, W. J.; STOKES, D. L. Structure of a copper pump suggests a regulatory role for its metal-binding domain. Structure, Elsevier, v. 16, n. 6, p. 976-985, 2008. Citado na página 22. 
[11] PHILP, D.; STODDART, J. F. Self-assembly in natural and unnatural systems. $A n$ gewandte Chemie International Edition in English, Wiley Online Library, v. 35, n. 11, p. 1154-1196, 1996. Citado na página 23.

[12] LEHN, J.-M. Perspectives in chemistry-steps towards complex matter. Angewandte Chemie International Edition, Wiley Online Library, v. 52, n. 10, p. 2836-2850, 2013. Citado na página 23.

[13] SHIMOMURA, M.; SAWADAISHI, T. Bottom-up strategy of materials fabrication: a new trend in nanotechnology of soft materials. Current Opinion in Colloid $\&$ Interface Science, Elsevier, v. 6, n. 1, p. 11-16, 2001. Citado na página 23.

[14] BALZANI, V.; CREDI, A.; VENTURI, M. The bottom-up approach to molecularlevel devices and machines. Chemistry-A European Journal, Wiley Online Library, v. 8, n. 24, p. 5524-5532, 2002. Citado na página 23.

[15] LU, W.; LIEBER, C. M. Nanoelectronics from the bottom up. In: Nanoscience And Technology: A Collection of Reviews from Nature Journals. [S.l.]: World Scientific, 2010. p. 137-146. Citado na página 23.

[16] LEHN, J.-M. Perspectives in supramolecular chemistry-from molecular recognition towards molecular information processing and self-organization. Angewandte Chemie International Edition in English, Wiley Online Library, v. 29, n. 11, p. 1304-1319, 1990. Citado na página 23.

[17] LEHN, J.-M. Perspectives in chemistry-aspects of adaptive chemistry and materials. Angewandte Chemie International Edition, Wiley Online Library, v. 54, n. 11, p. 32763289, 2015. Citado na página 23.

[18] HOLLIDAY, B. J.; MIRKIN, C. A. Strategies for the construction of supramolecular compounds through coordination chemistry. Angewandte Chemie International Edition, Wiley Online Library, v. 40, n. 11, p. 2022-2043, 2001. Citado 3 vezes nas páginas 11, 24 , e 25 .

[19] GIANNESCHI, N. C.; MASAR, M. S.; MIRKIN, C. A. Development of a coordination chemistry-based approach for functional supramolecular structures. Accounts of Chemical Research, ACS Publications, v. 38, n. 11, p. 825-837, 2005. Citado na página 25.

[20] TOMA, H. E.; ARAKI, K. Exploring the supramolecular coordination chemistrybased approach for nanotechnology. Progress in Inorganic Chemistry, Wiley Online Library, v. 56, p. 379-486, 2009. Citado na página 25.

[21] DENTI, G.; CAMPAGNA, S.; SABATINO, L.; SERRONI, S.; CIANO, M.; BALZANI, V. Luminescent and redox-reactive building blocks for the design of photochemical molecular devices: mono-, di-, tri-, and tetranuclear ruthenium (II) polypyridine complexes. Inorganic Chemistry, ACS Publications, v. 29, n. 23, p. 4750-4758, 1990. Citado na página 25.

[22] DENTI, G.; CAMPAGNA, S.; SERRONI, S.; CIANO, M.; BALZANI, V. Decanuclear homo- and heterometallic polypyridine complexes: syntheses, absorption spectra, luminescence, electrochemical oxidation, and intercomponent energy transfer. Journal 
of the American Chemical Society, v. 114, n. 8, p. 2944-2950, 1992. Citado na página 25 .

[23] CAMPAGNA, S.; DENTI, G.; SERRONI, S.; CIANO, M.; JURIS, A.; BALZANI, V. A tridecanuclear ruthenium(II)-polypyridine supramolecular species: synthesis, absorption and luminescence properties and electrochemical oxidation. Inorganic Chemistry, v. 31, n. 13, p. 2982-2984, 1992. Citado na página 25.

[24] CONSTABLE, E. C. 2, 2': 6', 2"-terpyridines: From chemical obscurity to common supramolecular motifs. Chemical Society Reviews, Royal Society of Chemistry, v. 36, n. 2, p. 246-253, 2007. Citado 7 vezes nas páginas 11, 12, 26, 27, 30, 32, e 55.

[25] ARAKI, K. Estratégia supramolecular para a nanotecnologia. Química Nova, POLIMERO ISOLUVEL, v. 30, n. 6, p. 1484, 2007. Citado na página 26.

[26] SAALFRANK, R. W.; MAID, H.; SCHEURER, A. Supramolecular coordination chemistry: the synergistic effect of serendipity and rational design. Angewandte Chemie International Edition, Wiley Online Library, v. 47, n. 46, p. 8794-8824, 2008. Citado na página 26.

[27] BOULAS, P. L.; GÓMEZ-KAIFER, M.; ECHEGOYEN, L. Electrochemistry of supramolecular systems. Angewandte Chemie International Edition, Wiley Online Library, v. 37, n. 3, p. 216-247, 1998. Citado na página 26.

[28] SCHUBERT, U. S.; ESCHBAUMER, C.; AN, Q.; SALDITT, T. Terpyridine metal complexes as building blocks for supramolecular assemblies and polymers: thermal stabilities and thin film preparation. Journal of Inclusion Phenomena and Macrocyclic Chemistry, Springer, v. 35, n. 1-2, p. 35-43, 1999. Citado na página 26.

[29] SCHUBERT, U. S.; ESCHBAUMER, C. Macromolecules containing bipyridine and terpyridine metal complexes: towards metallosupramolecular polymers. Angewandte Chemie International Edition, Wiley Online Library, v. 41, n. 16, p. 2892-2926, 2002. Citado na página 26.

[30] BLAU, F. Die destillation pyridinmonocarbonsaurer salze. Chemische Berichte (now European Journal of Inorganic Chemistry), v. 21, p. 1077-1078, 1888. Citado na página 27.

[31] BLAU, F. Über die trockene destillation von pyridincarbonsauren salzen. Monatshefte für Chemie/Chemical Monthly, Springer, v. 10, n. 1, p. 375-388, 1889. Citado na página 27.

[32] BLAU, F. Über neue organische metallverbindungen. Monatshefte für Chemie/Chemical Monthly, Springer, v. 19, n. 1, p. 647-689, 1898. Citado na página 27.

[33] DOnNiCI, C. L.; OliveirA, I. M. F. de; TEMBA, E. S. C.; CASTRO, M. C. R. de. Métodos sintéticos para preparação de 2, 2'-bipiridinas substituídas. Química Nova, SciELO Brasil, v. 25, n. 4, p. 668-675, 2002. Citado na página 27.

[34] MORGAN, G. T.; BURSTALL, F. H. 3. dehydrogenation of pyridine by anhydrous ferric chloride. Journal of the Chemical Society (Resumed), Royal Society of Chemistry, p. 20-30, 1932. Citado na página 27. 
[35] SCHUBERT, U. S.; HOFMEIER, H.; NEWKOME, G. R. Modern terpyridine chemistry. [S.l.]: John Wiley \& Sons, 2006. Citado 2 vezes nas páginas 27 e 54.

[36] KROEHNKE, F. The specific synthesis of pyridines and oligopyridines. Synthesis, (C) Georg Thieme Verlag, Rüdigerstr. 14, 70469 Stuttgart, Germany., v. 1976, n. 01, p. 1-24, 1976. Citado na página 28.

[37] ABRUÑA, H. D. Coordination chemistry in two dimensions: chemically modified electrodes. Coordination Chemistry Reviews, Elsevier, v. 86, p. 135-189, 1988. Citado na página 28.

[38] HJELM, J.; HANDEL, R. W.; HAGFELDT, A.; CONSTABLE, E. C.; HOUSECROFT, C. E.; FORSTER, R. J. Conducting polymers containing in-chain metal centers: electropolymerization of oligothienyl-substituted $\left\{M(t p y)_{2}\right\}$ complexes and in situ conductivity studies, $\mathrm{M}=\mathrm{Os}(\mathrm{II}), \mathrm{Ru}(\mathrm{II})$. Inorganic Chemistry, ACS Publications, v. 44, n. 4, p. 1073-1081, 2005. Citado na página 28.

[39] TOMA, S. H.; BONACIN, J. A.; ARAKI, K.; TOMA, H. E. Selective host-guest interactions on mesoporous $\mathrm{TiO}_{2}$ films modified with carboxymethyl- $\beta$-cyclodextrin. Surface Science, Elsevier, v. 600, n. 19, p. 4591-4597, 2006. Citado na página 28.

[40] Altobello, S.; ARGazZI, R.; CARAmori, S.; CONTADO, C.; FRÉ, S. D.; RUBinO, P.; CHONÉ, C.; LARRAMONA, G.; BIGNOZZI, C. A. Sensitization of nanocrystalline $\mathrm{TiO}_{2}$ with black absorbers based on os and $\mathrm{Ru}$ polypyridine complexes. Journal of the American Chemical Society, ACS Publications, v. 127, n. 44, p. 1534215343, 2005. Citado na página 28.

[41] ASHFORD, D. L.; SONG, W.; CONCEPCION, J. J.; GLASSON, C. R.; BRENNAMAN, M. K.; NORRIS, M. R.; FANG, Z.; TEMPLETON, J. L.; MEYER, T. J. Photoinduced electron transfer in a chromophore-catalyst assembly anchored to $\mathrm{TiO}_{2}$. Journal of the American Chemical Society, ACS Publications, v. 134, n. 46, p. 1918919198, 2012. Citado na página 28.

[42] DARABAntu, M.; BOUlly, L.; TURCK, A.; PLÉ, N. Synthesis of new polyaza heterocycles. part 42: Diazines. Tetrahedron, Elsevier, v. 61, n. 11, p. 2897-2905, 2005. Citado na página 28.

[43] MILLER, R. G.; BROOKER, S. Spin crossover, reversible redox, and supramolecular interactions in 3d complexes of 4-(4-pyridyl)-2, 5-dipyrazyl-pyridine. Inorganic Chemistry, ACS Publications, v. 54, n. 11, p. 5398-5409, 2015. Citado 2 vezes nas páginas 29 e 62 .

[44] YIN, Z.; ZHANG, G.; PHOENIX, T.; ZHENG, S.; FETTINGER, J. C. Assembling mono-, di-and tri-nuclear coordination complexes with a ditopic analogue of 2, 2': 6', 2"terpyridine: syntheses, structures and catalytic studies. RSC Advances, Royal Society of Chemistry, v. 5, n. 45, p. 36156-36166, 2015. Citado 3 vezes nas páginas 11, 29, e 59 .

[45] VICHI, E. J. Pawel krumholz: Dez anos depois. Química Nova, v. 6, p. 154, 1984. Citado na página 29. 
[46] KRUMHOLZ, P. Iron (II) diimine and related complexes. In: Structutal and Bonding. [S.1.]: Springer, 1971. p. 139-174. Citado na página 29.

[47] KRUMholz, P. Ferrous mono- $\alpha$, $\alpha$-dipyridyl. Journal of the American Chemical Society, ACS Publications, v. 71, n. 11, p. 3654-3656, 1949. Citado na página 29.

[48] KRUMHOLZ, P. Abnormal colour of chelate compounds. Nature, Nature Publishing Group, v. 167, n. 4249, p. 570, 1951. Citado na página 29.

[49] KRUMHOLZ, P. Studies on the coördinate bond. II. ferrous complexes of $\alpha$-diimines. Journal of the American Chemical Society, ACS Publications, v. 75, n. 9, p. 2163-2166, 1953. Citado 2 vezes nas páginas 29 e 66.

[50] SONE, K.; KRUMHOLZ, P.; STAMMREICH, H. Studies on the coördinate bond. III. absorption spectra of mono- $\alpha, \alpha$ "-dipyridyl and mono-o-phenanthroline complexes1. Journal of the American Chemical Society, ACS Publications, v. 77, n. 3, p. 777-780, 1955. Citado 3 vezes nas páginas 29, 65, e 66.

[51] KRUMHOLZ, P. Studies on the coordinate bond. VI. the nature of the chromophoric group in iron (II) complexes of tridentate imine ligands. Inorganic Chemistry, ACS Publications, v. 4, n. 5, p. 612-616, 1965. Citado 2 vezes nas páginas 29 e 66.

[52] KRUMHOLZ, P. Formation and decomposition of ferrous $\alpha \alpha$-Dipyridyl. Nature, Nature Publishing Group, v. 163, n. 4149, p. 724, 1949. Citado na página 29.

[53] KRUMHOLZ, P. Studies on the coördinate bond iv. the mechanism of formation and of dissociation of the tris-(2, 2'-dipyridyl)-iron (II) complex. The Journal of Physical Chemistry, ACS Publications, v. 60, n. 1, p. 87-91, 1956. Citado na página 29.

[54] TOMA, H. E.; SANTOS, P. S. Cyclic voltammetry and resonance raman studies of the (pyridine-2-carbaldoxime) tetracyanoferrate (II) complex: evidence of a nitrosooxime equilibrium. Inorganic Chemistry, ACS Publications, v. 26, n. 19, p. 3218-3221, 1987. Citado na página 30.

[55] HOLYER, R.; HUBBARD, C.; KETTLE, S.; WILKINS, R. The kinetics of replacement reactions of complexes of the transition metals with 2, 2', 2"-terpyridine. Inorganic Chemistry, ACS Publications, v. 5, n. 4, p. 622-625, 1966. Citado na página 30.

[56] GOODWIN, H. A. Spin crossover in iron (II) tris (diimine) and bis (terimine) systems. In: Spin Crossover in Transition Metal Compounds I. [S.l.]: Springer, 2004. p. 59-90. Citado na página 31.

[57] HOFMEIER, H.; SCHUBERT, U. S. Recent developments in the supramolecular chemistry of terpyridine-metal complexes. Chemical Society Reviews, Royal Society of Chemistry, v. 33, n. 6, p. 373-399, 2004. Citado na página 31.

[58] THOMPSON, A. M. C. The synthesis of 2, 2': 6', 2'-terpyridine ligands-versatile building blocks for supramolecular chemistry. Coordination Chemistry Reviews, Elsevier, v. 160, p. 1-52, 1997. Citado 3 vezes nas páginas 31, 32, e 52.

[59] HOUSECROFT, C. E. 4, 2': 6', 4'-terpyridines: diverging and diverse building blocks in coordination polymers and metallomacrocycles. Dalton Transactions, Royal Society of Chemistry, v. 43, n. 18, p. 6594-6604, 2014. Citado na página 31. 
[60] HAENSCH, C.; CHIPER, M.; UlBRICHT, C.; WINTER, A.; HOEPPENER, S.; SCHUBERT, U. S. Reversible supramolecular functionalization of surfaces: terpyridine ligands as versatile building blocks for noncovalent architectures. Langmuir, ACS Publications, v. 24, n. 22, p. 12981-12985, 2008. Citado na página 31.

[61] TOMA, S. H.; SANTOS, J. J.; VELHO, R. G.; NAKAMURA, M.; TOMA, H. E.; ARAKI, K. Electrochemically activated coordenative assembly of a triruthenium cluster metallopolymer. Electrochimica Acta, Elsevier, v. 66, p. 287-294, 2012. Citado 3 vezes nas páginas 11, 32, e 34 .

[62] MAEDA, H.; SAKAMOTO, R.; NISHIHARA, H. Interfacial synthesis of electrofunctional coordination nanowires and nanosheets of bis (terpyridine) complexes. Coordination Chemistry Reviews, Elsevier, v. 346, p. 139-149, 2017. Citado 3 vezes nas páginas 11,34 , e 35 .

[63] HAGFELDT, A.; GRÄTZEL, M. Molecular photovoltaics. Accounts of Chemical Research, ACS Publications, v. 33, n. 5, p. 269-277, 2000. Citado na página 35.

[64] Matias, T. A.; MANGONI, A. P.; TOMA, S. H.; REIN, F. N.; ROCHA, R. C.; TOMA, H. E.; ARAKI, K. Catalytic water-oxidation activity of a weakly coupled binuclear ruthenium polypyridyl complex. European Journal of Inorganic Chemistry, Wiley Online Library, v. 2016, n. 36, p. 5547-5556, 2016. Citado na página 35.

[65] HARLANG, T. C.; LIU, Y.; GORDIVSKA, O.; FREDIN, L. A.; JR, C. S. P.; HUANG, P.; CHÁBERA, P.; KJAER, K. S.; MATEOS, H.; UHLIG, J. et al. Iron sensitizer converts light to electrons with $92 \%$ yield. Nature Chemistry, Nature Publishing Group, v. 7, n. 11, p. 883,2015 . Citado na página 35.

[66] WINNISCHOFER, H. Porfirinas pentacianoferrato e estruturas supramoleculares auto-organizadas. Dissertação (Mestrado) - Universidade de São Paulo, 2000. Citado na página 36 .

[67] FORMIGA, A. L. B. Estudo teórico e experimental de estruturas supramoleculares obtidas com clusters trinucleares de rutênio e porfirinas. Tese (Doutorado) - Universidade de São Paulo, 2005. Citado na página 36.

[68] BONACIN, J. A. Sistemas supramoleculares e nanodispositivos baseados em complexos terpiridínicos. Tese (Doutorado) - Universidade de São Paulo, 2007. Citado na página 36.

[69] TOMA, S. H. Química supramolecular e aplicações nanotecnológicas de compostos polipiridínicos de rutênio. Tese (Doutorado) — Universidade de São Paulo, 2007. Citado na página 36.

[70] MELO, V. H. S. d. Investigação por meio de efeito SERS e SERRS dos sistemas híbridos formados pela interação da 3, 6-bi-2-piridil-1, 2, 4, 5-tetrazina e complexos de rutênio com ouro macroscópico e nanoparticulado. Tese (Doutorado) - Universidade de São Paulo, 2010. Citado na página 36.

[71] ASSUMPÇÃA, A. M. C. Desenvolvimento de nanossistemas supramoleculares baseados em complexos terpiridínicos de ferro (II). Tese (Doutorado) - Universidade de São Paulo, 2008. Citado 2 vezes nas páginas 36 e 55. 
[72] BARTOLL, J. The early use of prussian blue in paintings. In: Proceedings of the 9th International Conference on NDT of Art. [S.l.: s.n.], 2008. Citado na página 36.

[73] DUNBAR, K. R.; HEINTZ, R. A. Chemistry of transition metal cyanide compounds: Modern perspectives. Progress in Inorganic Chemistry, Wiley Online Library, p. 283391, 1996. Citado na página 36.

[74] SHATRUK, M.; AVEnDANO, C.; DUNBAR, K. R. Cyanide-bridged complexes of transition metals: A molecular magnetism perspective. Progress in Inorganic Chemistry, Wiley Online Library, v. 56, p. 155-334, 2009. Citado na página 36.

[75] ROCHA, J. C. d. Complexos macrocíclicos tetraiminodifenólicos de cobre, manganês e zinco e caracterização estrutural, espectroscópica, magnética e eletroquímica. Dissertação (Mestrado) - Universidade Federal do Paraná, 2013. Citado 3 vezes nas páginas 11,36 , e 37 .

[76] TOMA, H. E. Cianoferratos: correlação de estrutura, reatividade e intervalência. Tese (Doutorado) — Universidade de São Paulo, 1979. Citado na página 37.

[77] TOMA, H. E.; MALIN, J. M. Kinetics of formation and stability constants of some pentacyanoferrate (II) complexes of aromatic nitrogen heterocycles. Inorganic Chemistry, ACS Publications, v. 12, n. 9, p. 2080-2083, 1973. Citado 2 vezes nas páginas 37 e 38 .

[78] TOMA, H. E.; MALIN, J. M. Dissociation kinetics of pentacyanoiron(II) complexes of ammonia and methylamine. Inorganic Chemistry, v. 13, n. 7, p. 1772-1774, 1974. Citado na página 37.

[79] TOMA, H. E.; BATISTA, A. A. Self-exchange rates and electron transfer kinetics of horse heart ferricytochrome $\mathrm{c}$ with amino acid-pentacyanoferrate (II) complexes. Journal of Inorganic Biochemistry, Elsevier, v. 20, n. 1, p. 53-59, 1984 . Citado na página 37.

[80] TOMA, H. E.; MALIN, J. M. Properties and reactivity of some pentacyanoferrate (II) complexes of aromatic nitrogen heterocycles. Inorganic Chemistry, ACS Publications, v. 12, n. 5, p. 1039-1045, 1973. Citado 5 vezes nas páginas 38, 87, 90, 92, e 94.

[81] DELIGKIOZI, I.; VOYIATZIS, E.; TSOlOMITIS, A.; PAPADAKIS, R. Synthesis and characterization of new azobenzene-containing bis pentacyanoferrate(II) stoppered pushepull [2] rotaxanes, with $\alpha$-and $\beta$-cyclodextrin. towards highly medium responsive dyes. Dyes and Pigments, v. 113, p. 709-722, 2015. Citado na página 38.

[82] BURGER, N.; KARAS-GAŠPAREC, V. The reactions of pentacyanoferrate (II) ions: Spectrophotometric study, detection and determination of N-heterocyclic aldoximes. Talanta, Elsevier, v. 28, n. 5, p. 323-326, 1981. Citado na página 38.

[83] BURGER, N.; KARAS-GAŠPAREC, V. Spectrophotometric studies of the reactions of pentacyanoferrate (II) complexes with three N-heterocyclic aldoximes. Talanta, Elsevier, v. 31, n. 3, p. 169-172, 1984. Citado na página 38.

[84] BRATSKAYA, S. Y.; ZHELEZNOV, V.; PRIVAR, Y. O.; MECHAEV, A.; ZUB, Y. L.; PESTOV, A. Pentacyanoferrate (II) complexes with N-containing derivatives 
of chitosan and polyallylamine: Synthesis and cesium uptake properties. Colloids and Surfaces A: Physicochemical and Engineering Aspects, Elsevier, v. 460, p. 145-150, 2014. Citado na página 38.

[85] NIEH, C. H.; KITAZUMI, Y.; SHIRAI, O.; KANO, K. Sensitive d-amino acid biosensor based on oxidase/peroxidase system mediated by pentacyanoferrate-bound polymer. Biosensors and Bioelectronics, v. 47, p. 350-355, 2013. Citado na página 38.

[86] TOMA, H.; LEVER, A. Spectroscopic and kinetic studies on a series of di-to heptanuclear tris (bipyrazine) ruthenium (II)-pentacyanoferrate (II) complexes in aqueous solution. Inorganic Chemistry, ACS Publications, v. 25, n. 2, p. 176-181, 1986. Citado 5 vezes nas páginas $12,38,39,92$, e 96 .

[87] CAMERA, S. G.; TOMA, H. E. Photophysical behavior of molecular dyads and triad comprising tris (bipyrazine) ruthenium II, bis (bipyridine) chlororuthenium II and pentacyanoferrate II complexes. Journal of Photochemistry and Photobiology A: Chemistry, Elsevier, v. 151, n. 1-3, p. 57-65, 2002. Citado na página 39.

[88] TOMA, H. E.; MATSUMOTO, F. M.; CIPRIANO, C. Spectroelectrochemistry of the hexanuclear cluster $\left.\left[R u_{3} O \text { (acetate }\right)_{6}-\mu-(\text { pyrazine })_{3}-\left\{F e(C N)_{5}\right\}_{3}\right]^{n-}$ and of its modified nickel electrode in aqueous solution. Journal of Electroanalytical Chemistry, Elsevier, v. 346, n. 1-2, p. 261-270, 1993. Citado 2 vezes nas páginas 39 e 86.

[89] WINNISCHOFER, H.; ENGELMANN, F. M.; TOMA, H. E.; ARAKI, K.; RECHENBERG, H. R. Acid-base and spectroscopic properties of a novel supramolecular porphyrin bonded to four pentacyanoferrate (II) groups. Inorganica Chimica Acta, Elsevier, v. 338, p. 27-35, 2002. Citado na página 39.

[90] STEEL, P. J. Aromatic nitrogen heterocycles as bridging ligands; a survey. Coordination Chemistry Reviews, Elsevier, v. 106, p. 227-265, 1990. Citado 2 vezes nas páginas 40 e 41 .

[91] TOMA, H. E. Influências das interações de transferência de elétrons no comportamento dos complexos de pentaaminrutênio (II) e de pentacianoferrato (II) com ligantes insaturados. Tese (Doutorado) — Universidade de São Paulo, 1974. Citado 7 vezes nas páginas 43, 76, 86, 87, 90, 92, e 94 .

[92] RIDLEY, J.; ZERNER, M. An intermediate neglect of differential overlap technique for spectroscopy: pyrrole and the azines. Theoretica Chimica Acta, Springer, v. 32, n. 2, p. 111-134, 1973. Citado na página 46.

[93] RIDLEY, J. E.; ZERNER, M. C. Triplet states via intermediate neglect of differential overlap: benzene, pyridine and the diazines. Theoretica Chimica Acta, Springer, v. 42, n. 3, p. 223-236, 1976. Citado na página 46.

[94] BACON, A. D.; ZERNER, M. C. An intermediate neglect of differential overlap theory for transition metal complexes: Fe, $\mathrm{Co}$ and $\mathrm{Cu}$ chlorides. Theoretica Chimica Acta, Springer, v. 53, n. 1, p. 21-54, 1979. Citado na página 46.

[95] ZERNER, M. C.; LOEW, G. H.; KIRCHNER, R. F.; MUELLER-WESTERHOFF, U. T. An intermediate neglect of differential overlap technique for spectroscopy of transition-metal complexes. ferrocene. Journal of the American Chemical Society, ACS Publications, v. 102, n. 2, p. 589-599, 1980. Citado na página 46. 
[96] STEWART, J. J. Optimization of parameters for semiempirical methods II. applications. Journal of Computational Chemistry, Wiley Online Library, v. 10, n. 2, p. 221-264, 1989. Citado na página 46.

[97] CLARK, T. Quo vadis semiempirical mo-theory? Journal of Molecular Structure: THEOCHEM, Elsevier, v. 530, n. 1-2, p. 1-10, 2000. Citado na página 46.

[98] WANG, J.; HANAN, G. S. A facile route to sterically hindered and non-hindered 4'-aryl-2, 2': 6', 2'-terpyridines. Synlett, (C) Georg Thieme Verlag Stuttgart- New York, v. 2005, n. 08, p. 1251-1254, 2005. Citado 2 vezes nas páginas 47 e 53.

[99] CÁRDENAS, D. J.; SAUVAGE, J.-P. Improved synthesis of 2, 6-oligopyridines by stille cross-coupling reaction. Synlett, (C) Georg Thieme Verlag, Rüdigerstr. 14, 70469 Stuttgart, Germany. All rights, v. 1996, n. 09, p. 916-918, 1996. Citado na página 52.

[100] GOODALL, W.; WILD, K.; ARM, K. J.; WILLIAMS, J. G. The synthesis of 4'-aryl substituted terpyridines by suzuki cross-coupling reactions: substituent effects on ligand fluorescence. Journal of the Chemical Society, Perkin Transactions 2, Royal Society of Chemistry, n. 10, p. 1669-1681, 2002. Citado na página 52.

[101] CONSTABLE, E. C.; LEWIS, J.; LiPTROT, M. C.; RAITHBY, P. R. The coordination chemistry of 4'-phenyl-2, 2': 6', 2"-terpyridine; the synthesis, crystal and molecular structures of 4'-phenyl-2, 2': 6', 2'-terpyridine and bis (4'-phenyl-2, 2': 6', 2'terpyridine) nickel (II) chloride decahydrate. Inorganica Chimica Acta, Elsevier, v. 178, n. 1, p. 47-54, 1990. Citado na página 55.

[102] ELSBERND, H.; BEATTIE, J. K. The NMR spectra of terpyridine and the bisterpyridine complexes of cobalt (III) and iron (II). Journal of Inorganic and Nuclear Chemistry, Elsevier, v. 34, n. 2, p. 771-774, 1972. Citado na página 56.

[103] CONSTABLE, E. C.; THOMPSON, A. M. C. Ligand reactivity in iron (II) complexes of 4'-(4'-pyridyl)-2, 2': 6', 2"-terpyridine. Journal of the Chemical Society, Dalton Transactions, Royal Society of Chemistry, n. 20, p. 2947-2950, 1992. Citado 2 vezes nas páginas 58 e 79 .

[104] KRUMHOLZ, P.; SERRA, O.; PAOLI, M. D. Studies on the coordinate bond. vii. complexes of diimines with iron, synthesis and spectral properties. Inorganica Chimica Acta, Elsevier, v. 15, p. 25-32, 1975. Citado na página 66.

[105] COnStable, E. C.; HOUSECROFT, C. E.; THOMPSON, A. C.; PASSANITI, P.; SILVI, S.; MAESTRI, M.; CREDI, A. pH-sensitive Ru (II) and Os (II) bis (2, 2': 6', 2"-terpyridine) complexes: A photophysical investigation. Inorganica Chimica Acta, Elsevier, v. 360, n. 3, p. 1102-1110, 2007. Citado na página 79.

[106] BEVES, J. E.; DUNPHY, E. L.; CONSTABLE, E. C.; HOUSECROFT, C. E.; KEPERT, C. J.; NEUBURGER, M.; PRICE, D. J.; SCHAFFNER, S. Vectorial property dependence in bis \{4'-(n-pyridyl)-2, 2': 6', 2"-terpyridine $\}$ iron (II) and ruthenium (II) complexes with $\mathrm{n}=2,3$ and 4. Dalton Transactions, Royal Society of Chemistry, n. 3, p. 386-396, 2008. Citado na página 79.

[107] ALBRECHT, A. C. On the theory of raman intensities. The Journal of Chemical Physics, AIP, v. 34, n. 5, p. 1476-1484, 1961. Citado na página 79. 
[108] CLARK, R. J. H.; DINES, T. J. Resonance raman spectroscopy, and its application to inorganic chemistry. new analytical methods (27). Angewandte Chemie International Edition in English, v. 25, n. 2, p. 131-158, 1986. Citado na página 80.

[109] EFREMOV, E. V.; ARIESE, F.; GOOIJER, C. Achievements in resonance raman spectroscopy: Review of a technique with a distinct analytical chemistry potential. Analytica chimica acta, Elsevier, v. 606, n. 2, p. 119-134, 2008. Citado na página 80.

[110] ŠLOUFOVÁ, I.; VLČKOVÁ, B.; PROCHÁZKA, M.; SVOBODA, J.; VOHLÍDAL, J. Comparison of SERRS and RRS excitation profiles of $\left[f e(t p y)_{2}\right]^{2+}\left(t p y=2,2^{\prime}\right.$ : $6^{\prime}, 2^{\prime \prime}$ - terpyridine) supported by DFT calculations: effect of the electrostatic bonding to chloride-modified ag nanoparticles on its vibrational and electronic structure. Journal of Raman Spectroscopy, Wiley Online Library, v. 45, n. 5, p. 338-348, 2014. Citado na página 80.

[111] ROFFIA, S.; MARCACCIO, M.; PARADISI, C.; PAOLUCCI, F.; BALZANI, V.; DENTI, G.; SERRONI, S.; CAMPAGNA, S. Electrochemical reduction of (2, 2'bipyridine)-and bis ((2-pyridyl) pyrazine) ruthenium (II) complexes used as building blocks for supramolecular species. redox series made of 8, 10, and 12 redox steps. Inorganic Chemistry, ACS Publications, v. 32, n. 14, p. 3003-3009, 1993. Citado na página 86.

[112] NAVARRO, J. A.; LIPPERT, B. Simple 1: 1 and 1: 2 complexes of metal ions with heterocycles as building blocks for discrete molecular as well as polymeric assemblies. Coordination Chemistry Reviews, Elsevier, v. 222, n. 1, p. 219-250, 2001. Citado na página 86.

[113] REAL, J. A.; GASPAR, A. B.; NIEL, V.; MUÑOZ, M. C. Communication between iron (II) building blocks in cooperative spin transition phenomena. Coordination Chemistry Reviews, Elsevier, v. 236, n. 1-2, p. 121-141, 2003. Citado na página 86.

[114] Willermann, M.; MUlCAHY, C.; SIGEL, R. K.; CERDÀ, M. M.; FREISINGER, E.; MIGUEL, P. J. S.; ROITZSCH, M.; LIPPERT, B. Pyrazine as a building block for molecular architectures with $P t^{I I}$. Inorganic Chemistry, ACS Publications, v. 45, n. 5, p. 2093-2099, 2006. Citado na página 86.

[115] GLASSON, C. R.; LINDOY, L. F.; MEEHAN, G. V. Recent developments in the d-block metallo-supramolecular chemistry of polypyridyls. Coordination Chemistry Reviews, Elsevier, v. 252, n. 8-9, p. 940-963, 2008. Citado na página 86.

[116] STEEL, P. J. Nitrogen heterocycles as building blocks for new metallosupramolecular architectures. Molecules, Molecular Diversity Preservation International, v. 9, n. 6, p. 440-448, 2004. Citado na página 86.

[117] DEROSSI, S.; CASANOVA, M.; IENGO, E.; ZANGRANDO, E.; STENER, M.; ALESSIO, E. Self-assembled metallacycles with pyrazine edges: a new example in which the unexpected molecular triangle prevails over the expected molecular square. Inorganic Chemistry, ACS Publications, v. 46, n. 26, p. 11243-11253, 2007. Citado na página 86. 
[118] LEININGER, S.; OLENYUK, B.; STANG, P. J. Self-assembly of discrete cyclic nanostructures mediated by transition metals. Chemical Reviews, ACS Publications, v. 100, n. 3, p. 853-908, 2000. Citado na página 86.

[119] ACHELLE, S.; PLÉ, N. Pyrimidine ring as building block for the synthesis of functionalized $\pi$-conjugated materials. Current Organic Synthesis, Bentham Science Publishers, v. 9, n. 2, p. 163-187, 2012. Citado na página 86.

[120] CHAKRABARTY, R.; MUKHERJEE, P. S.; STANG, P. J. Supramolecular coordination: self-assembly of finite two-and three-dimensional ensembles. Chemical Reviews, ACS Publications, v. 111, n. 11, p. 6810-6918, 2011. Citado na página 86.

[121] TOMA, H. E.; SANTOS, P. S. Mixed valence properties of a pyrazine bridged ruthenium-iron complex. Canadian Journal of Chemistry, NRC Research Press, v. 55, n. 20, p. 3549-3553, 1977. Citado na página 86.

[122] TOMA, H.; SANTOS, P. A resonance raman investigation on the ct spectra and photochromism of the binuclear complex $\left(\mathrm{NH}_{3}\right)_{5} \mathrm{Ru}^{I I}(\mu-$ pyrazine $) \mathrm{Cu}^{I I}$. Inorganica Chimica Acta, Elsevier, v. 24, p. L61-L63, 1977. Citado na página 86.

[123] TOMA, H. E.; SERNAGLIA, R. L. Equilibrium reactions network for the cis-or trans-bis (pyrazine) tetraammineruthenium (II/III) and ruthenium (II/III)-edta complexes. Talanta, Elsevier, v. 42, n. 12, p. 1867-1874, 1995. Citado na página 86.

[124] ARAKI, K.; ANGNES, L.; AZEVEDO, C. M.; TOMA, H. E. Electrochemistry of a tetraruthenated cobalt porphyrin and its use in modified electrodes as sensors of reducing analytes. Journal of Electroanalytical Chemistry, Elsevier, v. 397, n. 1-2, p. 205-210, 1995. Citado na página 86.

[125] TOMA, H. E.; ALEXIOU, A. D. Synthesis and characterization of a dodecanuclear ruthenium pyrazine cluster. Journal of the Brazilian Chemical Society, v. 6, n. 3, p. 267-270, 1995. Citado na página 86.

[126] TOMA, H. E.; CHAVEZ-GIL, T. E. Synthesis and characterization of a polymetallic supermolecule containing four ruthenium (II)-bipyridine complexes attached to an iron (II) polyimine center. Inorganica Chimica Acta, Elsevier, v. 257, n. 2, p. 197-202, 1997. Citado na página 86.

[127] CHAVEZ-GIL, T. E.; FARIA, D. D.; TOMA, H. E. Resonance raman investigation of the chromophore centers in an iron (II)-polyimine supermolecule containing four ruthenium (II)-bipyridine groups. Vibrational Spectroscopy, Elsevier, v. 16, n. 1, p. 89-92, 1998. Citado na página 86.

[128] TOMA, H. E.; ARAKI, K.; SILVA, E. O. Synthesis and characterization of a novel dodecanuclear porphyrin ruthenium cluster. Monatshefte für Chemie/Chemical Monthly, Springer, v. 129, n. 10, p. 975-984, 1998. Citado na página 86.

[129] TOMA, H. E.; CHAVEZ-GIL, T. E. Spectroscopic and electrochromic behavior of a pentanuclear cyanoiron (II)-polyimine supermolecule and its corresponding prussian blue film. Spectroscopy Letters, Taylor \& Francis, v. 32, n. 6, p. 963-971, 1999. Citado na página 86 . 
[130] TOMA, H. E.; NIKOLAOU, S. Self-assembly of a supramolecular cyclic polymer containing pyrazine bridged trinuclear $\mu$-oxo-ruthenium-acetate clusters. Journal of Chemical Research, Science Reviews 2000 Ltd, v. 2000, n. 7, p. 326-327, 2000. Citado na página 86.

[131] NIKOLAOU, S.; TOMA, H. E. Synthesis, spectroscopy and electrochemistry of a $\mu$-oxo-triruthenium cluster containing a bridged bis (2, 2'-bipyridyl) ruthenium (II) moiety. Polyhedron, Elsevier, v. 20, n. 3-4, p. 253-259, 2001. Citado na página 86.

[132] ARAKI, K.; WINNISCHOFER, H.; VIANA, H. E.; TOYAMA, M. M.; ENGELMANN, F. M.; MAYER, I.; FORMIGA, A. L.; TOMA, H. E. Enhanced electrochemical and electrocatalytic activity of a new supramolecular manganese-porphyrin species containing four bis (bipyridine)(aqua) ruthenium (II) complexes. Journal of Electroanalytical Chemistry, Elsevier, v. 562, n. 2, p. 145-152, 2004. Citado na página 86.

[133] MAYER, I.; TOMA, H. E.; ARAKI, K. Electrocatalysis on tetraruthenated nickel and cobalt porphyrins electrostatic assembled films. Journal of Electroanalytical Chemistry, Elsevier, v. 590, n. 2, p. 111-119, 2006. Citado na página 86.

[134] NIKOLAOU, S.; TOMA, H. E. A convergent approach for the generation of dendrimers containing the $\left[\mathrm{Ru}_{3} \mathrm{O}\left(\mathrm{CH}_{3} \mathrm{COO}\right)_{6}\right]$ electroactive core. European Journal of Inorganic Chemistry, Wiley Online Library, v. 2008, n. 14, p. 2266-2271, 2008. Citado na página 86.

[135] NIKOlAOU, S.; TOMAZELA, D. M.; EBERLIN, M. N.; TOMA, H. E. Synthesis and characterization of the $\left[\mathrm{Ru}_{3} \mathrm{O}\left(\mathrm{CH}_{3} \mathrm{COO}\right)_{6}(\mathrm{py})^{2-}(\mathrm{BPE}) \mathrm{Ru}(\mathrm{bpy})_{2} \mathrm{Cl}\right]\left(\mathrm{PF}_{6}\right)_{2}$ dimer. Transition Metal Chemistry, Springer, v. 33, n. 8, p. 1059-1065, 2008. Citado na página 86.

[136] NIKOLAOU, S.; FORMIGA, A. L. B.; TOMA, H. E. Probing the electronic delocalization in a cyclic pyrazine ruthenium cluster hexamer. Inorganic Chemistry Communications, Elsevier, v. 13, n. 9, p. 1032-1035, 2010. Citado na página 86. 


\section{Anexo A}

\section{Resultados de espectrometria de}

\section{massas (ESI-MS)}

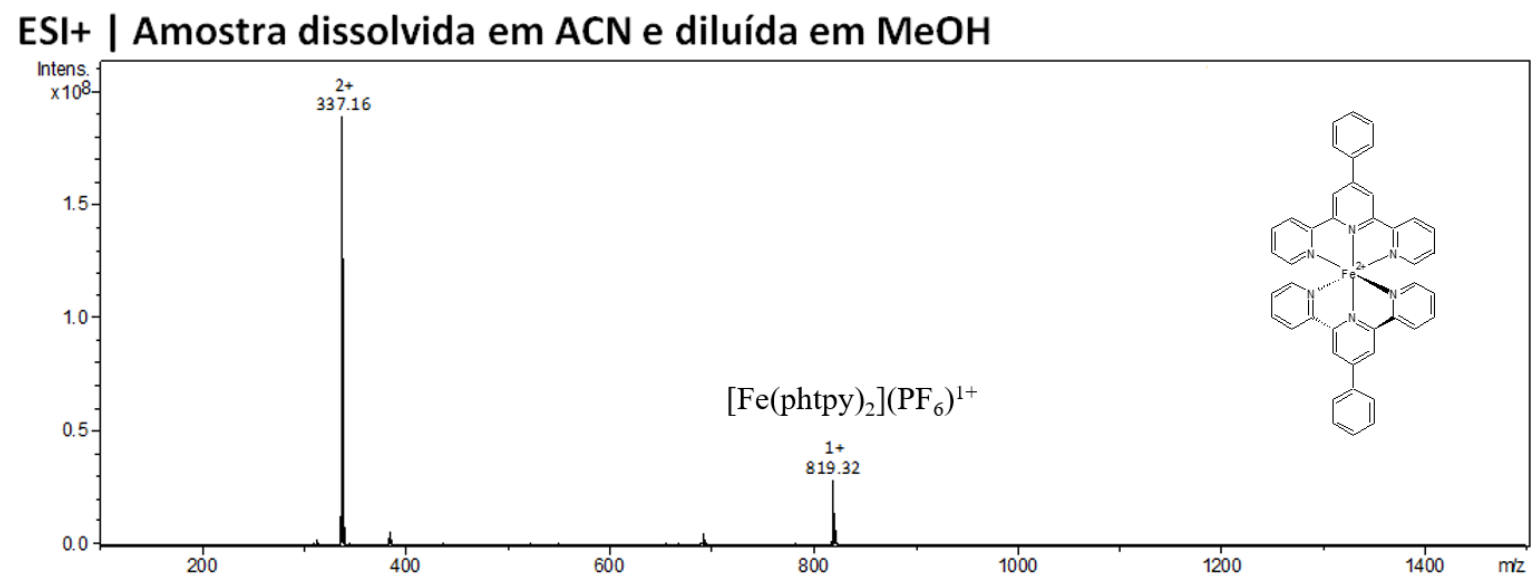

Figura A.1: Espectro ESI-MS do complexo $\left[\mathrm{Fe}(\text { phtpy })_{2}\right]\left(\mathrm{PF}_{6}\right)_{2}$.

$\mathrm{ESI}+$ | Amostra dissolvida em ACN e diluída em $\mathrm{MeOH}$

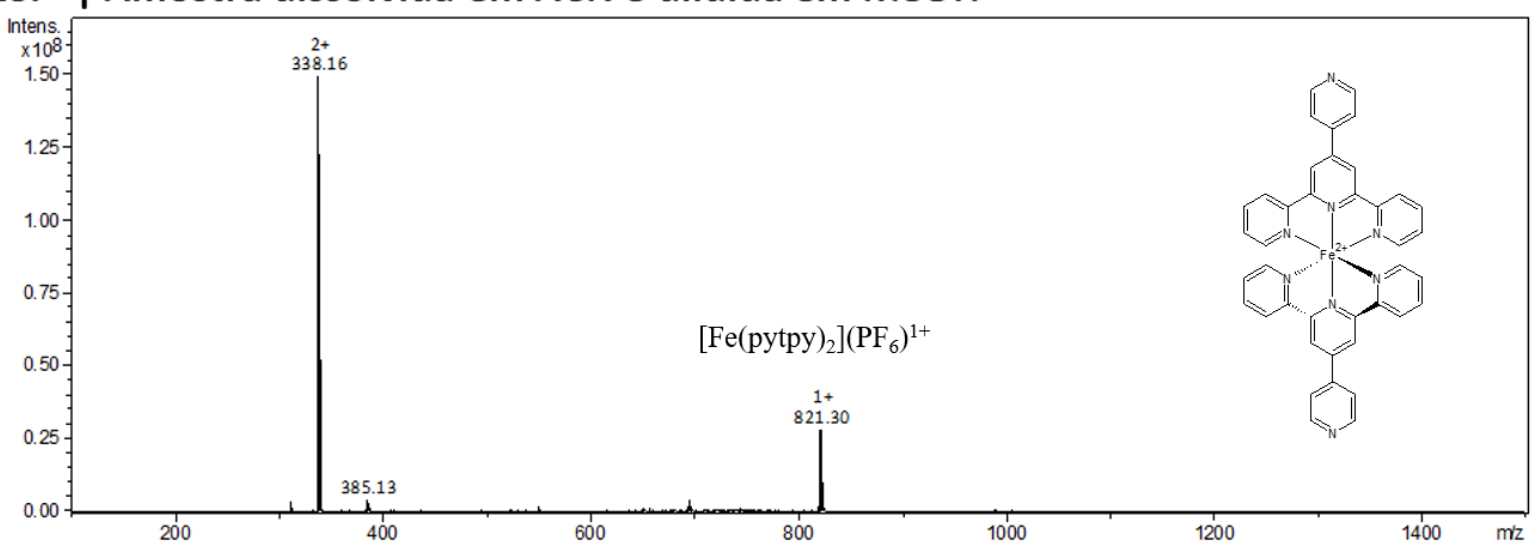

Figura A.2: Espectro ESI-MS do complexo $\left[\mathrm{Fe}(\text { pytpy })_{2}\right]\left(\mathrm{PF}_{6}\right)_{2}$. 


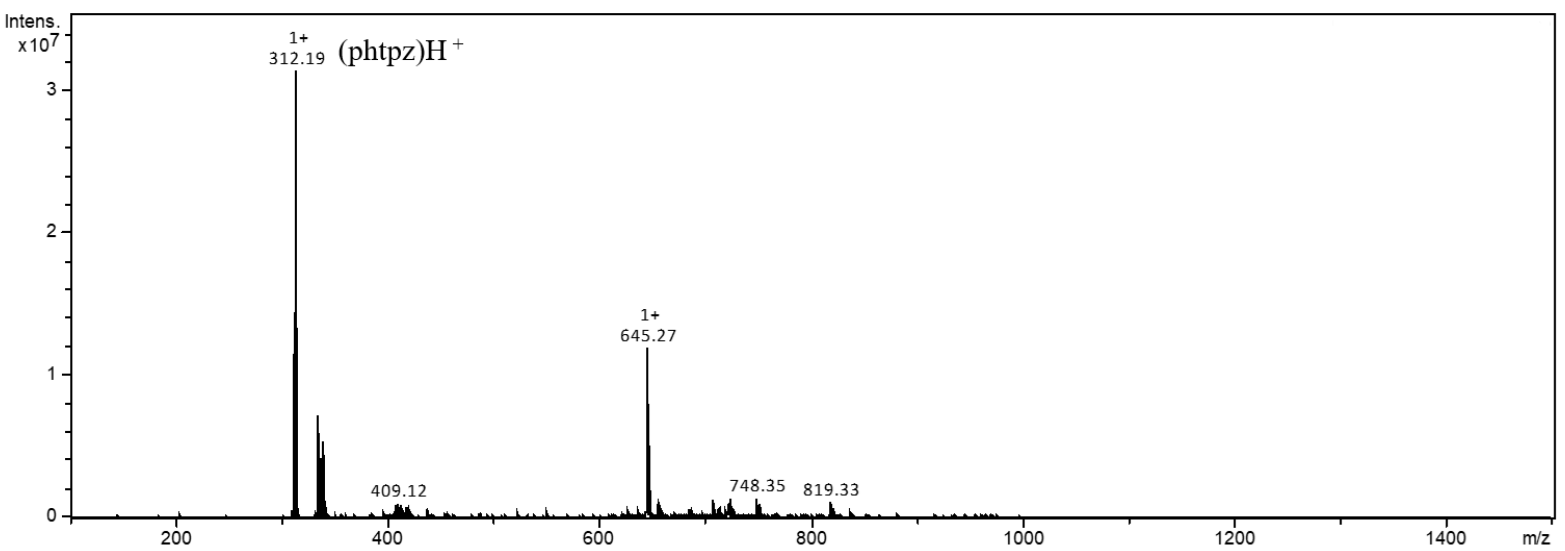

Figura A.3: Espectro ESI-MS do complexo $\left[\mathrm{Fe}(p h t p z)_{2}\right]\left(\mathrm{PF}_{6}\right)_{2}$.

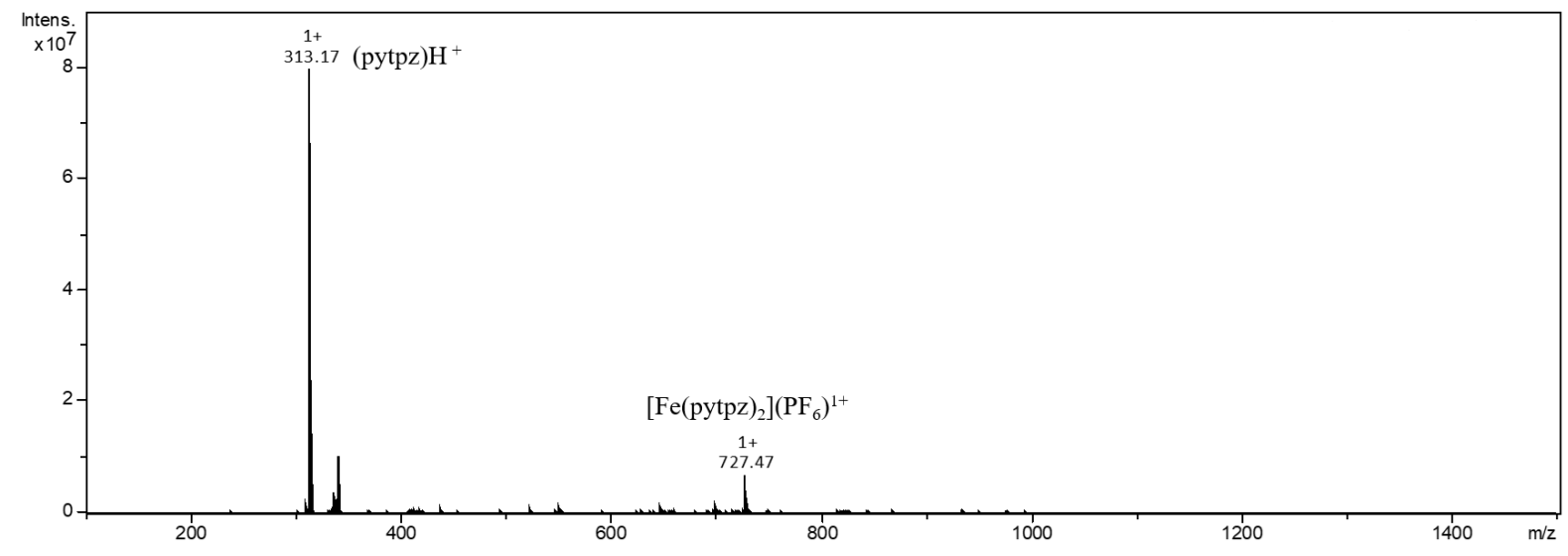

Figura A.4: Espectro ESI-MS do complexo $\left[\mathrm{Fe}(\text { pytpz })_{2}\right]\left(\mathrm{PF}_{6}\right)_{2}$. 


\section{Anexo B}

\section{Valores de absortividade molar}

Tabela B.1: Comprimentos de onda e intensidades (log $\varepsilon$ ) das bandas dos complexos ter-iminicos de Fe(II).

\begin{tabular}{cccc}
\hline Complexo & $\lambda_{\text {exp. }}($ nm $)$ & Transição eletrônica & $\log \varepsilon$ \\
\hline$\left[F e(\text { phtpy })_{2}\right]^{2+}$ & 285 & TIL & 4,80 \\
& 321 & TIM & 4,56 \\
& 566 & TCML & 4,23 \\
\hline & 246 & TIL & 4,65 \\
{$\left[F e(\text { pytpy })_{2}\right]^{2+}$} & 276 & TIL & 4,84 \\
& 284 & TIL & 4,88 \\
& 323 & TIM & 4,63 \\
\hline$\left[F e(p h t p z y)_{2}\right]^{2+}$ & 569 & TCML & 4,35 \\
& 226 & TIL & 4,59 \\
& 333 & TIL & 4,80 \\
& 565 & TIM & 4,62 \\
{$\left[F e(\text { pytpz })_{2}\right]^{2+}$} & 238 & TCML & 4,16 \\
\hline & 338 & TIL & 4,62 \\
& 563 & TIL & 4,86 \\
& TIM & 4,62 \\
& TCML & 4,19
\end{tabular}

Onde: TCML $=$ Transferência de carga metal ligante; TIM = Transição interna do metal e TIL $=$ Transferência interna do ligante. 


\section{Anexo C}

Titulação $\left[F e(p h t p y)_{2}\right]^{2+}$ com $\left[\mathrm{Fe}(\mathrm{CN})_{5}\right]^{3-}$

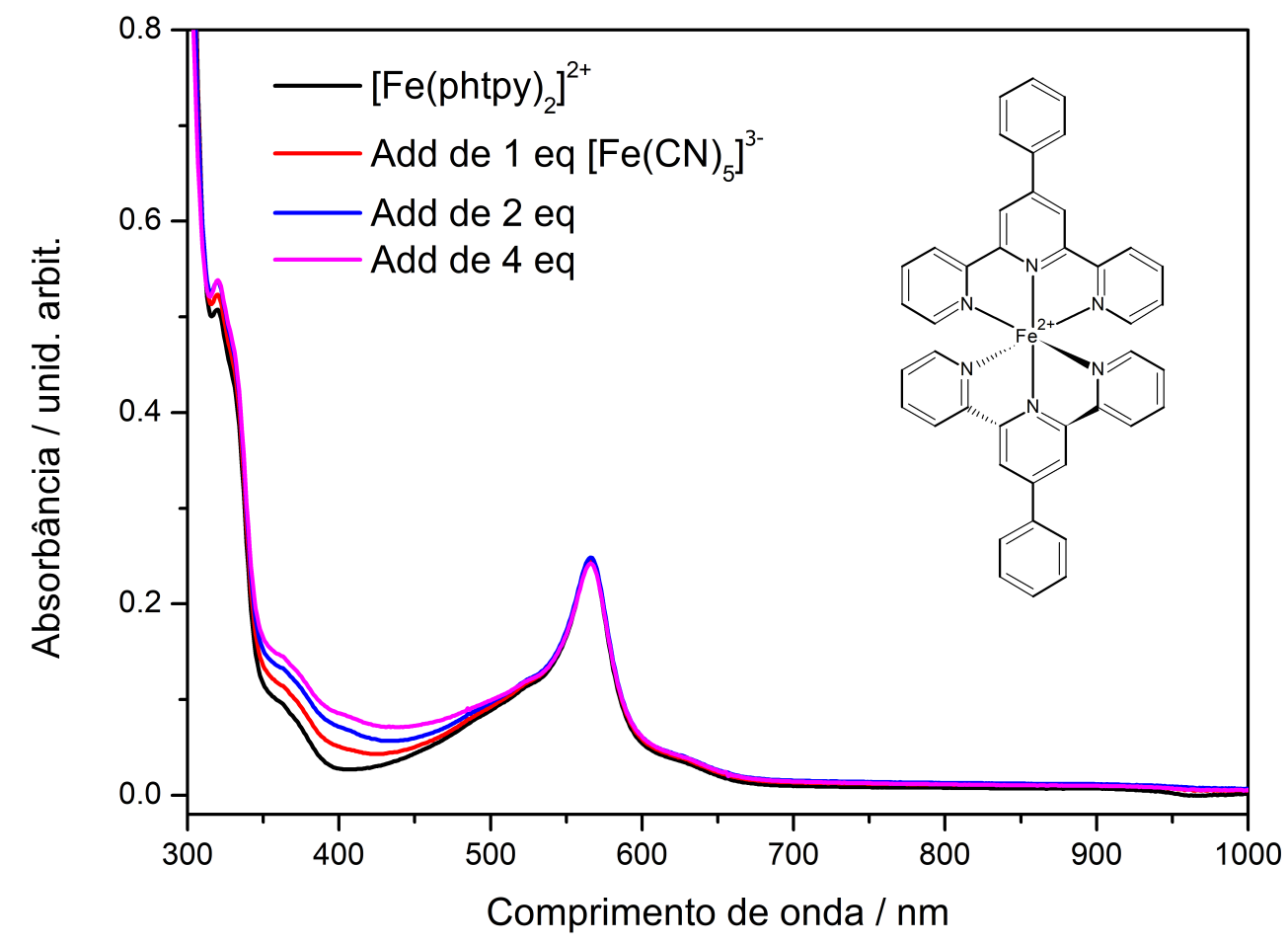

Figura C.1: Monitoração espectrofotométrica da titulação do complexo $\left[\mathrm{Fe}(\text { phtpy })_{2}\right]^{2+}$ com ions $\left[\mathrm{Fe}(\mathrm{CN})_{5}\right]^{3-}(1,2$ e 4 equivalentes $)$ em solução aquosa. 


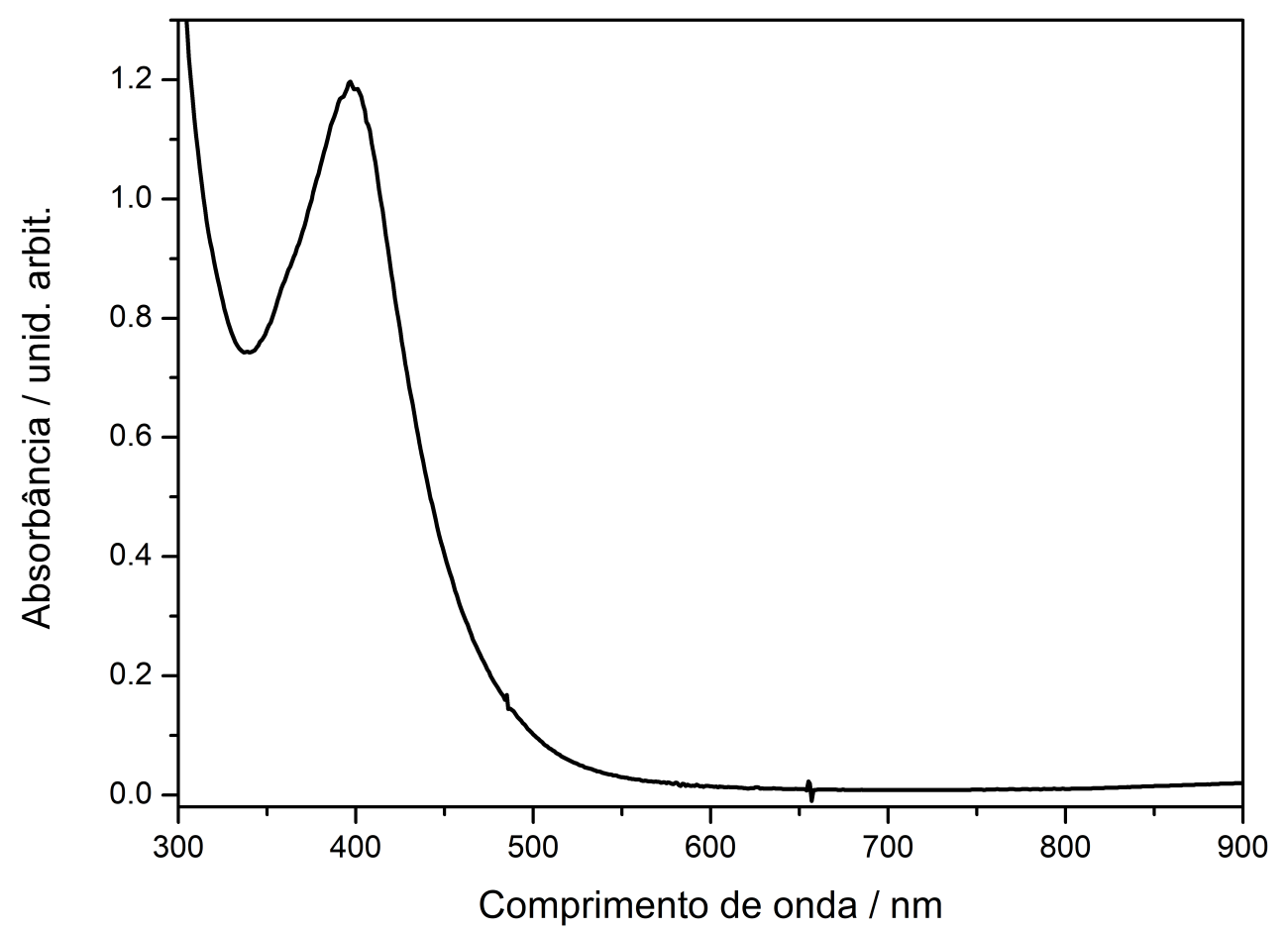

Figura C.2: Espectro eletrônico do ion $\left[\mathrm{Fe}(\mathrm{CN})_{5}\right]^{3-}$ em solução aquosa. 


\section{Anexo D}

\section{Súmula Curricular}

\section{Dados pessoais}

Nome: Ana Paula Mangoni

Filiação: Marques Delci Mangoni e Marilene Carme Marafon Mangoni

Nascimento: 21/08/1987 - São Jorge d'Oeste/PR - Brasil

\section{Endereço profissional}

Universidade de São Paulo, Instituto de Química

Av. Professor Lineu Prestes, 478, Bloco 2 inferior

Butantã - São Paulo

05508-000, SP - Brasil

\section{Endereço eletrônico}

e-mail: anapaulamangoni@gmail.com

\section{Formação acadêmica/titulação}

\section{(2015 - em andamento) - Doutorado em Química.}

Universidade de São Paulo, USP, Sao Paulo, Brasil

Título: Química Supramolecular de Complexos Ter-Imínicos de Ferro(II). Orientador: 
Henrique Eisi Toma.

Bolsista do(a): Conselho Nacional de Desenvolvimento Científico e Tecnológico.

(2011 - 2014) - Mestrado em Química.

Universidade de São Paulo, USP, Sao Paulo, Brasil

Título: Materiais híbridos baseados em argilas catiônicas e espécies com potencial terapêutico. Orientador: Vera Regina Leopoldo Constantino.

Bolsista do(a): Conselho Nacional de Desenvolvimento Científico e Tecnológico.

(2005 - 2007) - Início da graduação em QUÍMICA (Licenciatura e Bacharelado).

Universidade Federal de Santa Catarina, UFSC, Florianópolis, Brasil

(2008 - 2010) - Conclusão da graduação em QUÍMICA (Licenciatura e Bacharelado).

Universidade Federal do Paraná, UFPR, Curitiba, Brasil

\section{Formação complementar}

2012 - Participação da $6^{\text {a }}$ Escola de Nanociência e Nanotecnologia da UFRJ. Rio de Janeiro, RJ. 20 Horas.

2011 - Curso de curta duração em Acidentes em Laboratórios de Química. Instituto de Química de São Paulo. São Paulo, SP. 2 Horas e 30 Minutos.

2011 - Curso de curta duração em Primeiros Socorros na Parada Cardiorespiratória. Instituto de Química de São Paulo. São Paulo, SP. 5 Horas.

2011 - Curso de curta duração em Filosofia e juízo científico. $2^{0}$ Encontro sobre Di- 
vulgação e Ensino de Ciências. São Paulo, SP. 4 Horas.

2011 - Curso de curta duração em A importância dos modelos miméticos bioinspirados na química bioinorgânica. Sociedade Brasileira de Química. Florianópolis, SC. 6 Horas.

2010 - Curso de curta duração em Determinação de Estruturas Cristalinas e Moleculares por Difração de Raios X. IV Semana Acadêmica do Setor de Ciências Exatas da Universidade Federal do Paraná. Curitiba, PR. 8 Horas.

2010 - Curso de curta duração em Ressonância Paramagnética Eletrônica. XVIII Encontro de Química da Região Sul. Curitiba, PR. 5 Horas.

2009 - Curso de curta duração em Ciência de interface e sistemas coloidais. XVII Encontro de Química da Região Sul. Rio Grande, RS. 8 Horas.

2009 - Curso de curta duração em Análise Térmica. XVI Semana Acadêmica de Química. Curitiba, PR. 6 Horas.

2009 - Curso de curta duração em Mecânica Quântica e a Revolução do Pensamento Científico. XVI Semana Acadêmica de Química. Curitiba, PR. 6 Horas.

2009 - Curso de curta duração em O Significado Pedagógico da Experimentação no Ensino de Química. XVI Semana Acadêmica do Curso de Química da UFPR. Curitiba, PR. 6 Horas.

2009 - Curso de curta duração em Alfabetização Científica e Tecnológica, Contextualização e abordagem CTS no Ensino de Química: Uma reflexão sobre os conceitos e possibilidades de aplicação. XVI Semana Acadêmica de Química da UFPR. Curitiba, PR. 6 Horas. 
2009 - Curso de curta duração em Química de Novos Fertilizantes Visando Ganhos Econômicos e Ambientais. V Workshop Paranaense de Pós-Graduação em Química. Curitiba, PR. 4 Horas.

2008 - Curso de curta duração em Biodiesel. 31ª Reunião Anual da Sociedade Brasileira de Química. Águas de Lindóia, SP. 6 Horas.

2008 - Curso de curta duração em Ferramentas Multivariadas para Análise Química. XV Semana de Química da UFPR. Curitiba, PR. 6 Horas.

2008 - Curso de curta duração em Jogos em ensino de Química: Formando Professores Divertidos. XIV Encontro Nacional do Ensino de Química. Curitiba, PR. 4 Horas.

2008 - Curso de curta duração em Química Forense. XVI Encontro de Química da região Sul. Blumenau, SC. 5 Horas.

2007 - Curso de curta duração em Qualidade de águas: novos poluentes ,novos desafios. XV Encontro de Química da Região Sul. Ponta Grossa, PR. 5 Horas.

\section{Atuação profissional}

1. Instituto Técnico de Barueri - Fundação Instituto de Educação de Barueri

Vínculo empregatício

(05/2018 - Atual) - Vínculo: Professora, Enquadramento funcional: Professor PEB III. 
Vínculo institucional

(2010 - 2011) - Vínculo: Iniciação Científica (IC), Enquadramento funcional: Iniciação Científica (IC) sob a orientação do Professor Antonio Salvio Mangrich, processo 106926/2010-1. Carga horária: 20. Regime: Dedicação exclusiva.

\section{Universidade Federal do Paraná - UFPR}

Vínculo institucional

(2008 - 2010) - Vínculo: Iniciação Científica, Enquadramento funcional: Iniciação Científica (IC) sob a orientação do Professor Antonio Salvio Mangrich, processo 127001/2008-5. Carga horária: 20. Regime: Dedicação exclusiva. Vinculada ao Departamento de Química (UFPR).

\section{Universidade Federal de Santa Catarina - UFSC}

Vínculo institucional

(2006 - 2007) - Vínculo: Iniciação Científica, Enquadramento funcional: Aluno de Iniciação Científica (PIBIC/CNPq) sob a orientação do professor Bruno Szpoganicz, projeto de pesquisa: Estudo da Afinidade da Melanina por Metais. Carga horária: 20. Regime: Dedicação exclusiva.

\section{Universidade Federal de Santa Catarina - UFSC}

Vínculo institucional

(2006 - 2006) - Vínculo: Iniciação Científica, Enquadramento funcional: Aluno de Iniciação Científica (PIBIC/CNPq) sob a orientação do professor Bruno Szpoganicz, projeto de pesquisa: Estudo da Afinidade da Melanina e Agentes Anti-Melanomas por Íons Metálicos Bivalentes e Trivalentes. Carga horária: 20. Regime: Dedicação exclusiva.

\section{Produção bibliográfica}




\section{Artigos completos publicados em periódicos}

1. MATIAS, TIAGO A.; MANGONI, ANA P.; TOMA, SERGIO H.; REIN, FRANCISCA N.; ROCHA, REGINALDO C.; TOMA, HENRIQUE E.; ARAKI, KOITI. Catalytic Water-Oxidation Activity of a Weakly Coupled Binuclear Ruthenium Polypyridyl Complex. European Journal of Inorganic Chemistry (Print), v. 2016, p. $5547-5556,2016$.

2. MANGOni, Ana Paula; DiAS, P. M.; CONSTANTINO, V. R. L. A versatilidade das argilas e as propriedades dos sítios superficiais de interação. Eclética Química. v. 40, p. 192-203, 2015.

3. COSTA, THIAGO G.; SZPOGANICZ, BRUNO; CARAMORI, GIOVANNI F.; DE ALMEIDA, VICENTE R.; MANGRICH, ANTÔNIO S.; MANGONI, ANA P.. Spectroscopy and theoretical studies of natural melanin ( eumelanin ) and its complexation by iron(III). Journal of Coordination Chemistry (Print), v. 67, p. 1-28, 2014.

4. REZENDE, E. I. P.; MANGRICH, A. S.; MANGONI, A. P.; SCARPELlini, M.; CASELLATO, A.; FERNANDEZ, T. L. Estudo espectroscópico de compósito obtido da reação no estado sólido entre um complexo mononuclear de vanádio(IV) e caulinita. Química Nova (Impresso). v. 35, p. 257 - 261, 2012.

5. CERqueirA, S. da C. A.; ROMÃO, L. P. C.; LUCAS, S. C. O.; FrAGA, L. E.; SIMÕES, M. L.; HAMMER, P.; LEAD, J. R.; MANGONI, A. P.; MANGRICH, A. S. Spectroscopic characterization of the reduction and removal of chromium (VI) by tropical peat and humin. Fuel (Guildford). v. 91, p. 141 - 146, 2012.

6. RAChinski, S., CARUbelli, A., MAngOni, A. P., MANGriCH, A. S. Pilhas de Combustíveis Microbianas Utilizadas na Produção de Eletricidade a Partir de Rejeitos Orgânicos: Uma Perspectiva de Futuro. Química Nova (Impresso). v. 33, 
p. $1773-1778,2010$.

\section{Trabalhos apresentados em eventos}

1. MAngoni, Ana Paula, COnStantino, V. R. L. Immobilization of L-Lysine Amino Acid Into Natural Montmorillonite Clay. XV International Clay Conference. Rio de Janeiro, RJ, 2013.

2. MAngoni, Ana Paula, CONSTANTINO, V. R. L. Intercalation of L-carnosine into Veegum HS clay. IV International Workshop on Layered Materials. Campinas, SP, 2012.

3. MAngOni, Ana Paula, REZEnde, E. I. P., BATISTA, M. G. de F, MANGRICH, A. S. Biocarvão que sequestra carbono no solo e complexa íons metálicos nutrientes de plantas. XVIII Encontro de Química da Região Sul. Curitiba, PR, 2010.

4. MANGONI, Ana Paula, MANGRICH, A. S. Biocarvão que sequestra carbono no solo e complexa íons metálicos nutrientes de plantas. $18^{0}$ Evento de Iniciação Científica da Universidade Federal do Paraná. Curitiba, PR, 2010.

5. CerqueirA, S. C. A., ROMAO, L. P. C., MAngOni, Ana Paula, REZEnde, E. I. P., MANGRICH, A. S. Caracterização Espectroscópica da Redução e Remoção de Cromo (VI) por Turfa Tropical e sua Fração Humina. XI Jornada Brasileira de Ressonância Magnética. Curitiba, PR, 2010.

6. MAngoni, Ana Paula, REZEnde, E. I. P., MAngriCH, A. S., CASELATTO, A., FERNANDEZ, T. L., SCARPELlinI, M. Ressonância Paramagnética Eletrônica (RPE) no Estudo de Mistura Sólida de Complexo de Vanádio com Caulinita. XI Jornada Brasileira de Ressonância Magnética. Curitiba, PR, 2010.

7. MAngRiCH, A. S., NOVOtny, E. H., Velloso, M. H. R., REZENDE, E. I. P., MANGONI, Ana Paula, MESSERSCHMIDT, I. Preparação de "biochar"imitando 
as Terras Pretas de Índio da Amazônia. $33^{\mathrm{a}}$ Reunião Anual da Sociedade Brasileira de Química. Águas de Lindóia, SP, 2010.

8. MAngOni, Ana Paula, MAngriCH, A. S., RIBEIRO, R. R. Nova Terra Preta de Índios da Amazônia obtida por pirólise a partir da torta de mamona. XVII Encontro de Química da Região Sul. Rio Grande, RS, 2009.

9. MANGONI, Ana Paula, MANGRICH, A. S., RIBEIRO, R. R. Preparação de húmus

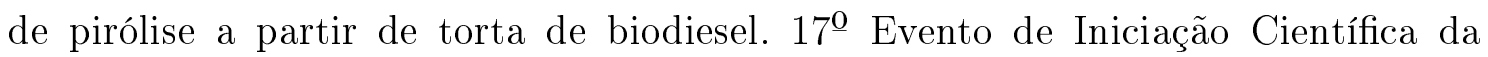
Universidade Federal do Paraná. Curitiba, PR, 2009.

10. MAngOni, Ana Paula, SZPOGAnICZ, B., SCHU, A., NASS, F. Estudo do Fungibiopolímero Micoton: um novo composto para a remoção do cromo hexavalente em águas residuais. 30 a Reunião Anual da Sociedade Brasileira de Química. Águas de Lindóia, SP, 2007.

11. MAngOni, Ana Paula, SCHU, A., SZPOGANICZ, B. Estudos da Afinidade da Melanina pelo Íon Mn(II). XV Encontro de Química da Região Sul. Ponta Grossa, PR, 2007.

12. MAngOni, Ana Paula, SZPOGANICZ, B. Estudos da Afinidade da Melanina e Agentes Anti-Melanomas por Íons Metálicos Bivalentes e Trivalentes. XVI Seminário de Iniciação Científica da UFSC. Florianópolis, SC, 2006.

13. MANGOni, Ana Paula, SZPOGAnICZ, B., SCHU, Â. Estudos de Equilíbrio de Complexos de Cobre. 14 SBQ Sul. Erechim, RS, 2006. 


\section{Participação em eventos}

1. Workshop em Nanobiotechnologia - Polímeros Avançados, Sistemas de Liberação, Curativos e Engenharia de Tecidos. Realizado no Instituto de Pesquisas Energéticas e Nucleares. São Paulo, SP, 2013. 24 Horas.

2. XV International Clay Conference. Rio de Janeiro, RJ, 2013.

3. IV International Workshop on Layered Materials. Campinas, SP, 2012.

4. Post Workshop School in Advanced Characterization Techniques of Layered Materials, 2012.

5. USP Conferences on Nanotechnology. São Paulo, SP, 2011.

6. 28 $8^{\text {a }}$ Semana da Química - Ano Internacional da Química: celebrando as conquistas da Química para Humanidade. São Paulo, SP, 2011.

7. $2^{0}$ Encontro sobre Divulgação e Ensino de Ciências. São Paulo, SP, 2011. 20 Horas.

8. III Encontro da Pós-Graduação do Instituto de Química da Universidade de São Paulo. São Paulo, SP, 2011.

9. USP Conference - Chemistry and Earth Sciences. São Paulo, SP, 2011.

10. $34^{\mathrm{a}}$ Reunião Anual da Sociedade Brasileira de Química. Florianópolis, SC, 2011.

11. XVIII Encontro de Química da Região Sul, Curitiba, PR, 2010.

12. IV Semana Acadêmica do Setor de Ciências Exatas da Universidade Federal do Paraná. Curitiba, PR, 2010.

13. XVII Encontro de Química da Região Sul. Rio Grande, RS, 2009.

14. V Workshop Paranaense de Pós-Graduação em Química. Curitiba, PR, 2009.

15. XVI Semana de Química da UFPR. Curitiba, PR, 2009. 20 Horas. 
16. XIV Encontro Nacional de Ensino de Química. Curitiba, PR, 2008.

17. $31^{\text {a }}$ Reunião Anual da Sociedade Brasileira de Química. Aguas de Lindóia, SP, 2008.

18. XV Semana de Química da UFPR. Curitiba, PR, 2008. 20 Horas.

19. XVI Encontro de Química da Região Sul: A Química como Ciência, Educação e Tecnologia. Blumenau, SC, 2008. 30 Horas.

20. XV Encontro de Química da Região Sul. Ponta Grossa, PR, 2007. 30 Horas.

21. XIV Encontro de Química da Região Sul: Química na Sociedade: significados e implicações. Erechim, RS, 2006.

22. XIII Encontro de Química da Região Sul. Florianópolis, SC, 2005.

23. I Semana da Física - Ano Mundial da Física na UFSC. Florianópolis, SC, 2005. 14 Horas.

\section{Organização de evento}

1. 1. MANGONI, Ana Paula. XVIII Encontro de Química da Região Sul, Curitiba, PR, 2010. 